\title{
Franz-Josef Leithold
}

\section{Studien zu \\ A. P. Čechovs Drama \\ "Die Möwe"}

Verlag Otto Sagner München · Berlin - Washington D.C.

Digitalisiert im Rahmen der Kooperation mit dem DFG-Projekt „Digi20“

der Bayerischen Staatsbibliothek, München. OCR-Bearbeitung und Erstellung des eBooks durch den Verlag Otto Sagner:

http://verlag.kubon-sagner.de

( bei Verlag Otto Sagner. Eine Verwertung oder Weitergabe der Texte und Abbildungen, insbesondere durch Vervielfältigung, ist ohne vorherige schriftliche Genehmigung des Verlages unzulässig.

«Verlag Otto Sagner» ist ein Imprint der Kubon \& Sagner GmbHofusef Leithold - 9783954792030 


\title{
SLAVISTISCHE BEITRÄGE
}

\author{
BEGRÜNDET VON \\ ALOIS SCHMAUS \\ HERAUSGEGEBEN VON \\ HEINRICH KUNSTMANN \\ PETER REHDER - JOSEF SCHRENK \\ REDAKTION \\ PETER REHDER
}

Band 238 


\section{FRANZ-JOSEF LEITHOLD \\ STUDIEN ZU A.P. ČECHOVS DRAMA \\ "DIE MÖWE“}

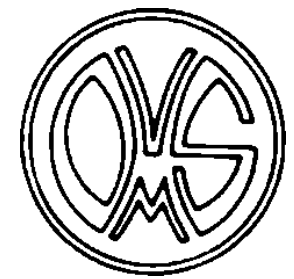

VERLAG OTTO SAGNER • MÜNCHEN 

D 25

\section{Bayerische Staatsbititiothok München}

ISBN 3-87690-422-6

(C) Verlag Otto Sagner, München 1989

Abteilung der Firma Kubon \& Sagner, München 
Vorwort

Die vorliegende Arbeit, die vom Gemeinsamen Ausschuß der Philosophischen Fakultaten der Albert-Ludwigs-Universitât Freiburg als Dissertation angenommen wurde, geht ursprunglich auf das Vorhaben zurùck, die Dramen A.P. Cechovs und A. Schnitzlers vergleichend zu analysieren. Bei der Beschätigung mit dem dramatischen Werk des russischen Autors fiel mir dann auf, das die "Mōme" zwar zu den vier "großen" stücken Cechovs gezāhlt wird, in Form einer Monographie jedoch bislang unzulanglich gewürdigt murde. Je mehr ich mich mit diesem Theaterstück auseinandersetzte. desto starker faszinierte es mich, reizte zu intensiverer Analyse.

Mein besonderer Dank gilt Herrn Professor Dr. Peter Drews. der die Arbeit betreute und mit wertvollen anregungen förderte. Danken mōchte ich auch Brau PD Dr. Maria Deppermann für viele hilfreiche Hinweise und ermutigende Gespräche. Dr. Felix Reller. Dr. Wolfgang Rieger und Marek Skopiec für die kritische Durchsicht des Manuskripts. Meine verehrte Russischlehrerin. Soja Ivanova. stand mir mit Rat und Tat immer gern zur Seite. Marion Müller danke ich fúr die orobe Geduld, die sie in den vergangenen Monaten autbrachte, meinem Bruder Walter für die vielen Nachhilfestunden as Computer.

Zu Dank verpflichtet bin ich auch Herrn Professor Dr. Peter Rehder. der diese arbeit in die Reihe "slavistische Beitrage" autnahm.

Freiburg i.Br.. Februar 1989

Pranz-Josef Leithold 


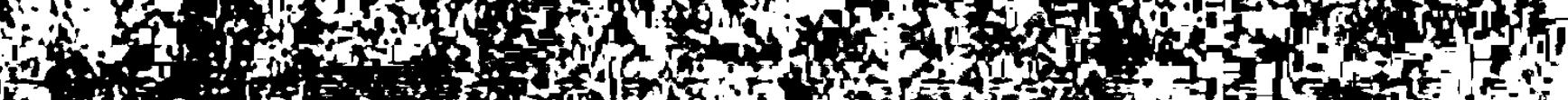

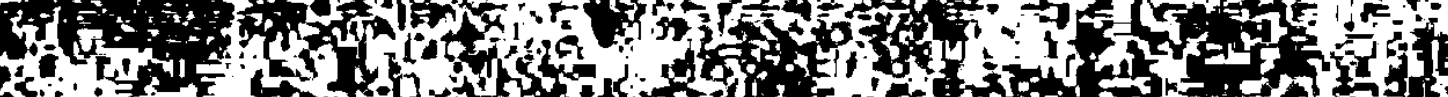
$\because$ of

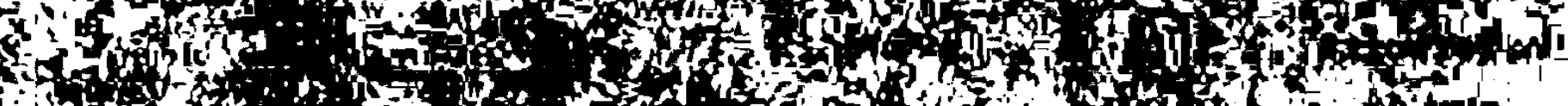

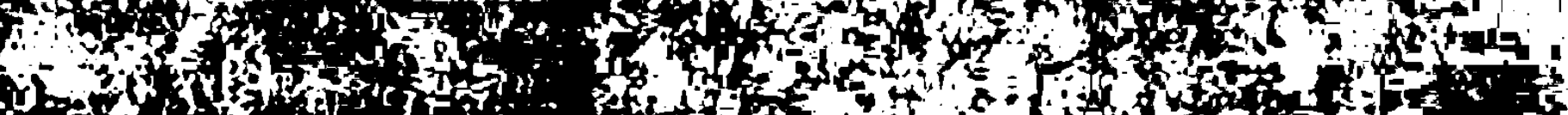

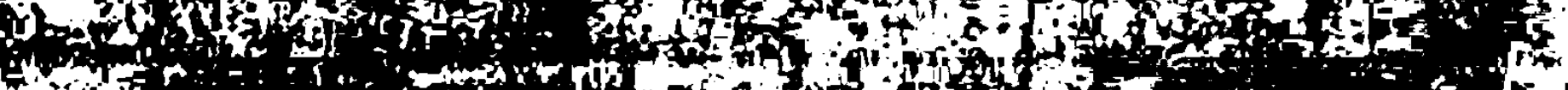
ofos (n) Wh

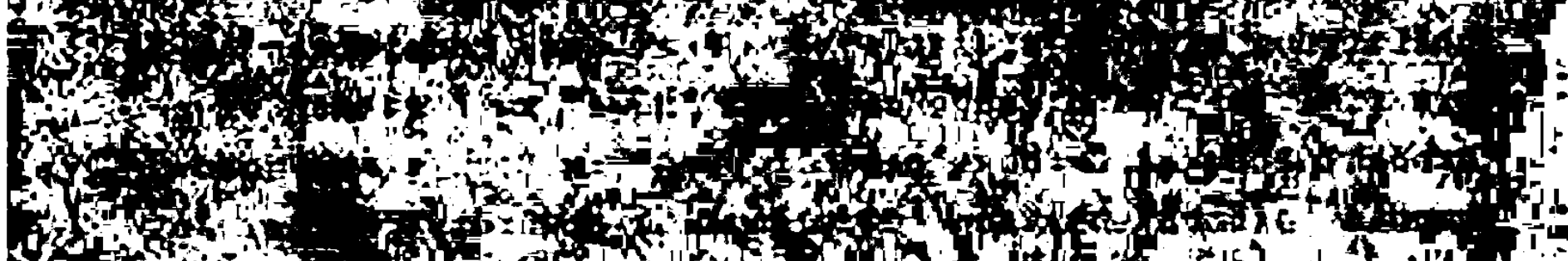

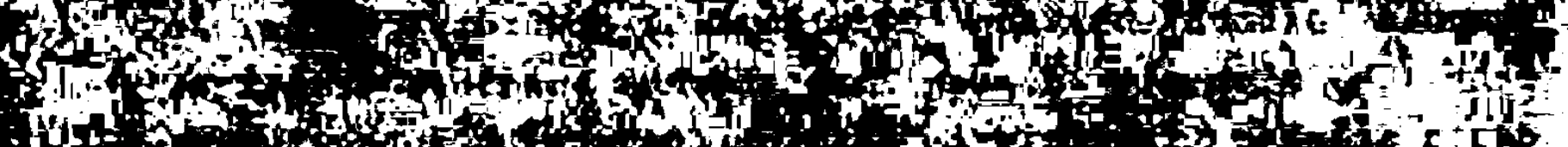

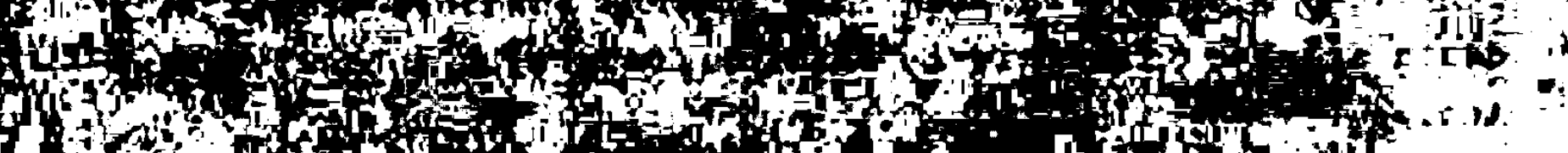

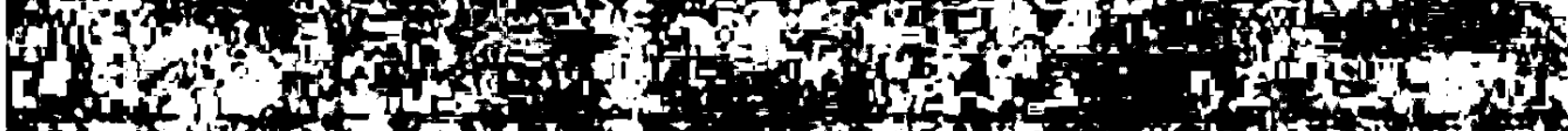

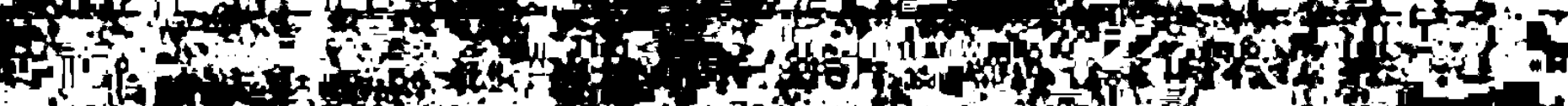

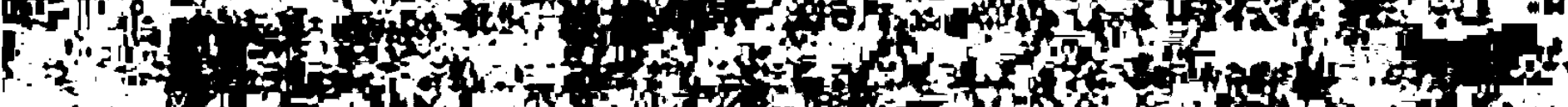

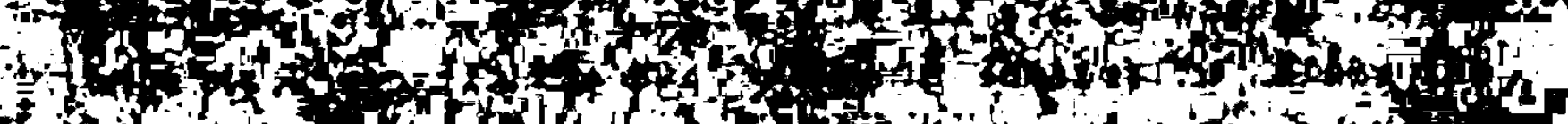
in

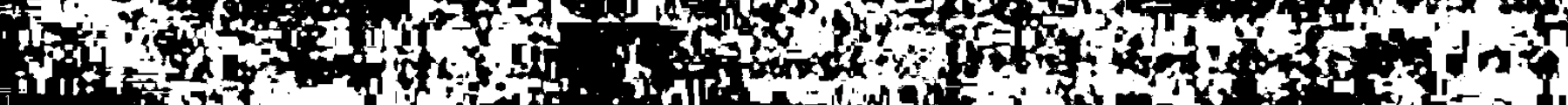

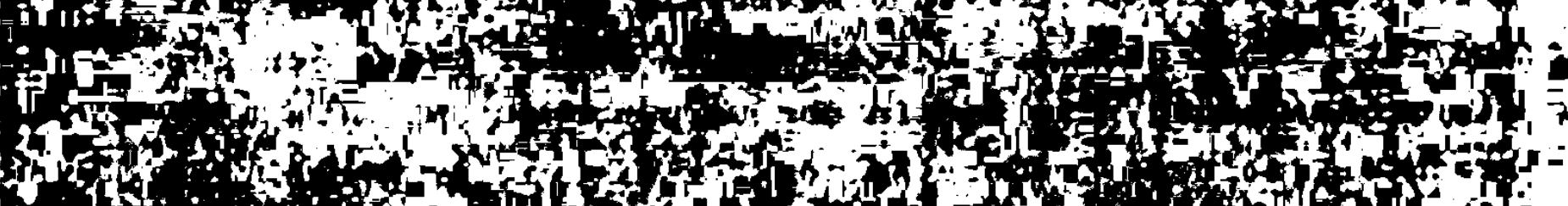

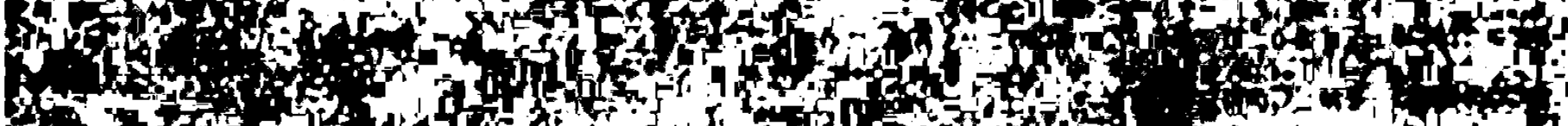

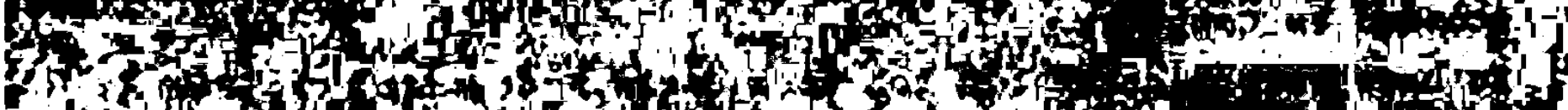

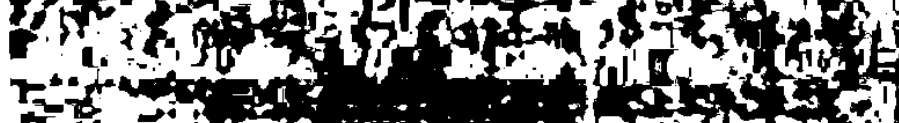

Th 5 Hot

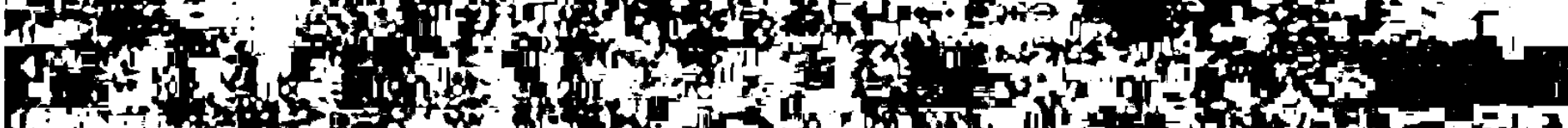

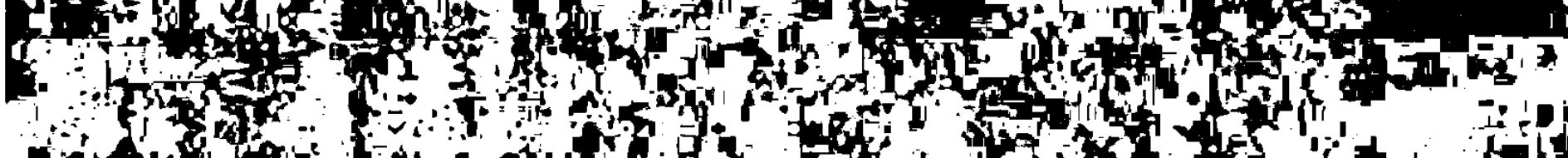

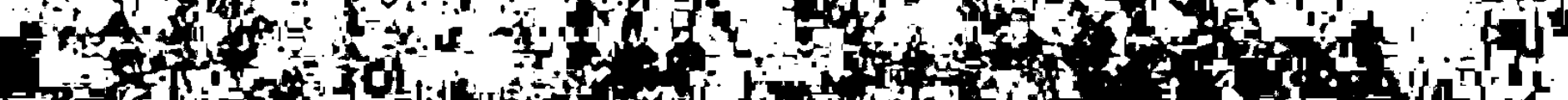

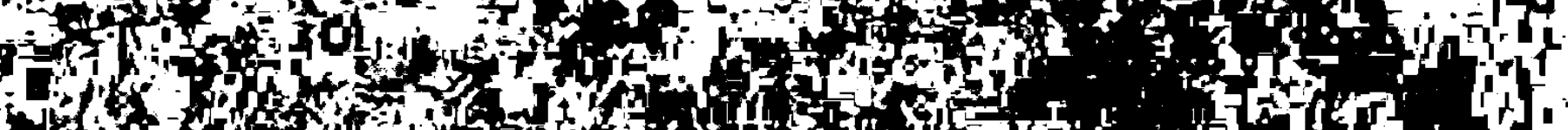

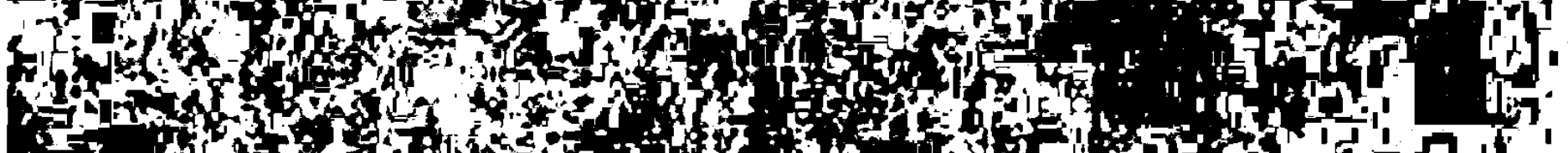

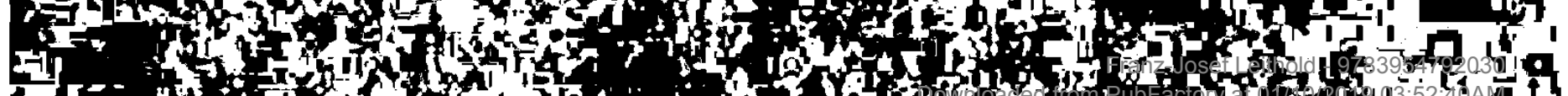
(1) 
Binleitung . . . . . . . . . . . . . . . . 11

1. Das Problen dramatischer Handlung in Cechove

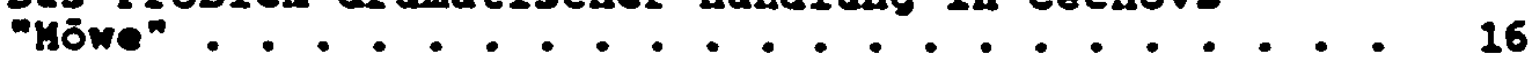

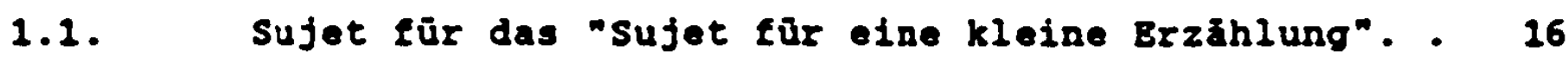

1.2. Drama ohne Bandlung? . . . . . . . . . . . . . 18

1.3. Zum Begriff der "dramatischen Bandlung". . . . . . 19

1.4. Handlung, komplementāre Handlungsstrānge und

handelnde Personen in der "Mowe"........ . . 27

1.5. Spmbole als handlungskonstituierende Blemente . . $43 \times$

2. Kommunikations- und Beziehungsstrukturen . . . . . 54

2.1. Untersuchungsmethode . . . . . . . . . . . . . 54

2.2. Binzelanalysen . . . . . . . . . . . . . . . 59

2.3. Ergobnisse . . . . . . . . . . . . . . . . 80

3. Kunst und Leben . . . . . . . . . . . . . . . . 84

3.1. Die Xstheten . . . . . . . . . . . . 84

3.1.1. Die Welt als Bühne: Arkadina . . . . . . . . . . 85

3.1.2. Die Welt als Motiv: Trigorin . . . . . . . . . . 90

3.1.3. Cechov - Trigorin . . . . . . . . . . . . . . 94

3.2. Die Suchenden . . . . . . . . . . . . . . . 97

3.2.1. Suche nach neuen Formen: Treplev . . . . . . . . . 98

3.2.2. Suche nach Lebenssinn: Nina . . . . . . . . . 101

3.3. Komplementaritā . . . . . . . . . . . . . 107

4. Intertextuelle Bezũge . . . . . . . . . . . . . 109

4.1. Cechovs "Möwe" und Shakespeares "Bamlet" . . . . . 110

4.1.1. Cechov und Shakespeare . . . . . . . . . . . . . 110

4.1.2. "Bamlet" in Cechors "Möwe" . . . . . . . . . . . . 112

4.1.3. Die Unfähigkeit zur Tragōdie . . . . . . . . . . . 118

4.1.3.1. zūge von Tragikomōdie und Farce . . . . . . . . . 126

4.1.4. Die Bedeutung von Turgenevs "Hamlet und

Don Quifote" für Cechovs "Möwe" . . . . . . . . 129

4.1.5. Bamlet und "Bamletchen" . . . . . . . . . . . . . 136

4.1.6. Hamlettypen in den Dramen Cechors . . . . . . . . 143

4.1.7. "Die vaterlose Gesellschatt" . . . . . . . . . . 153 
Bxkurs Cechov und schnitzler . . . . . . . . . 164

4.1.7.1. Treplev und Bamlet: Der Geist der vater . . . . 165

4.2. Weitere intertextuelle Bezūge . . . . . . . . 169

4.2.1. Maupassants "Sur l'eau" . . . . . . . . . 169

4.2.2. Puskins "Rusalka" . . . . . . . . . . . . . 172

4.2.3. Verweise aut Turgener .............. 173

4.2.4. Ibsens "Wildente" ................ 176

Schlubbemerkung . . . . . . . . . . . . 179

Literaturverzeichnis . . . . . . . . . . 181 
So lebte ein wundervolles Mädchen wie eine entzūckende Mōwe ruhig an einem etillen see. Aber in ihre seele kam ein Fremder. Unbekannter, sie gab ihm ihr Herz und ihr Leben. Nie ein Jager eine Mowe, scherzend und spielend, so zerstöte er das junge Herz fúr immer. - Eūr immer ist zerstōt das ganze junge Leben, kein Leben, kein Glaube, kein GIück, keine kraft...

\section{Russische Romanzel}

Tak devuska Cudnaja cajkoj prelestnoj nad ozerom tichim spokojno zila. No $v$ dusu vosel $k$ nej cuzoj, neizvestnyj, ona emu serdce i zizn otdala. Kak cajkoj ochotnik, sutja i igraja. on junoe serdce naveki razbil.naveki razbita vsja zizn molodaja, net zizni. net very, net scastja. net sil...

2zit.b. Ermilov (1948), S. 15. 


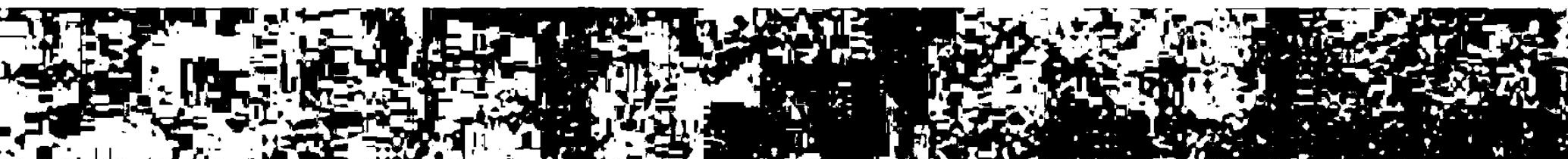
$7, \Rightarrow=0, y, y$

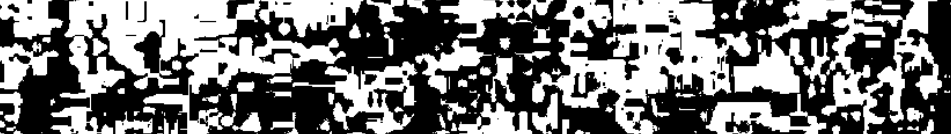

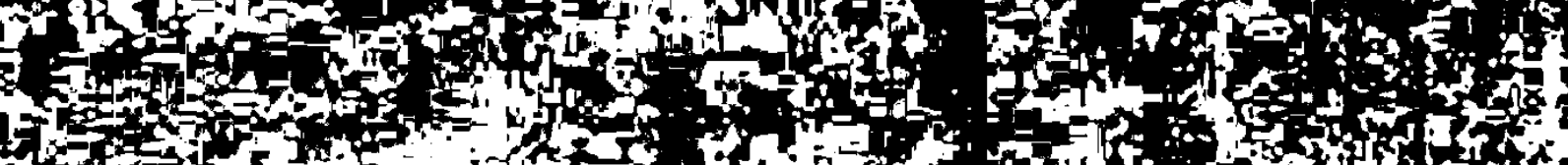

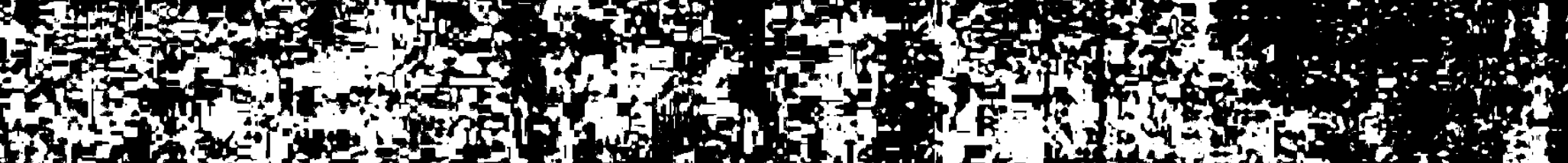

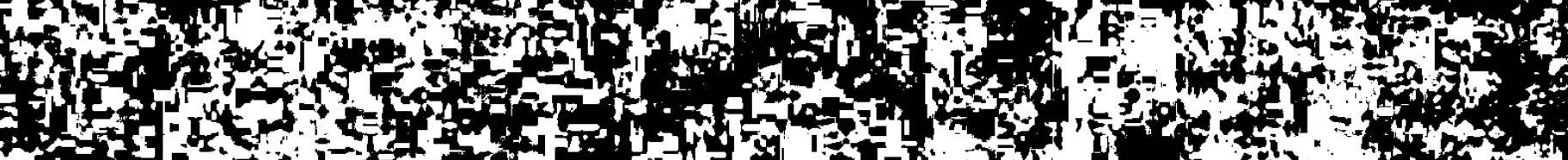

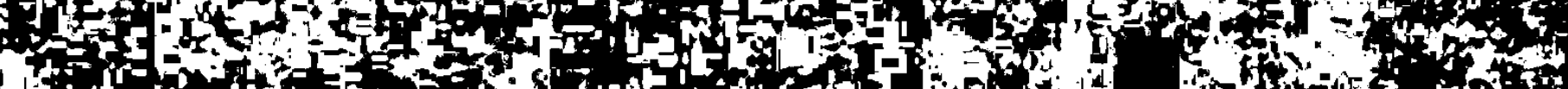

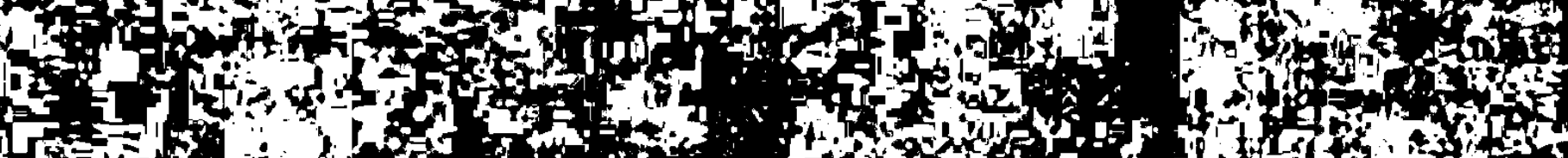

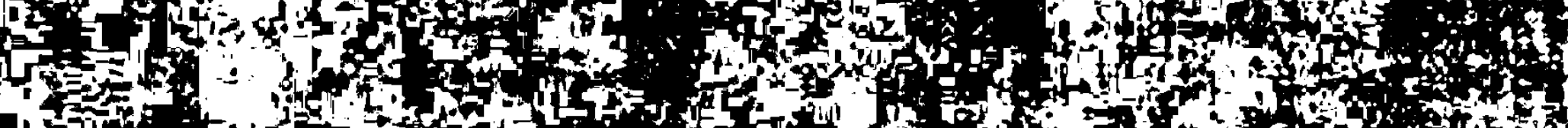
4 4.

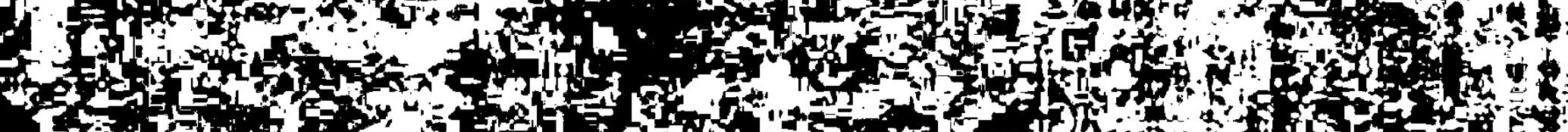

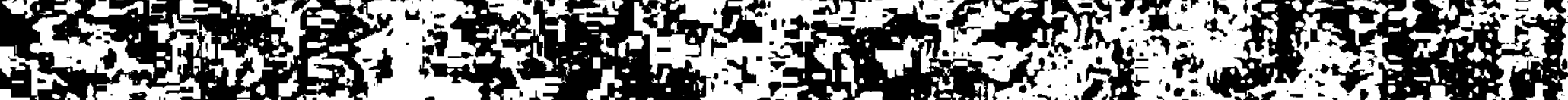

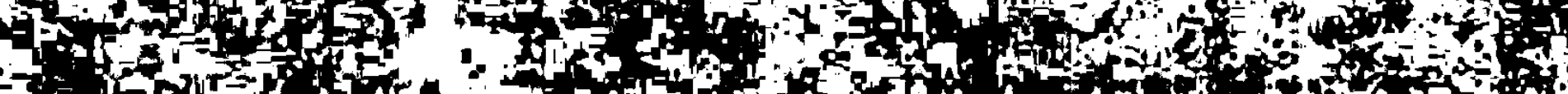

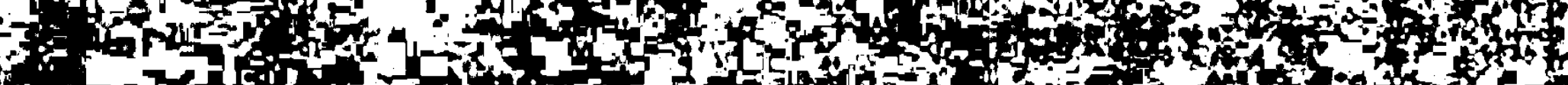

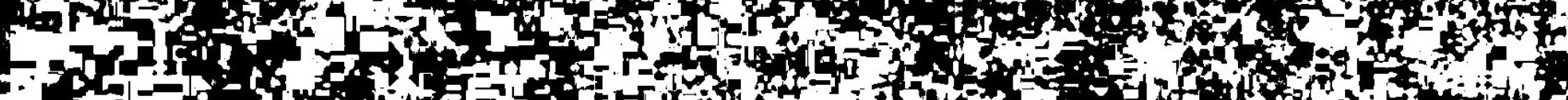

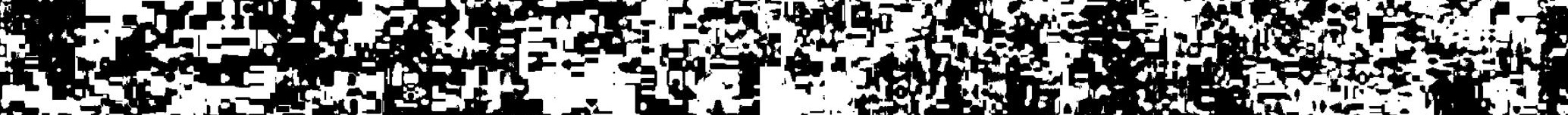

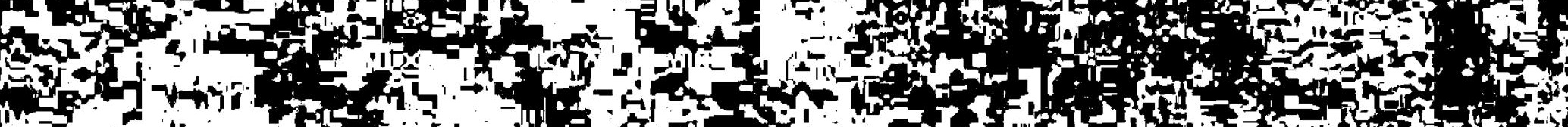

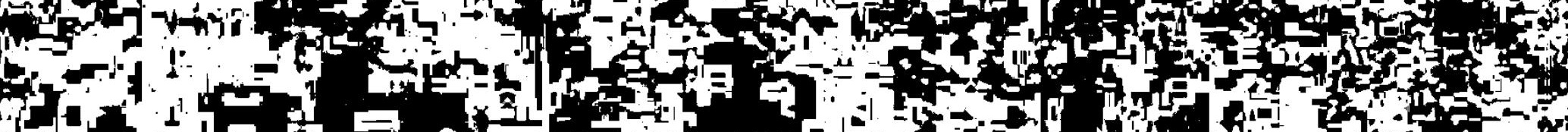

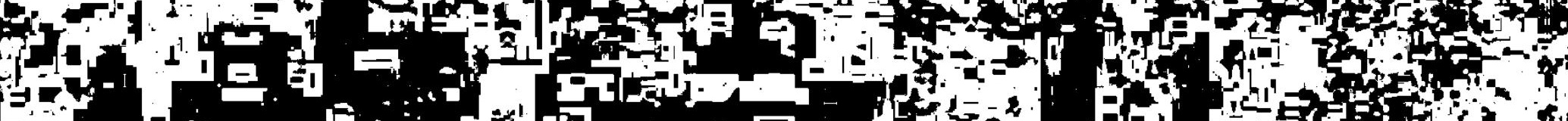

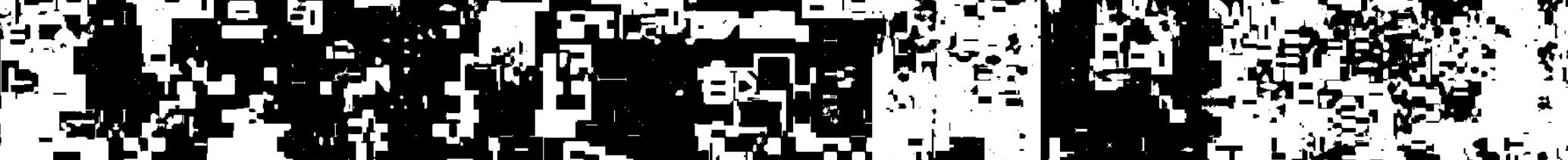
Xo 
Binleitung

Ich verstehe vorlaufig nur, daß das stūck begabt, interessant ist, aber von welchem Bnde man an es herangehen soll - das weib ich nicht.

K.S. Stanislarskij

Ja ponimaju poka tol'ko, čto p'esa talantliva, interesna, no $s$ kakogo konca $k$ nej podchodit' - ne znaju.

Ober das Werk Čechovs existiert eine kaum mehr zu überschauende Eülle an Forschungsliteratur, die eine bestimme Tendenz aufzeigt: Die Theaterstūcke des Autors murden und werden als undramatisch, handlungsarm, ohne Kommunikation charakterisiert.

Was macht dann aber die Anziehungskraft der Čchovschen stūcke aus, die immer wieder zu neuen Inszenierungen reizt, was veranlabt Laien und "Fachwelt". sich so intensiv mit diesen Werken zu beschātigen?

Sichtet man die Monographien zu den Dramen des russichen Autors, so fallt auf, daß man die "Möwe" zwar 24 den vier "groben" stūcken zāhlt, eine eingehende Gesamtuntersuchung, die dem stūck gerecht wird, bislang jedoch nicht geleistet hat. ${ }^{3}$

In der deutschsprachigen Fachliteratur sind entweder Einzelaspekte des dramatischen stils insgesamt untersucht."

\section{stanislavskij (1960), S. 145 .}

'Beispielsweise fehlt im Band zum russischen Drama von zelinsky (Hg.) (1986) eine Interpretation zur "Möwe". wāhrend "Onkel Vanja". "Drei Schwestern" und der "Rirschgarten" Beachtung finden.

Hahn (1977) betitelt ihre Arbeit als "a study of the major stories and plays". geht jedoch nicht nảher auf die Möwe ein.

12.8. Gruber (1950): Hübner (1971): Scheibitz (1972): Kirschstein-Gamber (1979): Szondi (1.1983). 
oder es wird versucht, anhand einzelner Dramen allgemeingūltige Charakteristika aufzuzeigen."

Die englischsprachigen Untersuchungen befassen sich zwar größtenteils mit den "four major plays", können aber einer angemessenen Analyse der "Möwe" insgesamt nicht gerecht werden.

Bbenso verhalt es sich ait den sovetischen Monographien zum dramatischen Werk Cechovs.'Papernyjesetzt sich zwar ausführlicher mit der "Möwe" auseinander, bleibt in vesentlichen jedoch deskriptiv und geht nicht naher auf die strukturelle und inhaltliche Komplexitāt des stũcks ein. Artikel in Sammel- und Pachzeitschriften zu Binzelfragen der Dramen des russischen Dramatikers sind mittlerweile in kaum mehr zu fassender Anzahl erschionen."

Nicht ohne Grund hat man sich bis heute weitgehend vor einer eingehenden Untersuchung der "Möwe" gescheut. Wie die vorliegende Arbeit zeigen soll, ist dieses Drama bis ins kleinste Detail durchkomponiert, voller intertextueller Anspielungen, verschlūsselter symbolmotive und komplizierter kommunikativer Prozesse. Daber ist Nabokovs Auffassung, Cechov habe mit der "Möwe" "das vollkommene Meisterwerk nicht geschaffen" und "sich nicht hinreichend mit der

\footnotetext{
- Schmid (1973;1978); Dlugosch (die sich weitgehend auf "Drei Schwestern" bezieht; 1977).

Brahms (1976): Magarshack (1972: 1980): Peace (1983); Pitcher (21985).

Wesentifche Teilaspekte werden berũcksichtigt im samelband von Barricelli (Hg.) (1981).
}

Paluchatyj (1927; 1936); Brmilov (1948; 21949): : Roskin (1959): Bjalyj (1981); Berdnikov (31981; 21984); Papernyj (1982); die aufschlubreiche Monographie von Zingerman (1988) war mir erst nach AbschluB der Arbeit zugănglich.

\section{- Papernyj (1980).}

- In diesem zusammenhang sei darauf hingewiesen, daB keine auf dem modernen Forschungsstand basierende CechovBibliographie existiert. Lediglich einige Teilbibliographien (s. Literaturverzeichnis) ermóglichen einen begrenzten Oberblick. 
Runst des Schauspiels beschaftigt", zu relativieren'•. Bs ist zudem das einzige größere stūck Cechovs, in welchem er sich vorwiegend auf den Problemkreis Runst-Leben konzentriert.

So entwirft er in der Schauspielerin Arkadina und dem Schriftsteller Trigorin zwei routinierte Rūnstlertypen. für die die Grenzen zwischen Lebenspraxis und Runst verschwimen. Die Außenwelt hat für diese "Xstheten" nur noch Objektcharakter.

Ihnen gegenüber stellt er die jungen, anfangs noch enthusiastischen Rünstler Nina und Treplev. An ihrem Schicksal demonstriert Cechov, daß für diese Generation eine ästhetische Lebenshaltung nicht mehr möglich ist.

Um die mittlerwelle zum Allgemeinplatz gevordene Behauptung zu überprūten, in Cechovs Dramen fehle eine Handlung, sollen im ersten Kapitel - Das Problem dramatischer Handlung in Cechovs "Möwe" - zunāchst einmal Begriffe wie Handlung, Geschehen, Situation, handelnde Person etc. geklärt werden, un Rategorien fūr eine genaue Arbeit am Text zu finden.

Wenn in der "Möwe" kein klassischer dramatischer Ronflikt existiert, auf den sich eine Gesamthandlung konzentrieren kōnnte, so fragt sich, ob nicht wenigstens einzelne Bandlungsstränge dem stūck Dynamik und Progression verschatEen. Untersucht werden sollen auch zentrale symbolmotive in ihrer Funktion als handlungskonstituierende Blemente und verschlüsselte Hinweise auf die Charaktereigenschaften einzelner Protagonisten.

Das zweite Rapitel widmet sich den Rommunikations- und Beziehungsstrukturen in der "Möwe" - aus zweierlei Grūnden. Erstens, um der allgemeinen Aussage uber "fehlende" Kommunikation in Cechovs Dramen eine Untersuchung entgegenzusetzen, die auf einer fundierten Rommunikationstheo-

10 Nabokov (1984), S. $378 f f$. 
rie Lußt.'1 zweitens sollen die Kommunikationsprozesse und -storrungen den wechselseitigen zusammenhang von Handlung und Rommunikation verdeutlichen.

Das dritte Kapitel konzentriert sich auf die in der "Möwe" thematisierte Problematik von Kunst und Leben. Es stellt die "impressionistische" Lebenshaltung der Routiniers Arkadina und Trigorin der Suche der jungen Protagonisten Nina und Treplev nach persónlicher und künstlerischer sinngebung gegenüber. Die in den ersten beiden Kapiteln gewonnenen Brgebnisse werden hier ihre thematische wie inhaltliche Brklärung erhalten.

Da Cechov in der "Möwe" den Zusammenhang von Kunst und Leben thematisiert, liegt es nahe, sich diesem thema auch anhand anderer literarischer Herke zu nähern; "er führt", wie Roskin richtig anmerkt, " mit den zuschauer ein Gespräch über seine Lieblingsschriftsteller der Weltliteratur."12 Hier ist noch viel unentdeckt, und Urban weist aus gutem Grund daraul hin, daß "zu viele zitate im Nerk techovs (...) als zitat noch gar nicht erkannt oder als solche beschrieben" sind.13

Das vierte Rapitel - Intertextuelle Bezüge - interpretiert die Gesantstruktur der "Möwe" als eine noderne "Bamlet-Roaodie". Dabei ist die verwittelnde Rolle von I.S. Turgenevs Aufsatz "Hamlet und Don Quijote"l zu berūcksichtigen. Die zeichnung der Figuren Ireplev, Nina und Dorn ist deutlich von Turgenevs Deutung dieser beiden literarischen schlüsselfiguren beeinflußt.

IIDiese Untersuchung wird sich hauptsalchlich aut Hatzlawicks u.a. (41974) pragmatische Nxiome stutzen. Nkzeptiert man dessen erstes Axiom. "man kann nicht nicht komunizieren". wird die Behauptung einer "fehlenden" Rommunikation bei Cechov bereits fragmürdig.

18 Roskin (1959), S. 131 (...vedet so zritelem besedu - svoich ljubimych mirovych pisateljach...).

13 Urban (1983: Vorwort S. 12).

14 Turgenev (1964), S. 171-192. 
In Bezug auf das "Stūck ohne Titel" und den "Ivanov" wird sich zeigen, daß sich Cechov bereits in seinen frühen Dramen mit Shakespeares "Bamlet" auseinandergesetzt hat. In der Bewertung der Bamletfiguren Platonov, Ivanov und Treplev ist jedoch ein Wandel festzustellen. Sind die ersten beiden noch beeinflubt von der allgemeinen Diskussion innerhalb der Narodniki-Bewegung, legt Cechov in der "Möwe" den schwerpunkt auf psychologische, kommunikative und intertextuelle Prozesse.

Mit der Hamletproblematik verbunden ist auch das Phānomen der "Vaterlosigkeit", auf das Cechov bereits mit dem Titel "Bezotcovłtina" anspielte, den er seinem ersten Drama geben wollte. Die "vaterlose Gesellschaft" treffen wix in all seinen stūcken an. Aut diese problematik gehe ich in Rapitel 4.1.7. ein.

Auf der inneren Rommunikationsebene's verweist Cechov auf Maupassants Reisenotizen "Sur l'eau". Puskins fragmentarisches Versdrama "Rusalka". Turgenevs "Rudin" und im Titel auf Ibsens "Wildente". Die Anspielungen auf diese literarischen Vorlagen werden daraufhin untersucht, welche Bedeutung sie für den thematischen und strukturellen Aufbau der "Möwe" gewinnen.

1 Die Begriffe âßeres und inneres Kommunikationssystem werden hier gebraucht im Sinne Pfisters (41984). 
Der Leser, der sich beschwert, daß nichts geschähe, aubert in Wirklichkelt eine Rritik an sich selbst; das "Bs geschieht nichts" ist bedauerlicherweise in seinem eigenen Kopf.

Herbert Brnest Batesi*

\subsection{Sujat fur das "Sujet für eine kleine Brzahlung"}

Das sujet fūr eine Brzāhlung, das der schriftsteller Trigorin aus der Möwe, die Treplev geschossen hatte, und dem schicksal Ninas konstruiert, speist sich aus mehreren quellen. Da wäe zunächst die von allen Biographen und der sovetischen forschung hāufig erwāhnte Affäre zwischen den mit Cechov befreundeten Schriftstellern Lidija Avilova und I.N. Potapenko. Heiter existiert ein Brief Cechovs vom 8.4.1892 an Suvorin, in dem er von einem Jagderlebnis mit dem Maler I.I.Levitan berichtet. Dieser hatte eine Schnepte angeschossen, die techov schlieblich tōten mubte. "Bin schōnes, verliebtes Hesen weniger auf der Welt, und zwei Idioten gingen nach Hause und setzten sich an den Abendbrottisch". so Cechov." In Verbindung mit Levitan steht auch die dritte mögliche quelle. Am 1. Juli 1895 erhalt Cechov einen Brief der Gutsbesitzerin A.N. Turcaninova. sie berichtet, daß der Maler sich zur zeit bei ihr aufhalte und versucht habe, sich das Leben zu nehmen. Als Cechov am 5. Juli auf dem Gut der Turcaninova ankommt, findet er eine situation vor, die in manchen Details an die "Möwe" erinnert. Avdeev berichtet", daß das an einem see gelegene Anwesen an das Gut sorins erinnere. Levitan

10 Bates (1988), S. 175.

17 Cechov, Anton Pavlovic: Polnoe sobranie sočinenij i pisem $v$ tridcati tomach. Pis'ma $v$ dvenadcati tomach. Bd. 5. Moskva 1974, S. 49. In folgenden zitiert als: Pis'ma. Bd. 5. S. 49 .

1. Avdeev (1973). 
malte dort einige Bilder. Bine Kunnstlerin und die Gutsbesitzerin warben um den Maler, die Turtaninova trug den sieg davon und baute Levitan auf ihrem Anwesen ein eigenes Bauschen. Damit aber nicht genug. Ihre alteste Tochter verliebte sich ebenfalls in den kūnstler, die jūngere vergötterte ihn. Die angespannte situation lóste bei Levitan dann eine Kurzschlubreaktion aus." Cechovs Bruder Michail erwänt, daß Anton Pavlovic auf dem Gut den Maler angetroffen hat, "mit einer schwarzen Binde am Kopf, welche er sich sogleich im Gespräch mit den Damen abgerissen und auf den Boden geworfen hat. Dann nahm Levitan ein Gewehr und ging zum see. Br kehrte zu seiner Dame mit einer veißen Mōwe zurūck, die er fūr nichts und wieder nichts getōtet hatte und warf sie ihr zu Füßen."ro Als vierte quelle kommt die als Motto angefunrte russische Romanze in Frage. Die Affăre zwischen Nina und Trigorin und das "sujet fūr eine kleine Brzählung" klingen hier deutlich an.

Nicht nur in der zusamensetzung des "sujets für eine kleine Brzahlung" wird deutlich, daß Cechov seine Motive und stoffe aus verschiedenen quellen schöpt. Auch in der zeichnung Trigorins (Rapitel 3.1.3.). der Anekdote über das Amulett. welches Nina Trigorin schenkt (Rapitel 3.1.2.) und in den intertextuellen Bezūgen ist diese vielschichtigkeit zu erkennen.2s

19Papernyj (1980), S $67 f f .$. berichtet ausfūhrlicher über diese Affare, wie Čechov sie in seinen Notizbūchern festhät und schileßlich in der "Möve" künstlerisch umsetzt. Vor allem die Figur Treplevs erinnert stark an den Maler Levitan.

so Cechov, M.P. (1923), S. 121.

21 papernyj (1980), S. 67-102, geht ausfūhrlicher auf Bntsprechungen zwischen Figuren aus der "Môwe" und Personen aus Cechovs Bekanntenkreis ein. 


\subsection{Drana ohne Bandlung?}

Bs ist mittlerweile zu einem Allgemeinplatz geworden, daß eine dominante tragende dramatische Handlung in den Dramen Cechovs fehlt, zumindest ist man sich über den Begriff "handlungsarm" einig. worunter die Reduktion der Bandlung auf ein Mindestmak verstanden wird.

Biner der ersten, die so urteilten, war Cechov selbst, als er am 21.10 .1895 an A.S. Suvorin schrieb:

... stellen sie sich vor, ich schreibe an einem stück, das ich wahrscheinlich, nicht vor Ende November abschlieben werde. Ich schreibe nicht ohne vergnügen daran. obwohl ich mich schrecklich an den Bedingungen der Būhne vergehe. Bine Komódie, drei Erauenrollen, sechs Mannerrollen, vier Akte, eine Landschaft (Blick auf einen See); viele Gesprāche über die Literatur, wenig Handlung, füf Pud Liebe.zz

Binen Monat später, am 21.11.1895, schreibt er wieder an Surorin:

Nun denn, ich habe mein stūck abgeschlossen. Ich habe es forte begonnen und pianissimo beendet - gegen alle Regeln der dramatischen Runst. Bs ist eine Novelle geworden. Ich bin eher unzufrieden als zufrieden, und wenn ich mein neugeborenes stūck lese, gelange ich einmal mehr zu der oberzeugung, das ich absolut kein Dramatiker bin ....s

Und am 13.12 .1895 an Suvorin:

Was meine eigene Dramatik betrifft, so ist es mir offenbar nicht beschieden. Dramatiker zu sein. Ich habe kein Glück.24

Die Binschätzung der Cechovschen Dramen durch Mirskij ist fūr die Forschung kennzeichnend:

In den Dramen Cechovs gibt es keinen 'Gégenstand'. keine Pabel. keine Handlung; sie bestehen einzig aus 'oberflāchlichen und ūberflüssigen Details' und sind

22 Pis'ma, Bd. 6, S. 85.

2 ebda... S. 100 .

sebda.., S. 108. 
in der Tat die undramatischsten Dramen der Weltliteratur.:8

Und nicht nur die slavistik stimmte weitgehend dem Urteil zu. Cechovs Būhnenstūcke seien undramatisch, und es fehle vor allem die Handlung. Auch Hauser schreibt in seiner "Sozialgeschichte der Kunst und Literatur". Cechovs Dramenform sei "die am wenigsten theatralische der Weltliteratur".

Es gibt kein Drama, in welchem weniger geschieht, in welchem weniger dramatische Bewegung. weniger dramatischer Kampf zu finden ist. Die Charaktere kämpfen nicht, wehren sich nicht, werden nicht besiegt - sie gehen einfach unter, versinken langsam, werden vom Alltag ihres ereignisiosen, aussichtslosen Lebens verschlungen. Sie lassen ihr schicksal über sich ergehen, ein Schicksal, das sich nicht in der Form von Katastrophen, sondern von Enttäuschungen vollzieht.2*

szondi kommt in seiner "Theorie des modernen Dramas" zu einer ăhnlichen Einschātzung. Ansatzweise erkennt er in den stūcken Kechovs folgende. Eür das moderne Drama charakteristischen Besonderheiten:

Absage an die landlung und den Dialog - die zwei wichtigsten Formkategorien des Dramas -. Absage also an die dramatische Form selbst scheine dem doppelten Verzicht (auf Gegenwart und Rommunikation, F.-J.L.). der die Menschen Tschechows kennzeichnet, entsprechen zu mūssen.:

\subsection{Zun Begriff der "dramatischen Bandlung"}

Bei der Beschāftigung mit der Sekundärliteratur zu Cechovs Dramen fällt auf, daß über den Begriff "dramatische Bandlung" weitgehend Unklarheit herrscht. Bine Definition fehlt meist, Handlung, Geschehen, theatralische und dramatische Handlung werden synonym behandelt, ebenso die Begriffe szene und situation sowie Pabel und Geschichte; die

\footnotetext{
sMirskij (1964), S. 342.

2*Hauser (1953), Bd. 2, S. 462.

I szondi (1*1983). S. 35.
} 
Aktivitäten einzelner protagonisten werden mit dramatischer Handlung insgesant in Einklang gebracht. In der sovetischen Forschung wird meist übersehen, daß sich fūr den Fortgang des Dramas wichtige Breignisse hinter der Būhne abspielen. Henn beispielsweise Brmilov und Berdnikov Nina als zielstrebige und handelnde person charakterisieren, unterscheiden sie nicht zwischen dramatischer Handlung und vermitteltem bzw. durch andere dramatis personae (hier Treplevl erzāhltem Breignisverlauf.:

Auch bei der wissenschaftichen Diskussion dieser dramenspezifischen Begriffe herrscht Uneinigkeit.

Unter dew Stichwort "Handlung" finden wir 2.B. im "Sachwörterbuch der Literatur" folgende Definition:

Handlung als Umsetzung innerseelischer WillensãuBerungen in die Tat, in der Bpik und bes. als unentbehrliche Ursache der Ronflike in Drama ...."

Im "Handbuch Iiterarischer Eachbegriffe":

... beruht als Brscheinungsform der Willensfreiheit auf (verantwortl.) Handeln des Menschen und konstituiert Geschehen in epischer und dramat. Dichtung.

- ist H. primär bestimmend = Haupthandlung. sekundar - Nebenhandlung; Nbfolge der Ereignisse = aubere handlung: Seelisches und Geistiges umfassende Tiefenhandlung = innere Handlung. ${ }^{\circ}$

Und in einem der neueren Theaterlexika:

... Gesamtprozeß des auf der Būhne dargesteliten Geschehens als Ronzentration der Vorgange, Dialektik zwischen inneren Geschehnissen und Juberen Breignissen. Tiefenstruktur der dramatischen Entwicklung..'s

Eine eindeutige, ausführliche Definition der Begriffe Handlung und Geschehen, Binzelhandlung, Situation, szene und Breignis. die auch eine konkrete Untersuchung einzelner Dramen auf den Grad ihrer Handlungshaftigkeit hin er-

20Ermilov (1948); Berdnikov ("1981).

"wilpert ('1969), S. 311.

'PBest ('1982), S. $198 f$.

's Brauneck/Schneilin (Hg.) (1986), S. 389. 
laubt, gibt keines dieser Beispiele. Ebenso wird der wechselseitige BinfluB von dramatischer aktivităt und sprache auber dcht gelassen.

Bine dramenspezifische Definition dieser Termini und eine Untersuchung der Dramen Cechovs (am Beispiel der "Mōwe") anhand der folgenden Rlassifizierungen soll im weiteren geleistet werden.

Hübler sieht das Drama als eine Binheit von Handlung (als das Vermittelte). Sprache und szene (als die Vermittelnden) und definiert dramatische Handlung wie folgt:

1. Handlung ist die sprachliche und/oder aubersprachliche Verwirklichung eines weitgehend sozial motivierten, wiewohl nicht kausal abhängigen ziels zur Rnderung einer situation, insofern es in Antizipation gewāhlt ist aus Möglichkeiten. die die jeweilige Ausgangssituation bereitstellt. 2. Handlung vollzieht sich nur innerhalb der Gegebenheit physikalischer objekte. 3. Sie wird durch Gesellschafts- und Rulturnormen reguliert. 4. Sie ist eine Energieleistung. die in der actio fabbar wird.jz

Als gemeinsamer Nenner sowohl fūr die Einzelhandlung (Handlungsschritt) als auch für eine größere Handlungseinheit erscheint die Situation "als ein Detail, bisweilen fast als eine Momentaufnahme innerhalb einer fortschreitenden Bewegung $z u$ verstehen, dann aber auch als statische Lage, der jede eigene innere Dynamik, wie sie der situation als Momentaufnahme eignet, abgeht." (H..S.4) Letztere bezeichnet Hübner als zustand. Die situation ist sowohl Bndpunkt einer vorausgegangenen Handlung als auch Ausgangspunkt einer folgenden Aktion. Sie ist gekennzeichnet durch ein subjekt, das die vorhandene situation verandert und Objekte (die Umgebung) als "jene Faktoren, aufgrund derer jemand handelt, ohne aber deshalb kausal abhangig zu sein, und auf die seine Handlungen ausgerichtet sind." (A. . S.6)

S. 12).

" Hübler (1973), S. 12. In folgenden zitiert als (H.. Diese Definition ist für die offone wie geschlossene Form des Dramas relevant.

Der Handlungsdefinition von Hübler schließt sich auch Pfister (41984) an. 
Objekte können klassifiziert werden in "soziale" (Personen oder Personengruppen) und "nicht-soziale" (physikalische Objekte, kulturbedingte Instanzen etc.l.

Bei einer Binzelhandlung folgen Anfangs- und Bndsituation direkt aufeinander. Jede situation ist voraussetzung fūr eine Handlung, da sie dem subjekt als orientierung dient. Bs erhalt aus ihr seine Handlungsmotivationen und gibt ihm die Möglichkeit, sich für eine bestimmte Handlungsweise zu entscheiden (stellung zu beziehen) und stellt den Handlungsraum zur verfũgung.

Sie mus inm die Gelegenheit der Wahl zwischen mindestens zwei Alternativen bieten und die einer Verānderung in der zukunft. Handlung bedeutet demnach nicht die Wiederherstellung einer ehemaligen situation, "sondern Umatrukturieren im Sinne einer Innovation. Situation - Nenden." (B. . S.11)

Der Wille zu einer Veränderung muß sichtbar sein, ansonsten kann nur von Geschehen gesprochen werden.'3

Handlung und Geschehen bedürfen einer dialogischen Basis. Fehlt diese. "steht monologisch das Breionis fūr ein punktuelles Akzidenz im nicht-sozialen Raum ohne jede Auswirkung auf den sozialen..." (H..S.15f.) Als tat bezeichnet hūbner die nicht situationsorientierte Aktivitä des personalen subjekts. Bin Vorgang wiederum ist ider neutralste gemeinsame Minimalterminus fūr alles, was sich überhaupt auf der Būhne wie auch immer ereignet..." (H.. S.16). Jede handlung und jedes Geschehen sind zwar vorgānge. nicht aber ungekehrt, d.h.. nicht jeder vorgang ist eine Handlung oder ein Geschehen.

Im folgenden entwickelt Hūbler die Begriffe Handlung und situation aus dem sprachbegriff, wobei sprache hier gedacht ist als Binheit von langue und parole: beide Komponenten manifestieren sich im sprechakt. Dieser Gedankenschritt ist insofern logisch, als sich gerade im Drama

os Bntweder mit dem sozialen Objekt geschieht etwas = "situative Objektsdominanz" oder es handelt sich un einen - Obergang von einer Lage in die andere im Sinne einer Entwicklung" "situative Dominanz". (H..S.15). 
Bandlung zumeist sprachlich vollzieht bzw. vermittelt wird. Oder, un mit Hamburger 24 sprechen: Drama ist der ort, wo "das Wort Gestalt und die Gestalt Wort wird."34 pfister bezeichnet dieses Merkmal als "sprechendes Handein" oder "aktionales Sprechen".o" Br rảumt jedoch ein, daß auch eine Diskrepanz zwischen Rede und Handlung möglich ist und ein Unterschied besteht zwischen kommentierter Bandiung und nachfolgender kommentierender Begründung oder Rechtfertigung einer Handlung.

Das Sprechen ist eine Primarfunktion der sprache. Deshalb ist sie nicht nur zeichen, sondern erfüllt sich "in ihrer Beziehung (worūber sie etwas sagt) und ihrem Gegenüber (dem sie etwas sagt)." (H.,S.18)

In einem sprachvorgang manifestiert sich eine wechselseitige Beziehung: Sender und smpfanger beeinflussen nicht nur den Sprachvorgang, sondern werden gleichzeitig durch diesen wieder beeinflußt. Handeln durch sprache ist wiederum nur moglich in einer "situative(n) dynamische(n) ICh-Du-Relation..." (H.,s.21)

Da nun ein grundsātzlicher Unterschied besteht zwischen einer materiell gegebenen situation und einer sprachlich entworfenen, unterscheidet Hübler zwischen "Realsituation" und "sprachsituation".

Unter (dramatischer) Realsituation ist die lubere Ronstellation zu verstehen, die sowohl das intersubjektive Verhãltnis als auch die Beziehung zwischen sozialer und nicht-sozialer sphare umschließt. $(\ldots)$ Die Sprachsituation dagegen ist die sprachlich entworfene und konstituierte sitation, die nur in der sprache, in ihrer semantik zustandekommt, von dem voraufgegangenen sprachlichen Rontext erzeugt wird, und auch nur im semantischen verharrt, d.h. in ihrer situativen stobkraft nicht über das Innersprachliche hinausgeht. (B.,S.22)

\footnotetext{
Q4 Bamburger (21977), S. 177.

s'pfister (1984), S. 169.
} 
Sprache vollzieht sich in Monologen und Dialogen." wobei wichtigstes Rriterium für den Dialog die"semantische Wende" lst (fūr den Monolog demzufolge eine semantische Ronstanzl. Durch diese semantische Bestimmung des Dialogs gelangt Hübler nun zur Definition von sprachhandlung und Sprachgeschehen.

Sprachbandlung ist die durch sprachliche actio aus mehreren Möglichkeiten bewußt herbeigeführte semantische Wende, die sich in einer neuen, d.h. einer semantisch unterschiedlichen spachsituation kundtut. Sprachgeschehen ist die sprachliche Bvozierung einer bestimmten neuen Sprachsitutation, die als so beschaffene, d.h. in dieser bestimmten semantischen gūllung nicht intendiert war. (B..S.24)

Dominiert das Monologische, kann von einem Sprachvorgang gesprochen werden.

Bringen wir nun die Begriffe Realsitution und Sprachsituation sowie Geschehen und Sprachgeschehen in Bezug. wird eine Definfition von durch sprache realisierter dramatischer Handlung und dramatischem Geschehen möglich:

Die sinnvoll gewählte Oberfūhrung einer sprachsituation in eine andere, die sprachhandlung also, und der Wechsel von einer Sprachsituation in eine andere, das Sprachgeschehen also, sind im allgemeinen nur dann reale, d.h. dramatische Handlung bzw. dramatisches Geschehen, wenn mit der Veranderung der sprachsituation auch die (dramatische) Realsituation verāndert wird. Und diese wird nachhaltig nur dann verāndert. menn zumindest die an der Realsituation beteiligten Personen verändert werden. (H..S.31)

Die Szene, neben der sprache eine weitere vermittelnde Instanz, also auch ein semantischer zwischenschritt, unter-

* Sowohl Būbler als auch Pfister weisen (unter Bezug auf staiger und Mukařovskyl darauf hin, das die Begriffe Monolog und Dialog der Genauigkeit halber durch die Bestimmungen monologisch und dialogisch zu ersetzen sind. Denn es existieren ja sowohl Dialoge, die eher zum Monolog tendieren als auch ungekehrt Monologe mit ausgeprägt dialogischen strukturen.

Zu den verschiedenen Formen von Monolog und Dialog siehe Hūbler (1973), S. 261 . 
teilt Hūbler in Gebārden' ${ }^{7}$ und Raum. Dabei kōnnen drei Formen von Gebārden unterschieden werden:

... die natürlichen Gebārden, insofern sie expressiv zurūckgebunden bleiben, und die zeichenhaften. Insofern sie zu kommunikativen An-Zeichen verden oder sogar den personalen Bezug abstreifen und generell manipulativ verfügbar sind. ...schlieblich noch die absoluten Gebãden bestimmter Täigkeiten. (H..S. 35f.120

Das Verhältnis der Gebārden zur Handiung zu erhellen, wird auch hier über das situationsmodell erleichtert.

Die absolute Gebārde kann am ehesten eine Vende auslōsen. da sie direkt in eine Tātigkeit einzugreifen oder eine solche auszulōsen vermag. Die zeichenhafte ist zu wenig systematisiert (wie 2.B. die Sprache), der natūrlichen Gebärde wiederum fehlt wegen ihrex Monologhaftigkeit der Bandlungscharakter.

Ihrer Funktionalitāt nach ist die natūrliche Gebārde ausdrucksorientiert, die absolute dagegen eher aufgabenorientiert. So weisen diese beiden Gebārdenformen direkt auf die Realsituation hin. Die Gebārden kōnnen in unterschiedlicher Weise eine Situation beeinflussen. Dominiert in einer situation das subjekt, so hat die natūrliche Gebārde rein mimische (und somit monologische) Eunktion. Die Mimik kann zwar beim Gegenüber eine Reaktion auslōsen, ist aber von sich aus nicht situationswendend und daher höchstens Ausgangspunkt für Geschehen. Ist das nich-soziale objekt dominant, "so dient die zeichenhafte Gebārde der sachmanipulation." (B..S.39) Lediglich bei Dominieren des personaIen Objekts kōnnen die absoluten Gebārden zu einer situationswende fūhren. Binzelhandlungen auslōsen (zeichenhafte Gebārden kōnnen dies nur eingeschränkt).

IT Gerade die Gebārden ermōglichen es, einen inneren Konflikt nonverbal zu aupern bzw. anzudeuten. Dies ubersieht Asmuth (2 1984), S. 145, wenn er konstatiert, ein innerer Ronflikt müsse immer "sprachlich in Brscheinung treten."

- Eine natūrliche Gebārde wäre beispielsweise das Putzen der Nase, eine zeichenhafte das Drohen mit dem Zeigefinger, eine absolute das Aufstampfen mit dem Fuß. 
Der dramatische Raum schließlich (im Gegensatz zum theatralischen, d.h. erst durch eine Inszenierung realisierten) bietet in den seltensten Fällen mehr als nur den Raum fūr die Aktion. Wird or jedoch zum objekt oder lóst sogar eine Geschehensstruktur aus, so bleibt dies doch monologisch und damit nicht situationswendend.

Hüblers Festlegung der Begriffe Handlung und Geschehen bedart jedoch noch einer Brweiterung.

Br spricht auch dann von Geschehen, wenn ein Protagonist eine situationswende zwar plant und auszuführen versucht, letztendich aber scheitert. Er versteht dies als eine

2wischenform, wo ein Vorgang von einem Subjekt geplant ist, also von der Intention her Handlung anzusetzen ware, wo sich aber vom Bffekt, pon der Endsituation her deshalb ein Geschehen herauskristallisiert, weil die Ausgangssituation zwar durch die actio des subjokts, aber anders als geplant, verándert worden ist. (H..S.15)

stimnt man dieser situation $2 u$, so kann eigentlich bei keiner Tragódie von Handlung, sondern nur von Geschehen gesprochen werden. Denn gerade der tragische Held scheitert ja im Endeffekt an den bestehenden, sich als übermāchtig erweisenden Verhaltnissen oder an einer gegen ihn gerichteten Intrige.

Auch Pikulik bemerkt, wenn man nur das autonome, frei entscheidende Individuum als handlungstrāger erklāre,

so bestūnde der größte Teil der Dramenliteratur absurderweise aus Nichthandlung oder aus einem Gemisch von Handlung und Nichthandlung. Denn entgegen einer weitverbreiteten Klischeevorstellung kommt das autonom über sich verfügende Individuum im Drama entweder gar nicht vor oder Autonomiegebaren entlarvt sich aufs kläglichste als fruchtlos, illusionãr und sinn103.30

3'Greiner/Hasler/Kurzenberger/Pikulik (1982), Bd. 1 . S. 15. Wenn Pikulik im weiteren jedoch alles auf der Bühne Vorsichgehende als Handlung bezeichnet, jedes Wort, jede Geste, jeden Blick, da all das fūr den zuschauer eine situationsveranderung erkennen 1asse, unterscheidet er nicht zwischen innerem und auberem Kommunikationssystem. Denn wesentlich ist doch, ob ein Protagonist bemut eine situationswende herbeiführen will, oder ob nur fūr den zuschau- 
Wenn von den Protagonisten in den Stücken Cechovs gesagt wird, sie handeln nicht, seien unfahig zu Aktivitat und Verānderung, versinken in Lethargie, dann muß geklärt werden, was unter dem Begriff "handelnde Person" zu verstehen ist.

Man kann nicht bei einem fūr ein Drama konstatierten Geschehen oder der soeben beschriebenen zwischenform die Schlubfolgerung ziehen, in einer im Endergebnis vorhertschenden Handlungslosigkeit verhielten sich die Dramenpersoner passiv.

Um hier zu einer genaueren Lösung zu kommen, sollte das Problem "handelnde Person" an den Begriffen situation und Binzelhandlung bzw. Handlungsschritt entwickelt werden. Bine Dramenfigur kann dann als aktiv oder handelnd bezeichnet werden, wenn sie eine situation zur Wende bringt und somit zum Träger einer Binzelhandlung wird. Denn hierzu bedarf es ja eines handelnden Subjekts. Wenn das Endergebnis aber Geschehen ist, kann man aufgrund der in der Binzelsituation erbrachten Aktivitat und situationswende dem Protagonisten ja nicht Bandlungslosigkeit oder Passivitat bescheinigen.

Durch eine solche Festlegung kann also tūr ein Drama insgesamt Geschehen oder Handlungslosigkeit konstatiert werden bei gleichzeitiger Bxistenz handelnder Personen. Dies gilt gerade fūr die zwischenform von Handlung und Geschehen und wird für die Untersuchung der Cechovschen Dramen relevant werden.

1.4. Bandlung, komplementare Handlungsstrange und handelnde Personen in der "Möwe"

Die Ausgangssituation des stūcks enthät in sich nicht einen allumfassenden Grundkonflikt, der den kūnftigen Gesamtgang des Dramas bestimmen wird. Die Binzelhandlungen der Protagonisten sind nicht durch einen zentralkonflikt (weder durch ein soziales noch ein nicht-soziales objekt)

er eine andere Perspektive sichtbar wird. 
motiviert und kōnnen folglich auch nicht auf die Bewältigung eines solchen zielen. Der Ausgangspunkt ist also nicht so konzipiert, daß or ein Anderswerden, eine Wende evoziert. Dieser handlungsmotivierende Brennpunkt wird auch nicht spater nachgeliefert, wie es in der offenen dramatischen Form der "Mōwe" durchaus möglich wäre. Was also die Gesantstruktur des stūckes betrifft, ist nicht von handlung, sondern von Geschehen zu sprechen. Auch wenn keine, Iür alle Protagonisten gleichsam relevante Ausgangssituation, an der sich mehr oder weniger alle Binzelhandlungen orientieren oder auf die sie letztlich ausgerichtet sind, und keine aus einem situationsentmurf resultierende situationswende am Bnde des Dramas existieren, so sind aber doch einige Binzelhandlungen vorhanden. sie stehen in der linie einzelner Handlungsstrānge, an deren Ende eine landlung oder die bereits erwähnte zwischenform steht. Diese sollen nun auf ihre sprachliche Manifestation hin untersucht werden. Dabei wird das gebārdliche Verhalten berūcksichtigt.

Die sprache, in der die Figuren dargestellt werden und gleichsam sich selbst darstellen, enhalt zweierlei Bbenen. zum einen die direkten Aussagen der Personen über sich und ihre Gegenūber, also sprachliches Bandeln, zum anderen die sich durch ein bestimmtes sprachverhalten ausdrückenden Beziehungsstrukturen. Diese sollen dann in einem gesonderten Kapitel mit Hilfe der Kommunikationstheorie Natzlawicks untersucht werden.

Doch zunachst zu den direkten Sprachsituationen. Der erste Nkt der "Mōwe" kann fũr das Drama lals sume von Binzelhandlungen) und die verschiedenen situationen, in denen meist jeweils zwei der protagonisten sprachlich agieren. durchaus als Bxposition gesehen werden. Alle für das Geschehen relevanten interpersonellen konflikte werden kurz angerissen und als situationen oder zustande dargestellt. Als Situationen sind sie das Produkt einer Bntwicklung. die in der Vergangenheit eingeleitet murde und in sich die Mōglichkeit einer Weiterentwicklung in der zukunft birgt. 
Im wesentlichen durchziehen das Stück vier zentrale Handlungsstränge bzw. Beziehungskonflikte. Der eine nimmt seinen Anfang im ersten Akt. Bs ist das Verhältnis MinaTrigorin. Die beiden anderen haben sich schon in der Vergangenheit herauskristallisiert, erscheinen also als situationen und werden in den ersten szenen weiterentwickelt. Bs sind dies die hoffnungslose liebe Masas $2 \mathrm{u}$ Treplev, die Treplevs zu Ninato und das problematische Verhätnis zwischen Treplev und seiner Mutter. Binzu kommen zwei zentrale Handlungslinien, die mit den Beziehungskonflikten eng zusammenhängen: Ninas und Treplevs Bemūhungen um kūnstlerische Anerkennung.

Maša und Treplev drāngen jeweils auf eine veränderung der situation, d.h. auf eine Erwiderung ihrer Liebe durch den von ihnen geliebten Menschen.

Diese Handlungsstränge münden am Bnde jedoch in ein Geschehen, da keines der handelnden Subjekte sein ziel erreichen kann. Letztendlich 'geschieht' mit ihnen etwas, verursacht durch den Verlauf der anderen Handlungslinien. Treplev gelangt zu der Erkenntnis, daß er die Liebe Ninas niemals gewinnen wird und sein streben nach einer neuen Form (anstatt neuen Inhalten) in der Runst ein Irrweg war. Nina, deren ziel es war, eine berūhmte Schauspielerin zu werden, muß sich mit Bngagements an drittklassigen Provinzbūhnen zufriedengeben. Trigorin, den sie noch immer liebt, hat ihre beruflichen ziele nie erstgenomen, sie mit ihrem kind zurūckgelassen und sich wieder in sein 'normales' Leben zurūckgezogen.

In der Gewisheit, daß Treplev ihre zuneigung nicht erwidert, flüchtet sich Maša in den Alkohol und in die the mit Medvedenko. Als auch das ihre Liebe zu dem jungen Schriftsteller nicht mindern kann, labt sie den Bntschlub zu tliehen.

- Die Handlungen gehen in diesen Beziehungen immer von den erstgenannten Personen aus. In der beschriebenen Reihenfolge heibt das also von Nina. Masa und Treplev. 
Bin anderer Handlungsstrang auf der Beziehungsebene wäre das Verhaltnis Polina Andreevna und Dorn. Den Hoffnungen der Frau Samraevs, mit dem Arzt ein neues Leben beginnen zu können, setzt dieser jedoch bereits in zweiten Akt ein deutliches Bnde ("Ich bin 55 Jahre alt, da ist es 24 spãt, sein Leben $z u$ andern." me pjat'desjat pjat' let, uze pozdno menjat' svoju zizn'; S. 26).4' Dorn beendet die bis dahin offene situation und deklariert durch diese sprachhandlung sowohl seine Beziehung zu Polina Andreevna als auch deren unglūckliche the mit Samraev als unveránderlichen zustand.

Bin weiterer Strang könnte das Verhältnis zwischen Arkadina und Trigorin sein. Hier ist fedoch keine Entwicklung einer situation in Richtung einer Wende zu erkennen, an deren Ende eine neue situation steht, die sich rom Ausgangspunkt unterscheidet. Denn Arkadinas Beschwörung Trigorins (3.Akt) zielt auf die Hiederherstellung des alten zustands, der, was ihre Beziehung betrifft, am Bnde auch wiederhergestellt ist. Um den schriftsteller wieder für sich zu gewinnen, tritt die Arkadina allerdings bewubt handelnd auf. Durch absolute Gebāden unterstūtzt, setzt sie all ihre schauspielerischen Fähigkeiten ein, um Trigorin umzustimmen. Wir kommen an späterer stelle noch daraú zurūck.

Der erste Akt beginnt mit der Figurenkonstellation MasaMedvedenko. Der Lehrer erklät sich der jungen Frau, wird jedoch deutlich abgewiesen. Wir haben es also gleich zu Beginn mit einer sprachhandlung zu tun, deren Resultat jedoch keine Situationswende, sondern die Manifestierung der Nicht-Beziehung (im Sinne einer Verbindung) zwischen beiden Protagonisten als zustand ist.

\footnotetext{
1 Die zitate aus den Dranen Cechovs werden übersetzt und in transliterierter Form angegeben. Die deutschen obertragungen richten sich weitgehend nach den obersetzungen Urbans (1973-1981) und werden dort. wo eine Rorrektur als nötig erscheint, verandert angeführt.

Die angegebenen Seitenzahlen von zitaten aus der "Möwe" beziehen sich auf Band 13 der Gesamtausgabe. Moskau 1978.
} 
Sorin erklart dann Treplev in einer Replik mit monologischer Tendenz, daß ihm das Landleben zuwider sei und er sich nur in einer stadt wohlfühlen könne. An diesem zustand wird sich aber im Verlauf des stūckes nichts āndern. Da Treplev nur die Ansichten seines onkels bestätigt. kommt es zu keiner Inderung der sprachsituation.

In dem Wortwechsel mit der hinzugekommenen Mas̆a lüber den 'heulenden Hund') wird deren ablehnendes Verhältnis zu ihrem Vater angedeutet, wiederaufgenommen am Ende des ersten Akts gegenūber Dorn. Bine Inderung in der Beziehung zwischen Vater und Tochter wird bis zum Schlub von keinem der beiden intendiert. Sie bleibt zustand.

Im Gespräch mit Sorin macht Treplev seine Kritik am gegenwärtigen Theater und seine eigenen Ideen über eine zeitgerechte Dramatik deutlich. Seine Liebe zu Nina, das gespannte Verhāltnis zu seiner Mutter, aber auch seine verstāndnisvolle und besorgte Beziehung zu sorin (begleitet durch eine absolute Gebārde:'Rūckt seinem Onkel die Rrawatte zurecht') werden thematisiert. Weiterhin seine Meinung über Trigorin, die hier noch positiv ausfält, was die Person betrifft ("Ein kluger, unkomplizierter Mann... Sehr anstāndig." Celovek unnyj, prostoj...ocen' porjadocnyj; S. 9). zurūckhaltend bis reserviert in der Beurteilung dessen kūnstlerischer Fāhigkeiten.

Zwischen Nina und Treplev wird deutlich, das die liebe des jungen schriftstellers von der zarečnaja nicht erwidert wird. Während sie sich ausweichend verhält, handelt er sprachlich und gebãrdlich ('Ruß'). Die situation wendet sich insofern, als er durch die Liebeserklārung seine Position mitteilt, Nina läßt durch ihre zurūckhaltung jedoch die Möglichkeit einer weiteren Entwicklung offen. Sie gibt dem Gesprãch semantische Nenden, un von Treplevs Liebeserklärung abzulenken.

Treplev. Wir sind allein.

Nina. Ich glaube, da iat jemand.

Treplev. Niemand.

(RuB)

Nina. Was ist das tūr ein Baum?

Treplev. Bine Ulme. 
Nina. Narum ist sie so dunkel?

Treplev. Ba ist schon Abend, da werden alle Gegenstande dunkel. Fahren sie nicht so frūh wieder weg. Ich flehe sie an.

Nina. Bs geht nicht.

Treplev. Und wenn ich zu innen komme, Nina? Ich werde die ganze Nacht in Garten stehen und inr Fenster anschauen.

Nina. Das geht nicht, der Nachtwāchter wird sie

bemerken. Tresor ist noch nicht an sie gewōhnt und wird bellen.

Treplev. Ich liebe sie.

Nina. Passt...

Treplev. My odni.

Nina. Razetsja, kto-to tam...

Treplev. Nikogo.

(Poceluj.)

Nina. Sto kakoe derevo?

Treplev. vjaz.

Nina. Otcego ono takoe temnoe?

Treplev. Uze vecer, temnejut vse predmety. Ne

uezzajte rano. umoljaju vas.

Nina. Nel'zja.

Treplev. $\lambda$ esli poedu $k$ van, Nina? Ja vsju noć budu stojat $v$ sadu $i$ smotret na vaśe okno.

Nina. Nel'zja, vas zametit storoz. Trezor esce ne privyk $k$ vam $i$ budet lajat.

Treplev. Ja ljublju vas.

Nina. Tss... (s. 10)

Bin weiterer strang, die Beziehung zwischen Dorn und Polina Andreevna wird angerissen: Polinas Liebe zum Arzt, dessen zurūckhaltung und Ausweichen. Bei Dorn tallen Sprache und Gebärde zusammen, wenn er seine Bemerkungen meist singend vorbringt. Dies Verhalten zeigt eine Distanz seinem Gesprächspartner und dem Gesprächsgegenstand gegenüber: auberdem fehlt das Interesse an einem Dialog und damit an (sprachlichem) Bandeln, dessen Folge eine lnderung der feweiligen Situation sein kōnnte. Lediglich im Bezug zu Masa und Treplev (Ende erster Akt) versucht Dorn zu vermitteln und helfen. also den augenblicklichen zustand zu verāndern.

Vor (durch das Bamlet-zitat), wahrend und nach der Theaterauffūhrung wird der vorher schon von Treplev artikulierte Konflikt zwischen ihn und seiner Mutter verdeutlicht. Bs kommt jedoch zu keiner Lōsung oder einer vende. Die Standpunkte Arkadinas und Treplevs verhärten sich, der 
Sohn reagiert abweisend mit einer Gebärde (die seine Position nur unterstreicht), Indem er den ort des Geschehens verläbt.

Angedeutet wird auch die Beziehung zwischen Arkadina und rrigorin. Die schauspielerin redet meist anstelle des schriftstellers, wenn dieser angesprochen wird. Ihr Verhalten ist ein zeichen $f u \bar{r}$ ihre Bevormundung und Dominanz und labt daraut schlieben, dab eine situationswende in diesem Verhälnis nur schwer zu vollziehen sein wird, von ihrer seite jedenfalls nicht beabsichtigt ist.

Der Handlungsstrang Nina - Trigorin beginnt im ersten Akt. Die junge zarečnaja lernt durch die Vermittlung Arkadinas den berühmten schriftsteller kennen. Das folgende kurze Gespräch gibt Aufschluß darüber. wie beide der Uneerhaltung eine semantische lende $z u$ geben versuchen, um fūr sich Informationen oder Bestatigungen zu erhalten.

Nina. (zu Trigorin) Nicht wahr, ein merkwürdiges Stūck? habe ich mit vergnügen zugeschaut. Sie haben so aufrichtig gespielt. Auch die Dekoration war sehr schön. (Pause). Sicher gibt es in diesem see viele Bische. Nina. Ja.

Trigorin. Ich angle sehr gern. Für micht gibt es keinen gröberen GenuB als gegen Abend am Ufer zu sitzen und auf den Schwimmer zu schauen.

Nina. Aber ich glaube, wer den Genub des Schaffens erfahren hat. fưr den existieren alle anderen Genūsse nicht mehr.

Nina. (Trigorinu). He pravda li, strannaja p'esa?

Trigorin. Ja niठego ne ponjal. Vprocem, smotrel ja udovol'stviem. Vy tak iskrenno igrali. I dekoracija byla prekrasnaja. (Pauza). Dolzno byt., v etom ozere mogo ryby.

Nina. Da.

Trigorin. Ja ljublju udit rybu. Dlja menja net bol'se naslazdenija, kak sidet pod večer na beregu i smotret na poplavok.

Nina. No, ja dumaju, kto ispytal naslazdenie trorcestva, dija togo uze vse drugie naslazdenija ne suscestrujut. (s. 16f.)

In der ersten Replik aubert sich Trigorin gleich zu drei Themen: Nie er das stūck rreplevs fand, daß ibm rinas spiel und die Dekoration gut gefalien haben. Dann gibt er dem Gesprāch eine semantische Vende durch die Bemerkung 
uber den Fischbestand des Sees, die Nina als Frage auflabt. Ihre Bejahung ist für ihn Anlab, pon seiner Angelleidenschaft zu erzahlen. Jetzt gibt Nina dem Gesprăch eine lende, indem sie auf das für sie interessante Thema künstlerischer Tatigkeit lenkt. Weitere XuBerungen werden jedoch von arkadina verhindert. Jeder der beiden wird sprachlich aktiv und gibt dem Gesprâch semantische Wenden. un ron sich erzâhlen zu können oder seine Meinung bestătigt zu bekommen.

Die letzte Handlungslinie nimmt an Ende des ersten Akts ihren weiteren Verlauf. Masa gesteht Dorn ihre Liebe zu Treplev.

Masa: Ich will es Ihnen noch einmal sagen. Ich will wit Ihnen reden... (Brregt.) Ich liebe meinen Vater nicht... aber Ihnen ist mein Herz zugetan. Irgendwie fühle ich mit ganzer seele, daß sie mir nahe sind... Helfen Sie mir doch. Helfen sie, sonst mache ich eine Dumbeit, verspotte mein Leben, verpfusche es... Ich kann nicht länger...

Dorn: Was denn? Wobei soll ich helfen?

Masa: Ich leide. Niemand, niemand weib, was ich leide! (Lehnt ihren Ropt an seine Brust, leise.) Ich liebe Konstantin.

Masa. Ja esce raz chocu ram skazat'. Mne chocetsja pogovorit... (Volnujas'.) Ja ne ljublju svoego otca... no $k$ vam lezit moe serdce. Pocemu-to ja vseju dusoj cuvstruju. cto vy mne blizki... Pomogite ze me. Pomogite, a to ja sdelaju glupost: ja nasmejus' nad svoeju zizn'ju, isporč ee... Ne mogu dol'se... Dorn. ¿to? V cem pomod'?

Masa. Ja stradaju. Nikto, nikto ne znat moich stradanij! (Kladet emu golovu na grud'. ticho.) Ja Ijublju Konstantina. (s. 20)

Diese situation enthalt mehrere semantische Bbenen. Durch die verschiedenen Informationen, die Masa darin gibt, wird die Replik besonders dialogisch, obwohl Dorn nur eine zwischenfrage stellt. Wir erfahren, dap sie schon einmal ein Gesprảch hatten, daß die Beziebung zwischen Maša und ihren Vater gestört ist und sie sich stattdessen zu dem arzt hingezogen funlt:`z weiterhin, daß sie verzweifelt ist und

- 2 Durch die Beziehung Dorns zu Polina Andreevna und die empfundene Nahe Masas zu dem Arzt konnte man schilessen, daß Dorn vielleicht ogar der leibliche Vater Masas ist. 
Hilfe braucht und der Grund hierfür ihre Liebe zu Treplev ist. Ihre gebärdliches Verhalten drückt sowohl ihre Verzweiflung als auch ihre Zuneigung 24 Dorn aus.

Soweit also die Ausgangsposition, die der erste Akt eroffnet. Die einzelnen interpersonellen Bandlungslinien sollen nun durch das stūck weiterverfolgt werden, beginnend mit der Bbene Maša - Treplev.

Auffallend ist, daß Maša nie direkt auf Treplev zugeht, um ihm ihre liebe zu gestehen oder ihn für sich zu gewinnen. Nachdem sie Dorn ihre Verzweiflung gestanden hat, sehen wir sie im zweiten akt in totaler Lethargie.

Und ich habe ein Gefühl, als wäre ich vor Urzeiten geboren; ich ziehe mein Leben hinter mir her wie eine endlose schleppe... Und oft habe ich überhaupt keine Lust mehr zu leben.

A u menja takoe čuvstuo, kak budto ja rodilas' uże davno-davno: zizn svoju ja tascu volokom, kak beskonečnyj jlejf... I casto ne byvaet nikakoj ochoty zit'. (S. 21)

Sie kann sich zwar selbst begeistern, wenn sie von Treplev erzählt, fallt jedoch gleich wieder in Passivität l'Geht trägen, schlaffen Schrittes." Mir ist das Bein eingeschlafen..." Idet lenivoju, vjaloju pochodkoj. "Nogu otside1a..."; S. 24). Von Dorn erfahren wir zudem, daß sie trinkt, um ihr Unglūck zu vergessen. Am Anfang des dritten Akts hat sie ihre Resignation kompensiert. Als sie mit Trigorin spricht, steht ihr Bntschlub bereits fest, Medvedenko $2 u$ heiraten. Ihre Bntschlossenheit zeigt sich auch gebārdlich ('Drūckt ihm kräftig die Hand.' Rrepko pożimaet ruku; S. 34). Die Repliken Mašas enthalten einige semantische Wenden und kennzeichnen somit ihre Handlungsbereitschaft. Sie bekommen dadurch dialogischen Charakter, obwohl inre Redeteile im Gegensatz zu denen Trigorins, der nur kurze Zwischenfragen stellt oder eine knappe stellungnahme abgibt, relativ lang ausfallen. Zunächst gesteht sie, dab sie sich etwas angetan hatte, wenn rreplevs Selbstmordversuch gelungen wäre, dann spricht sie von 
ihrem Bntachluß, Medvedenko zu heiraten, um thre liebe zu Konstantin zu vergessen. Auf eine zwischenfrage Trigorins begründet sie ihren Bntschluß nochmals ausführlicher. Ausgelöst durch eine mimische Gebärde des schriftstellers spricht sie dann offen von ihren Alkoholproblemen und daß solche bei vielen Frauen nichts Ungewöhnliches seien. Sie ist sich dessen bewrit, daß die Heirat Medvedenkos eine Flucht bedeutet und sie nicht glücklicher machen wird. Sonst würde sie sich auch nicht von Trigorin folgende Vidmung minschen: "Für Mar'ja, die nicht weiB, wo sie hingehōrt und wozu sie lebt auf dieser Helt." (Mar'e, rodstoa ne pomnjaščj, neizvestno dlja ¿ego živuščj na ètom svete: S. 34)

Die ersten Repliken des vierten Akts machen deutlich, daß Maśa in ihrer she den dominierenden part übernommen hat. Um die Nacht auf dem Gut Sorins verbringen zu kōnnen lalso in der Nảhe Treplevsl. wendet sie das Gesprāch von indirekten Schuldzumeisungen Medvedenkos ab, ihr Kind mūsse ihretwegen hungern und die Mutter entbehren, und wirft ihrem Mann Einfallslosigkeit vor. Auch in dem Wortwechsel mit ihrer Mutter bringt sie die situation zu einer semantischen Wende. Mitleidsbezeugungen Polina Andreevnas verwirft Masa und bekraftigt ihre Absicht, die (hoffnungslose) Liebe zu Treplev zu beenden. Sie ist bereits vorher aktiv geworden und hat sich um eine Versetzung ihres Lehrers in einen anderen kreis bemüht. Dies zeigt, daß Maša durchaus eine handelnde person ist, die versucht, ihrer aussichtslosen Fixierung auf Treplev zu entkommen. Allerdings finden ihre Aktivitāten hinter der Būhne statt: über ihre Heirat und die Versetzungsbemühungen erfahren wir nur vermittelt.

Verfolgen wir nun die Handlungslinie Nina - Treplev weiter. An Bnde des ersten Akts sehen wir den jungen schriftsteller auf der Suche nach Nina. Seine Bemerkungen zu den längeren Ausfūhrungen Dorns über Kunst zeigen zielgerichtete Handlungsbereitschaft. Nachdem er von dem Arzt die Bestätigung seines Talents erhalten hat ("Sie sagen also-

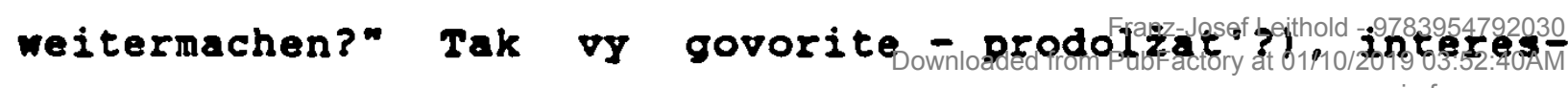


siert ibn nur noch die zarečnaja ("Verzeihung, wo ist die zarečnaja?" Vinovat, gde zarečnaja?). Treplev wendet das Gespräch sehr deutlich auf das, was fûr ihn im Moment wichtig ist, und läbt ein Abreichen Dorns nicht zu ('ungeduldig' "Wo ist die Zarečnajap" 'neterpelivo'. Gde Zarečnaja; S. 19). Er läbt sich von diesem auch nicht beruhigen und reagiert auf die Einmischung Mašas mit einem emotionaIen Ausbruch.

Das zusammentreffen Treplevs mit wina im zweiten akt ist auch von Seiten Konstantins emotionsgeladen und enthait semantische Wenden. Auf Treplevs selbstmorddrohung reagiert die Zarečnaja mit Unverständnis ("Ich erkenne sie nicht wieder." Ja vas ne uznaju; S. 27), woraut er mit einem Gegenvorwurf erwidert, sie habe sich ihm gegenüber stark verāndert. Als Nina nun einrāumt, sie sei zu einfach, um inn zu verstehen, antwortet Treplev in einer langen Replik mit dialogischer Tendenz. Er interpretiert Ninas Verānderung als Reaktion auf seinen künstlerischen Mißerfolg, gesteht, daß sein eigener Ergeiz ihn belastet, kommt dann auf Trigorin und wirft Nina indirekt vor, daß ihre Sympathie für den berühmten schriftsteller auf dessen gesellschaftliche Anerkennung zurūckzuführen ist.43 Treplevs Rede ist auch durch eine gebärdiche Geste unterstützt ("Mit den Fuß aufstampfend" Topnuv nogoj; S. 27). Im dritten Akt kommt es zu keiner zusammenkunft zwischen Treplev und Nina. Wir erfahren jedoch von Masa, daß er tatsachlich versucht hat, sich zu erschieben, und Trigorin zum Duell forderte. Diese aggressiven Handlungen, die sich zunāchst gegen sich selbst, dann gegen den Konkurrenten richteten, hatten bei einem Brfolg natürlich eine situation gewendet, letztlich aber nicht zu Treplevs ursprūnglichem ziel gefūhrt: die Liebe Ninas zu gewinnen. Sie sind daher nicht als zielgerichtet in sinne einer geplanten situationswende $z$ sehen, sondern als Affekthandlungen. Im 
Gesprach mit Dorn erfahren wir dann von Treplev, das ex Nina gefolgt ist, nachdem sie von zu Hause weggelaufen ist.

Ich habe sie damals nicht aus den Augen gelassen und bin thr eine zeitlang auf schritt und Tritt gefolgt. (...) Ich habe sie gesehen, aber sie hat mich nicht sehen wollen, und das Hotelpersonal hat mich nicht zu ihr aufs zimner gelassen.

Togda ja ne upuskal ee iz vidu i nekotoroe vremja kuda ona. tuda i ja. (...)

Ja ee videl, no ona ne chotela menja videt. i prisluga ne puskala menja $k$ nej $v$ nomer. (S. 50)

Treplev handelte also weiterhin, allerdings ohne Erfolg (und für den zuschauer nicht sichtbar).

Und auch die letzte Begegnung zwischen Nina und Treplev ist. was die Repliken Konstantins betrifft. voller semantischer Wenden und Handlungsabsichten. Er schwankt zwischen verzweifeltem Bingeständnis seines Scheiterns und seiner Binsamkeit und einem letzten, hoffnungslosen Versuch. Nina fūr sich zu gewinnen. Sein Selbstmord verewigt in fataler Weise seine unglūckliche Beziehung zu Nina als Zustand.

Was Treplevs schriftstellerische rätigkeit betrifft, so lst diese zielgerichtet auf eine veranderung bestehender kūnstlerischer Formen." Sie ist handlungsorientiert, da sie eine bestehende situation zu verändern plant und dies auch in Angriff nimmt. MuB sich Treplev anfangs noch gegen die Anfeindungen seiner Mutter und das Unverstandnis anderer Personen durchsetzen, so ist er an Ende des stūcks doch offentlich anerkannt (von Arkadina allerdings nicht). und seine Erzāhlungen werden gedruckt. Doch mub er sich am Bnde des stūcks eingestehen, daß sein Handeln zwar erfolgreich war, jedoch keine Inderung seiner psychischen situation bewirkte.

schon vor der ersten persōnlichen Bekanntschaft zwischen Nina und Trigorin im ersten akt ist der schriftsteller für

"Treplevs literarische Konzeption erinnert sehr an die der russischen Symbolisten, vor allem an den Entwurk der "poezija namekov" Valerij Brjusovs. 
die Zarečnaja kein Unbekannter. Sie kennt seine literarischen Werke und hat sich ein festes Bild von ihm gemacht. wie die ausfuhrliche szene in zweiten Akt zeigt, versucht Nina die Realitat ihrer Phantasie anzupassen (und nicht umgekehrt). zwar bietet Trigorin in seinen langen, von semantischen Wenden reichen Ausführungen Nina die Möglichkeit, ihr vorgefabtes Bild von ihm und von kūnstlerischer Popularitāt überhaupt 24 korrigieren. Sie ist jedoch nicht bereit dazu, weigert sich sogar explizit, seine duffassungen zu akzeptieren ("Verzeihen sie, ich lehne es ab. Sie zu verstehen." Prostite, ja otkazyvajus' ponimat' vas; $s$. 30). In dieser szene ist Trigorin sicherlich derjenige. der die situation wenden möchte (konkret: Ninas vorgefabte Meinung andern), jedoch zu keinem Ergebnis kommt, da sein Gegenüber nicht bereit (oder fāhig) ist, diese Handlung mitzuvollziehen. Im folgenden ist trotzdem die zarecnaja diejenige, die in dieser Handlungslinie die aktivere ist. sie schenkt Trigorin das Medaillon und demonstriert ihm durch dieses Geschenk und die Inschrift darauf auf doppelte Weise ihre zuneigung. Die Widnung ist zudem eine direkte Aufforderung, aktiv zu werden. Und sie unternimm noch einen zweiten Schritt: sie fapt den Bntschlub, ihr Blternhaus zu verlassen und Schauspielerin zu werden. Brst jetzt (Ende des dritten Akts) wird Trigorin aktiv und verabredet sich mit Nina in Moskau und erst nach einer gebārdichen Reaktion ihrerseits ('sie lehnt sich an seine Brust'. Ona sklonjaetsja $k$ nemu na grud'; $s$. 44) erfolgt eine liebeserklärung des Schriftstellers. Und auch in Moskau, so erfahren wir von Treplev, hat Nina eines ihrer Handlungsziele weiterverfolgt und erreicht - sie ist schauspielerin geworden. Ihre Liebe zu Trigorin (der sie ja ruiniert hat) ist, nach all ihren Brlebnissen, noch stärker als frūher. Trigorins Verhaltensweise in Moskau kann man durchaus als Binzelhandlung verstehen. Br hat eine situation bewubt geandert (seine bis dahin unbestimmte Beziehung 24 Nina) und ein Verhätnis mit der zarecnaja begonnen. Von einer Gesamthandlung kann jedoch nicht gesprochen werden. Wāhrend

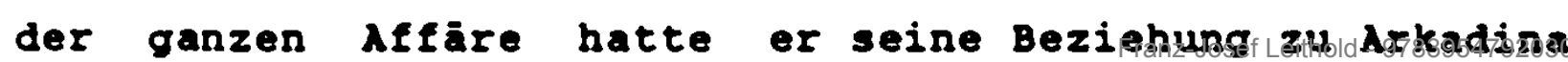


afrechterhalten und sich nach seinem Abenteuer wieder etabliert. Sein Verhaltnis zur Zarečnaja war von Anfang an als befristetes geplant. Seine Lebensweise ist zu Beginn und am Anfang des Dramas die gleiche.

Wie bereits erwähnt, gilt dies auch für Arkadina. Sie hat inren großen Auftritt gegenüber Trigorin am Bnde des dritten Aktes. Ihre Redeteile sind voller semantischer Wenden und sie versteht es wirklich, die situation schlieblich zu ihren Gunsten zu wenden. Zunāchst fragt sie, ob sie schon zu alt und häßlich fūr Trigorin sei; bei ihrem narzißtischen Charakter kann diese Prage natürlich nur rhetorisch sein : und so behandelt sie sie auch, d.h. sie wartet keine Antwort ab. Dann droht sie indirekt, seinen Verlust nicht überleben zu können. Nachdem sie direkte Besitzansprúche angemeldet hat ("Du gehörst mir... du gehörst mir" Ty moj... ty moj; S. 421, versucht sie künstlerischen Fäbigkeiten zu loben, und betont schlieblich die Ernsthattigkeit ihrer Xußerungen. Und auch das (absolute) gebārdliche Handeln Arkadinas unterstreicht die Dramatik und Bandlungsintensitat dieser Situation: 'Mit Zorn; weint; umarmt ihn und küßt ihn; fällt in die knie; umarmt seine Rnie; kūßt ihm die Hānde; lacht.'(s gnevom; plačet; obnimaet ego i celuet; stanovitsja na koleni; obnimaet ego koleni; celuet emu ruku; smeetsja. S. 41fl

Als sie ihr ziel erreicht hat, ist sie 'gelóst, als sei nichts geschehen.' (Razvjazano, kak ni $\nabla$ čem ne byvalo; $S$. 42). Bs bleibt offen, ob ihre Gebārden zu Beginn der Auseinandersetzung mit Trigorin ('in starker Erregung; zitternd; mit zorn.' $\nabla$ sil'nom volnenii; droža; $s$ gnevom; $s$. 11) bereits gespielt sind oder einen echten Gefühlsausbruch ausdrücken, den sie dann aber überwindet.

Auch in der szene zuvor wird Arkadina ihrem Sohn gegenüber aktiv, um das Verhältnis zwischen Treplev und Trigorin zu entkrampfen. Dabei geht es ihr letztlich natürlich auch um die Lösung der eigenen Gespanntheit. 
Schlupfolgerung

Bs lassen sich folgende Feststellungen treffen:

1. Bine dramatische Gesamthandlung fehlt sowohl in der Konzeption des stūcks, als auch im Ergebnis der einzelnen Handlungsstrange. "Wobei alle Teilsituationen nicht in einen allgemeinen knoten verbunden sind, nicht zusammengefast in eine allgemeine Konzentrik der Ereignisse." "s

2. Fehlt eine Einheit der Bandlung, so sind doch einzelne Handlungsstränge zu erkennen. Bezeichnet man das Thema der "Mōwe" als die Darstellung der Diskrepanz zwischen Kunst und Leben, des Konflikts, privates Glück und gesellschaftliche dufgaben auf der einen seite und kūnstlerisches Schaffen auf der anderen seite harmonisch zu verbinden, so kann man im sinne von Klotz von "komplementären strängen" (für das Drama der offenen Form) sprechen. Dem Kollektivstrang "Kunst-Leben" stehen die Privatstränge TreplevNina, Nina-Trigorin, Maśa-Treplev, Arkadina-Trigorin, PoIina Andreevna-Dorn sowie Medvedenko-Masa gegenüber (wobei die Handlung jeweils von den erstgenannten personen ausgeht).

Das Prinzip der komplementảen stränge ist eines der Mittel, der Dispersion des Geschehens im Drama der offenen Form zu steuern. der zerborstenen Form Fluchtinien zu setzen, innere Rommunikation zu stiften zwischen dem auberlich zerstreuten und Vereinzelten. Jeweils auBerpragmatische Mittel sind es, die dieser Aufgabe obliegen. Bei den komplementaren Strāngen geschieht es vom Thema her. welches die Beziehung zwischen zustand und Vorgang, zwischen allgemeinem sachverhalt und exemplifizierendem Einzelfall im Gegen- und Miteinander von Kollektiv- und Privatstrang konstituiert."*

Dabei fällt auf, daß die privatstränge komplementär angelegt sind. Jede Handlungsinie spiegelt bzw. doppelt die

4skaftymov (1948), S. 164 (Pricem vse castnye situacii ne svjazany $v$ obscij uzel, ne svedeny $v$ obscij koncentr sobytij).

- Klotz (1960). S. 105 . 
anderen Stränge. Medvedenko liebt Maša, die sich jedoch zu Treplev hingezogen fūhlt. Dieser wiederum ist auf Nina Eixiert, die aber für Trigorin schwärmt, der am Ende endgültig zu Arkadina zurūckkehrt. Ahnlich verhält es sich andeutungsweise in einer schwächeren Linie, die jedoch nicht durch das ganze stūck eingehalten und so stark ausgeprägt ist: Polina Andreevna liebt Dorn, der jedoch nicht auf ihr Werben eingeht und eher von Arkadina angetan ist (erster Akt).

Es wurde zudem deutlich, daß in der "Möwe" durchaus handelnde Personen zu finden sind.

3. Pūr die "Möwe" läßt sich das dramatische personal in zwei handlungsspezifische Guppen unterteilen.

a) Handelnde Personen, die eine situationswende planen und auf ihr ziel hin aktiv werden, schlieblich aber scheitern, d.h. diesen geplanten Endpunkt nicht erreichen. Zu dieser Gruppe gehören Nina. Treplev, Masa, Polina Andreevna. Fūr Treplev und Nina bestätigt sich hier, dab sie wie in Rapitel 3.2. als Personen charakterisiert sind. die nach einem Lebenssinn und einer sinnvollen Aufgabe suchen. Die von ihnen ins Auge gefabten ziele versuchen sie zu realisieren.

b) Personen, die in begrenztem Rahmen handeln, um eine neue Erfahrung zu machen, letztlich aber am Ausgangspunkt festhalten, wie Trigorin, oder eine Einzelhandlung vollbringen, un den status quo zu erhalten, wie Arkadina.

In der Handlungsführung sind auch sie von techov in der im Rapitel 3.1. als Astheten charakterisierten Heise gezeichnet. Zu dieser Gruppe gehoren auch Samraev, der dann zu Binzelhandlungen fähig ist, wenn er die "Ordnung" auf dem Gut gefährdet glaubt, sowie Sorin, wenn er zwischen Mutter und Sohn zu vermitteln versucht. Hierzu zählt auch Medvedenko, der zwar zu Beginn des stūcks einen bescheidenen versuch unternimnt, Masa auf sich aufmerksam zu machen, im folgenden aber von seiner späteren frau bestimmt wird. Binen weiteren Handlungsversuch unternimmt er am Ende des stücks, als er um seine familiāre Harmonie fūrchtet. 
Schlieblich gehōrt auch Dorn, der an seiner jetzigen lage festhalt und nur in Binzelfallen rom standpunkt des Arztes oder Ratgebere aus handelt, zu diesem Kreis. So am Bnde des ersten Akts, wenn er Treplev zu ermuntern versucht, oder Maša gegenüber, der er jedoch nur emotional beistehen kann. Ansonsten bleibt Dorn Beobachter. Lediglich am Schluß wird er deutlich aktio mit seiner strategischen Lüge, um Arkadina den Schock zu ersparen, zumal er wohl weiß, daß sie auch den Bruder verlieren wird.

1.5. Symbole als handlungskonstituierende slemente

Die Handlungen derjenigen Personen, die ein bestimmtes ziel verfolgen, letzelich aber scheitern, werden durch zentrale Symbole in der "Möwe" verdeutlicht."

Der Begriff "Symbol" wird hier verstanden in sinne Goethes, d.h. "der Symboltrāger ist nicht nur zeichen fūr etwas, sondern zunāchst und vor allem er selbst, zugleich aber ist er entgrenzt, steht in vielfäligen Bezügen, die freilich kaum definierbar sind." "

In der "Mowe" zeigen die symbole einen der jeweiligen Handlungslinie adäquaten Veränderungsprozeb. Bs handelt sich dabei un die zentralen Bilder der Möwe, der Theaterkulisse und des sees. Jedes dieser symbole ist dabei nicht nur einer Person und deren EntwicklungsprozeB zugeordnet. Vielmehr besitzen sie für die einzelnen dramatis personae unterschiedlichen Aussagecharakter. Sie können aber auch zur verdeutlichung eines bestimmten charakterzugs dienen.

"'Mit der Symbolik in der "Möwe" setzt sich auch Peace (1983), S. 33 ff auseinander.

- Hermann (1976), S. 264.

Hermann bezieht sich hier auf Goethes Symboldefinition aus "Maximen und Reflexionen": "Das ist die wahre Symbolik, wo das Besondere das Allgemeine reprasentiert, nicht als Traum und Schatten, sondern als lebendig-augenblickliche offenbarung des unerforschlichen." 2it. S. $263 \mathrm{f}$. Bei Cechov offenbaren die symbole fedoch nicht das Unerforschliche, sondern es geht um die subtile Interdependenz der verschiedenen Binzelaspekte der Gesamtsituation, die dadurch in ihrer Komplexitat "theatralisiert" wird. 
Dies bei denjenigen Protagonisten, die kein bestimmtes Bandlungsziel erkennen lassen.

Durch die Symbolmotive wird im äußeren Rommunikationssystem" auf die Handlungslinien der jugendlichen Protagonisten Nina und Treplev hingewiesen. Dadurch erhät das Drama insgesamt eine Einheitlichkeit, die den zerfall in einzelne Handlungsstränge abschwācht.

Bines der zentralen Symbole stellt die Möwe dar. Mit ihr bringt sich zunächst einmal Nina in Verbindung, die es an den see auf Sorins Landgut zieht "wie eine Möre". (S. 10) sie bezeichnet sich hier aber noch nicht als eine Möwe. wie Berdnikov anführt,30 sondern vergleicht sich nur mit ihr. Diese unterscheidung ist wesentlich; denn erst am Ende des stūcks nennt sich die Zarečnaja eine Mōwe. Noch im zweiten Akt drūckt sie Treplev gegenūber aus, daß sie der gerade getōteten Mōwe keine Bedeutung zusprechen kann.

sie sind in letzter zeit so reizbar geworden, sie drücken sich so unverständich aus, in irgendwelchen Symbolen. Und hier, diese Mowe, ist of fenbar auch ein symbol, aber verzeihen sie, ich verstehe es nicht... (Legt die Mowe auf die Bank) Ich bin zu einfach, um Sie zu verstehen.

$\checkmark$ poslednee vremja vy stali razdražitel'ny, vyražaetes. vse neponjatno, kakimi-to simvolami. I vot ta ćajka toże, po-vidimomu, simvol, no, prostite, ja ne ponimaju... (Rladet čajku na skam'ju.) Ja sliškom prosta, etoby ponimat vas. (S. 27)

10peister (41984), S. 28, sieht den Unterschied zwischen innerem und auberem Rommunikationssystem im Drama vor allem in der unterschiedichen steliung der code Typen:

- Im äußeren Kommunikationssystem wird dieses Nebeneinander der verschiedenen Code-Typen jedoch in ein hierarchisches Obereinander transformiert: der Text erscheint als ikonisierendes superzeichen, in dem auch die symbolische und indizierende zeichenvergabe zum fiktionalen Modell realer Kommunikation ikonisiert wird. Dieses ikonische Superzeichen ist selbst bestimmt durch die übergreifenden sekundären Codes der geltenden literarischen und dramatischen Konventionen und Gattungsnormen und wird über die Distributionsmedien $\mathcal{L}$ r dramatische Texte übermittelt."

- OBerdnikor (31981), S. 150. 
Brst nach ihrer unglūcklichen Beziehung mit Trigorin unterschrieb sie ihre Briefe an Treplev als "Die Mowe". Die Wandlung Ninas in inrem verhaltnis zu diesem symbol unterstreicht den Bntwicklungsproze $\beta$ der Protagonistin. Im Bild der zunachst freien, ihrem Instinkt folgenden Möwe über das sujet fūr eine Brzăhlung bis hin zur ausgestopften Trophäe ist die Bntwicklung der Zarečnaja symbolisch nachvollzogen.

Fūr die Bntwicklung Treplevs besitzt das symbol der Möwe einen verdoppelnden Hinweischarakter. Aus Bifersucht auf Ninas Schwärmerei fūr trigorin schießt er in blinder wut eine Möve und sagt zu dem Mãdchen:

Ich besab die Gemeinheit, heute diese mōwe zu töten. Ich lege sie ihnen zu Eüßen. (...)

Bald werde ich mich auf dieselbe Weise töten.

Ja imel podlost ubit segodnja etu čajku. Rladu u vasich nog. (...)

Skoro takim ze obrazom ja ub'ju samogo sebja. (S. 27)

Seine Drohung macht Ronstantin schlieblich wahr. Der Selbstmord am Ende des stūcks läßt diese zunächst kindisch wirkende Geste Treplevs in anderem Licht erscheinen. Sein Selbstmordversuch, von dem wir in dritten akt erfahren, deutet auf das tragische Bnde hin. Br unterstützt die ProzeBhaftigkeit des Symbolmotivs der Mówe in ihrer Beziehung zu Treplev.

Im Hinblick auf Trigorin besitzt die môwe einen vesentlichen Hinweischarakter. Sie zeigt nicht einen Prozeß wie bei Nina oder einen vorgegebenen Weg wie bei Treplev, sondern verdoppelt auf der symbolischen Bbene das Verhälnis des Schriftstellers zu der jungen Theaterdebūtantin. Nina und die mōwe dienen von Anfang an als sujet fũr eine personliche Erfahrung und deren literarische Verarbeitung. Wie Mrosik richtig bemerkt, deutet der ausgestopfte Vogel an Bnde des stūcks auf den objektcharakter hin, den Nina fūr Trigorin besab.ol Daß or schlieblich vergibt, den Auftrag zum Präparieren des Tieres gegeben zu haben, weist 
auf die Bpisodenhaftigkeit und das Bnde in seiner Beziehung zur Zarečnaja hin.

Das Symbol der Mōwe besitzt also eine dreifache, jeweils verdoppelnde Funktion: Im Hinblick auf Nina verdeutlicht es den BntwicklungsprozeB der Protagonistin - symbolisch vom Vergleich zur partiellen Identifikation mit dem Seevogel. Br zeigt die Veranderung von individueller Freiheit zum bloben objekt fremder Interessen. Im zusammenhang mit Treplev macht es auf die Erfolglosigkeit seiner Bemūhungen aufmerksam und weist darauf hin, daß sein scheitern bereits im zweiten Akt vorherbestimmt ist. Bezūglich Trigorin deutet das Symbol der Mōwe auf dessen lim ersten Kapitel beschriebenel äshetische Lebenshaltung und damit sein Verhãltnis zu Nina hin.

Auch dramentechnisch wirkt dieses Bild in dreifacher Hinsicht als "Motor fūr die Handlung", "eine Klammer fūr die Integration des Dramas" und als ein Mittel. den im Drama sich vollziehenden Breignissen "Allgemeingūltigkeit" zu verleihen. 92

Xhnlich wie mit dem symbol der Mōwe verhālt es sich mit dem Bild der Theaterkulisse. Sie macht aut Ninas und Treplevs Traum von einer Künstlerkarriere und deren Desillusionierung aufmerksam. Sie ist der ort ron Ronstantins Theaterinszenierung und Ninas erstem Auftritt als schauspielerin.

rreplev beschreibt die Rulisse selbst:

Und das ist das Theater. Vorhang, dann die erste RuIisse, dann die zweite und dahinter der leere Raum. Reinerlei Dekorationen. Der Blick eroffnet sich direkt auf den See und auf den Horizont.

Vot tebe i teatr. Zanaves', potom pervaja kulisa, potom vtoraja i dal'se pustoe prostranstvo. Dekoracij nikakich. Otkryvaetsja vid prjamo na ozero i na gorizont. (S. 7)

Der freie Blick auf den Horizont läßt noch die Unbekūm- 
mertheit und hoffnungsvolle zuversicht von Konstantins kûnstlerischen Ideen ahnen.

Cechov macht uns erst wieder in vierten akt auf die theaterkulisse aufmerksam. Zwei Jahre sind seit der Inszenierung Treplevs vergangen. Medvedenko bemerkt:

Man sollte anweisen, dap jenes Theater im Garten abgerissen wird. Bs steht nackt da. hälich, wie ein skelett. und der Vorhang schlagt im Wind. Als ich gestern abend daran vorbeiging. schien mir. als ob jemand darin weinte.

Nado by skazat' ctoby slomali $\mathbf{v}$ sadu tot teatr. Stoit golyj. bezobraznyj. kak skelet, i zanaveska ot vetra chlopaet. Kogda ja vcera vecerom prochodil mimo, to mne pokazalos'. budto kto v nem plakal. (S. 45)

Das Bild dieser skeletthaften Kulisse weist zurūck auf die Träume der beiden jungen Protagonisten zu Beginn des Geschehens. Und es weist voraus auf das dann Folgende.

Konstantins Bemūhungen un eine Brneverung des Theaters sind gescheitert. Seine literarischen arbeiten haben inm zwar begrenzte Anerkennung, aber keinen kūnstlerischen Durchbruch gebracht. Auberdem hat er sein ziel, ein bedeutender Theaterautor in kūnstlerischer und persōnlich glūcklicher Gemeinsamkeit mit Nina als schauspielerin nicht erreichen kōnnen.

Medvedenkos Worte deuten auch auf den Auftritt Ninas hin. Denn. wie sich spāter herausstellen wird, war sie es. die dort weinte. Sie hatte noch einmal den ort aufgesucht, an dem sie zwei Jahre zuvor noch ihren Traum von einer glanzenden Theaterkarriere besab und wo der Prozeb ihrer Desillusionierung begann.

Ich habe schon zwei Jahre nicht mehr geweint. Gestern war ich spāt am Abend im Garten un nachzusehen, ob unser Theater noch da ist. Und es steht immer noch. Ich habe zum ersten Mal seit zwei Jahren geweint, und mir murde es leichter, klarer in der seele.

Ja uže dva goda ne plakala. veera pozdno večerom ja posla posmotret $\nabla$ sadu, cel li nas teatr. $A$ on do sich por stoit. Ja zaplakala pervyj raz posle druch let, $i$ menja otleglo, stalo jasnee na duše. (s. 57)

Indem Nina zum ort des Geschehens zurückkehrt, wird sie mit den Brlebnissen und Träumen ihrer Jugend und Rindheit 
konfrontiert. Der Rreis schließt sich, als sie noch einmal den Anfang von Treplevs Theaterstūck, ihrer ersten Rolle, zitiert. Nicht grundlos sind dies inre letzten Worte in diesem Drama.

Wie auch bei dem Symbol der Môwe gibt das Verhalten Trigorins zur Theaterkulisse einen Hinweis auf dessen àsthetische Lebenseinstellung. Zu Treplev äubert er:

...ich mup mir den Garten und jene stelle anschauen, wo man - erinnern sie sich - ihr stūck spielte. In mir ist ein Motiv herangereift, ich mub mir nur den Ort der Handlung wieder vergegenwärtigen.

...nado osmotret sad i to mesto, gde - pomnite?igrali vaśu p'esu. U menja sozrel motiv, nado tol'ko vozobnovit $\nabla$ pamjati mesto dejstvija. (S. 52)

Die stelle, wo zwei Jahre zuvor seine Affäre mit Nina begann, taugt, wie zuvor die Mōwe, nur noch zu einem literarischen Motiv für ihn.

Das zentrale symbol in diesem Drama ist jedoch nicht das Titel-Symbol der "Möwe". sondern das verdeckte Dramensymbol des sees.

Der see im stück ist mehr als ein Landschaftsbild: ohne ihn kann man schwer dessen ganze bildhaftsymbolische Atmosphäre empfinden.s

An ihm vollzieht sich das Geschehen des stūcks. Auf ihn beziehen sich auch die beiden anderen symbole. Die Mōwe ist ja nicht ohne Hasser zu denken, und die Theaterkulisse Treplevs steht am see und bildet zusammen mit dem Horizont Hintergrund und Blickpunkt für seine Inszenierung.

In der Regieanweisung des ersten Akts deutet Cechov aut die zentrale Bedeutung dieses Bildes. Bine breite Allee führt im Hintergrund zum see, der zunächst noch durch die Theaterkulisse verdeckt wird.

An Bnde des ersten Akts verweist Dorn auf den see, den er gleichsam verantwortlich macht für die gespannte stimmung unter den Protagonisten.

spapernyj (1980), S. 33 (Ozero v p'ese - bol'se, cem pejzaz; bez nego trudno ošcutit Ceskuju atmosferul. 
Wie nervōs alle sind! Wie nervōs alle sind! Und soviel Liebe... Oh, dieser Zaubersee!s 4

Kak vse nervny! Rak vse nervny! I skol'ko ljubvi... o. koldovskoe ozero! (S. 20)

Bereits vorher macht Dorn deutlich, daß der Blick auf den see seine stimmung beeinflubt. Nachdem Treplevs Theaterstūck beendet murde, bittet er, den Vorhang wieder aufzuziehen, damit die sicht auf den see trei wird.

Ich nehme an, man kann jetzt den Vorhang aufiehen, es ist sonst so unheimlich.

Polagaju, teper' možno podnjat' zanaves, a to žutko. (S. 16)

Auch im zweiten Akt wird wieder aut den see in der Regieanweisung hingewiesen. Zu Beginn des vierten Akts bemerkt Masa, daß infolge des schlechten Netters der See riesengrobe Wellen habe. Dies ist ein Vorzeichen für die nun folgenden, bezūglich Treplev und Nina "stürmischen" Ereignisse. Die von Dorn dem See zugeschriebene Zauberkraft nimmt im letzten Akt bedrohliche Formen an.

Wir haben bereits darauf hingewiesen, daß horizont und see die noch unbegrenzten zukunftsträume Ronstantins symbolisieren. Als er den MiBerfolg seines Theaterstücks erleben muß und die zuneigung Ninas tür Trigorin bemerkt, Elüchtet er sich zunächst an den See. Arkadina weist darauf hin, dak ihr sohn "ganze Tage auf dem see verbringt" (celye dni provodit na ozere; $S$. $221 \mathrm{Als}$ er die Hoffnung auf eine künstlerisch und emotionell glūckliche zukunft schwinden sieht, bringt er seine Enttauschung und Frustration (gegenūber der zarečnaja) mit dem Bild des sees in zusammenhang.

Wenn sie wübten, wie unglücklich ich bin. Ihre plotzliche Rühle ist schrecklich, ist unglaublich, als ob ich aufgewacht ware und sehe, das dieser see plotzlich ausgetrocknet oder in die Brde versickert ist.

Bsli by vy znali, kak ja nescastliv! Vaše ochlażdenie straśno, neverojatno, toćno ja prosnulsja i vižu vot.

S "Roldovskoj" bedeutet im Russischen "zauberisch". Das heibt, daß vom see eine zauberkraft ausgeht; er schlagt die Menschen in seinen Bann. 
budto dto ozero vdrug vysochlo ili uteklo v zemlju. (s. 27)

Nina verbindet mit diesem symbol die Erinnerung an ihre Kindheit, die sie hier unbeschwert und geborgen verbrachte.

Ich habe mein ganzes Leben an diesem see verbracht und kenne auf ihm jede kleine Insel.

Ja vsju iizn' provela okolo etogo ozera i znaju na nem kazdyj ostrovok. (s. 31)

Bereits in ihrem Namen wird die dffinitä zum see angedeutet. Denn wōrtlich übersetzt bedeutet zarečnaja "jenseits des Flubes gelegen".

Dies ist aber auch der Ort, an dem die Bohdme verkehrt, also derjenige kulturelle Rreis, dem sie als schauspielerin so gerne angehōren mōchte. Deswegen zieht es sie "an den see wie eine Mōwe". Die stätten ihrer kindheit sucht Nina im vierten Akt noch einmal auf, un sich dann in eine ungewisse zukunft zu begeben ("seit meiner Ankunft gehe ich hier herum... am see." S samogo priezda ja vse chodila tut... okolo ozera. S. 56).

Wie auch bei den Symbolen der Möwe und der Theaterkulisse dient der see zur Charakterisierung Trigorins. Zunächst stellt er fur inn ein objekt dar. Denn zuerst erkundigt sich der schriftsteller nach den Fischbeständen lerster Akt). Später bringt er den see in zusammenhang mit dem Bild der Mōwe, das er literarisch verwerten will.

Br ist aber auch ein Zufluchtsort, an den sich der leidenschaftiche Angler sowohl vor der dominierenden arkadina flüchtet als auch vor dem eigenen schreibzwang. der sich bereits verselbstandigt hat. Bs ist daher bezeichnend, daß Trigorin bei seiner Abreise (dritter Akt) Jakov die Anweisung gibt, seine Bücher zu verschenken, aber die Angeln einzupacken, denn die brauche er ja noch.

Arkadina und Dorn verbinden mit dem see die Brinnerung an ihre Jugend. Im ersten Akt bemerkt die schauspielerin:

Vor zehn, fünfzehn Jahren konnte man hier, am see, Last jede Nacht ununterbrochen Musik und Gesang horen. Hier am Ufer sind sechs Landsitze. Ich weiB 
noch, Gelachter, Lärm, Schieben, Romanzen, immer Romanzen ... Jeune premier und Abgott aller sechs Güter war damals, hier, darf ich bekanntmachen (nickt zu Dorn herüberl Doktor Bøgenij Sergeic. Auch heute ist er noch bezaubernd, aber damals war or unwiderstehlich.

Let 10-15 nazad, zdes', na ozere, wuzyka i penie slyJalis' nepreryvno pocti každuju nod'. Tut na beregu Jest pomešic'ich usadeb. Pomnju, smech, Sum, strel'ba, $i$ vse romany, romany... Jeune premier'om $i$ kumirom vsech etich šesti usadeb byl togda vot, rekomenduju (kivaet na Dorna). doktor Ergenij Sergeic. I teper' on ocarovatelen, no togda byl neotrazim. is. 15f.)

In seinem Notizbuch hatte sich Cechov zunächst notiert:

stück: die schauspielerin fing an zu schluchzen, als sie den Teich sah. sie hate sich an ihre Rindheit erinnert.'s

Dieses Motiv taucht in Cechovs letztem stūck wieder auf. bezogen auf ein anderes symbol. Dort verbindet Ljubov' Ranevskaja mit dem Rirschgarten die Erinnerung an eine glūckliche Rindheit.s.

Das Symbol des Sees trảgt seit jeher viele Bedeutungen. Im Mārchen grenzt das Meer oder der see immer die hiesige von einer anderen Welt ab. In diesem Sinne kōnnte das Bild des Wassers fūr die zarečnaja zutreffen, ihre Herkunft vom "anderen Ufer" klingt bereits in ihrem Namen an (siehe Kapitel 3.2.2.). Auch wenn man ihr schicksal mit der am AnEang dieser Arbeit zitierten russischen Romanze in Verbin-

osoln.sobr.sod.. Bd. 17, Moskva 1980, s. 39.

" Wie der see in der "Mōwe" besitzt das symbol des Rirschgartens in Cechovs gleichnamiger Romódie eine zentrale Bedeutung. Besetzt wird dieses Bild von den Protagonisten mit unterschiedichen Inhalten: Anja bedeutet er heimat und Geborgenheit, Lopachin sieht ihn aus den Blickwinkel des früheren Leibeigenen und, verbunden mit seinem sozialen Aufstieg, unter dem Aspekt seines heutigen Verkaufswerts, Firs erinnert er an die "gute alte zeit". den studenten Trofimov hingegen an unmenschliche Leibeigenschaft und Ausbeutung und an die Aufgabe der Intelligenz, ganz RuBland $z u$ einem "blühenden Garten" zu machen. 
dung bringt, llegt eine Interpretation anhand folkloristischer Motive nahe.

Aber auch das Unbewubte wird oft durch Wassersymbolik angedeutet. Treplevs unbewubte zuflucht zum see (zweiter Akt), sein Gefangensein an den Ufern seiner Rindheit, symbolisiert, dap or noch nicht einen zustand klarer Bemutheit erreicht hat.

Wasser ist aber auch ein Symbol für zeit und Schicksal. schicksalshaft drohend erscheint der see schlieblich 24 Beginn des vierten Akts.

Die hardlungskonstituierenden Symbole in der "Möwe" unterscheiden sich in ihrem Wesen folgendermaßen: Der see steht fūr die unbelebte, sich gleichbleibende Natur, die sich nur im Bewutsein der Personen verāndert (mit Ausnahme des hohen Hellengangs, auf den Maśa zu Beginn des vierten Akts hinweist). Die Mowe entstamm der belebten Natur, die zerstort wird. die Theaterkulisse der unbelebten Welt der Runst.

Der Gebrauch zentraler Symbolmotive in der "Mowe" weist auf ein spezifisches Charakteristikum des Dramas der Jahrhundertwende hin. Klotz konstatiert fūr die Handlung im Drama der offenen form, daß neben Polymythie, komplementáren Handlungsstrāngen, zentralem Ich, Totalitäscharakter einzelner Ausschnitte und einern Integrationspunkt auch die metaphorische Klamerung den Gesamtzusammenhalt der dramatischen Form bewirkt.

Metaphern des gleichen Bildfeldes, vereinigt 24 enggeknüpten Bildketten, stiften ein eng verschlungenes latentes Bezugssystem von Punkt zu Punkt ihres Brscheinens. 37

Bin innerer Zusammenhang wird dadurch gestiftet, daß verschiedene Metaphern, verstreut über das Drama, auf einen bestimsten Sachverhalt hinweisen, "die als wiederholte und variierte Wortmotive oder Bildketten, gespeist aus einem

1Klotz (I960), S. 115. 
Eestumrissenen Bildfeld, sich von szene zu szene spannen und einen inneren Konnex bilden." ws

In der "Mōwe" stiften Jedoch nicht Metaphern, sondern Symbole einen zusammenhalt. Doch führen diese nicht zu einem einzigen sachverhalt hin. sondern deuten verschiedene Bandlungsstrānge an. Durch diese "Dingsymbole" wird der Gesamtzusammenhang exhalten, indem das Augenmerk des Rezipienten immer wieder auf die leitmotivisch wiederkehrenden Bilder gerichtet wird. Vir haben zuvor diesen Aspekt als Handlungsdopplung gekennzeichnet.

Andererseits aber deutet die (relative) offenheit der Symbole auch auf die Vereinzelung der protagonisten hin. Indem jedes Bild $f \bar{x}$ die einzelnen Personen eine andere Bedeutung erhālt und im ảuberen Kommunikationssystem jeweils auf einen anderen Handlungsstrang verweist, wird das zentrale Problem der Einsamkeit verdeutlicht.

Die Symbole gelangen nicht wie die Metaphern "aus dem Bereich des bildichen sprechens in den der szenisch konkreten Begebnisseng. sondern der Wandel des Geschehens und die symbolverảnderung verlaufen parallel.

Die Symbolik in Cechovs "Môwe" besitzt auch noch eine weitere, fủr die Dramatik wesentliche Bedeutung.

Da das Bild durch die Gleichzeitigkeit, mit der es mehreren Sinnebenen angehort, und die Freibeit, mit der es neue sinnstrukturen schafft, der eigentlichen Rede gegenüber einen höheren Informationsgehalt hat. kommt es der Notwendigkeit von Rūrze und Dichte entgegen. Bs kann mehreres auf einmal ausdrūcken. Auch bleibt seine Aussage in der schwebe. legt sich nicht fest, ist offen für weitere Gehalte, die sich ihr anlagern wollen. Beide Bigenschaften haben einen überraschenden Bffekt auf den zuschauer und aktivieren ihn. In dieser Weise dient das Bild der Hirkung.:0

\footnotetext{
- ebda. S. 107.

- ebda. S. 223.

- Hermann (1976). S. 268.
} 
2. Rommunikations- und Beziehungsstrukturen

\subsection{Untersuchungsmethode}

Fūr die Untersuchung der Beziehungsstrukturen soll eine Methode herangezogen werden, die sich vorwiegend auf den pragmatischen Aspekt von Kommunikation konzentriert. Wichtig ist also nicht die isolierte Analyse einzelner sprachlicher גußerungen, sondern auch die Reaktion der jeweiligen partner darauf, die Rūckkoppelung und die Einbeziehung des gesamten aubersprachlichen Rontextes.

Als Untersuchungsmethode, die diese Forderungen zu erfüllen vermag, erscheint mix der behavioristische Ansatz von Watzlawick/Beavin/Jackson als der geeignetste." 1 Ex beschaftigt sich im Gegensatz zur Sprechakttheorie Wittgensteins und seiner schule mit "strukturen von Interaktionen (patterns of interaction)."'s $\mathrm{Da}$ bei versteht Watzlawick unter "Interaktion" eine wechselnde Abfolge von Mitteilungen zwischen wenigstens zwei Kommunikationspartnern. Er untersucht die "Sender-Empfanger-Beziehung auf der Basis der Romnunikation", (H.,S.23) mobei Rommunikation und Verhalten gleichbedeutend behandelt werden.

Watzlawick entwickelt fünt pragmatische Axiome menschlicher Rommunikation:

Ausgehend vom menschlichen Verhalten, das nie ein NichtVerhalten sein kann, lautet der erste Grundsatz:

1. Axiom: Man kann nicht nicht kommunizieren. (W..S. 53)

Rommunikation ist also nicht nur ein bewuter sprachlicher

- 1Hatzlawick/Beavin/Jackson (41974).

Die Brgebnisse der Untersuchungen von Hatzlawick u.a. legen ihren Arbeiten auch zugrunde: Divis (1983) und Müller-Zannoth (1977).

- \& Watzlawick/Beavin/Jackson (41974), S. 51. Im folgenden direkt in Text angefübrt als (W..S.51). 
Vorgang, der gegenseitige Verstandigung voraussetzt." Jede Mitteilung besitzt sowohl einen Inhalt als auch "einen Binweis darauf, wie ihr Sender sie vom Empfanger verstanden haben möchte." (W..S.53)

2. Axiom: jede Rommunikation hat einen Inhalts- und einen Beziehungsaspekt, derart, das letzterer den ersteren bestimmt und daher eine Metakommunikation ist. (H. S.56)

Von Bedeutung ist auch, wie jeder Kommunikationspartner den KommunikationsprozeB interpretiert und auch über diesen zu metakommunizieren in der Lage ist.

3. Axiom: Die Natur einer Beziehung ist durch die Interpunktion der Rommunikationsabiaufe seitens der Partner bestime. (W..s.61)

In kommunikativen Interaktionen kommen sowohl rein sprachliche als auch paralinguistische Phänomene zum tragen. Rein begriffiche Inhalte werden durch digitale. Beziehungsaspekte mittels analoger Xommunikation übermittelt:

4. Axiom: Menschliche Rommunikation bedient sich digitaler und analoger Modalitäten. Digitale Rommunikationen haben eine komplexe und vielseitige logische Syntax, aber eine auf dem Gebiet der Beziehungen unzulangliche Semantik. Analoge Rommunikationen dagegen besitzen dieses semantische Potential, ermangeln aber die für eindeutige Rommunikationen erforderliche logische syntax. (W.,S.68)

Watzlawick unterscheidet nun in seinem letzten Axiom symmetrische und komplementare Interaktionen. Als symetrisch bezeichnet er all die Beziehungen, die eine Tendenz zur Gleichheit erkennen lassen. Komplementăr sind all die Interaktionen, in denen sich gegenseitig ergänzende Unterschiedlichkeiten ausbilden, sich ein partner als dominierend, der andere sich unterwerfend erweist.

5. Axiom: Zwischenmenschliche Rommunikationsablaufe sind entweder symetrisch oder komplementăr, je nach-

- Jies brachte Matzlawick und seinen Mitautoren den Vormurf ein, dab "die Grenzen des Signalverhaltens zum Gebrauchsverhalten nun aber nach und nach verwischt" werden. was furr unsere Untersuchung jedoch nicht von Bedeutung ist. Ralkofen (1983), S. 143 . 
dem, ob die Beziehung zwischen den partnern auf Gleichheit oder Unterschiedichkeit beruht. (H.,S.70)

In folgenden beschreibt Watzlawick Formen gestōrter Kommunikation, wie sie in den fünf angeführten Grundmustern auftreten kōnnen. Fūr die Untersuchung der Kommunikationsstrukturen in Cechovs "Möwe" sind, neben strategien zur (scheinbaren!) Vermeidung von Kommunikation, stōrungen in den Bereichen der Inbalts- und Beziehungsaspekte sowie in symmetrischen und komplementāren Interaktionen von Bedeutung.

Folgende, fūr dieses Kapitel wichtige Formen, einer Kommunikation aus dem Heg zu gehen, können beobachtet werden.*4 Zunāchst einmal die direkte "Abweisung" (H..S. 75) eines Gesprāchs durch Bekundung von Desinteresse, wodurch naturlich trotzdem eine Beziehung. wenn auch eine negative. hergestellt wird.

Die "Annahme" (W..S.75) einer Unterhaltung aus reiner Höflichkeit ist zwar keine direkte Vermeidung, kann aber als eine Art von gestōter Kommunikation gesehen werden. sie findet nur gezmugenermaben statt und hinterläbt bei demjenigen, der sie annimmt, meist das Emptinden eigener Schwäche.

Bei der "Entwertung (disconfirmation)" (H..S.75) kann derjenige, der an einem Gespräch nicht interessiert ist, die eigenen KuBerungen oder die des anderen bewubt und unbewubt entwerten, den sinn entstellen.

Hierfūr gibt es eine ganze Reihe semantischer MōgIichkeiten, wie Widersprüchlichkeit, Ungereimtheiten. Themawechsel. unvollstandige sātze, absichtiches Mibverstehen, unklare oder idiosynkratische Sprachformen, Konkretisierung von Metaphern oder metaphorische Auslegung konkret gemeinter Bemerkungen und dergleichen mehr. (H..S.75)

Bel der Untersuchung der Rommunikation in der "Möwe" ist die Form der Entwertung fūr uns die interessanteste.

-Die "Verneinung von Kommunikation bei schizophrenie" wird hier ausgeklammert. 
Bine weitere Mōglichkeit bietet "das Symptom als Rommunikation". Um einem Gesprach auszuweichen, gibt der Gesprächspartner z.B. vor, Kopfschmerzen zu haben. Bekommt er nun ein schlechtes Gewissen, weil er sich seiner Ausrede bewubt ist, versucht er sich und den anderen davon zu überzeugen, daß er tatsächlich Ropfschmerzen hat.

All dies ist jedoch nichts anderes als eine etwas kompliziertere Umschreibung der Tatsache, dap man ein psychoneurotisches, psychosomatisches oder psychotisches Symptom hat. (H..S.78)

Der Idealfall auf dem Gebiet der Inhalts- und Beziehungsaspekte ist natūrlich eine Binigkeit über den Inhalt der Kommunikation wie auch in der Definition der Beziehung. Der schlechteste Fall ist die Umkehrung des Idealfalls. Mischformen sind solche Interaktionen, in denen über einen Aspekt Binigkeit, über den anderen Uneinigkeit besteht. Zu störungen in der Ich- und Du- Definition kommt es, wenn die Sichtweise des eigenen selbst vom Geprächspartner nicht bestātigt wird. Fūr diesen Aspekt fūhrt Watzlawick zwei Möglichkeiten an: Die eine ist die 'Verwerfung', die sichtweise des anderen wird nicht bzw. nur begrenzt anerkannt. die andere ist die 'Bntwertung'. bei der die menschliche Wirklichkeit des anderen nicht wahrgenommen wird.

störungen in symmetrischen und komplementären Interaktionen sind zum einen 'symmetrische Bskalationen'. versteckte oder offene Auseinandersetzungen, in denen jeder der partner vom anderen die "Verwerfung der selbstdefinition" (H.. S.104) verlangt. Zum anderen die Form 'starrer Romplementarität: Die selbstdefinition des partners wird nicht verworfen sondern entwertet. Die Folge einer solchen störung ist die Auflósung eines gefestigten komplementāren systems und die bedingungslose Unterwerfung des einen Partners unter den anderen.

Was jedoch das Kommunikationsmodell Watzlawicks nicht liefert, sind Brklärungen fūr bestimmte Kommunikationsformen. es beschreibt diese lediglich. zudem ist nicht zu klaren, ob ein bestimmtes verhalten bewubt oder unberubt 
erfolgt: Ursachen in der Vergangenheit werden nicht berūcksichtigt.

Um die Kommunikationsablāufe zwischen den Personen in der "Mōwe" ausfủhrlich zu untersuchen, mūssen auch die Regieanweisungen berūcksichtigt werden. Gerade im Beziehungsbereich spielen die paralinguistischen phānomene ja eine weitaus größere Rolle als Mitteilungen auf der digitalen Bbene. Wesentliche Bedeutung kommt dabei denjenigen Regieanweisungen zu, die Kirschstein-Gamber als "die Mittel der Darstellung: Xußere Bewegung, Affektgestaltung, Pantomime und Alltäglichkeit"os zusammentaBt.

Unter Affektgestaltung werden "symptomatische Anweisungen" verstanden, sie "geben das Mittel an (xörperbewegung, Mimik, Sprachgestaltungl, mit welchem ein Affekt sichtbar gemacht werden sol1".. sowie "Regieanweisungen, die allgemeine Affektbezeichnungen beinhalten".' also erklāren. welcher Bindruck durch sie entstehen soll.

Der Begriff der Alltäglichkeit umfasst alle Tãtigkeiten des täglichen Lebens wie Essen, Trinken, Gesellschaftsspiele etc.. die in Cechovschen Drama eine wichtige Rolle spielen. Für die Untersuchung der Rommunikation in der "Möwe" ist dieser Begriff auch nicht uninteressant, denn wenn die Protagonisten lieber Lotto spielen, als sich zu unterhalten. Ist dies ein Hinweis auf die art und Weise der zwischenmenschlichen Beziehungen.

Mit einbezogen werden auch Xußerungen von Personen über Abwesende. Sie charakterisieren die zwischenmenschlichen Beziehungen und ihre Binschatzung durch die Protagonisten selbst und geben Hinweise auf Rommunikationsablaufe, die bereits stattgefunden haben.

Der in den Analysen angewandte Begriff des Gesprāchs wird verstanden in der Definition von Dittmann:

- Kirschstein-Gamber (1979), S. 71-91.

- ebda.. S. 76 .

- 7 ebda. S. 77 . 
Bin Gesprach ist jener spezialfall von zentrierter Interaktion, in dem mindesten zwei Beteiligte sprachlich kommunizieren (sei es von Angesicht zu Angesicht oder, unter Hahrung der Identitat des zeitraumes. über ein technisches Medium vermittelt), derart, daß sie

1. nicht nur handlungsbegleitend sprechen, sondern über ein Thema, das im Brennpunkt ibrer kognitiven Aufmerksamkeit: steht.

2. mindestens einmal einen Sprecherwechsel vol1ziehen...

\subsection{Binzelanalysen}

Im folgenden stelle ich die Beziehungen und Interaktionen der Protagonisten zueinander dar, zunāchst die der hauptpersonen Arkadina, Treplev, Trigorin und Nina. Genauer betrachtet werden auch die Kommunikationsstrukturen zwischen der Arkadina. Treplev und Sorin, un zu sehen, ob die Personen innerhalb der Verwandtschaft verstandnisvoller und problemloser miteinander umgehen als mit den anderen. Anschließend wird die Aufmerksamkeit auf die ūbrigen Personen gerichtet, vor allem auf ihren Rontakt zu ihnen nahestehenden Protagonisten: Medvedenko und Masa sowie deren Beziehung zu ihren Bltern. Masa und Treplev, Šamraev und Polina Andreevna sowie das Verhālenis des Arztes Dorn zu den übrigen.

Innerhalb der Untersuchung der Nebenfiguren kann man auch das komunikative Verhalten der Hauptpersonen zu ihnen erkennen, auf weitere Binzelanalysen soll daher verzichtet werden.

Abschliebend wird in einer zusamentassung der Versuch einer Gesamtanalyse der in der "Möwe" vorherrschenden Rommunikationsstrukturen vorgenommen.

Arkadina - Treplev

Das Verhāltnis der Schauspielerin Arkadina zu ihrem sohn weist typische zūge einer gestörten symmetrischen Beziehung in der Inhaltsobene auf.

- Dittmana (1979). S. 5. 
Zunachst beschreibt Treplev in der Unterhaltung mit Sorin seine Mutter als geltungssūchtig, ja geradezu narzißtisch und geizig. Positiv erwahnt er ihr schauspielerisches Talent, ihre Rlugheit und die Fähigkeit, mitleiden zu kōnnen.

Die Meinung der beiden über das Theater sind kontrax. Der Hauptkonflikt zwischen Treplev und seiner Mutter ist vor allem seine empfundene Minderwertigkeit ihr gegenüber.

...manchmal sind bei ihr nur Berūhmtheiten zu Gast. schauspieler und schriftsteller, und unter ihnen bin nur ich - ein Nichts, ich werde geduldet, nur weil ich ihr Sohn bin. Wer bin ich? Was bin ich?

...byvalo, u nee sidjat $\nabla$ gostjach splos' vse znamenitosti, artisty i pisateli, i mezdu nimi tol'ko odin ja - nicto, i menja terpjat tol'ko potomu, Cto ja ee syn. Rto ja? Čo ja? (S. 8)

Zum offenen Konflikt komnt es dann bei der Theateraufführung. Hier zeigt sich, dab keiner der beiden bereit ist, die Auffassung des anderen über Theaterkunst zu akzeptieren. Da das Theater jedoch die Hauptbeschätigung sowohl der Arkadina (als Ausführende) als auch Treplevs (als Schriftstellerl ist, kann bier von einer Verwerfung der Selbstdefinition des Gegenūbers auf der Inhaltsebene gesprochen werden. Die eigene sichtweise und Tätigkeit wird vom anderen nicht akzeptiert, keiner ist bereit, einzulenken.

Treplev bricht die Theaterauführung ab, indem er erbost die Bühne verläbt. Arkadina vertritt inren standpunkt weiter im Gesprach mit ihrem Bruder und ist weiterhin nicht bereit, die Tātigkeit ihres sohnes anzuerkennen. Br tühlt sich verspottet, sie sich durch seine neue Theaterkonzeption bedroht. Im zweiten Akt treffen die beiden nicht aufeinander. Der dritte Akt zeigt eine ahnliche Auseinandersetzung. Anfangs verstehen sich die beiden gut auf der analogen Beziehungsebene, den Selbstmordversuch Treplevs kommentiert Arkadina in infantiler Ausdrucksweise : 
Und wenn ich weg bin, machst du nicht wieder piffpafe?

A ty bez menja opjat' ne sdelaes' cik-cik? (s. 37)

In dem Augenblick, in dem es wieder um einen wesentichen Aspekt der selbstdefinition geht - die Beziehung arkadinas zu Trigorin, seine schriftstellerische. Täigkeit und Treplevs Kunstauffassung - andert sich die situation erneut schlagartig. Wiederum kommt es zur Verwerfung der selbstdefintion. die in gegenseitigen Beschimplungen gipfelt. Brst als Treplev zu weinen beginnt, lenkt seine Mutter ein, ist eine Verstāndigung auf analoge Neise mōglich. Jetzt wird die Beziehung komplementãr. Treplev nimmt quasi die Rolle eines Kleinkindes gegenūber seiner Mutter ein. Im vierten Akt kommt es zu keiner wesentlichen Unterhaltung zwischen den beiden - kurze, belanglose Nortwechsel. ein KuB in Vorbeigehen. Die psychisch-depressive Verfassung ihres sohnes bemerkt die Arkadina nicht. Die Binsilbigkeit, den melancholischen Walzer, den er auf dem Klavier spielt und schlieblich die verbale Xuberung über seine Gemūtsverfassung (am offenen Fenster) Iảbt die Arkadina nur zu der Bemerkung hinreiBen:

Kostja, mach das Fenster $2 u$, sonst zieht es. Kostja, zakroj okno, a to duet. (S. 55)

Und selbst den SchuB, mit dem sich thr sohn umbringt, ist sie nicht fảhig, richtig zu deuten, er erinnert sie nur an Breignisse in der Vergangenheit.

Gegen Bnde des stūckes gipfelt also die Kommunikation zwischen beiden nicht nur in der verwerfung der selbstdefinition des anderen auf der Inhaltsebene. Die Protagonisten scheinen auch auf der Gefühlsebene uninteressiert und hilflos zu sein. Der analoge Bereich, die nonverbalen signale und schlieblich die direkte Aussage Treplevs über seine psychische verfassung, wird von der Arkadina nicht mehr wahrgenommen.

Bemerkenswert ist auch, daß Treplev noch wenige Augenblikke vor seinem selbstmord, nach dem zusamentreffen mit Nina, Angst hat, seine Mutter zu verärgern: 
Es wāre schlecht, wenn jemand sie im Garten trifft und es dann Mama sagt. Das könnte Mama Rummer bereiten..

Nechorošo, esli kto-nibud' vstretıt ee $v$ sadu i potom skazet mame. Bto mozet ogorcit mamu... (S. 59)

Die Komplementaritāt im Beziehungsbereich ist selbst noch im Moment äuBerster Verzweiflung wirksam.

Arkadina - Trigorin

Schon in ersten Akt wird das Verhaltnis zwischen der Arkadina und ihrem Lebensgefahrten deutlich. In Gepräch mit Nina antwortet die schauspielerin zunāchst fũr Trigorin. obwohl dieser anwesend ist.

Br ist eine Berūhmtheit, aber er hat eine einfache Seele.

On znamenitost', no u nego prostaja dusa. (s. 16)

Btwas spāter:

Reden sie nicht so. Wenn man ihm schōne Worte sagt. versinkt er im Brdboden.

Ne govorite tak. Kogda emu govorjat chorošie slova. to on provalivaetsja. (s. 17)

Der ironische Tonfall dieser Repkliken ist deutlich. Her den dominierenden part in dieser Beziehung einnimmt. deutet Cechov in folgender Regieanweisung, nach dem streit un die Rutschpferde zwischen Samraev und der Arkadina, an:

(Arkadina) Gaht nach links ab. wo man das Badehaus vermutet-nach einer Minute sieht man, wie sie ins Haus hinübergeht: hinter ihr her geht Trigorin mit Angeln und einem Bimer.

(Arkadina) Uchodit vlevo, gde predpolagaetsja kupal'nja: Eerez minutu vidno, kak ona prochodit $v$ domi za neju idet Trigorin s udockami i s vedrom. (S. 25)

Arkadina hat also beschlossen, abzureisen. Trigorin muB seine Lieblingsbeschātigung (das Angeln) aufgeben und ihr folgen.

Im zweiten Akt kommt es nur an Bnde zu einem kurzen Wortwechsel:

Arkadina: Boris Alekseevic. wo sind sie?

Trigorin: Sofort. (Geht und sieht sich nach Nina um: am Fenster, zur Arkadina.) Has ist?

Arkadina: Wir bleiben. 
Arkadina: Boris Alokseevic, gde vy?

Trigorin: Sejcas! (Idet i ogljadyraetsja na Ninu: $u$ okna, Arkadinoj.l Cto?

Arkadina: My ostaemsja. (S. 32)

Ob die beiden abfahren oder nicht, entscheidet ausschlieblich die Arkadina. Trigorins Meinung zảhlt nicht. Lediglich im dritten akt scheint sie die Rolle der aberlegenen dem Schriftsteller gegenüber aufzugeben. Aber es wird schnell deutlich, daß sie die verzweifelte, demūtige Frau nur spielt. (s. Rapitel 3.1.1.). un ihren Villen durchzusetzen. Nachdem Trigorin eingelenkt hat, verhalt sie sich, als sei nichts gewesen.

Trigorin: Ich habe keinen eigenen Willen ... Ich habe niemals einen eigenen Wilien gehabt ... Schlaff, schlapp, immer gehorsar - kann das einer Frau gefallen? Nimm mich, bring mich fort, aber lab mich keinen Schritt von dir fort...

Arkadina (zu sich): Jetzt gehört er mir. (ungezwn gen, als sei nichts geschehen.) Obrigens, wenn du willst, kannst du bleiben.

Trigorin. U menja net svoej voli... U menja nikogda ne bylo svoej poli... vjalyj, rychlyj, vsegda pokornyj - neużeli eto mozet nravitsja zenścine? Beri menja, uvozi. no tol'ko ne otpuskaj ot sebja ni na sag....

Arkadina (pro sebja). Teper' on moj. (Razvjazno, kak ni $v$ Čm ne byvalo.) vpročem, esii chočs., mozes. otstat'sja. (S. 42 )

Bemerkenswert ist, dab beide hier nur ihr ziel verfolgen, keiner auf die argumente des anderen eingeht, jeder sich unverstanden sieht.

Im vierten Akt haben beide dann wieder ihre Position eingenommen. Die Arkadina bestimmt (hier: Lotto zu spielen). und Trigorin gehorcht. Zu einem Gespräch kommt es auch nicht, als es un Treplevs schlechte Kritiken geht:

Arkadina: Warum dem überhaupt Aufmerksamkeit schenken.

Trigorin: Br hat kein Glūck. Br kann einfach den richtigen Ton nicht finden.

Arkadina: Ochota obraśčat vnimanie.

Trigorin: Bmu ne vezet. Vse nikak ne mozet popast. $v$ svoj nastojašcij ton. (S. 54) 
Die letzte Xußerung macht die Arkadina dann wieder über den anwesenden Trigorin, in ironischer Weise, wie zu Beginn dess stūcks:

Arkadina: Dieser Mensch hat doch immer und überall Glück. (...) Unsere Berühmtheit hat heute nicht $2 u$ Mittag gegessen.

Arkadina: ítomu celoveku vsegda i vezde vezet. (...) Naša znamenitost ne obedala segodnja. (S. 55 )

Die strukturen in dieser Beziehung sind also fest, weisen alle Merkmale einer starren Romplementaritat auf, wobei die Arkadina den dominierenden Part einnimm, Trigorin sich bedingungslos unterwirft, keinen eigenen willen zeigt. Bs kommt weder zu einer Metakommunikation über ihre Beziehung, noch zu einem normalen Gespräch auf der Inhaltsebene.

Treplev - Trigorin

Obwohl der Ronflikt zwischen diesen beiden protagonisten fūr das stūck wesentlich ist, treffen sie lediglich (von der Theaterauffuhrung im ersten Akt abgesehenl im vierten Akt kurz aufeinander. Nach der formellen Begrūßung versucht Trigorin hier zwar mit Treplev ins Gespräch zu kommen, indem er über die Aufnahme dessen literarischer Werke berichtet. Treplevs Reaktion ist jedoch nur die Prage: "Sind sie auf langer hier?" (Nadolgo $k$ nam? S.52), womit sein Desinteresse an einem weiteren Gesprach deutlich gemacht ist. Im ersten Akt außert er sich Sorin gegenüber noch rohlwollend über Trigorin.

Bin kluger, einfacher Mann, ein bißchen melancholisch, weibt du. Sehr anstandig.

Celovek umnyj, prostoj, nemnožko, znaes', melancholičnyj. Ozen' porjadočnyf. (s. 9)

Brst als sich das Verhaltnis Trigorin - Nina anbahnt, beginnt er den Ronkurrenten $2 u$ verachten. Im dritten Akt erfahren wir aus dem Gespräch mit seiner Mutter, dab Treplev Trigorin zum Duell gefordert hatte. Am Ende dieser szene verlät er den Raum, als er Trigorin kommen sieht. 
Insgesant kann man in dieser Personenkonstellation folgendes konstatieren: Trigorin nimmt Treplev gegenüber eine reservierte Haltung ein, âußert sich lediglich (beilâutig) über dessen literarische Tãtigkeit. Binem Gesprāch geht er zwar nicht aus dem Weg, bemūht sich aber auch nicht darum. Treplev ändert sein Verhalten Trigorin gegenüber von anfảnglich wohlwollenden bis gleichgūltigen XuBerungen zu offener Verachtung. Er versucht jedoch ständig. der Kommunikation auszuweichen, und verläbt entweder den Raum oder bekundet sein Desinteresse, indem er das Gesprāch durch eine belanglose Frage unterbricht. Die Forderung zum Duell ist ein weiteres symptom $t u ̄ r$ das Ausweichen vor verbaler Kommunikation.

Arkadina - Sorin

Die Momente, in denen die arkadina mit ihrem Bruder in Kontakt tritt, sind selten. Auf der Beziehungsebene kommt es zu gar keinen kuberungen.

Im ersten akt versucht Sorin den streit zwischen Treplev und dessen Mutter zu schlichten, scheitert aber. Die einzigen Bemerkungen. die er den Austührungen seiner schwester hinzufügen kann, sind:

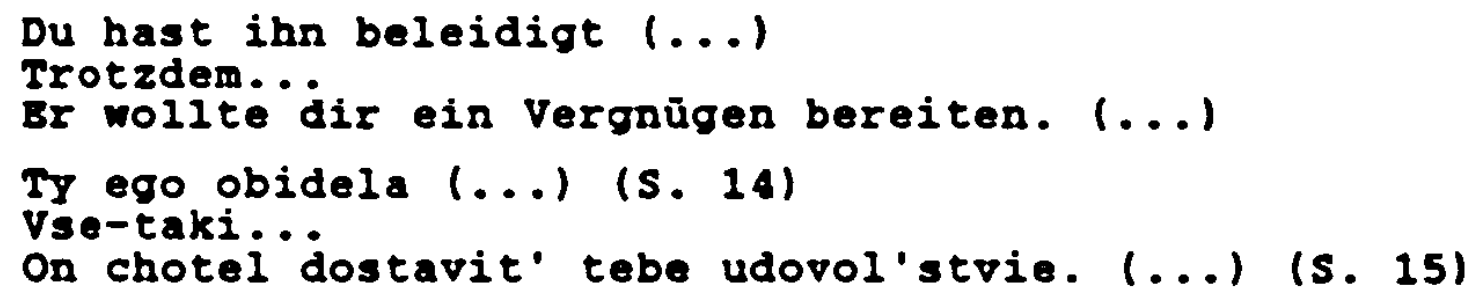

Im zweiten akt gibt es zunāchst ein kurzes Gesprāch zwischen den beiden und Dorn darüber, ob sorin sich ärztich behandeln lassen soll. Anschliebend aubern sich Arkadina und ihr Bruder über das langweilige handleben und die Annehmlichkeiten der stadt. Anscheinend verstehen sie sich hier auf der Inhaltsebene:

Arkadina: Ach was kann langweiliger sein als diese liebe landliche Langeweile! Ba lat heib. still. niemand tut etwas, alle philosophieren... Bs ist schön bei euch. Freunde, ich höre gern zu, aber... in seinen Hotelzimer zu sitzen und seine Rolle zu lernenvieviel schōner ist das. 
Nina: (begeistert.) Das ist schōn! Ich verstehe Sie. Sorin: Natūrlich, in der stadt ist es schōner. Du sitzt in deinem Kabinett. der Lakai lả nt niemanden unangemeldet herein, das relephon ... auf der straße Droschken und so ...

Ach. cto možet byt' skučnee etoj vot miloj derevenskoj skuki! Zarko, ticho, nikto nikego ne delaet, vae Eilosofstvujut... Chorošo $s$ vami, druz'ja, prijatno vas alusat'. no... sidet u sebja $v$ nomere i učit. rol' - kuda lučš!

Nina (vostorżenno): Chorošo! Ja ponimaju vas.

Sorin: Ronečno, $\nabla$ gorode luçse. Sidis' $v$ svoem kabinete. lakej nikogo ne ppuskaet bez doklada. telefon... na ulice izvozciki i vse... (s. 24)

Aus dem Kontext wird jedoch ersichtlich, daß die Interpunktion jeweils eine völlig andere ist. Die Arkadina assoziiert mit dem Leben in der stadt ibre Tätigkeit als Schauspielerin und ihren Brfolg beim publikum. Sorin schätzt eher die kleinen Annehrlichkeiten, das Leben um ihn herum. Wahrend seine schwester bewundert werden will. ist ex eher Bewunderer, geniebt die allgemeine Geschátigkeit."Beide träumen jedoch davon, in einem abgeschlossenen, von der AuBenwelt isolierten Raum zu sein. Wie auch Arkadina nur über thre Kunst mit der Umwelt in Kontakt tritt (s.Rapitel 3.1.1.), will sorin nur durch einen Lakaien und das Telefon mit seiner umgebung in Verbindung kommen.

Beim streit um die pferde fūr die Ardadina zeigt sorin das einzige Mal in diesem stũck, daß er der Gutsbesitzer ist. und ergreift erregt $f u ̄ r$ seine schwester Partei. Nachdem diese erbost gegangen ist, sagt er zu Nina:

Kommen sie mit zu meiner schwester... Wir wollen sie alle anflehen, nicht abzufahren. Nicht wahr?

pojdemte $k$ sestre... My vse budem umoljat' ee, čtoby ona ne ueziala. Ne pravda li? (S. 25)

Ein Beweis dafūr. wie sehr er der Mrkadina ergeben ist.

- Und Nina assoziiert mit der stadt den Beginn ihrer Theaterkarriere. Diese Textstelle zeigt eine typische Kommunikationsstruktur der Dramen Cechovs. Inhaltich scheinen die protagonisten übereinzustimmen. die Interpunktion ist aber bei jedem eine andere. 
In dritten akt uberhört sie zunächst, daß er mit in die stadt fahren will ("Also lebe hier, langweile dich nicht...: Nu, zivi tut, ne skukaj...s.35).t• Als sorin dann über Treplev spricht, nimmt sie erst dann Bezug, als ihr munder Punkt, nämlich ihr Geiz, berūhrt wird. Und auch hier āubert er Verstāndnis fūr die angeblich schlechte materielle situation seiner schwester, obwohl er spätestens seit dem Gesprāch mit seinem Neffen im ersten Akt weiB. wie ihre finanzielle Lage wirklich ist: oder er täuscht seine Binsicht nur vor, um die Arkadina nicht zu verärgern. 12

Die dann folgende szene ist bezeichnend für das Verhältnis zwischen Bruder und Schwester. Als Sorin erfahren mub, daB er Arkadina nicht umstimmen kann, reagiert er mit einem Schwācheanfall ("Symptom als Rommunikation"). Dieser Situation gegenūber zeigt sich die schauspielerin vōllig hilflos. Sie bemerkt nicht, dab ihre unnachgiebige Haltung gegenüber Treplev die Ursache für das körperliche Unwohlsein ihres Bruders ist. Dieses signal auf der analogen Bbene nimmt sie nicht wahr.

Der vierte Akt bringt dann keinen Dialog mehr zwischen den beiden; als Arkadina ihn anzusprechen versucht, schlaft sorin.

Treplev - Sorin

zu einem Gespräch zwischen den beiden kommt es lediglich im ersten Akt. Den Ausfūhrungen Sorins, er müsse in der stadt leben, stimmt Treplev bei. Ihre Unterhaltung wird zunāchst von Masa, dann von Jakov unterbrochen. Sorin versucht, wie auch spāter bei der Theaterauffūhrung, zwi-

70 Obwohl sie selbst sich auf dem Land nicht vor Langeweile zu retten weib und ihr bekannt ist, dab ihr Bruder sich grundsatzlich auf seinem Landgut langweilt. macht sie diese XuBerung. Man kann hieraus annehmen, daß ihr das Befinden ihres Bruders egal ist.

1 Man kōnnte Sorins Reaktion hier auch als Ironie deuten. Seine ganze bisherige charakterzeichnung. sein eher naives und unbeholfenes auftreten in den übrigen Repliken schliebt eine solche sichtweise jedoch aus. 
schen Treplev und dessen Hutter zu vermitteln. Aut die Vorwürfe der Arkadina gegenüber geht er inhaltlich nicht ein, sondern versucht ihn zu überzeugen, dab sie ihren Sohn vergōttert. Ebenso verhālt sich Sorin spāter, als er seine schwester überzeugen will, daß Treplev ihr eine Freude mit dem Theaterstück machen wollte. Auf Treplevs Ausfūhrungen über das Theater kann er nur antworten: "Ohne Theater geht es nicht." (Bez teatra nel'zja; S. 8) Die Darstellung der persōnlichen Situation seines Neffen scheint er gar nicht zu registrieren, sondern nimmt sie zum Anlaß. Informationen über Trigorin zu erfragen, diese wiederum, un über sich und sein vertanes Leben zu erzāhlen.

Bine Verstandigung auf der Inhaltsebene ist also kaum gegeben. Beide wissen jedoch die situation des anderen gut einzuschātzen. Im dritten Akt kann jeder gegenüber der Arkadina die persōnliche lage des anderen verständich darstelien.

Vor allem im vierten Akt wird durch eine XuBerung Masas und aus Regieanweisungen deutlich, das auf der analogen Beziehungsebene Binvernehmen zwischen den beiden herrscht. Zunächst sagt Masa:

Der Alte fragt jede Minute, wo ist Rostja, wo ist Rostja... Br kann ohne inn nicht leben ...

starik každuju minutu vse sprašivaet, gde Rostja, gde Rostja... Zit' bez nego ne možet... (s. 45)

Dann erfahren wir, daß Sorin darum bat, sein Bett bei Treplev aufzuschlagen, er mōchte in dessen Nāhe sein. Spāter. nachdem wir über den melancholischen Gemūtszustand seines Neffen informiert murden, heipt es in der kegieanweisung:

Treplev kommt und setzt sich auf ein Bankchen, sorin zu EüBen.

Vchodit Treplev i saditsja na skameečke u nog sorina. (S. 49)

Br sucht also im Moment psychischer Not den Rontakt zu seinem Onkel, allerdings nur auf der analogen Bbene. Verbal stellt er ihn seine Beziehung zu seiner Mutter wie 
auch zu Nina nur im ersten akt dar, zu einer richtigen Aussprache kommt es dort allerdings auch nicht. Arkadina - Mina

Das Verhāltnis zwischen diesen beiden Personen ist komplementār angelegt. Die arkadina nimb die position einer ūberlegenen, meist verstāndnisvolien Mutterfigur ein. Im ersten Akt ermutigt sie Nina, die Theaterlaufbahn einzuschlagen und versucht, ihr die Befangenheit gegenüber dem berūhmten Trigorin $2 u$ nehmen. Gleichzeitig demonstriert sie durch ihr Auftreten ihre dominante Position gegenūber dem schriftsteller.

Als sie jedoch das sich anbahnende verhältnis zwischen Nina und Trigorin bemerkt, reagiert sie reservierter:
Arkadina: Wer ist da eben weggegangen? Nina?
Trigorin: Ja
Arkadina: Pardon, wir haben gestört...
Arkadina: Ėto kto sejčas vyśel? Nina?
Trigorin: Da.
Arkadina: Pardon, my pomesali... (s. 35)

In ihrer Auseinandersetzung mit Trigorin bezeichnet sie Nina schlieblich als Provinzmädchen: "Die Liebe eines Provinzmadchens?" (Ljubov' provincial'noj devocki? S. 41) Nina vergötert die Arkadina. verkörpert sie doch ihren Traum vom Leben als gefeierte Schauspielerin. Dieser auch nur einen Wunsch abzuschlagen, erscheint ihr unmogglich.

Irina Nikolaevna etwas abzuschlagen. einer berūhmten Künstlerin! Ist nicht jeder Wunsch, sogar Laune von ihr wichtiger als eure Wirtschaft? Bs ist einfach unglaublich!

otkazat' Irine Nikolaevne, znamenitoj artistke! Razve vsjakoe zelanie ee, daze kapriz. ne vaźnee vasego chozjajstra? Prosto neverojatno! (S. 25)

Im dritten und vierten Akt treffen die beiden nicht aufeinander. Nina geht der schauspielerin aus dem Weg. Ihre Bhrfurcht zeigt sich auch am Ende des stūcks, als sie noch einmal mit Treplev zusammentrifft. zweimal erkundigt sie sich danach, ob die Arkadina anwesend ist, will ein zusammentreffen unbedingt vermeiden. 
Ich weiß, Irina Nikolaewna ist hier. Schließen sie die Tür $a b . .$.

Ist Irina Nikolaevna hier?

Ja znaju, Irina Nikolaevna zdes'. Zaprite dveri... (s. 56 )

Irina Nikolaevna zdes'? (S. 58)

Treplev - Nina

Die Rommunikation zwischen den beiden ist weder aut der Inhalts- noch auf der Beziehungsebene normal.

Schon aus einer der ersten Jußerungen Ninas erfahren wir, daß nicht Treplev der Grund ihres Interesses ist, sondern die auf dem Gut Sorins herrschende Boheme-Atmosphäre:

Mein Vater und seine Frau lassen mich nicht bierher. sie sagen, hier ist die Boheme... sie haben Angst. ich konnte ans Theater gehen... Und mich zieht es hierher an den see, wie eine Mówe... Mein Herz ist voll von Ihnen.

Otec $i$ ego żena ne puskajut menja sjuda. Govorjat. cto zdes bogema... bojatsja, kak by ja ne posia $v$ aktrisy... $\lambda$ menja tjanet sjuda, $k$ ozeru, kak cajku... Moe serdce polno vami. (S. 10)

Auf Xußerungen Treplevs, die die Beziehungsebene betreffen. sei es digital oder analog, reagiert Nina ablenkend:

Treplev: Wir sind allein.

Nina: Bs scheint, da ist jemand...

Treplev: Niemand.

$$
\text { (KuB) }
$$

Nina: Was ist das fûr ein Baum?

Treplev: My odni.

Nina: Każetsja, kto-to tam...

Treplev: Nikogo.

(Poceluj)

Nina: Bto kakoe derevo? (s. 10)

Das Schwärmen Ninas fūr Trigorins Erzahlungen und die Frage, ob Treplev diese gelesen habe, blockt er abrupt ab: Treplev: (Kalt) Ich weis nicht, Ich habe sie nicht gelesen. ('Cholodno'. Ne znaju, ne Cital: S. 10)

Br versucht hier einem Gespräch auf der Inhaltsebene auszuweichen, indem or Unkenntnis des Gesprächsinhalts vortảuscht, als auch analog ("kalt") Desinteresse bekundet. Daß seine Vorgabe, er habe noch nichts von Trigorin gele- 
sen, nicht stimmt, geht aus seinem vorherigen Gespräch mit sorin hervor.

Auch in dem folgenden Wortwechsel über Theater zeigt sich eine störung auf der Inhaltsebene. Wahrend Treplev seine Auffasssung vom modernistischen Theater vertritt, kann Nina darauf inhaltich nicht eingehen, sondern fordert naiv, ein Theaterstūck mūsse unbedingt von liebe handeln. Daß keine inhaltliche Gemeinsamkeit über das Thema Theater besteht, zeigt sich auch zu Beginn des zweiten Aktes. Maša bittet Nina, etwas aus Treplevs Theaterstück zu sprechen. Ihre Reaktion ist aber nur:

Nina (zuckt die Achseln): Wollen Sie? Das ist so uninteressant!

Nina (požav plečami): Vy chotite? Eto tak neinteresno! (S. 23)

Durch Nina erfolgt hier eine Verwerfung der Selbstdefinition Treplevs. Bin wesentlicher Punkt seiner intellektuellen Bxistenz wird von ihr nicht akzeptiert.

Btwas spāter kommt es dann zu einem kurzen Gesprāch ūber ihre Beziehung, als Treplev ihr die tote Möwe zu Eūßen legt. Doch eine Verstāndigung ist nicht möglich:

Nina: Ich erkenne sie nicht wieder.

Treplev: Ja, seit ich Sie nicht wiedererkenne. Sie haben sich mir gegenüber verāndert. Ihr Blick ist kalt, meine Anwesenheit macht sie verlegen.

Nina: Sie sind in letzter zeit reizbar geworden. Sie drücken sich so unverständlich aus, durch irgendwelche Symbole. Und hier, diese Mowe ist anscheinend auch so ein Symbol, aber verzeihen sie, ich verstehe es nicht ...(...) Ich bin zu einfach, un sie zu verstehen.

Nina: Ja vas ne uznaju.

Treplev: Da. posle togo, kak ja perestal uznavat. vas. Vy izmenilis' ko me, vas vzgljad choloden, moe prisutstvie stesnjaet vas.

Nina: $v$ poslednee vremja v stali razdražitel'ny. vyrazaetes' vse neponjatno, kakimi-to simvolami. I vot eta čajka toze, po-vidimomu, simvol, no, prostite, ja ne ponimaju...(...) Ja silskom prosta, etoby ponimat' vas. (S. 27)

Als Grund fūr das plötzliche Desinteresse Ninas an ihn sieht er seinen literarischen MiBerfolg. weshalb er keine Chance gegenüber Trigorin habe. 
In dritten akt gibt es kein zusammentreffen, erst am Bnde des vierten Aktes erfahrt man zunāchst von Treplev in Gesprãch mit Dorn, wie es Nina in den letzten zwei Jahren ergangen ist. Bine zusammenkunft mit inm hat sie vermieden. Bezeichnend $f u ̄ r$ die Binseitigkeit ihrer Beziehung ist Treplevs Aussage: "Ich habe sie gesehen, aber sie wollte mich nicht sehen. .... (Ja ee videl, no ona ne chotela menja videt'... S.50). Spater bekam er Briefe von Nina. aber zu einer offenen schilderung ihrer psychischen situation scheint sie nicht fâhig zu sein:

Treplev: ... Rluge, warme, interessante Briefe; sie beklagte sich nie, aber ich fühlte, sie war tiefunglücklich: jede zeile ein kranker, zum zerreiben gespannter Nerv. Und sie war ein wenig verwirrt. Sie unterschreib als Die Möme...

Treplev: ... Pis'ma unnye, teplye, interesnye: ona ne zalovalas'. no ja cuvstroval, ¿to ona gluboko nescastna: cto ni strocka. to bol'noj. natjanutyj nerv. I voobrazenie nemnogo rasstroeno. Ona podpisyralas' Cajkoj... (s. 50)

Selbst beim letzten zusammentreffen ist die Rommunikation gestört. Auf die Ausfūhrungen Ninas reagiert Treplev zunāchst nur auf eine analoge Xußerung, nämlich ihr Schluchzen. und stellt dann eine kurze Erage, warum sie nach Blec fahren.

Wie Nina auf die Schilderung von Treplevs Gefūhlen $2 u$ ihr reagiert, ist bezeichnend fūr die gestörte Romunikation zwischen beiden:

Nina (verwirrt): Harum redet er so, warum redet er so?

Nina (rasterjanno). Zaćem on tak govorit, zacem on tak govorit? (S. 57)

Ihre Reaktion auf Treplevs verzweifelte Bitte, bei ibm zu bleiben, ist nonverbal, sie macht Anstalten zu gehen. Brst einige Nortwechsel spāter geht sie auf eine XuBerung Treplevs ein, er habe den Boden gekūbt, auf dem sie gegangen sei.

Hâtte er Nina bisher richtig zugehört, ihre Zerstreutheit und Verwirrung bemerkt, müßte er folgenden satzen von ihr skeptischer gegenüberstehen: 
Ich weiß, ich verstehe jetzt, Kostja, daß fūr unsere Arbeit - egal ob wir Theater spielen oder schreibendie Hauptsache nicht der Ruhm ist, nicht der Glanz. nicht das, wovon ich geträumt hatte, sondern die Pahigkeit durchzuhalten. Trage dein kreuz und glaube. Ich glaube, und es tut mir nicht mehr so weh, und wenn ich an meinen Beruf denke, habe ich keine Angst mehr vor dem Leben.

Ja teper' znaju, ponimaju, Kostja, cto $\nabla$ nasem delevse ravno, igraem my na scene ili pisem - glavnoe ne slava, ne blesk, ne to, o cen ja mectala, a umen'e terpet. Umej nesti svojkrest i veruj. Ja veruju i mne ne tak bol'no, i kogda ja dumaju o svoem prizvanii. to ne bojus' zizni. (s. 58)

Treplev antwortet aber:

Sie haben Ihren Heg gefunden, Sie wissen, wohin sie gehen, ich dagegen treibe immer noch in Chaos der Träume und Bilder, ohne zu wissen, wozu und wer das braucht. Ich habe keinen Glauben und weib nicht, worin meine Lebensaufgabe besteht.

Vy naśli svoju dorogu, vy znaete, kuda idete, a ja vse ešce nošus' $v$ chaose grez i obrazov, ne znaja. dIja čego i komu èto nużno. Ja ne veruju i ne znaju. $\checkmark$ cem moe prizvanie. (s. 59)

Nina wiederum geht auf diese Aussage mit keinem Wort ein.

Trigorin - Nina

Schon im ersten Gespräch mit Treplev erfahren wir von Ninas Begeisterung für Trigorin, der ihr bis dahin persōnlich unbekannt war: "was für munderbare Erzählungen er schreibt!" (Kakie u nego čudesnye rasskazy! s.10)

Beim ersten zusammentreffen reagiert sie befangen und verlegen vor dem berühmten Schriftsteller. Dieser wiederum erscheint gleichgūltig. macht Nina ein oberflachliches Kompliment und erkundigt sich gleich danach, ob es in dem See Fische gibt.

Im ersten langen Gespräch zwischen den beiden (zweiter akt) nimmt Nina die Rolle der Fragenden ein, die den bekannten Autor interviewt. Trigorin antwortet bereitwillig und offen, auch über private Dinge. Nina will nicht verstehen, dap er ron sich und seiner arbeit nicht begeistert ist. Sie reagiert auf seine Ausfūhrungen mit Unverständnis, decken sie sich doch nicht mit ihren vorstellungen 
von einem ruhmoollen Leben als Künstler. Sie weigert sich sogar, seine Unzufriedenheit zu verstehen:

Verzeihen sie, ich bin nicht in der Lage, sie zu verstehen. Sie sind einfach rom Brfolg verwönt.

Prostite, ja otkazyoajus' ponimat' vas. Vy prosto izbalovany uspechom. (s. 30)

Und später:

Sie sind überarbeitet, und sie haben keine zeit und Lust, sich Ihrer eigenen Bedeutung bewubt zu werden. Seien sie ruhig unzufrieden mit sich, aber fūr andere sind Sie grob und herrlich!

Vy zarabotalis', i u vas net vremeni i ochoty soznat' svoe znacenie. Pust' vy nedovol'ny soboju, no dlja drugich vy veliki i prekrasny! (s. 31)

Man kann hier, wie schon in der Beziehung zu Treplev, von einer Verwerfung der selbstdefinition des anderen sprechen. Jedoch aus einer anderen Perspektive. Nina will das Banale und Triviale im Leben dieses berūhmten Literaten nicht wahrhaben, da es nicht in ihre Phantasiewelt past. Fūr Trigorin bietet Nina zunāchst einmal ein sujet fūr eine Brzählung. Was er über die Art seiner (möglichen) Beziehung zu Nina denkt, erfahren wir im dritten Akt im Gesprāch mit der Arkadina:

Bine junge liebe, entzückend, poetisch, die mich ins Reich der Träume bringt, - auf Erden kann sie allein mir Glück schenken! Bine solche Liebe habe ich noch nicht orfahren... In meiner Jugend hatte $i c h$ keine zeit dazu, ich habe den Redaktionen die Türen eingerannt, gegen die Not angekampft... Und jetzt sie, diese liebe, endlich ist sie da, sie lockt... Was für einen Sinn hat es, vor ihr zu fliehen?

Ljubov' junaja, prelestnaja, poetičeskaja, unosjaščaja $\nabla$ mir grez, - na zemle tol ko ona odna možet dat' sćast'e! Takoj ljubvi ja ne ispytal esce... V molodosti bylo nekogda, ja obival porogi redakcij, borolsja 3 nuzdoj... Teper vot ona, eta ljubov', prisila nakonec, manit... Rakoj ie smysl beiat ot nee? ( $S$. 41)

Fūr beide bietet der andere jeweils Anlaß zu romantischen Traumereien und Spekulationen. Nina sieht in Trigorin den Inbegriff ihrer schwämerischen vorstellungen von einem berūhmten Schriftsteller, dem sich hinzugeben ("Wenn du je 
mein Leben brauchst, dann komm und nimm es." Esli tebe kogda-nibud' ponadobitsja moja zizn', to pridi i voz'mi ee: S.40) das höchste aller Gefūhle ist.

Trigorin sieht in Nina die Möglichkeit zu einer poetischen, bisher nie erfahrenen Beziehung mit einem jungen Madchen. Die reale situation des anderen wird in keinem Fall wahrgenommen. Nina will das Alltägliche in ihrem Bild von Trigorin verdrangen, der Schriftsteller will ihr Verhaltnis zu ihm nicht als das unreife schwarmen eines jungen Mãchens erkennen.

Im vierten Akt erfahren wir dann aus dem Gespräch zwischen Dorn und Treplev, wie sich das Verhältnis von Nina und Trigorin weiterentwickelte. Trotz der persönlichen Katastrophe, in die der schriftsteller sie stürzte, liebt sie inn noch genauso wie frūher. Trigorin hingegen hat sein früheres Leben nie aufgegeben und kann sich noch nicht einmal daran erinnern, was fūr eine Bedeutung die Möwe hat, die er auszustopfen in Auftrag gegeben hatte.

Die übrigen Personen

Die Nebenfiguren des Dramas sollen hier nicht so detailliert analysiert werden, wie die Hauptpersonen. Im folgenden wird schematisch umissen, auf welche Weise sie kommunizieren und welcher Art ihre Beziehungen zueinander sind. Zu Beginn des Stūcks treffen Medvedenko und Masa zusammen. Weder auf der Inhalts- noch auf der Beziehungsebene kommt es zu einer Annāherung. Der Dorfschullehrer kann es. nicht verstehen, daß Masa unglūcklich ist, wo sie doch materiell besser gestellt ist als er. Ihre eher allgemein gehaltene Antwort.

"Es liegt nicht am Geld. Auch ein vittelloser kann glũcklich sein."

Delo ne $v$ den'gach. I bednjak możet byt' sčastliv. (S. 5)

bringt er sofort wieder in Bezug zu seiner finanziellen Situation. Wohl erkennend, daß eine digitale Verstāndigung auf der Inhaltsebene nicht möglich ist, wechselt Masa das Thema. Medvedenko benutzt ein paar allgemeine Bemerkungen 
über das Theaterstūck Treplevs, um Maśa seine Liebe zu erklären, setzt die Hof fnungslosigkeit einer Erwiderung jedoch wieder in Bezug zum vorherigen Gesprãchsthema. Maśa stellt ihre Beziehung zu Medvedenko kurz und rein digital dar: "Ihre liebe rührt mich, aber ich kann sie nicht erwidern, das ist alles." (Vaśa ljubov' trogaet menja, no ja ne mogu otvecat' vzaimnost'ju, vot i vse; s.6) Den nochmaligen Versuch, ihs ihre persōnliche situation (ihre unglückliche liebe zu Treplev) zu erklären, bricht sie selbst ab:

"...Im übrigen, Sie verstehen das nicht ..." (Vpročem, vam ne ponjat' etogo...; S.6) Im dritten Akt erklärt Maša Trigorin, daß sie Medvedenko heiraten wird: "Wenn ich heirate, geht es nicht mehr um Liebe, neue sorgen ersticken dann das ganze Alte." (A kak vyjdu zamuż, budet uże ne do ljubvi, novye zaboty zaglusat vse staroe; s.33) Und etwas spãter:

Mein Lehrer ist nicht gerade sehr klug, aber ein guter Mensch und armer schlucker, und er liebt mich sehr. Br tut mir leid. Und seine alte Mutter tut mir leid...

Moj učitel' ne očen'-to umen, no dobryj čelovek $i$ bednjak, i menja sil'no ljubit. Ego zalko. I ego mat' starušku żalko. (S. 34)

Masa und Medvedenko heiraten und haben zusammen ein Rind. Die Rommunikation auf der Inhaltsebene verlāuft knapp (Anfang vierter Akt) und beschränkt sich auf das Nötigste. Ihre Beziehung ist komplementaar, mobei Masa die Dominierende ist (Regieanweisungen: Medvedenko 'Elehentlich', 'schuldbewußt', 'bekümmert', 'schuldbewußter Gang'; umoljajušce, vinovato, opećalennyj, pochodka vinovatajal. Ihre zwischen Gleichgültigkeit und Mitleid angelegte Beziehung zu Medvedenko schlägt zum Schlub sogar in Verachtung um: "(mit bitterem $x r g e r, ~ h a l b l a u t)$ Wenn meine Augen dich nie gesehen hätten!" ('s gor'koju dosadoj, opolgolosa'. Glaza by moi tebja ne videli! $\mathrm{S.48)}$

Beide Protagonisten sind den fūr sie wichtigen Belangen so verhaftet, das sie andere Inhalts- oder Beziehungsebenen kaum wahrnehmen können. Medvedenko bezieht jedes Ge- 
sprächsthema, ob sein Verhältnis zu Maša oder eine Unterbaltung über Theater, auf seine materielle situation." Maša nime die Umwelt nur wahr in zusammenhang mit ihrer unglūcklichen Iiebe zu Treplev. Ihr persönliches Unglūck macht sie zum Thema fast jeder kuperung.

Mit Treplev selbst kommt sie aber während des ganzen stücks nicht ins Gespräch, eine klärende Aussprache über ihre Beziehung findet nicht statt. Masas Liebe wird ron ihn nicht erwidert, Dorn gegenūber bezeichnet er sie sogar als "unerträgliches Geschöpf." (Nesnošnoe sozdanie: S.18) Am Ende des ersten Aktes sagt er zu den Anwesenden:

Und ich bitte sie alle, lassen sie mich in Ruhe! Lassen Sie mich! Gehen Sie mir nicht dauernd nach!

I prošu vas vsech, ostav'te menja $v$ pokoe! ostav'te! He chodite za moj! (S. 19)

Diese Aussage bezieht sich vor allem auf Masa, die ihn vorher gesucht hatte.

Sie ist die Binzige, die von dem Theaterstūck und seiner literarischen Tätigkeit begeistert ist:

(Ihre Begeisterung unterdrūckend). Nenn er selbst etwas liest, dann brennen seine Augen und sein Gesicht wird blaß. Br hat eine schöne, traurige stimme: und Manieren. wie ein Dichter.

(Sderíivaja vostorg). Kogda on sam citaet cto-nibud'. to glaza u nego gorjat i lico stanovitsja blednym. U nego prekrasnyj. pećal'nyj golos; a manery. kak u poeta. (s. 23)

Zwischen beiden zu vermitteln, versucht lediglich Masas Mutter. Treplev will daraut jedoch nicht eingehen:

Polina Andreevna: (zu Treplev) sie ist ein hūbsches Mădchen. 'Pause.' Bine Prau braucht nichts. Kostja, nur einen freundlichen Blick. Das weip ich von mir. (Treplev steht rom Tisch auf und geht schweigend ab.)

Polina Andreerna: (Trepleru) Ona slavnen'kaja. 'Pauza.' Zenscine, Kostja, ničgo ne nužno, tol'ko vzgljani na nee laskovo. Po sebe znaju.

(Treplev ostaet iz-za stola i molca uchodit) (s. 47)

72 Varum Medvedenko fūr Nabokor (1984), S. 377. deshalb "sozialistische Neigungen" hat, bleibt unverstandlich. 
Trotz ihrer Heirat mit Medvedenko ist Maša immer noch auf den jungen schriftsteller fixiert, demūtigt sogar ihren Mann vor den anderen Personen, un in der Năhe Treplevs bleiben zu können.

Im ganzen stūck verstāndigen sie sich also weder auf der Inhalts-noch aut der Beziehungsebene. Treplev versucht die Kommunikation durch direkte Abweisung oder Verlassen der szene zu vermeiden.

Zwischen Mašas Eltern Samraev und Polina Andreevna kommt es zu keiner kommunikativen Interaktion. Ihre Beziehung erschōpt sich in alltāglichen Mechanismen, von Cechov in Regieanweisungen gekennzeichnet.

'Reicht seiner Frau den Arm'

'Samraer kome, hinter ibm Polina Andreevna.

'Podavaja ruku żene' (S. I8)

' Vchodit Samraev. $2 a$ nim Polina Andreevna (S. 24)

Die einzige digitale Kommunikation zwischen beiden ist im ganzen stūck nur folgende:

Polina Andreevna: Kostja spielt. Er ist traurig. der Arme.

Samraev: In den zeitungen verreibt man ihn sehr.

Polina Andreevna: Rostja igraet. Toskuet, bednyj.

Samraev: $V$ gazetach branjat ego ocen'. (S. 54)

Ihre Bhe weist viele Parallelen zu der von Maša und Medvedenko auf. Polina Andreevna liebt, wie auch ihre Tochter. einen anderen. Zu Dorn sagt sie:

... Ich ertrage seine Grobheiten nicht.

(Flehentlich.) Bvgenij mein Lieber, Liebster, nehmen Sie mich zu sich... Unsere zeit vergeht, wir sind nicht mehr jung, und wenn wir uns wenigstens am Ende unseres Lebens nicht mehr verstecken müBten, nicht mehr lügen...

... Ja ne vynoß̌u ego grubosti. (Umoljajušce.) Bvgenij, dorogoj, nenagljadnyj, voz'mite menja k sebe... Vremja naše uchodit, my uze ne molody, $i$ chot' by $v$ konce zizni nam ne prjatat'sja, ne lgat'... (s. 26)

Doch ihre liebe $z u$ ihm ist ohne Aussicht auf eine feste Bindung.

Samraev ist, wie Medvedenko, vollkommen fixiert auf seine alltāglichen Sorgen, nämlich das Gut Sorins zu verwalten. 
Geht es un diesen Bereich, wagt or es sogar, der von ihm hochverehrten Arkadina einen Wunsch abzuschlagen und lät es bis zu einer symmetrischen Bskalation kommen. Wenn er nicht über das Gut, die Ernte oder peerde spricht, langweilt er seine Umgebung mit Anekdoten aus dem Provinztheater.

Die Beziehung zu seiner Tochter ist emotional auch nicht normal, wie kōnnte sonst Maša zu Dorn sagen: "Ich liebe meinen Vater nicht ... aber Ihnen ist mein Herz zugetan." IJa ne ljublju svoego otca... no $k$ vam lezit moe serdce: S.201

Der Arzt Dorn führt mit keiner der Personen ein normales Gesprāch, hindert inhaltliche Annäherungen durch kurze. unumstöblich scheinende Feststellungen oder beginnt ein lied zu singen, un einer Kommunikation auszuweichen. Sein einziger Versuch, mit Treplev über Teater zu sprechen. wird von diesem abgeblockt. Im vierten Akt treibt er lediglich das Gespräch voran, indem er Fragen zum schicksal Ninas stellt.

Auf Hašas Gestāndnis, daß sie Dorn mehr achtet als ihren Vater und inm deshalb ihre liebe zu Treplev gesteht, kann er inhaltlich nicht eingehen.

Nie nervös alle sind! Hie nerös alle sind! Und soviel Liebe ... Oh. dieser zaubersee! (zärlich.) Aber was kann ich denn tun, mein Kind? Has? Has?

Kak vse nervny! Kak vse nervny! I skol'ko ljubvi... o. koldovskoe ozero! (Nežno.) No cto że ja mogu sdelat'. ditja moe? Čto? ¿to?

Lediglich analog ('zärtlich') weip er zu reagieren. Dennoch hat er kein Mitleid mit Masas Unglūck:

Dorn: Sie geht und genehmigt sich schon vor dem Frühstūck zwei Glāschen.

Sorin: Die Arme hat kein Glück in Privatleben.

Dorn: Unsinn, Buer Bxzellenz.

Dorn: Pojdet $i$ pered zavtrakom dve rjumočki propustit.

Sorin: Ličnogo sčast'ja net u bednjažki.

Dorn: Pustoe, vaše prevoschoditel'stvo. (s. 24)

Dorn geht auf der Inhaltsebene auf seine Gesprächspartner selten ein. Has in ersten Moment den Anschein einer Ver- 
stảndigung erweckt, erweist sich bei näherer Betrachtung nur als das Bntgegensetzen des eigenen Standpunktes. Sorin gegenüber ist er offen und völig verstāndnislos. Br verwirft sogar dessen Wunsch nach ärzticher Behandlung und seine Klagen über das vertane Leben. Das erste Gespräch zwischen ihm. Sorin und der Arkadina bricht er brüsk ab:

Arkadina: Das soll einer verstehen. Dorn: Da gibt es nichts zu verstehen. Alles klar.

Arkadina: Vot i pojmi.

Dorn: I ponimat' nećego. Vse jasno. (S. 23)

In dem Gesprảch im vierten Akt kommt es sogar zu einer symmetrischen Bskalation, er verwirft Sorins Wunsch zu leben:

Sorin: Has fũr ein Dickkopt. Begreiten sie doch, ich nöchte leben!

Dorn: Das ist Leichtsinn. Nach den Gesetzen der Natur mub jedes Leben ein Bnde haben.

Sorin: Kakoj uprjamec. Pojmite, zit' chočetsja!

Dorn: Eto legkomyslie. Po zakonam prirody vsjakaja iizn' dolžna imet' konec. (S. 49)

Bbenso nūchtern verhält er sich zu Polina Andreevna. Auf ihre Bitte, sie zu sich zu nehmen, antwortet er nur:

Dorn: Ich bin 55 Jahre alt, da ist es zu spāt, sein Leben zu àndern.

Dorn: Mne pjat'desjat Iet, uze pozdno menjat svoju zizn'. (S. 26)

Auch die Mitteilung über Treplevs selbstmord ist nüchtern und kūhl. Dies ist übrigens die einzige szene, in der er (gezmugenermaßen) zu Trigorin spricht.

Brstaunlich ist seine Bemerkung Treplev gegenūber, Genua sei fūr inn im Ausland die interessanteste stadt gewesen. Der Wunsch, seinen rationalen, naturwissenschaftichen standpunkt aufzugeben, sich zu verlieren, kommt hier das einzige Mal zum Ausdruck. (s.hierzu Kapitel 4.1.4.)

\subsection{Brgebnisse}

Die Untersuchung der Kommunikations- und Beziehungsstrukturen hat gezeigt, das die kommunikativen Interaktionen in 
der "Mōwe", im Sinne von Hatzlawicks Definition, weitgehend als gestōrt bezeichnet werden kōnnen.

Die Protagonisten entwickeln verschiedene strategien. Kommunikation $2 u$ vermeiden bzw. ihr Desinteresse an einer digitalen Unterhaltung auf der Inhaltsebene auszudrūcken. Dabei kōnnen folgende Grundmuster als Formen der Bntwertung beobachtet werden:

1. Räumliches Ausweichen:

Treplev weicht während des ganzen stūcks seinem Rivalen Trigorin aus. Ebenso verhät er sich zu Maja, die er unertraglich findet. Nina geht von dem Moment an der Arkadina aus dem Weg, wo sich ihre Beziehung zu Trigorin anbahnt.

2. Abbruch der Unterhaltung durch Schlubbemerkung:

Der Arzt Dorn vermeidet weitere Diskussionen über den physischen und psychischen zustand sorins, indem er ein (für sich) abschließendes Urteil verkūndet. Die Arkadina bezeichnet die Theaterversuche ihres Sohnes als Aufsassigkeit inr gegenüber und schliebt damit jede inhaltiche Diskussion aus.

\section{Themenwechsel:}

Bine von allen Protagonisten angewandte strategie ist, einem fūr sie unangenehmen oder uninteressanten Thema auszuweichen, indem sie entweder eine andere Inhaltsebene ansprechen oder eine Frage stellen, die mit dem momentanen Gesprächsgegenstand nichts zu tun hat. Oft richten sie ihre Aufmerksameit auf furr sie wichtige Detailinformationen, um dann in dieser Richtung weiter fragen zu kōnnen oder wechseln das Thema, nachdem sie für ihre Person oder ihre rätigkeit wesentliche Bestatigungen (besonders die Arkadina, aber auch Treplev) erhalten haben. 
Folgende stōungen auf dem Gebiet der Inhalts- und Beziehungsaspekte lassen sich feststellen:

1. Verwerfung oder Ignorierung der Ich- und Du-Definition: Bine solche Verwerfung konnten wir zunāchst einmal konstatieren in der Beziehung zwischen der Arkadina und ihrem Sohn. Nicht akzeptiert wird jeweils der fūr den anderen wichtige Beschäftigungsbereich.

Maja hat kein Verstāndnis fūr die materiellen Bxistenzàngste Medvedenkos, dieser wiederum kann Mašas psychischen zustand nicht verstehen.

Nina akzeptiert nicht die Selbsteinschātzung Trigorins, da sie sich nicht mit ihren romantischen Vorstellungen deckt.

- Dorn verwirft die selbstdefinition sorins und akzeptiert eine sichtweise auberhalb naturwissenschafticher Grundsātze nicht. Die Arkadina ist nicht bereit, Šamraevs Sorgen als Gutsverwalter zu respektieren.

Nina kann sich nicht mit Treplev über dessen Theatertheorien auseinandersetzen, da sie sich nicht mit ihren Erwartungen decken.

Trigorin ignoriert vōllig, daß Ninas Gefūhle ihm gegenūber die romantisch verklarten Trāune eines naiven Mãdchens sind.

2. Ignorierung einer Aussage

Auf eine Bemerkung nicht einzugehen, also ein Pseudogesprāch zu fūhren, indem feder seine Aussagen weiter ausführt, ohne das vom anderen Gesagte zu berūcksichtigen. ist eine ständig wiederkehrende kommunikative stōrung in der "Mōwe".

störungen in symmetrischen und komplementären Interaktionen finden wir vor allem folgende:

1. Symmetrische Eskalationen:

Wie bereits erwāhnt, verwerfen die Arkadina und Treplev gegenseitig die selbstdefinitionen des anderen. Die Folge sind symmetrische Bskalationen, die sogar in gegenseitigen 
Beschimpfungen gipfeln können. Binzulenken oder den standpunkt des anderen $2 u$ tolerieren, ist niemand bereit. 2u einer ahnlichen situation kommt es zwischen der Ardadina und Samraev, als es um die Bereitstellung pon Kutschpferden geht.

2. Starre Romplementaritat:

Zwischen Maša und Medvedenko sowie der Arkadina und Trigorin herrscht eine starre Komplementaritat, wobei die Prauenfiguren die Dominierenden sind. Watzlawick hebt zwar hervor, dap die Ronstatierung von Symetrie oder Romplementaritat grundsatzlich keine Nertung beinhaltet. In unseren Fällen ist jedoch die Untergebenheit Trigorins und Medvedenkos so stark, dab man sogar die Aufgabe des eigenen Willens bis hin zum Brdulden von Erniedrigungen feststellen kann.

Das folgende Kapitel beschaftigt sich mit dem Themenkomplex Runst und Leben. Bs soll auch verdeutlichen, das die impressionistische Lebenshaltung Arkadinas und Trigorins sowie die scheiternden Bemühungen Ninas und Treplevs, Runst- und Lebenspraxis miteinander zu verbinden, die bis hierhin beschriebenen Kommunikationsstorungen und das zertallen einer Gesamthandlung in einzelne Handlungslinien bedingen. 
3. Kunst und Leben

3.1. Die Xstheten

Her ästhetisch lebt, sieht nämlich allenthalben nichts als Moglichkeiten. diese machen fûr ihn den Inhalt der Zukunft aus...

Wer asthetisch lebt, der erwartet alles von außen...

S. Kierkegaard? 3

Wenn in folgenden die Figuren arkadina und Trigorin als Astheten bezeichnet werden, so sind sie nicht als der Xsthetik, also der Lehre vom Schönen, verpflichtete Personen zu verstehen, sondern als dem Xsthetizismus nahestehende.

Zwar fehlt den Cechovschen Xstheten das oberfeinerte und Oberspannte, was beispielsweise die literarischen Figuren der Decadence des österreichischen oder französischen "Fin de sidcle" auszeichnet.

Doch stimmt man Rasch 24 , daß "der Asthetizismus die Welt nicht als Wirkungsfeld der Aktivitat, des planens und Handelns, sondern als Brscheinung, als Gegenstand blober Betrachtung, als bedeutsames Schauspiel'mit versteht, so kann man Arkadina und Trigorin in ihrer Distanz und Gleichgūltigkeit gegenüber ihrer Umwelt durchaus als Vertreter eines ausgeprägt russischen Xsthetizismus sehen. In ihrer übersteigert subjektivistischen Lebenshaltung sind sie unfähig, sich ihren Mitmenschen gegenüber verantwortungsbemut und teilnahmsvoll 24 verhalten. Fūr diese Form der Lebenspraxis, die besonders im Impressionismus ausgeprägt ist, konstatiert offermanns:

T3Rierkegaard (1957), S. 268.

T'Rasch (1986), S. 60 . 
Das impressionistische Ich bleibt unfahig zu jeglicher Objektivation, die Helt sein Bindruck, das Du seiner Abenteuer Projektion des eigenen selbst."

\subsubsection{Die Velt als Būhne: Arkadina}

Die 43jāhrige Arkadina ist eine anerkannte, berūhmte Schauspielerin. Durch Treplev erfahren wir zunāchst von ihren Launen, ihrer Ruhmsucht und dem Glauben an die Notwendigkeit ihrer Tãtigkeit.

Nur sie allein darf man loben, über sie muß man schreiben, schreien, sich begeistern fūr ihr ungewōhnliches spiel in "La dame aux camelias" oder im "Rausch des Lebens"...

sie liebt das Theater, ihr scheint, daß sie der Menschheit dient, der heiligen Kunst...

Nužno chvalit tol'ko ee odnu, nuzño pisat'o nej. kricat'. vostorgat'sja ee neobyknovennoju igroj "La dame aux camélias" ili v "Cad zizni"... (S. T)

Ona ljubit teatr, ej kazetsja. Cto ona sluzit celovecestou. svjatomu iskusstvu... (S.8)

Sie ist als Diva eine Repräsentantin des "Starsystems"," die nur in klassischen Theaterstūcken auftritt. Ihr Verlangen nach Brfolg und Anerkennung geht nach den Aussagen ihres sohnes soweit, dap sie sogar auf den Auftritt der jungen Nina zarečnaja in Treplevs stück eifersūchtig ist. Pūr Arkadina verschwimmen die Grenzen zwischen Theater und Realităt nur zu oft. Ihre schauspielerischen Fảhigkeiten setzt sie auch im Privatleben bewubt ein, um Beifall zu erhalten und ihre position verteidigen zu kōnnen. Dies zeigt sich an deutlichsten in der Beziehung zu Trigorin.

schon im zweiten akt wird deutlich, daß sie sich ihres Spiels bempt ist. Dorn gegenüber bricht sie die vorgelesene Passage aus Maupassants "Sur l'Bau" mit dem Binweis

Ts offermanns (1973). S. 10.

r Zum sogenannten starsystem und der situation des russischen Theaters Bnde des 19. Jh.s siehe auch Dlugosch (1977). S. 15-54. Daß gerade die "Stars" mitverantwortich waren fúr den Miberfolg bei der Urauffūbrung der "Möwe". entbehrt nicht einer hintergründigen Ironie. 
$a b$, das nun Folgende sei zu unwahrscheinlich, zu Nina sagt sie, es sei unwahr und uninteressant. Die von Arkadina ausgelassene Textstelle wirft jedoch ein erhellendes Licht auf ihre Beziehung zu Trigorin, wie auch J.H. Katsell ausführlich darstellt.'T Bei Maupassant heiBt es weiter:

Comme l'eau qui, goutte a goutte, perce le plus dur rocher, la louange tombe, d chaque mot, sur le coeur sensible de I'homme de lettres. Alors, des qu'elle le voit attendri, emu, gagné par cette constante flatterie, elle l'isole, elle coupe, peu d peu, les attaches qu'il pouvait avoir ailleurs, et l'habitue insensiblement d venir chez elle, a s'y plaire, a y installer sa pensée. Pour le bien acclimater dans la maison, elle lui ménage et lui prépare des succes, le met en lumière, en vedette, lui témoigne devant tous les anciens habitues du lieu une consideration marquée, une admiration sans egale.

Dies kann sowohl als Verhaltensanleitung fūr die schauspielerin gelten als auch eine warnung für den schriftsteller darstellen. Betrachtet man aber dessen Verhalten der Arkadina gegenūber, seine Abhāngigkeit und Ergebenheit, so läbt sich die angefūhrte passage deutlich als ironische Anspielung verstehen. Die Schauspielerin erkennt sich und Trigorin wieder und stellt die Textstelle als unwirklich dar."*

Berdnikov macht darauf aufmerksam, daß Arkadinas Urteil über Maupassant nicht ehrlich ist.०० Dies verdeutlicht die szene im dritten Akt. in der die schauspielerin versucht, Trigorin von Nina abzubringen und fūr sich zu gewinnen. In dieser Replik verhält sie sich genau so, wie es Maupassant

TRatsel1 (1981).

roupassant (1947), S. 31f.

TDas zitierte lāßt deutlich eine Thrlichkeit in Verhalten Arkadinas zu Trigorin erkennen und charakterisiert nicht, wie Mrosik (1967), s. 29f, meint, das Verhältnis Nina-Trigorin. Nur das von der schauspielerin Vorgelesene für sich genommen liebe eine solche Interpretation $2 u$.

- Berdnikov (*1981), S. 135 E. 
in "Sur l'Bau" fũr eine Erau empfiehlt, wenn sie einen berūhmten schriftsteller an sich binden will.

An dieser stelle zeigt sich aber auch noch ein weiterer Charakterzug Arkadinas. Ihr ganzes Verhalten gleicht hier mehr einem Būhnenauftritt als einem echten Gefūhlsausbruch. Deutlich wird dies nicht nur durch ihr theatralisches Verhalten (s.Rapitel 1.4.). sondern vor allem im Obergang in einen normalen Ton, nachdem sie ihr ziel erreicht hat.

Arkadina (zu sich). Jetzt gehört er mir. (Ungezwungen, als sei nichts geschehen.) obrigens, wenn du willst, kannst du hierbleiben.

Arkadina (pro sebja). Teper' on mnoj. (Razvjazno, kak ni cem ne byvalo.) Vprocem, esli choces'. mozes. ostat'sja. (s. 42$) \cdot 1$

Daß Cechov Arkadina als eine zielstrebige und berechnende Person verstanden wissen wollte, verdeutlicht eine Textstelle aus der ersten Fassung. In Bezug auf Maupassants "sur l'eau" aubert die schauspielerin über ibre erste Bekanntschaft mit Trigorin:

Ich habe Boris Alekseic nicht ausgewählt, nicht belagert nicht gefangengenomen, sondern als wir uns kennenlernten, war in meinem Kopf alles drunter und drúber, und mir wurde ganz grun vor Augen, meine Lieben; ich stehe da. schaue ihn an und weine. Verstehen sie. ich heule und heule. Has war da schon fúr ein Programm dabei?

Ja ne izbirala Borisa Alekseica, ne osaźdala, ne polonila, a kak poznakomilas', vse u menja $\forall$ golove poslo vierch tormaskoj i, rodimye moi. pozelenelo $v$ glazach: stoju. byvalo. smotrju na nego i placu. Ponimaete, revu i revu. Kakaja uz tut programma?

(s. 261E.)

Cechov strich die Passage nicht ohne Grund: denn ein solch unkontrollierter Gefūhlsausbruch paßt nicht zur charakte-

- Auch Scheibitz (1972), S. 76f. weist darauf bin. daß sich Arkadinas Verhalten in dieser szene kaum von einem Bühnenauftritt unterscheidet.

Dieser bewubte Binsatz ihrer Schauspielkunst ist ein wichtiges Detail fūr die Charakteristik Arkadinas. das gübner (1971). S. 67f. allerdings übersieht.

Auseủhrlicher analysiert mrde diese szene schon in Kapitel 1. Bandlung. 
ristik dieser sonst beherrschten und reservierten protagonistin."2

Arkadina selbst spricht nie davon, in welchen Theaterstūkken sie aufgetreten ist, sondern erwānnt nur die begeisterte Reaktion des Publikums. Man kann lediglich aus dem "Hamlet"-zitat im ersten Akt der "Möwe" schließen, daß sie in dem Shakespeare-stūck die Rolle der Kōnigin gespielt hat.

Die Schauspielerin inszeniert ihr Leben als Schauspiel. wobei sie sich der Künstlichkeit dieses Verhaltens durchaus bewubt ist. Bs ist ein spiel mit sich und ihrer Ungebung. das letztendich die Gefahrlichkeit dieses "Theaters" übersieht. So zeigt sie sich unempfindlich gegenūber dem Unglūck ihrer Mitmenschen und ignoriert die Katastrophe, auf die ihr sohn erkennbar zusteuert. Sie will auch nichts wissen von Rrankheit und Tod. Den zustand ihres kranken Bruders, dessentwegen man sie herbeirief, beachtet sie gar nicht; statt dessen spielt sie "Lotto".

Da sie ihr Alter als ein zeichen des "Verfalls" empfindet. versucht sie es zu verheimlichen oder zu überspielen. Von Treplev erfahren wir im ersten Akt:

Sie möchte leben, lieben, helle Blusen tragen, aber ich bin schon funfundzwanzig und standig erinnere ich sie daran, das sie nicht mehr jung ist. Wenn ich nicht da bin, ist sie erst zweiunddreibig, aber so ist sie dreiundvierzig, und darum habt sie mich.

Bj choćetsja zit', Ijubit', nosit' svetlye koftocki. a me uze dvadcat: pjat let, i ja postojanno napominaju ej, cto ona uie ne moloda. Kogda menja net, ej tol'ko tridcat' dva goda, pri mne ze sorok tri, i za eto ona menja nenavidit. (S. 8)

Sicherlich ist dies eine subjektive dussage und zeugt auch von Treplevs problematischer Beziehung zu seiner Mutter. Daß die Bemerkungen des Sohnes aber durchaus ihre Berechtigung haben, bekommen wir zu Beginn des zweiten Akts von Arkadina in Gesprảch mit Masa bestâtigt.

- Dies bemerkt auch Berdnikov ('1981), S. $134 f$. 
... Und ich habe eine Regel: nicht in die zukunft schauen. Ich denke nie ans Alter, nie an den Tod. Was kommen muB, dem entgeht man nicht. (...)

Außerdem. ich bin korrekt wie ein Bnglander. Ich. meine Liebe, lasse mich nicht gehen, wie man so sagt. und bin immer gekleidet und frisiert comme il laut.

... I u menja pravilo: ne zagljadyvat v buduscee. Ja nikogda ne dumaju ni o starosti. ni o smerti. Cemu byt'. togo ne minovat'. (...)

Zatem, ja korrektna, kak angličanin. Ja, milaja, derzu sebja $v$ strune, kak govorit'sja, i vsegda odeta i pričesana comme il caut. (s. 21)

Wie krankhaft übersteigert ihr NarziBmus wirkt, läbt sich an der Behauptung erkennen, sie kōnne auf der Būhne ein fūnfzehnjăhriges Mădchen darstellen, weil sie sich nie habe gehen lassen. Brmilov ignoriert vollkommen die Ironie dieser szene. Der unglūcklichen Masa stellt er als positive Bigur Arkadina gegenüber, die sich durch Arbeit und Dienst an Mitmenschen ihre Jugendlichkeit erhalten habe.'J Bine Textstelle aus dem Manuskript Cechovs belegt auch sehr deutlich die àsthetische Lebenshaltung Arkadinas. In ihrem Gesprāch mit Nina. Sorin und Dorn ūber die vorzūge des stadtlebens (zweiter Akt) entgegnet sie dem Arzt, der der Natur den Vorrang gibt:

Und die Būcher? In poetischen Bildern ist die Natur weitaus rührender und schöner als so.

A knigi? $V$ poètićeskich obrazach priroda gorazdo trogatel nee i izjaschnee, cem tak. (s. 263)

Die bereits kūnstlerisch bearbeitete Natur wird so zu einem je nach Bedarf verfügbaren objekt àsthetischer Betrachtungen und Bmpfindungen. Typisch für ihre Form der àsthetischen Bxistenz ist, daB sie durchaus kompetent im Sinne der Lebenstūchtigkeit ist. Sie erscheint zielstrebig. besitzorientiert (geizig), arbeitet hart und diszipliniert und ist bemūht, sich in allem "korrekt" zu verhalten. Sie findet eine Rombination von Rsthetizismus und būrgerlichen Neigungen.

- Brmilor (1948), S. 45. 
3.1.2. Die Welt als Motiv: Trigorin

Fûr Trigorin hat sich der Prozeß des Schreibens verselbstāndigt und ist zu einer 2wangsvorstellung geworden. Die Brwartungshaltung seines Publikums hat er bereits verinnerlicht; sie erweist sich schon als seine eigene Rontrollinstanz.

Tag und Nacht beherrscht mich der eine ständige Gedanke: ich muB schreiben, ich muß schreiben, ich muß...

Den' i noć odolevaet menja odna neotvjazcivaja mysl': ja dolzen pisat' , ja dolzen pisat', ja dolzen... (s. 29)

Es wundert nicht, dab sich Trigorin als Schriftsteller selbst nicht mag und sich sein Publikum feindselig vorstellt (s. 30). Diese sichtweise resultiert aus dem standigen Messen der eigenen Leistung an den Erwartungen des literarischen Marktes.

Der zwang zu literarischer Tätigkeit geht so weit, das Trigorin jede Empfindung, jeden Eindruck auf seine kūnstlerische Verwertbarkeit hin abschätzt.

Ich sehe diese Wolke dort, die einem Plügel'4 ähnlich ist. Ich denke: ich muß irgendwo in einer Erzāhlung erwähnen, daß eine Wolke dahinschwamm, ànnlich einem Flügel. Es riecht nach Heliotrop. Sofort schreibe ich mir hinter die ohren: sủblicher Geruch. Witwenblume, zu erwāhnen bei Beschreibung eines Sommerabends. Ich beobachte mich selbst und sie (Nina. F.-J.L.) bei jedem Satz, bei jedem Wort und schließe all diese Sätze und Worter schnellstens in meine literarische Vorratskammer ein: vielleicht wird es zu gebrauchen sein!

Vizu vot oblako, pochožee na rojal'. Dumaju: nado budet upomjanut gde-nibud' rasskaze, Eto plylo oblako, pochozee na rojal'. Pachnet geliotropom. Skoree motaju na us: pritornyj zapach, vdovij cvet, upomjanut pri opisanii letnego vecera. Lovlju sebja i vas na každoj traze, na každom slove i spešu skoree zaperet vse ti frazy i slova v svoju literaturnuju kladovuju: avos' prigoditsja! (S. 29)

gemeint.

'Mit flūgel (rojal') ist hier das Musikinstrument 
Brlebnisse können so im Augenblick des Brlebens nicht mehr genossen werden, da sich das erlebende subjekt gegen die Objektwelt stảndig abgrenzen und sie bewerten muB. Ix Moment der literarischen Verarbeitung gehört der Bindruck jedoch bereits der Vergangenheit an.

Dabei ist Trigorin sich bempt: sein ständiges suchen und Bewerten der Umwelt nach literarischen Motiven nimmt inm die innere Ruhe und den objekten inre Eigenstandigkeit.

Und so ist es immer, imer, und ich habe keine Ruhe vor mir selbst, und ich fühle, daß ich mein eigenes Leben verzehre, daß ich, für den Honig, den ich in den leeren Raum hinaus weitergebe, den staub von meinen schōnsten Blūten raube, die Blumen selbst ausreibe und ihre Wurzeln zertrample.

I tak vsegda, vsegda, i net mne pokoja ot samogo sebja, i ja cuvstruju, Eto s-edaju sobstrennuju zizn. eto dija meda, kotoryj ja otdaju komu-to $\nabla$ prostranstvo. ja obiraju pyl s lučsich svoich cvetov. rvu samye cvety i topću ich korni. (s. 29)

Diese Art, sich die Welt durch künstlerische Verarbeitung anzueignen, schliebt Erkenntnis aus und damit auch die Mōglichkeit, den eigenen standort kritisch zu reflektieren. So gelingt Trigorin die literarische Bewäligung gesellschafticher Prozesse nicht, er vermag nur landschaftliche Impressionen festzuhalten.

... ich sehe, daß das Leben und die Wissenschaft voran und voranschreiten und daß ich immer weiter zurückbleibe, wie ein Bauer, der den zug verpabt hat. und schlieslich und endich fühle ich, das ich eben doch nur Landschaften schildern kann, in allem anderen bin ich unwahr und unwahr bis ins Mark.

... vižu, cto zizn' i nauka vse uchodjat vpered $i$ ppered, a ja vse otstaju i otstaju, kak muzik, opozdavsij na poezd, $i$, $\nabla$ konce koncov. cuvstruju, tto ja umeju pisat tol'ko pejzaź, a vo vsem ostal'nom ja fal'siv i fal'siv do mozga kostej. (S. 39f.)

Auch Trigorins Verhältnis zu Nina ist vom ersten Moment an gepragt durch den zwang, es literarisch zu verarbeiten. Sein Gespräch mit ihr (Bnde zweiter Akt) und die von Treplev getōtete Mōwe verbindet er sofort zu einem sujet fūr -ine Erzảhlung. Dap sich dieses sujet in Realitāt unsetzen wird, ist von Trigorin anfäglich zwar nicht zielbewubt 
verfolgt (dafūr ist er viel zu schwach und Arkadina gegenüber willenlos), wird durch die Initiative Ninas jedoch ermöglicht. Bezeichnend ist, daß das auslösende Moment wiederum literarisch begründet wird. Denn Nina benutzt ein zitat aus Trigorins Werken, un ihre bedingungslose zuneigung auszudrūcken."s Diese vorgehensweise verdeutlicht einerseits die romantische schwärmerei Ninas, trifft jedoch unberupt das prinzip seiner Lebenshaltung und tūhrt es weiter aus. Nicht nur die Brlebnisse dienen Trigorin als literarische Motive, sondern auch bereits schriftich Fixiertes wird zur Vorlage oder Anregung fūr spātere Ereignisse.

Seine zuneigung zu Nina steht von Beginn an unter einer Brwartungshaltung: sie soll ihm eine persōnliche Erfahrung ermōglichen, die ihm bisher versagt blieb, weil er nur seine Rarriere im Sinn hatte.

Bine junge Liebe, entzückend, poetisch, die mich ins Reich der Träume bringt.- sie allein kann mir Glück auf Erden schenken! Eine solche liebe habe ich noch nicht erfahren...

Ljubov' junaja. prelestnaja, poetičskaja, unosjascaja mir grez, - na zemle tol'ko ona odna možet dat' scast e! Takoj ijubvi ja ne ispytal esce... (s. 41)

Schon im zweiten Akt erwänt Trigorin, daß er gerne einmal an Ninas stelle wäre, um die Bmptindungen einer jungen

- Welche biographische Bewandtnis es mit diesem zitat hat ("Wenn Du je mein Leben brauchst. so komm und nimm es"). konstatieren: Urban (1983). S. 10. in seinem Vorwort zu Eechovs Tage- und Notizbūchern. Troyat (1987). S. 203219. Berdnikow $(1985)$, S. $246 \mathrm{f}$.

Die Biographen kommen jedoch zu unterschiedlichen Ergebnissen. Urban und Troyat sind der Meinung. das zitat in der "Mōwe" stamme aus einer Erzāhlung Lidija Alekseevna Avilovas. Berdnikov gibt eine Erzählung Cechovs als Quelle an. Beide sind sich jedoch einig darüber, was auf "Seite

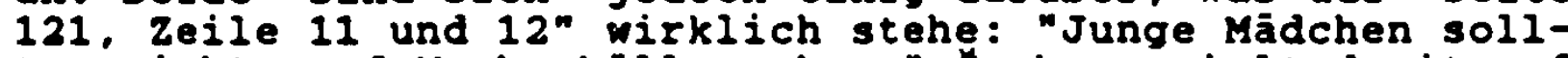
ten nicht auf Maskenbälle gehen." Cechov spielt damit auf eine Begegnung mit L.A. Avilova an, die er am 27.1. 1896 auf einem Maskenball getroffen hatte.

Tatsāchlich stammt das zitat aus Cechovs Novelle "Die Nachbarn" (Sosedi) aus dem Jahre 1892: "Esli tebe kogdanibud ponadobiesja moja zizn'. to pridi i voz'mi ee:" Poln.sobr. soc.. Bd. 8. Moskva 1977, s.60. Wortlich in die "Mowe" übernommen S. 41. 
Frau besser beschreiben zu können. Sein Verhalten ihr gegenüber wird dadurch bestimmt, daß er sich noch nicht gemachte Erfahrungen erhofft. So sind es auch auberliche Details, die er bei der Abschiedsszene hervorhebt (Bnde dritter $\Delta k t)$

Ich werde diese wunderbaren Augen wiedersehen, dieses unaussprechlich schöne, zärtilche Lācheln... diese sanften züge, diesen Ausdruck engelhafter Reinheit...

Ja opjat' uvizu eti cudnye glaza, nevyrazimo prekrasnuju, neznuju ulybku... éti krotkie certy, vyrazenie angel'skoj cistoty... (s. 44)

DaB Trigorin nie eine dauerhafte Beziehung zu Nina gesucht hatte, erfahren wir durch die Erzāhlung Treplevs im vierten Akt. Das Verhaltnis mit Arkadina gab der schriftsteller wăhrend seiner Affäre mit der zarećnaja niemals auf.

Bereits Erlebtes und Verarbeitetes gehöt nicht nur der Vergangenheit an, es wird zudem bald vergessen. So erinnert sich Trigorin lobwohl zweimal darauf angesprochen)० nicht mehr daran, das er die von Treplev geschossene Möwe Samraev gab, mit der Bitte, sie für ihn ausstopfen zu lassen. Stattdessen schwebt ihm ein neues Motiv vor, das mit dem der Möwe jedoch verbunden ist.

Apropos, ich muß mir den Garten und jene stelle anschauen, wo man - erinnern sie sich - Ihr (Treplevs, P.-J.L.) Stück spielte. In mir ist ein Motiv herangereift, ich mus mir nur den ort der Handlung wieder vergegenwārtigen.

Rstati, nado osmotret' sad i to mesto, gde - pomnite? - igrali vašu p'esu. U menja sozrel motiv, nado tol'ko vozobnovit vamjati mesto dejstvija. (S. 52)

Mrosik bemerkt, daß Trigorins Wunsch, die Möwe ausstopfen zu lassen, die Art seiner Beziehung zu Nina entlarvt. Wenn der schriftsteller selbst das Madchen und das getötete Tier im zweiten akt in zusammenhang bringt, so wird die

- Beide Male wird er von Samraev darauf angesprochen. jedesmal macht er sogar den Versuch, sich zu erinnern: "Ich erinnere mich nicht. 'Nachdenkend' Ich erinnere mich nicht!" (S. 55). "Die Möwe betrachtend" Ich erinnere mich nicht. 'Nachdem er nachgedacht hatte' Ich erinnere mich nicht!" (S. 60). 
präparierte Mōwe "zum Symbol einer nach Laune verfügbaren und deshalb beliebig und einseitig aufhebbaren 'Liebe ': dens der schōne Gegenstand eines ausgestopften Tieres kann bestenfalls ein spielzeug meinen, niemals einen partner, der Antwort zu geben vermag."

\subsubsection{Cechov - Trigorin}

In seinem Vorwort zu Cechovs Tage- und Notizbūchern weist Urban auf die Affinitäen zwischen dem Autor und seiner literarischen Pigur hin.

Der schriftsteller Trigorin in der "Möwe" ist ein zitat. Er ist nicht ausschlieblich zitat, er ist bei weitem auch nicht das einzige zitat in der "Möw" er ist vor allem aber ein stūck selbstzitat cechovs.:

Dabei macht Urban vor allem auf drei Entsprechungen aufmerksam. Erstens auf ein kūnstlerisches Prinzip Cechovs, an das sich auch sein alter ego hält: das postulat der Kürze und Prägnanz in Naturbeschreibungen.

So außert Treplev in vierten Akt über den literarischen stil Trigorins:

Bei ihm blitzt auf dem Wehr der Hals einer zerschlagenen Flasche und liegt der schwarze schatten eines Mūhlrades - und fertig ist die Mondnacht...

U nego na plotine blestit gorlysko razbitoj butylki i cerneet ten ot mel'ničnogo kolesa - vot i lunnaja nod' gotova...(s. 55)

Diese Beschreibung einer Mondnacht kehrt dann wieder in der Brzāhlung "Der Wolf" (Volk) aus dem Jahre 1886.

Aut dem von Mondlicht übergossen Wehr gab es nicht eine Spur von Schatten: in der Mitte glanzte wie ein stern der Hals von einer zerbrochenen Elasche.

Na plotine, zalitoj lunnym svetom, ne bylo ni kusocka teni: na seredine ee blestelo zvezdoj gorlyško ot razbitoj butylki.."

- Trosik (1967). S. 27.

- Urban (Hg.u.übers.) (1983). S.9.

- Poln.sobr.sod.. Bd. 5, Moskva 1976, S. 41. 
Bereits in einem Brief rom 10.5 .1886 riet Čchov seinem Bruder Aleksandr:

Du bekommst zum Beispiel eine Mondnacht, wenn du schreibst, das auf dem Mühlenwehr die scherbe einer zerbrochenen Flasche blitzt wie ein heller stern...

Naprimer, u tebja polucittsja lunnaja noc'. esli ty napišs.'. Eto na mel'ničnoj plotine jarkoj zvezdočkoj mel'kalo steklysko ot razbitoj butylki....0

Dann gibt es noch die szene, in der Nina Trigorin ein Amulett wit einem eingravierten Hinweis auf ein literarisches zitat schenkt." Und drittens Trigorins Angewohnheit, alle Beobachtungen stichwortartig fixieren und bei sich bietenden Gelegenheiten literarisch verarbeiten zu müssen.

Auch Cechov stand unter stāndigem schreibzwang. Er notierte sich Situationen und Ausdrūcke, die vielleicht einmal literarisch verwertbar sein wūrden, in seinen Notizbūchern. zur Verdeutlichung seien hier noch einige entsprechungen angefūhrt, die Urban nicht erwähnt.

Trigorins schilderung seiner ersten literarischen Versuche und des Kampfes un Anerkennung erinnern an Cechovs erste Bekanntschaft mit dem russischen Literaturbetrieb.

Trigorin gesteht Nina:

Ich fürchtete das Publikum, es erschreckte mich, und wenn ein neues stūck von mir aufgeführt murde, schien mir jedesmal. die Brūnetten wären mir gegenūber feindich. die Blonden kalt und glelchgültig.

Ja bojalsja publiki, ona byla strašna mne, i kogda me prichodilos' stavit svoju novuju p'esu, to mne kazalos' vsjakij raz. Cto brjunety vraźdebno nastroeny. a blondiny cholodno ravnodušny. (S. 30)

Cechov befūrchtete seinerseits in einem Brief vom 4.1.1889 an A.S. Suvorin anlāBlich einer "Ivanov"-Inszenierung.

daß alle Brünetten, die in den Logen sitzen, mir feindselig gesonnen erscheinen werden, und die Blonden kalt und unaufmerksam...

- P is'ma, Bd. 1, Moskva 1974, S. 242.

'1 siehe hierzu Anmerkung Nr.85, S. 92. 
Cto vse brjunety, sidjašcie $\nabla$ lozach, budut kazat'sja me vraždebno nastroennymi, a blondiny cholodnymi $i$ nevnimatel'nymi....

Diese zitate weisen vor allem aut ein Trauma des Dramaturgen Cechov hin. Die Kälte und Unaufmerksamkeit seines Publikums bekam der Autor dann vor allem bei der Premiere der "Mōwe" zu spüren.

Und auch Cechovs Traum von einem Landgut, einem ruhigen Leben fern des hektischen Literaturbetriebs, spiegelt Trigorin wieder (vierter $\mathrm{Nk}$ ).

Wenn ich auf so einem Gut leben würde, an einem see, würde ich dann anfangen $z u$ schreiben? Ich würde diese Leidenschaft überwinden und nichts anderes mehr tun als angeln. (...)

Einen Barsch oder Hecht zu fangen - das ist eine solche Wonne!

Esli by ja zil $\nabla$ takoj usad'be, u ozera, to razve ja stal by pisat'? Ja poborol by $\nabla$ sebe etu strast' i tol'ko $i$ delal by, eto udil rybu. (...)

Pojmat ersa ili okunja - eto takoe blazenstvo! (S.54)

Ċechov in einem Briet vom 18.2 .1889 an Leontev-śceglov:

Tag und Nacht träume ich von einem Anwesen... Im Heu zu liegen und einen Barsch an der Angel zu haben. befriedigt mein Gefühl weitaus spürbarer als Rezensionen und die applaudierende Galerie.

Denno i nośćno mectaju o chutore... Lezan'e na sene 1 pojmannyj na udockku okun udovletvorjajut moe cuvstvo gorazdo osjazatel nee, cem recenzii i aplodirujuścaja galereja.os

Bs darf aber nicht übersehen werden, das auch Treplev einige Merkmale Cechovs trägt." Daß der Autor den "dekadenten" künstlerischen Vorstellungen seines jungen Protagonisten nicht ablehnend gegenüberstand, beweisen zwei Briefe an A.S. Suvorin. Darin gesteht er seinen Wunsch. "dekaden-

- Pis'ma Bd. 3. Moskva 1976, S. 127.

o ebda.. S. 158 .

- siehe hierzu Kapitel 3.3. Komplementaritảt. 
te Theaterstūcke zu inszenieren's, wenn er Theaterdirektor wăre. Am 2.11.1895 bemerkt er:

Weshalb versuchen sie nicht, in Ihrem Theater Maeterlinck zu inszenieren? Wenn ich der Direktor Ihres Theaters ware, so würde ich es innerhalb von zwei Jahren $z u$ einem dekadenten machen oder mich bemühen. dies zu tun. Dieses Theater würde womöglich merkwürdig erscheinen. aber immerhin batte es ein eigenes Gesicht.・०

3.2. Die Suchenden

Die Seele mancher Menschen scheint aus einzelnen gewissermaben flottierenden Blementen zu bestehen. die sich niemals um ein zentrum zu gruppieren. also auch keine Binheit zu bilden imstande sind. So lebt der kernlose Mensch in einer ungeheuren und ihm doch niemals vollig zu Bewubtsein kommenden Binsamkeit dahin. Die grobe Mehrzahl der Menschen ist in diesem Sinne kernlos...

Arthur Schnitzler"?

Den asthetischen Lebenshaltungen der Routiniers Arkadina und Trigorin gegenūber stehen die romantischen vorstellungen Ninas und Treplevs von einer kūnstlerischen Rarriere. Die "Möwe" demonstriert, dả $f u ̈ r$ die jungen Protagonisten die Lebenshaltung der Bltern nicht mehr möglich sein wird. Dies deutet sich bereite im ersten Akt an. Konstantins Theaterstūck, in welchem die zarecnaja die Hauptrolle spielen wird, soll nicht nur dessen "avantgardistisches" Literaturkonzept ausdrūcken, sondern auch eine gemeinsame Basis fưr eine Beziehung zwischen ihm und Nina bilden. Dies bemerkt schon in den ersten Passagen der "Möwe" Medvedenko.

s. 100 .

- Brief vom 21.11.1895. Pis'ma, Bd. 6. Moskva 1978,

$$
\begin{aligned}
& \text { * ebda. S. } 89 . \\
& \text { - Schnitzler (1967), S. } 53 .
\end{aligned}
$$


Die zarečnaja wird spielen, und das stück ist von Ronstantin Gavrilovic. Sie sind ineinander verliebt. und heute werden ihre seelen im streben nach der Verwirklichung ein und desselben künstlerischen Bildes verschmelzen.

Igrat' budet Zarečnaja, a p'esa sočinenija Konstantina Gavrilovica. Oni vijubleny drug $v$ druga. i segodnja ich dusi sol'jutsja $v$ stremlenii dat odin $i$ tot ze chudożestvennyj obraz. (S. 5)

Doch bereits por der Inszenierung gibt Nina zu, daB sie Treplevs stūck nicht versteht. Der Abbruch der Auffūhrung deutet darauf hin. das sich die seelen der beiden eben nicht in einem "einheitlichen künstlerischen Bild" vereinigen werden. Treplevs Versuch. Kunst und Leben miteinander zu verbinden, scheitert.

Fūr Nina wird sich die Unmöglichkeit. eine Beziehung aut einer asthetischen sbene einzugehen, d.h. kūnstlerische und lebenspraktische Bereiche zu verknūpfen, in ihrer Affäre mit Trigorin erweisen.

\subsubsection{Suche nach neuen Formen: Treplev}

Treplevs Theater- und Literaturkonzeption ist Ausdruck und zugleich Anlaß fūr eine Bxistenzkrise."

Binerseits will er der "realistischen" Theater der Gegenwart und seinen moralisierenden stücken ein visionāres. symbolistisches Konzept entgegensetzen." Andererseits kämptt er un die Anerkennung durch die Träger der 'alten' Kunst. Vertreter dieses realistisch-naturalistischen Theaters sind vor allem Trigorin und Arkadina sowie ihr Bekanntenkreis, denen gegenüber sich Treplev als'Riever Kleinbūrger' (s.9) fühlt.

Der Kampe, durch den etablierten Kulturbetrieb anerkannt zu werden und gleichzeitig dessen formen und Inhalte abzu-

- Das Problem der Existenzkrise in einem bestimmten Lebensabschnitt hat in den Dramen Cechovs eine zentrale Bedeutung. Dies verdeutlicht für die Personen $\lambda$ strov und Vojnickij im "Onkel Vanja" auch Deppermann (1986a).

' Nāher ausgefūhrt in Kapitel 4.1.3. 
lehnen, erweist sich fûr Treplev als unlösbares Problem. Die Suche nach neuen Formen (Wlir brauchen neue Formen. und wenn es sie nicht gibt, dann brauchen wir besser gar nichts" S.8) erkennt or an Bnde als verfehlt.

Ich habe so viel über die neuen Formen geredet, und jetzt Eunhle ich, daß ich selbst langsam in die Routine abgleite. (...)

Ja. Ich kome mehr und mehr zu der Oberzeugung, das es nicht um die alten und nicht um die neuen Formen geht, sondern darum, das der Mensch einfach schreibt. ohne an irgendwelche Formen zu denken, dap er schreibt, weil es frei aus seiner seele strómt.

Ja tak mnogo govoril o novgch formach, a teper' cuvstruju; tto sam malo-pomalu spolzaju $k$ rutine. (...) (s. 55)

Da. ja vse bol'se i bol'se prichożu $k$ ubeždeniu, cto delo ne $\nabla$ starych i ne $\nabla$ novych formach, a $\nabla$ tom, cto celovek piset. ne dumaja ni o kakich formach, piset. potomu cto eto srobodno l'etsja iz ego dusi. (s. 56)

Dabei ging es Treplev nie un blobe Formkunst. Ihm schwebt eine literatur vor, die einen rein mimetischen Rahmen überschreitet.

Lebendige Menschen! Man mus das Leben nicht darstellen. wie es ist, und nicht, wie es sein soll, sondern so. wie es sich in Träumen zeigt.

Zivye lica! nado izobrazat' tizn' ne takoju, kak ona est. i ne takoju, kak ona doltna byt', a takoju, kak ona predatavijaetsja $\nabla$ mectach. (s. 11)

So zeigt sich auch der Anfang seines Theaterstücks nicht als reine Formkunst, sondern als der Versuch, in einem "Traumspiel" eine visionār geschaute Ideenwelt darzustelIen.

Was Trigorin und Treplev verbindet, ist der Kampl un Anerkennung. Wharend der Altere in seiner Jugend den Redaktionen die Türen einrannte, qualt sich der Jüngere mit seinem "Ehrgeiz, der mein Blut saugt und saugt wie eine schlange..." (samoljubiem, kotoroe soset moju krov', soset, kak zmeja... s.27) .

Das Scheitern Treplevs ist doppelt begründet. Zum einen sind persōnliches Glūck und künstlerische rătigkeit fûx ibn nicht zu trennen. Er will mit Nina zusammen künstlerisch arbeiten und zugleich mit ihr in einer glücklichen 
Liebe vereint sein. Daher kann der beginnende Brfolg kein Brsatz fūr den Verlust der geliebten Frau werden. Deswegen sagt er in vierten akt zu Nina:

Seit ich sie verloren habe und angefangen habe zu veróffentlichen. ist das leben für mich unerträglich - ich leide... Meine Jugend war plotzlich vorbei. und mir scheint, das ich schon neunzig Jahre auf der helt gelebt habe.

s tech por. kak ja poterjal vas i kak naćal pečatat'sa. tizn dlja menja nevpnosima.- ja stradaju... Molodost moju vdrug kak otorvalo, i mne kazetsja, cto ja uze prozil na svete devjanosto let. (S. 57)

Zum anderen hat die suche nach neuen Formen $f u ̈ r$ ihn in dern Homent ihren Reiz verloren, als er zwar offentlich anerkannt wurde, aber erkennen mubte, dab sich seine persōnliche situation dadurch nicht geändert hat. Wie wir von Polina Andreevna und Trigorin im vierten Nkt erfahren, werden Treplevs Arbeiten veroffentlicht, und er besitzt bereits einen festen Verehrerkreis. Obwohl inn das Publikum jetzt anerkennt, ist er mit seinen arbeiten nicht zufrieden:

... ich dagegen treibe imner noch im Chaos der Trāume und Bilder, ohne 24 wissen, wozu und wer das braucht. Ich habe keinen Glauben und weis nicht, worin meine Berukung bestebt.

... a ja vse esce nosus - chaose grez $i$ obrazov, ne znaja. dlja cego i komu dto nuzno. Ja ne veruju i ne znaju, $\nabla$ cea moe prizvanie. (s. 59)

Hier zeigt sich auch, dab der Kampt un neue Pormen und Jffentliche Anerkennung Brsatzhandlungen waren. Und gerade die Bestatigung durch seine Mutter und Trigorin erhalt er nicht: Arkadina hatte in Verlaufe von zwei Jahren offenbar keine zeit gefunden, etwas ron ihrem sohn zu lesen, und auch Trigorin interessiert sich nicht fūr Treplevs VeröfEentlichungen.100

1०० So bemerkt Treplev. als Trigorin ibr die Zeitschrift gibt, in der seine neueste Novelle abgedruckt ist: "Seine Novelle hat er gelesen, meine hat er noch nicht einmal aufgeschnitten" (svoju povest procel, a moej daže ne razrezal. S. 53). 
Das Treiben im "Chaos der Trãume" lst eigentlich genau die Art von Kunst, die der junge Künstler zunalchst anstrebte. Die Problematik hat sich aber offenbar verlagert: jetzt beschaftigt ihn weniger die suche nach neuen Formen in der Literatur, sondern die Frage der Virkung solcher Kunst. Cechov beschreibt in Treplevs Bemühungen um eine neue Literatur einen Prozeß, den spater ein reil der jüngeren Symbolisten und Futuristen auch erfahren mubte.lol Die Negation der realistisch-mimetischen Runst durch neue Formen und eine radikal andere Haltung zur sprache. d.h. zum Verhätnis ron Bezeichnendem und Bezeichnetem, lōste beim Publikum zunjchst den provozierten Schock aus.10z Jedoch nicht die Oberfūhrung von Runst in Lebenspraxis, die angestrebt murde, sondern die Anerkennung symbolistischer und avangardistischer Kunst durch den Kulturbetrieb, also das Gewöhnen an das Schockierende, war das Brgebnis. So erhielt auch die Avantgarde. wie schon ihr Gegner, die bürgerliche Rultur, unfreiwillig eine affirmative Bedeutung.

\subsubsection{Suche nach Lebenssinn: Nina}

Nina unterscheidet sich ron Konstantin durch ein wesentiches "ăußeres" Merkmal. Wâhrend dieser an see au sorins Gut lebt und dort auch stirbt, kommt jene von der anderen Seite des Sees. Darauf weist bereits der Name "Zarečnaja" hin. der übersetzt "jenselts des glusses befindlich" bedeutet. Br erinnert an die russische Bezeichnung fûr den "Eremden": "zamorskij gost". Nina kommt im ersten akt mit

101 Bereits die Vertreter der jüngeren symbolistengeneration strebten eine literatur an, die die herkómliche Form-Inhalt struktur negiert. Die literarischen Manifeste des jungen Valerij Brjusov beispielsweise stehen den Proklamationen der Futuristen an Radikalitat und Provokanz in nichts nach.

102 siehe hierzu vor allem: Bürger (1974). "...der Akt der Provokation selbst nimmt die stelle des Nerks ein." ebda. S. 77 . 
Pferden zum Gut Sorina, im letzten Akt erklart sie Treplev beim dbschied, daß ihr Magen auf sie warte. 1.8

Sie verkörpert nach den Kategorien von Smith'•4 und Moravcevichlos den Ćechovschen Typ der jugendlichen romantischen Heldin, die sich meist naiv, kindlich und unschuldig ihrer Unwelt gegenüber verhalt.

Fur Nina ist Arkadina die Personifizierung all ihrer Traume: eine berühmte Schauspielerin zu sein, der das Publikum zu Fūßen liegt und der man keinen Wunsch abschlagen kann. sie erkennt zwar bald, wieviel kleinliches und Alltägliches hinter der Fassade Arkadinas und Trigorins steckt.

Ich dachte, daß berūhmte Menschen stolz, unnahbar sind, daß sie die Menge verachten und mit ihrem Ruhm. mit dem Glanz ihres Namens sich dafúr an ihr răchen wurden, weil sie Herkunt und Reichtum hoher stellt als alles andere. Aber da wainen sie. angeln, spielen Rarten, lachen und argern sich, wie alle ...

Ja dumala, čto izvestnye ljudi gordy, nepristupny, cto oni prezirajut tolpu i svoeju slavoj, bleskom svoego imeni kak by mstjat ej za to, tto ona vyse vsego stavit znatnost proischotdenija i bogatstvo. No oni vot placut, udjat rybu, igrajut $\nabla$ karty, smejutsja i serdjatsja. kak vse... (s. 27)

Im folgenden Gesprach mit Trigorin verfallt Nina jedoch wieder in ihre bisherige schwärmerei.

Pūr ihr ziel, Schauspielerin zu werden, bricht sie die Bindung zu ihrem Blternhaus ab und fahrt nach Moskau (was ihr allerdings nicht allzu schwer gefallen sein muß, wenn man die Beschreibung ihrer privaten verhälnisse durch Dorn hötl. Wie Treplev und Nina selbst im vierten Akt berichten, mubte sie den Traum von einer groben Theaterkarriere aufgeben und sich mit Bngagements an Provinztheatern zufriedengeben. Bbenso wie fûr Treplev gilt fūr die zarečnaja, daß ohne persōnliches Glūck keine künstlerische Arbeit möglich ist. Wahrend ihres (unglūcklichen) Verhätnisses mit Trigorin mißlangen ihre Bühnenauftritte.

103 siehe hierzu auch Jackson (1981), S. 15.

10. Smith (1973), S. 71-125.

20:Moravćevich (2981). 
Nachdem sie die ziele, die sie noch zu Beginn des stũckes hatte, nicht, verwirklichen konnte, bemerkt Nina im vierten Akt:

Ich weiß, ich verstehe jetzt, Rostja, daß für unsere Arbeit - egal ob wir Theater spielen oder schreibendie Hauptsache nicht der Ruhm ist, nicht der Glanz, nicht das, wovon ich getraumt hatte, sondern die $\mathrm{Fa}-$ higkeit durchzuhalten. Trage dein Rreuz und glaube. Ich glaube, und es tut mir nicht mehr so weh, und wenn ich an meinen Beruf denke, habe ich keine Angst mehr vor dem Leben.

Ja teper znaju, ponimaju, Rostja, eto $\nabla$ nasem delevse ravno, igraem my na scene ili pisem - glavnoe ne slava, ne blesk, ne to, o cem ja mectala, a umen'e terpet. Umej nesti svoj krest $i$ veruj. Ja veruju $i$ we ne tak bol'no, i kogda ja dumaju o svoem prizvanii, to ne bojus' zizni. (S. 58)

Ihre stindigen Bemerkungen, sie sei die "Möwe", sind nicht so sehr Rennzeichen einer geistigen Verwirrung als vielmehr ein Ausdruck des tūr sie Unfabbaren, daß sie fúr Trigorin letztlich wirklich nur ein Sujet für eine Brzählung darstellte. Der Binschub "ein Sujet für eine kleine Brzählung", während sie Treplev ihre liebe zu Trigorin gesteht (Bnde vierter Akt), zeigt nicht, "dab Nina souverán über ihrer Leidenschaft steht"ill sondern thre empfundene Ohnmacht gegenüber dem Brlebten.

Im Gegensatz $2 u$ Arkadina und Trigorin sind Treplev und Nina zu Binsicht und Selbstkritik fähig. Aus der Brkenntnis, daß ihr bisheriges Handeln auf ein falsches ziel ausgerichtet war, ziehen die jungen Protagonisten jedoch unterschiedliche schlüsse. Während Treplev als einzigen Ausweg den selbstmord sieht, findet sich vina damit ab, eine unbedeutende schauspielerin zu bleiben.

Es scheint mir zu vordergründig, Treplev und Nina als vertreter einer ethischen Lebenshaltung $2 u$ sehen, wie Mrosik das tut. Fūr die zarečnaja glaubt er, "daß sie auf realistische $\lambda r t$ und Weise das über sie in den symbolmotiven der mutwillig geschossenen und spielerisch ausgestopften Möwe hereingebrochene Leid ethisch erfaßt, religiós

serosik (1967), S. 39. 
als Kreuz auf sich genommen und glaubig durchlitten hat."101 Fūr Treplev, "daß angesichts einer gescheiterten ethischen Existenz fúr ihn in der asthetischen keine Hoffnung nehr liegt." 10 .

Auch in jüngster zeit wird Nina imer wieder als eine Figur interpretiert, die ihr schicksal akzeptiert und sich den Anforderungen des Lebens stellt.10" Bine solche sichtweise ist nicht neu. Bereits Brailov sah in Nina die positive Heldin, die trotz aller ihr zugefügten Leiden den Weg zur "wahren" Runst und gesellschaftlicher verantwortung findet. 110

Gerade Ninas letzter Auftritt in vierten Akt ist aber von Cechov zu offen angelegt, um ihre Aussagen nicht auch (oder gerade) als eine konstruierte sinngebung interpretieren zu kōnnen, die ihrer verzweiflung entspringt. Has sie in ihrem Gesprāch mit Treplev zu sagen hat, ist eher Ausdruck ihres Unglūcks als die Hoffnung auf ein glūckliches Leben.

Nina und Treplev sind als nach einem Lebenssinn und einer Lebensaufgabe Suchende dargestellt. So vermerkt Cechov in seinem Notizbuch: "Treplev hat keine bestimmten ziele, das richtet ihn zugrunde."111 Bine ethische Lebenshaltung, auf die beide ihre Handlungen bewubt grūnden, ist im stūck kaum ausgepragt. Sie handeln zwar emotional (Nina und Treplev bekennen sich trotz ihrer Desillusionierung am Ende des Dramas immer noch zu den von innen geliebten Menschen), dies kann jedoch nicht als bemut ethische Lebensfūhrung bezeichnet werden.

(1981).

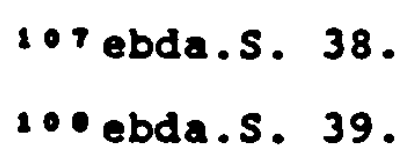

101 ebda.S. 38 .

100 ebda.S. 39.

109Jackson (1981); Ratsell (1981); Moravčevich 110 Brmilov (1948).

112 Zapisnaja knizka II, str.37; in: Poln.sobr.soč.. Bd. 17. Moskva 1980, S. 116. Weiter heiBt es: "Das Talent hat ihn zugrunde gerichtet" (Talant ego pogubil). 
Hübner bemerkt zu den "Helden" der Dramen Cechovs:

sie sind unfähig, ihre vorstellungen pom Leben, wie es sein soll, mit den Gegebenheiten der Realitat in Binklang zu bringen. Ihre Idee pom "wahren" Leben labt sich mit dem wirklichen Leben nicht vereinbaren.112

Bine solcbe Binschatzung übersieht, daß die saturierten Personen (Arkadina, Trigorin) keine Idee im sinne eines anzustrebenden Lebensziels besitzen, sondern den status quo aufrechtzuerhalten suchen. Das beweist auch die bereits zitierte XuBerung der Schauspielerin (Anfang zweiter Akt). niemals über die zukunft nachdenken zu wollen. Nina und Treplev mūssen einsehen, daß sie ihre ziele nicht erreichen konnten. Die zarečnaja hat den Traum von einer großen Rarriere als Schauspielerin aufgegeben, Treplev vermochte es nicht, die suche nach neuen künstlerischen Formen mit seinem Streben nach liebe und Anerkennung zu verbinden.

In der Person Treplevs beschreibt kechov eine existentielle Problematik, die im Laufe des 20. Jahrhunderts im Existentialismus auf breiter Basis eine philosophische Fundierung erfuhr. Ronstantins situation vor seinem Selbstmord, das Bewubtsein von sinnlosigkeit und undurchschaubaren privaten wie gesellschaftichen Prozessen und zusammenhägen, rufen in ibm ein Bmptinden von Absurditat hervor. Rund vierzig Jahre spater formuliert Albert Camus eine moderne Grundstimmung, die der Treplevs sehr nahe kommt.

Un monde qu'on peut expliquer même avec de mauvaises raisons est un monde familier. Mais au contraire, dans un univers soudain prive d-illusions et de lumidres, I'homme se sent un trranger. Cet exil est sans recours puisqu'il est prive des souvenirs d'une patrie perdue ou de l'espoir d'une terre promise. Ce divorce entre 1 homme et sa vie, l'acteur et son décor. c'est proprement le sentiment de 1 absurdite. Tous les homes sains ayant songt leur propre suicide, on pourra reconnaftre, sans plus d'explicati- 
ons, qu'il g un lien direct entre ce sentiment et l'aspiration vers le neant.113

Doch gelingt der Čechorschen Figur nicht, die Gedanken an den Selbstmord zu überwinden und - im sinne Camus' - der als absurd empfundenen Welt das eigene revoltierende Bandeln entgegenzusetzen.

Der von den Existentialisten erlebten Absurditat entspricht bei Čechov das Bmpfinden von Binsamkeit und einer allgemeinen Nervositat, wie sie auch Dorn am Ende des ersten Akts betont (siehe hierzu auch Rapitel 4.1.4.). Interessant ist an dieser stelle ein Brief Cechors an V.B. Mejerchol'd. Dieser bat den Autor der "Möwe", In der er 1898 den Treplev gespielt hatte, ihm bei der Interpretation einer neuen Rolle $z u$ helfen. Das künstlertheater plante, "Binsame Menschen" von Gerhart Hauptmann aufzuführen. Mejerchol'd sollte hierin den Johannes Vockerat darstellen. Cechov schrieb dem jungen Schauspieler Anfang Oktober 1899, was man unter anderem bei der Darstellung des Hauptmannschen Belden beachten müsse:

Man sollte die Nervositat nicht unterstreichen, damit nicht die neuropathologische Natur das obergewicht bekomint und dasjenige verdeckt, was wichtiger ist. nämlich die Binsamkeit, die nur von hoch entwickelten, dabei (in höchster Bedeutung) gesunden Menschen emprunden wird. Spielen Sie einen einsamen Menschen. und zeigen sie die Nervositat nur insoweit, als sie im Text selbst vorgegeben ist. Behandeln sie diese Nervositat nicht als eine private Erscheinung; denken Sie daran, daß gegenwartig beinahe jeder kultivierte Mensch, selbst der gesundeste, nirgends eine solche Gereiztheit erlebt wie zu Hause, in seiner eigenen Familie, denn die Disharmonie zwischen Vergangenheit und Gegenwart spūrt man por allem in der Familie. Bs ist eine chronische Gereiztheit, ohne pathos, ohne krampfhafte Ausbrūche, dieselbe Gereiztheit, die von Gasten gar nicht bemerkt wird und die in ihrer ganzen Schwere $\nabla 0 r$ allem auf den Allernachsten lastet - der Mutter, der frau, - sozusagen eine familiarre, intime Gereiztheit.124

I I Camus (1969), S. 181.

11413'ma, Bd. 8, Moskva 1980, S. 2746.

Die Briefe Mejerchol ds an Cechov sind abgedruckt in: Literaturnoe nasledstro, Bd. 68 (1960), s. 435-448. Von 


\subsection{Konplementaritat}

Bei der Charakteristik der vier Hauptpersonen dart nicht übersehen werden, daß die Figuren Trigorin und Treplev sowie Arkadina und Nina komplementár angelegt sind.110 Arkadina besitzt all das, was für Nina erstrebenswert erscheint: Ruhm, Talent, allgemeine Anerkennung und Bewunderung. Von diesen Attributen träumt die junge zarecnaja und sieht in ihnen das ziel ihrer Bestrebungen. Doch nichts von all dem wird sie erreichen. Ein weiteres Ideal ist fūr sie Trigorin, der Lebensgefahrte der Arkadina, den Nina aber nicht an sich binden kann. Bei Arkadina und Nina handelt es sich somit um zwei kontrār angelegte Charaktere: hier die altere, kūnstlerisch wie gesellschaftlich erfolgreiche Frau, dort das junge, erfolglose mãdchen. Beide unterscheiden sich auch noch in einem anderen wesentlichen Punkt grundsátzlich voneinander. Nina ist über ihr anfangliches schwämen tūr Trigorin zu einer bedingungslosen liebe fảhig. Obwohl sie der schriftsteller ruiniert hatte. gesteht sie in vierten Akt ihre ungebrochene zuneigung zu ihm. Der Rampt Arkadinas um Trigorin verlauft völlig rational, unter Binsatz ihres ganzen schauspielerischen Rónnens.

Ebenso kontră wie die beiden Frauenfiguren sind die mānnlichen Hauptpersonen gezeichnet. Trigorin ist der anerkannte, berūhmte schriftsteller, der sich auf dem zenit seiner Rarriere befindet. Der junge Treplev strebt all das an - wenn auch mit anderen kūnstlerischen kitteln - was

Ćechov 1st leider nur ein Brief an Mejerchol'd erhalten, aus den das oben angefürte zitat stammt. Ober die "Darstellung des nervósen Menschen" außert sich Cechov nochmals in einem Brief an 0.L. Knipper vom 2.1.1900. Zum Verhaltnis zwischen Cechov und Mejerchol d siehe auch Polockaja (1960).

113"Romplenentä" wird an dieser stelle nicht in Sinne der Rommunikationstheorie Hatzlawicks perstanden (s. Rapitel 2). Das Prinzip der Romplementaritat in der Personendarstellung bei Cechov beschreibt für "Onkel vanja" Deppermann (1986a). 
108

sein jlerer Konkurrent bereits erreicht hat. Der Routinier gewinnt ohne sein zutun Nina für sich, die rreplev vergebens an sich zu binden versucht.

Bin weiterer Aspekt der Komplementaritat murde bereits in Kapitel 3.1.3. beschrieben. 


\section{Intertextuelle Bezùge}

Mit "intertextuellen Bezügen" sind im folgenden Hinweise innerhalb eines künstlerischen Textes auf einen literarischen vortext gemeint. Solche Andeutungen finden wir in der "Möwe" mehrfach.

Cechov zitiert hier aus Shakespeares Tragōdie "The Tragedy of Hamlet. Prince of Denmark". Maupassants Reisenotizen "Sur 1'eau" und Turgenevs Roman "Rudin". Dabei befindet sich das zitat

in einer spannung, die der Text sich in unterschiedlicher Weise nutzbar zu machen vermag. Bs verweist metonymisch auf den Kontext. dem es entspringt, aber es erweist zugleich seine über den Rontext hinausreichende Potentialitä. indem es in den Funktionszusammenhang des neuen Textes eingeht, sich diesem zugleich unterwirft und entzieht, einen fremden Text in den Blick bringt und doch auch in diesem nicht aufgeht. 1 :

Cechov nennt zudem Puskins fragementarisches Versdrama "Rusalka" und spielt auf Ibsens Schauspiel "Die Nildente" an. Durch Erwähnung oder Anspielung verweist der Autor auf einen anderen literarischen Text, führt jedoch keine zitate an.

Is geht in diesem Rapitel jedoch nicht um eine reine Auflistung intertextueller Bezüge. Vielmehr soll es zeigen. wie diese den Bedeutungsaufbau der "Möwe" beeinflussen und dap Cechov durch den hinweis auf bekannte literarische Werke mit seinem Publikum in einen Diskurs tritt.

Der Rezipient erhät aus dem Vergleich des stücks mit den Vortexten "aus der Differenz die 'signifiance' des vor ibm liegenden Textes."117

11. stierle (1983). S. 19.

11'stempel (1983). S. 89. Cechov konnte davon ausgehen, daß seinem damaligen russischen Publikum die literarischen Verke, auf die er hinweist, bekannt waren. 
4.1. Cechovs "Mowe" und Shakespeares "Bamlet"

\subsubsection{Cechov und Shakespeare}

Binen Cechorschen Menschen zu spielen ist obenso wichtig und interessant. wie Shakespeares Hamlet zu spielen.

V.B. Mejerchol' dil

Sygrat' cechorskogo celoveka tak ze vatno i interesno, kak sygrat" sekspirovskogo Gamleta.

"Bs gab, so scheint es, in der Neltiteratur keinen Schriftsteller, der Cechov näher war als Shakespeare."il. Bine eingehende theoretische duseinandersetzung nit dem Werk des englischen schriftstellers suchen wir bei ċechov jedoch vergeblich. Seine Beschätigung mit shakespeare findet vor allew in der praxis seatt, besonders innerhalb des eigenen dramatischen schaffens.

Für den "Ivanov" murde dies schon verschiedentlich aufgezeigt,1se eine untassende vergleichende Analyse des dramatischen Gesamtwerks Cechovs steht immer noch aus. Dies. obwohl "shakespeare so oft in den Brzählungen und stücken Cechovs erwähnt wird, dap man thn einen Belden cechovs nennen kann. 121

110 Literaturnoe nasiedstvo (1960). S. 439.

11. Smolkin (1967), s. 72 (Ne bylo, kazetaja, v mirovof literature pisatelja, bolee blizkogo Cechovu. cem Sekspirl.

120Volkov (1966): Smolkin (1967): Berkovakif (1969): Norec (1974): Sach-Azizova (1977).

121 seolkin (1967), s. $80^{\circ}$.

Shakespeare oder dessen verke und literarische Figuren werden beispielsweise genannt in den Erzahlungen: "Baron" (1882), "Na kladbisce" (1884). "O drame" (1884). "Kalchas" (1886: dranatisiert $1887^{\circ}$ als "Lebedinaja pasnja"). "Rasskaz bez konca" (1886). "Duel"" (1891). In den Dramén "Platonor". "Ivanoo". "Die Móne" leiehe hierzu Rapitel 4.1.6.1. 
Auberhalb seines literarischen Werkes aubert sich der russische Autor über sein englisches Vorbild nur selten. Eine tiofe Bewunderung $f u ̄ r$ shakespeare ist aber deutlich zu bererken.

I.L. Leonter-śčeglov gesteht er in einem Brief rom 22.3. 1890:

Ich teile alle werke in zwei Sorten: die, die mir gefallen, und die, die mir nicht gefallen. Bin anderes Rriterium habe ich nicht, und wenn sie mich fragen, warum mir Shakespeare gefallt und zlatorratskij nicht gefallt, dann könnte ich nicht antworten.122

Cechov sah bereits in Taganrog shakespeare-Inszenierungen. Während seiner ersten Jahre in Moskau vermittelte inm vor allem das "Malyj teatr" weitere Binblicke in die Dramatik des englischen Rünstlers.123

Aufschlubreich ist eine Theaterkritik Cechovs, die er in Jahre 1882 anläblich einer Hamletauffühung verfabte. Zux Belebung der langweiligen und verstaubten zeitgenössischen Dramatik mūsse man unbedingt shakespearestūcke auffūhren.

Shakespeare muß man überall spielen, und sei es nur wegen der Erfrischung, wenn nicht zur Belehrung oder irgendwelcher anderer mehr oder weniger hohen ziele.124

Interessant für unsere Untersuchung der Hamletthematik in Čechovs "Mōwe" sind die Brinnerungen Gruzinskij-Lazarevs.13: Ex weist darauf hin, dap Cechov im Oktober 1887 ein vaudeville in zwei Akten 24 schreiben begann, das den

122 Pis'ma Bd. 4. Moskva 1976, S. 45.

123 zur verstäkten Shakespearerezeption in den 80er Jahren des 19. Jahrhunderts in RuBland siehe vor allem: Alekseev (Hg.) (1965), S. 627-698.

Dap die Figur des Hamlet in zeiten politischer stagnation und Reaktion nicht nur zum Sinnbild eines in sich zurúckgezogenen Intellektuellen, sondern auch eines die eigene Situation kritisch reflektierenden zeitgenossen wird, hat bis heute Gũltigkeit. Nicht von ungefahr war fúr vladimir Vysockij der Hamlet die "Rolle seines Lebens". die er am Moskauer Taganka Theater mehr als 200 Mal spieite.

$$
\begin{aligned}
& \text { s. Poln.sobr.soć.. Bd. 16, Moskva 1979, S. } 20 . \\
& \text { i2 Gruzinskij-Lazarev (1914). }
\end{aligned}
$$


Titel "Bamlet, der Dänenprinz" (Gamlet, princ datskif) tragen sollte. Cechov habe es mit ihm zusammen schreiben wollen. Gruzinskij-Lazarev betont ausdrūcklich, dab das Stūck keine Parodie auf Shakespeares "Hamlet" sein sollte. Bin wesentlicher Punkt war. "Kritik am Zustand der Theater; ohne Kritik ware unser Vaudeville bedeutungslos."120 Auch auf die lockeren sitten hinter der Būhne wollte cechov hinweisen, Ophelia betrügt Bamlet usw. Der erste Akt spielt hinter den Rulissen bei einer Bamlet-Probe. Der Darsteller des Geistes von Hamlets vater erzahlt von seinen jahrelangen Wanderungen von einer Provinzbühne zur anderen. Der erste Akt sollte dann "mit einem Skandal und ellgemeinem Durcheinander enden."1ziIm zweiten Akt war geplant, eine szene aus Shakespeares "Hamlet" aufzufūhren.180

Aus den beiden Briefen Cechovs und den Brinnerungen Gruzinskij-Lazarevs wird offensichtlich, daß Cechov schon 1887 mit dem Gedanken spielte, sich vor dem Hintergrund von Shakespeares "Hamlet" mit der Diskrepanz zwischen kūnstlerischen Ideal und realer Nirklichkeit auseinanderzusetzen.

\subsection{2. "Hamlet" in Cechovs "Mowe"}

Bs murde schon verschiedentlich aut die Bedeutung von Shakespeares Iragodie "The Tragicall Bistorie of Hanlet, Prince of Denmarke" fūr Cechovs Komödie "Die Möwe" hinge-

180 Cechov in einem Brief an Gruzinskif-Lazarev vom 15.11.1887. Pis'ma, Bd. 2, Moskva 1975, S. 148. Siche in diesen Zusammenhang auch den Brief vom 26.11 .1887 .

127Gruzinskij-Lazarev (1916), S. 169.

180 Auch hier beabsichtigte Cechor anscheinend, ein "Spiel im Spiel" einzubauen. 
wiesen,129sie wurde bisher fedoch noch nicht eingehend analysiert.

Die Bntsprechungen und Anspielungen, mit denen Cechov in seinem stūck auf Shakespeares Drama verweist, sollen im folgenden kurz skizziert werden, um dann naher auf ihre Bedeutungen für die "Möwe" einzugehen.

Der englische Dramatiker wird in Treplevs Theaterstūck genannt, wenn die Veltseele sagt, in ihr koexistieren "die Seele Alexanders des GroBen, und Caesars, und Shakespeares und Napoleons, und des letzten Blutegels (duša i Aleksandra Velikogo, i Cezarja, i Šekspira, i Napoleona, i poslednej pijavki. S. 131.

In zwei situationen, Eührt Čechov direkte Hamletzitate im dramatischen Text an.

Als Treplev und Arkadina sich im ersten Akt treffen, rezitieren beide jene stelle aus "Hamlet" (III,4), in der der Sohn seiner Mutter unmoralisches Verhalten vorwirft.

Arkadina (rezitiert aus 'Hamlet'). Mein Sohn! Du wendetest die Augen mir ins Innere der Seele, und $i c h$ erblickte sie in solch blutigen, tödlichen Wundenes gibt keine Rettung!

Treplev (aus dem 'Hamlet'). Und weshalb gabst Du dem Laster nach, suchtest liebe in Abgrund des Verbrechens? 20

Arkadina (citaet iz 'Gamleta'). "Moj syn! TY oči obratil mne vnutr' dusi. i ja uvidela ee $v$ takich krovavych, v takich smertel'nych jazvach - net spasen'ja!"

Treplev (iz 'Gamleta'). "I dlja ćego $z$ ty poddalas' poroku, ljubvi iskala $\nabla$ bezdne prestuplen'ja?" (S.12)

Das zitat kann als Anspielung auf das Verhältnis ArkadinaTrigorin gesehen werden, das Treplev nicht akzeptiert.

120 Winner (1956); Stroud (1958); Roskin (1959), S. 131f.: Volkov (1966): GrOmov (1970): Adler (1970/71): Hübner (I97I), S. 107-110; Bjalyj (1981). S. 80; Papernyj (1980) S. 58-60, textgleich (1982). S. 158-160; Porter (1981): Peace (1983). S. 20 f.

100Das zitat 1st hier wötlich aus dem Russischen übersetzt, da Eechov den "Hamlet" auch nur aus der Obertragung von A.I. Rroneberg aus dem Jahre 1844 kannte. Volkov (1966), S. 431; Alekseev (Bg.) (1965), S. 364 . 
Jedoch gründet diese Beziehung nicht auf einem Verbrechen, wie in Shakespeares Drama.

Bin meiteres dirokees zitat eus shakespeares Tragödie findet sich in zweiten Akt der "Mơr". In "Hamlet" II,2 antwortet der Held auf Polonius' Frage, was er gerade 1ese: "Worte, Horte, Norte." Als Treplev sich mit Nina unterhalt (zweiter $A k t$ ) und rrigorin auftritt, aubert Konstantin:

(Hat Trigorin gesehen, der, ein Buch lesend, kommt). Da kommt das wahre Talent; er tritt auf wie Ramlet. und auch mit Buch. (Hanselt) "Worte, Norte. Worte..." (Uvidev Trigorina, kotoryj idet, ditaja knizku.) vot idet istinnyj talant; stupaet, kak Gamlet, i toze 3 knitkoj. (Draznit.) "slova, slova, sova..." (s.27f.)

Treplevs Reaktion grủndet jedoch in seiner Bifersuche und dem Gefūhl kūnstlerischer Unterlegenheit dem Konkurrenten gegenüber. In Hamlets herablassendem Verhalten 24 Polonius erkennt man aber deutlich das Bewubtsein geistiger wie gesellschaftlicher oberlegenheit.

Hamlet unterbrach seine studien in Wittenberg und kehrte wegen des Todes seines Vaters nach Danemark zurũck. Treplev "verließ im dritten semester die Universitat. aus. wie man so sagt, von der Redaktion unabhangigen Grūnden..." ("Vysel.iz tret'ego kursa universiteta po obstojatel'stvam, kak govoritsja, ot redakcil ne zavisjajeia...: S. 8)

Auch Hamlet läßt ein Theaterstūck aufführen (III,2), welches vorzeitig durch Polonius (bzw. Claudius) abgebrochen wird. Der Dảnenprinz beabsichtigt mit dieser Inszenierung. den Mörder seines Vaters blobzustellen und zu entlarven. Diese von Hamlet selbst als "Mouse-Trap" bezeichnete szene besitzt in der Tragōdie shakespeares eine bedeutsame dramatische Funktion.121

132 Auf die vielschichtige Bedeutung des "play within the play" in der Dramatik shakespeares kann hier nicht năher eingegangen werden. Binen knappen und konzentrierten AbriB des Forschungsstandes bietet vor allem: Schmeling (1977), S. 36-49. 
Auf den ersten Blick verfolgt Treplevs Inszenierung kein direktes ziel, sondern scheint lediglich dem Ausdruck seiner künstlerischen vorstellungen zu dienen. Doch bei näherer Betrachtung ist Ronstantins Theaterstūck auch eine "myjelovka" (Mausefalle), wie Volkov feststellt.232 Der junge Schriftsteller will den Vertretern der "alten" Kunst sein Ronzept einer neuen literatur vorhalten. Treplev denkt sich seine Theaterinszenierung als Demonstration. Aber seine Absichten werden von seiner Mutter erkannt:

Er wollte uns belehren, wie man 24 schreiben und was man zu spielen hat.

Emu chotelos' poucit' nas, kak nado pisat' i cto nużno igrat'. (S. 15)

Volkov vermerkt zu dieser szene:

Eben das war eine "Mausefalle" - der entwickelte Moment des Rampfes des Neuen mit dem Alten.233

Unter diesem Aspekt kann die von Arkadina zitierte Replik aus dem "Hamlet" auch als ironische Vorbemerkung zur folgenden "Belehrung" ihres Sohnes verstanden werden.

Die Worte Arkadinas deuten jedoch noch mehr an. Ronstantin ist der einzige, der sie zwingt, in ihre seele hineinzuschauen. Gerade das versucht sie ja peinlich zu vermeiden und halt sich tattdessen an ihre selbstdisziplin und ihre "Rolle". Die Worte enthalten aber auch eine Vorausdeutung auf die Wunde, die inr der Selbstmord des Sohnes am Ende zufügen wird.

Daß das "play within the play" im "Hamlet" und in der "Mowe" auch eine unterschiedliche kompositorische Position einnehmen, verdeutlicht Jackson.

Just as in Shakespeare's "Hamlet", so in "The seagull". the play within the play reaches out into the psychological drama. But whereas the import of hamlet's theatrical is immediately evident, both before and after the performance, the significance of Ronstantin's play is fully apparent only by the end of

232 Volkov (1966).

233 ebda. S. 434 (B́to byla imenno "myśelovka" - razvitel'nyj moment bor'by novogo so starym). 
"The Seagul1". Chekhov's use of Ronstantin's play is cruical to his whole development of the character of Ronstantin and to the expression of some of the centrai ideas of "The Seaguli".124

In Unterschied zu Hamlet bricht Treplev die Auffūhrung seines Theaterstūcks selbst ab. Auslōser dafūr sind die fūr ihn unerträglichen, spöttischen Bemerkungen seiner Mutter.

Sowohl der Dänenprinz als auch der "Kronprinz" der neuen literarischen Form, Treplev, bewirken mit ihren Theaterinszenierungen eine Reaktion beim Publikum. Doch unterscheiden sich die Ergebnisse in einem wesentlichen Punkt. Hamlet entlarvt indirekt seinen Onkel, der - als er sich in dem Theaterstūck dargestellt sieht - den ort der Bandlung verläbt und damit die Inszenierung beendet (Ausfübrender ist Polonius). Das Publikum in Treplevs Theaterauffūhrung reagiert auf ganz andere Heise: Polina Andreevna spricht zu Dorn. Trigorin wirkt vōllig gleichgültig. Arkadina macht sich ūber das stūck lustig. Und selbst Mina, die Hauptdarstellerin, zeigt dem Text Konstantins gegenüber wenig Verständnis und Interesse.

Das spiel im spiel brachte seinem Autor nicht das gewünschte Brgebnis. Bntlarvende Bedeutung erhalt es lediglich auf der äuBeren Kommunikationsebene. Der Leser/zuschauer bekommt durch die Reaktionen der Protagonisten weitere Hinweise auf deren Beziehungen zueinander.

schmeling sieht in der Eunktion des spiels in spiel für die "Mōwe" "neuromantische Tendenzen":

Die "tragikomische Diskrepanz von Mensch und Nelt" (...) wird hier durchgespielt auf der Basis der Rünstlerproblematik. Die Protagonisten, spieler auf der Bühne und spieler im Leben, sind nicht nur mehr oder weniger realistisch gesehene Reprasentanten einer Gruppe, die bestimmen sozialen, moralischen oder asthetischen Problemen ausgesetzt ist. sondern sie symbolisieren letztlich den Ronflikt von Personlichkeit und Rolle. ICh und Nicht-Ich oder wahrer und scheinbarer Bxistenz. Kennzeichnend für die Darstellung dieses Konflikts ist, daß er in den "Romodien" oft auf tragische Weise endet. So verhält es sich in

134 Jackson (1981), S. 4. 
der "Mōwe", in der die Schauspielerin Nina den Dichter Treplev zum Selbstmord treibt... No die Illusion zur Wirklichkeit in Konkurrenz tritt, wird psychisch oder physisch menschliches Leben zerstört. Das Motiv des Scheiterns der Kunst ist hier eng mit dem menschlichen Schicksal verbunden...

... die Welt des spiels und des Theaters stellt den Ort fur die existentielle Auseinandersetzung des Individuums mit dem Leben, mit der Gesellschaft, mit dem eigenen Ich. Mithin befindet sich das Spiel im spiel in einem besonderen weltanschaulichen und, dadurch bedingt, gattungsspezifischen zusammenhang. Bs trāgt bei zur Konsolidierung eines Dramentypus, der zum bestimmenden Faktor moderner Dramaturgie geworden ist: der Tragikomödie.1 10

Winner sieht bei Shakespeares und Cechovs "spiel im spiel" auch eine ironische Anspielung aut jeweils aktuelle literarische stile. So spiele der englische autor auf das melodramatische "play within a play". wie es in jener zeit ūblich war, an, Ċechov ironisiere das dekadente Theater.230

Treplev spricht nur davon, das er Trigorin zum Duell fordern will. Hamlet tötet Claudius am Bnde tatsāchlich.

Beide ziehen einen Selbstmord in Erwägung. Doch nur Treplev bringt sich um, Hamlet gibt sein Vorhaben auf, un den Mord an seinem Vater zu rächen.

Shakespeares Held kann seine Mutter zu der Binsicht bringen, dab ihr verhaltnis zu Claudius verwertlich sei (III.4). Als Treplev Arkadina von ihrer Beziehung zu Trigorin abbringen will (s. 38ff.). läbt er sich schlieblich dazu uberreden, sich mit dem schriftsteller wieder zu versōhnen. Bei dessen Brscheinen verlabt er jedoch tluchtartig das zimmer.

Bleiben noch die Thnlichkeiten in den Beziehungen Bamlets zu Ophelia und Treplevs zu Nina. Die vater der weiblichen Protagonisten (beider Mūtter sind tot) verbieten ihren Töchtern den Umgang mit Hamlet brw. Treplev. Ninas Vater

13 schmeling (1977), S. 175. Daß "Nina den Dichter zum selbstmord treibt". ist allerdings zu kurz geschlossen und aus dem dramatischen Text kaum zu belegen.

19. Winner (1956), S. 107. 
will nicht, das seine Tochter mit der Bohdme auf dem Gut Sorins verkehrt. Polonius läbt sich von ophelia versprechen $(I, 3)$, den Liebesbezeugungen Hamlets zu niBtrauen und ihm aus dem Neg zu gehen.

Weder der Dānenprinz noch Treplev werden von Ophelia bzw. Nina verstanden und in ihren Bemūhungen unterstũtzt.

Also nicht nur durch die direkten zitate aus dem "Hamlet". sondern auch durch das Verhalten der protagonisten und die Personenkonstellation in der "Höwe" werden Xhnlichkeiten und Unterschiede zwischen bestimmten Personen beider stükke deutlich. Dies geschieht aus der Perspektive Treplevs bzw. in Bezug zu ihm. Soll sein Handeln an das Hamlets erinnern, dann auch das arkadinas an Gertrude und das Trigorins an claudius.

In allen oben angeführten situationen weicht jedoch das Verhalten Treplevs im Endergebnis von dem Hamlets ab.

\subsubsection{Die Unfähigkeit zur Tragödie}

Diese Abweichungen sind nicht nur eine Ironisierung der Figuren durch Cechov, wie Hübner bemerkt.13t Auch die sicht Brahms wird der Bedeutung des Hamlet-Hotivs nicht gerecht, wenn sie $2 u$ dem zitat Arkadinas und Treplevs im ersten Nkt schreibt:

Shakespeare's words could have been written to crystallize and illumine the situation between mother and son. to define their attitude to one another and incidentally to set the key of mockery in which Konstantin's offering is to be received.ise

Auch Smolkin sieht die Replik, in der Arkadina und Treplev aus "Hamlet" zitieren, als ein Mittel, den Rezipienten in das komplizierte psychologische Verhāltnis zwischen Mutter und Sohn einzutūhren.13* Die zitate haben auch

\footnotetext{
137 gübner (1971), S. $109 \ell$.

1 ง Brahms (1976), S. 33 .

130 smolkin (1967), S. 84 .
} 
nicht nur die Funktion, "die philosophische Allgemeingūltigkeit der Idee Cechovs und jener charakteristischen Besonderheiten der 'Möre' zu enthülien und unterstrelchen, die durch jene Idee bestimet sind."110sie besitzen auch nicht nur den Charakter eines Leitmotivs, wie Roskin es darstellt.141

Fūr Winner hat die Hamletthematik in der "Mówe" eine doppelte Funktion. Zum einen ist sie "an ironic commentary on Treplevs pretensions," zum anderen "a device for heightening the tension."142

Die Anspielungen auf Bamlet und das abveichende Verhalten Treplevs besitzen aber auch noch eine tiefere Dimension. Alle Handlungen Hamlets gründen auf einem ethischen Weltbild und werden ausgelöst durch einen tragischen Ronflikt. Br besitzt noch Wertvorstellungen von Liebe, Bhre, Treue und Moral. Als er von der Brmordung seines Vaters durch Claudius erfährt und sieht, daß seine Mutter den Mörder geheiratet hat, muß or sich mit seiner Umgebung auseinandersetzen. Die Diskrepanz zwischen dem ständischen Bhrenkodex und Hamlets (in wittenberg geschulten) Skeptizismus lösen in ihm einen psychischen tragischen Ronflikt aus. Anders in der "Mówe". Feste Wertvorstellungen, wie sie die in Shakespeares Tragódie dargestellte mittelalterliche Welt kennt, fehlen hier. Vielmehr lst Trepleo af der Suche nach festen Bandlungskriterien. Auch gibt es keinen tragischen Konflikt in Form einer obertretung pon gesellschaftlichen Normen. Treplevs Abneigung gegenüber Trigorin entspringt der Bifersucht und seinen Minderwertigkeitskomplexen inm gegenüber als kūnstler, ist also ein psychologisch-emotionaler, kein gesellschaftlicher Ronflikt Tre-

140 Berdnikov (31981), S. 185 (..obnażit' podcerknut" filosofskuju obobscennost zamysla Cechova i te charakternye osobennosti 'Cajki'. kotorye opredeleny dim zamyslom.

24 Roskin, A. (1959), S. 131 .

242 winner (1956), S. 111. 
plevs Verhalten muß sich also von dem Bamlets grundsātzlich unterscheiden.

cechop führt auf zwei Bbenen vor, dab die "Mōwe" keine Tragōdie und Treplev kein tragischer Held sein kann. Zum einen in der Makrostruktur, d.h. in der Gesamtkonzeption des Dramas. Zum anderen verdeutlicht er dies auf der intertextuelien Bbene durch die Anspielungen auf shakespeares "Hamlet". In Bezug auf Treplevs künstlerische Ambitionen erweist sich die "Möwe" als "a tragedy about mediocrity, a mediocrity which is sharpened in our minds by the constant allusions to 'Bamlet'. "Nil J

Ein tragischer Konflikt kann nur durch die Auseinandersetzung wit der AuBenwelt ausgelōst werden. Treplev lebt jedoch isoliert von der Umwelt auf dem Landgut seines onkels. Die einzigen Bezugspersonen sind Angehörige oder mit dem Anwesen auf irgendeine Heise Verbundene. So kreist rreplev in seinen Gedanken nur un sich selbst, d.h. seine Oberlegungen und Handlungen sind nicht auf die AuBenwelt gerichtet. Als Ausdruck seiner selbstreflexion erscheinen auch seine literarischen Arbeiten; denn schreiben ist ja zunachst einmal die Auseinandersetzung mit der eigenen Person.

Welche Wirkung seine literarischen Produkte aut das Publikum haben, erfahrt Treplev erst durch Trigorin.:

Sie fragen: was ist er fūr einer, wie alt, brünett oder blond. Alle glauben aus irgendeinem Grund, daB sie nicht mehr ganz jung sind. Und niemand kennt Ihren wirklichen Familiennamen, weil sie unter pseudonym schreiben. Sie sind geheimnisvoll wie die Biserne Maske.

sprabivajut: kakoj on, skol'ko let, brjunet ili blondin. Dumajut vse podemu-to, cto $\nabla y$ uze ne molody. I aikto ne znaet vasej nastojascej familii, tak kak oy pecataetes' pod psevdoninon. Vy tainstvenny. kak železnaja maska. (s. 52)

Treplevs situation wird durch Trigorins Hinweis auf den "Mann mit der eisernen Maske" angedeutet. Nhnlich wie der strafgefangene zur zeit Ludwigs XIV befindet sich auch

143 ebda. 
Ronstantin in einer Art Gefangenschaft. Binerseits ist er an das Gut seines onkels gebunden, da er über keine finanziellen Mittel verfügt. Andererselts libt inn eine unbewaltigte Adoleszenzkrise, die sich por allem in seinem gespannten Verhätnis zu seiner Mutter und Trigorin auBert, den ort seiner kindheit nicht verlassen.

Trigorin bemerkt in Abwesenheit Treplevs:

Br hat kein Glūck. Br kann scheinbar seinen wahren Ton nicht treffen. So etwas Merkwürdiges, Unbestimmtes, manchmal sogar wie Fieberphantasien. Nicht ein einziger lebender Mensch.

Bmu ne vezet. Vse nikak ne mozet popast. $\checkmark$ svoj nastojasti ton. Cto-to strannoe, neopredelennoe, poroj daze pochozee na bred. Ni odnogo zivogo lica. (S. 54)

Seinen Lesern gegenüber besitzt Tredlev keine Identitat. DaB er dem Publikum nicht mehr ganz jung erscheint und in seinen Werken keine lebenden Personen vorkommen, der Inhalt unbestimnt ist, zeigt, das seine literarischen Arbeiten keinen realistisch mimetischen Charakter haben. Deutlich wird diese kūnstlerische Ronzeption schon zu Beginn des stūcks, als er zu Nina sagt, man müsse das Leben so darstellen, wie es sich in Traumen zeige.

Weder naturalistische Wirklichkeitsbeschreibung noch kritisch-realistische Darstellung, die darauf zielt, Wirklichkeit zu verändern, strebt Treplev an. Sein Ronzept ist visionãr. Bs ist nicht der Traum von einer besseren Welt. Das Leben, wie es Treplev "im Traum erscheint", ist eben kein Leben mehr. Davon zeugt sein Theaterstūck. Was Treplev seine "Weltseele" sagen lät, wird am Bnde der "Mowe" Ausdruck seiner eigenen situation sein. Ober ihre Emptindungen aubert die "Weltseele":

Ich bin einsam. Binmal in hundert Jahren offne ich den Mund um zu sprechen, und meine stimme klingt in dieser Leere trostlos, und niemand hót sie ...

Wie ein Gefangener, in einen leeren, tiefen Brunnen geworfen, weib ich nicht, wo ich bin und was mich erwartet.

Ja odinoka: Raz $\nabla$ sto let fa otkryoaju usta, ttoby govorit'. i moj golos zvuoit $\nabla$ dtoj pustote unylo, i nikto ne siysit... (s. 13) 
Kak plennik, brosennyj $\nabla$ pustoj glubokij kolodec, ja ne znaju, gde ja $i$ cto menja zdet. (S. 14)

Kurz vor seinem Selbstmord sagt Treplev zu Nina:

Ich bin einsam, niemand wärmt mich mit seiner Anhänglichkeit, mir ist kalt, wie in einem Reller, und was ich auch schreibe, alles ist trocken, hart, finster. Bleiben sie hier. Nina, ich flehe sie an, oder erlauben Sie mir, mit Ihnen zu tahren.

Ja odinok, ne sogret nic'ej privjazannost'ju, me cholodno, kak $\nabla$ podzemel'e, $i$, tto by ja ni pisal. vse éto sucho, Cerstro, mracno. Ostan'tes'zdes', Nina, umoljaju vas, ili pozvol'te me uechat's vami! (S. 57)

In beiden fällen dominiert das Gefūhl der Binsamkeit, die Vorstellung, sich in einem menschenleeren Raum (Brunnen, Reller) zu befinden.

Brst aus diesem Bmpfinden heraus kann Treplev den Wunsch aubern, seine Isolation aufzuheben und Nina zu folgen. Gromov weist darauf hin, dab Treplevs Allegorie von der Weltseele stark an vladimir Solov'ev und Friedrich Nietzsche erinnere. Doch biete Ronstantins Theaterstūck keinen Ausweg, keine synthese, wie die Theokratie des russischen Religionsphilosophen oder der "Obermensch" des deutschen Philosophen. Seine Inszenierung stelle lediglich "die frage nach der zeitgenōssischen Miblichkeit des Lebens."i44 Wenn Gromor im folgenden jedoch Treplevs stäke darin sieht, die Widersprüchlichkeit des gesellschaftlichen Lebens klar erkannt und in seinem Theaterstūck bemul formuliert zu haben, dann übersieht er, dab es dem jungen Kūnstler lediglich um neue formen geht und nicht um die Beschreibung sozialer MiBstimmigkeiten. Gerade hier offenbart sich ein wesentlicher Unterschied: Hamlet weik, daß etwas "faul" ist "im Staate Danemark". Ronstantin besitzt nur ein Gefühl der Unglücklichkeit und zerrissenheit. Treplevs Binsamkeit, sein Getrenntsein von der Welt, nachen fūr ihn Handeln in zielrichtung auf die Außenwelt unmoglich. Als relegierter student ist inm das studium verwehrt, da er nicht über finanzielle Mittel verfúgt, 
kann er das Gut seines Onkels nicht verlassen. Sein Kontakt mit der Außenwelt verlauft nur über Vermittlung: von innen nach außen über die literatur, von außen nach innen über andere Personen (Trigorin, Arkadina). Die Welt ist für ihn nicht mehr sichtbar. Daher richten sich seine Bandlungen letztlich gegen sich selbst. Der Selbstmord am Bnde des stūcks erweist sich als Ausdruck der Urkehrung von ziellos nach außen gerichteten Energien ins Innere Treplevs. Fūr ihn gilt, was Norec fūr Ivanov im Unterschied zu Bamlet konstatiert.

Der selbstmord Ivanovs - das ist sein Protest, sein Rampf. In Unterschied zu Bamlet, der seine Feinde konkret kannte, sah Ivanov nicht die personellen Träger des Bösen, er wußte nicht, womit und wie er kämpfen sollte. Eben deshalb exhālt sein Kampl den Charakter des Protests.1.'s

Wie bereits in Kapitel 3.2.1. ausgeführt, entspricht Treplevs situation der des absurden im sinne Camus'. Bine durch die eigene geistige wie raumliche Isolation unzuganglich und undurchschaubar gewordene Welt verandert auch die Position des dramatischen Helden in ihr. So deutet Cechov in der Person Treplevs bereits das an, was beispielsweise Friedrich Dürrenmatt sechzig Jahre spāter zum Problen der Tragōdie in der Moderne anmerkte:

Das Drama Schillers setzt eine sichtbare Welt voraus. die echte staatsaktion. wie ja auch die griechische Tragödie. Sichtbar in der Runst ist das oberschaubare. Der heutige staat ist jedoch unüberschaubar. anonym, bürokratisch geworden. (...)

Die Tragodie, als die gestrengste Kunstgattung. setzt eine gestaltete Welt voraus. Die Romöde - sofern sie nicht Gesellschaftskomōie ist wie bei Moliere eine ungestaltete, im Nerden, im Umsturz begriffene, eine Welt. die an zusammenpacken ist wie die unsrige.14.

14 Norec (1974), S. 169 (Samoubijstro Ivanova - éto ego protest. ego bor'ba. v otlicie ot Gamleta. konkretno znavsego svoich vragov. Ivanov ne videl personalinych nositelej zla. ne znal, s tem i kak emu borot'sja. Imenno poétomu ego bor'ba priobretatet charakter protesta).

1* Dürrenmatt (1969), S. $1191 \mathrm{E}$. 
Fūr die "Möwe" besteht der Unterschied zum absurden Theater jedoch darin, daß eine Außenwelt noch existiert - wenn auch für die einzelnen Personen in unterschiedlicher Intensitat. Mit den Dramen Cechovs beginnt sich die Position der dramatis personae $z u$ inrer Umwelt 24 wandeln, was eine inderung der dramatischen Form zur Folge hat. Volkov konstatiert, die "Möwe" Eühre die Geschichte eines russischen intellektuellen Hamlet vor, der an den gesellschaftlichen Verhaltnissen der goer Jahre zerbreche.1'T Das tragische Bnde Treplevs beweise, daß Cechors stūck doch eine Tragōdie sei.

Gewiß ist der Selbstmord des jungen Protagonisten tragisch im Sinne von erschütternd oder ergreifend. Bin solches Bnde allein macht aus einem Drama jedoch noch keine Trägodie im gattungsspezifischen sinne.

Cechov zeigt nicht eine Tragödie, sondern verdeutlicht die Unfähigkeit seiner dramatis personae zu einer solchen.". Br kennzeichnet damit auch die gesellschaftliche position eines Großteils der adligen Intellektuellen vor der Jahrhundertwende, ihre Unfahigkeit zu kritischer Reflexion und Handlung. Diese Interpretation widerspricht auch Smolkins Ansicht, viele thnlichkeiten in den Werken Shakespeares und Cechors seien auf ahnliche gesellschaftliche und ökonomische Verbaltnisse in den obergangsperioden Englands und RuBlands zurūckzuführen.".

So wird auch deutlich, daß literarischer stil und Gattung historisch und gesellschaftich determiniert sind.

Ninas Brfahrungen mit der AuBenwelt verliefen negatio. Sie kehrt zwar nicht zurūck in ihr Blternhaus (was ihr vater auch zu verhindern sucht), zu ihrem Lebensprinzip wird jetzt jedoch, "leiden zu können" (s.58). Leidensfähigkeit

14TVolkov (1966), S. 435.

14" "Die Möwe" sollte daher auch nicht als Tragödie inszeniert werden, wie volkov aus seinen Ausfürungen schließt, sondern als eine gescheiterte Tragödie.

14 smolkin (1967), S. 73. 
und Duldsamkeit sind im Hinblick auf eine aktive duseinandersetzung mit der Umwelt aber Ausdruck von Passivitat. Auch Nina verkehrt mit dex Umelt über Vermittlung. Sie tritt mit dem publikum über das Medium des Theaters in Kontakt. Als Schauspielerin spielt sie eine Rolle, die in gewissem Rahmen zwar individuelle Gestaltung zulät, sich letztlich aber doch an die Vorgaben von Autor und Regisseur $2 u$ halten hat.

Der Ungang mit ihrem Publikum scheint sich neben dem Theater hauptsächlich auf gesellschaftliche Konventionen zu beschranken:

... und in Blec werden die gebildeten Kaufleute mich mit ihren Liebenswürdigkeiten belästigen. Das Leben ist brutal.

... a $\nabla$ Elce obrazovannye kupcy budut pristavat' s ijubeznostjami. Gruba zizn! (5. 57)

Die Routiniers Arkadina und Trigorin haben, wie bereits erwāhnt, Vermittlungstunktion.

Dabei unterscheiden sich die Binstellungen von Arkadina und Nina sowie Trigorin und Treplev zu ihrer Umwelt nicht wesentlich voneinander.

Die Ilteren haben sich lediglich mit ihrer Rolle abgefunden und etabliert.

arkadina spielt auf dem Landgut ihres Bruders und in der Gesellschaft die gleiche Rolle. Was sie von ihrem Publikum erwartet, ist Bestātigung, mehr noch, Verehrung.

Ebenso wie Treplev hat Trigorin keinen Kontakt zu seinem publikum. Er stellt es sich ihm gegenūber als feindich eingestellit vor und trāumt davon, sich aufs land zurūckziehen $z u$ kōnnen. Seine - eigentlich naturalistische Kunstkonzeption murde bereits in Kapitel 3.1.2. dargestellt.

Treplev, Trigorin und Arkadina baben kaum noch direkten Kontakt mit der AuBenwelt und erweisen sich so als "unfahiø zur Tragōdie". 
4.1.3.1. Züge von Tragikomödie und Farce

In der Auseinandersetzung mit shakespeares whe Tragicall Historie of Hamlet. Prince of Denmarke" verdeutlicht Cechov auf der intertextuellen Bbene die Abhangigkeit dramatischer Form ron der stellung des Individuums zu der ihn ungebenden Helt. Dazu bemerkt Szondi:

Diese Resignation, in der sich Sehnsucht und Ironie zu einer Haltung der Hitte verbinden, bestimmt auch die Form und damit Tschechows Ort in der Bntwicklungsgeschichte der modernen Dramatik. 130

In den Jahren 1887-1889 zeichnet sich bei Cechov neben einer neuen Poetik seiner Prosalst auch eine Handlung in seinem dramatischen schaffen ab. Nach sehr erfolgreichen Binaktern oder Vaudevilles wendet sich der Autor jetzt der groben dramatischen Forw 2u. Dabei verzichtet er auch in seinen Dramen nicht auf Blemente der Farce und des vaudeville. In ihrer Tendenz, menschliche Bestrebungen nach einer Veränderung der unglücklich empfundenen Helt schlechthin ad absurdum $2 u$ tühren, erhalten die stücke Cechovs auf der Bedeutungsebene zūge der Farce.1s

Das schicksal sorins "gibt viel für das Verständnis des Cechovschen sujets im Ganzen."Isoies verdeutlicht das sujet, das er Treplev für eine Novelle vorschlägt.

Sie mubte so heiben: "Der Mann, der wollte." "I'homme qui a voulu". In meiner Jugend wollte ich einmal literat werden - und bin es nicht geworden: ich wollte schōn reden können - und habe immer abscheulich gesprochen (...): ich wollte heiraten - und habe nicht geheiratet; ich wollte immer in der stadt leben

100 szondi $(1 \cdot 1983)$, S. 32 .

13 +Vur aliem perspaktivisches Brzahien, Jerzisht auf Wertungen durch den Autor, starkere Binbeziehung des Lesers in den literarischen ProzeB durch Andeutungen und offenen Schlub. "imperfektives Brzahlen". (1978).

iszzur Problematik der Farce siehe por allew Davis

183 papernyj (1980), S. 55 (...mnogoe daet dlja ponimanija cechovskogo sjuzeta $v$ celomi. 
- und jetzt beende ich mein Leben auf dem Land oder so.

Ona dolkna nazprat'sja tak: "Celovek, kotoryj chotel." "L'homme qui a voulu." $V$ molodosti kogda-to chotel ja sdelat'sja literatorom - i ne sdelalsja: chotel krasivo govorit' - i govoril otvratitel'no (...): chotel Zenit'sja - i ne Kenilsja: chotel vsegda zit. $\nabla$ gorode - i vot koncaju svoju zizn' $\nabla$ derevne, i vse. (s. 48)

Die Brwartungen, die Sorin an sein Leben hatte, haben sich nicht erfüllt. Auch die Hoffnungen Treplevs, Ninas, Masas und Polina Andreevnas verden enttauscht.

In der "Möwe" sind vor allem die Nebenfiguren Medvedenko und Samraev aus der Tradition der Farce gestaltet. Ihre stereotypen Verhaltensweisen und Xußerungen - der Lehrer spricht nur über seine finanziellen Verhaltnisse, der Gutsvervalter über Anekdoten aus Provinztheatern und über Landwirtschaft - sorgen vor allem für komisch wirkende Bffekte. In konzentrierterer form treten diese komischen Piguren dann im "Rirschgarten" mit Simeonov-Piscik, SarLotta Ivanovna und Epichodov auf.134

Die mehr oder weniger starke Betonung des farcenhaften in den Dramen Cechovs spiegelt sich auch in der Differenz zwischen den Inszenierungspraktiken der Regisseure X.S. Stanislavskij und V.B. Mejerchol'd wieder. Wăhrend ersterer sich mehr auf die psychotechnische Darstellung von stimmung und Gemūtsbewegung konzentrierte ("perezivanie"), verstārkte letzterer in seinem antiillusionistischen Theater das stereotype und Formelhafte in Sinne der Commedia dell'arte ("predstavlenie").190 Bine synthese dieser beiden Theaterkonzeptionen vollzieht dann der Regisseur B.B. vachtangov.

15'Die Bedeutung dieser Personen fūr die Komik des stūcks erkannte vor allem Niels-Peter Rudolph bei seiner Inszenierung des "Kirschgartens" in stuttgart 1986/87. Indem er ihre beinabe zirkushaften zuge unterstrich, verhinderte er das Abgleiten des Dramas ins Melancholische und bewahrte ihm so das Komödienhafte.

159 Siehe hierzu vor allem Schmid (1984a). 
Cechov selbst wies immer wieder darauf hin, daß er gegen die Ronventionen des (traditionellen) Theaters verstoBe.130 Beispielsweise schreibt or an 15.9 .1903 an M.P. Alekseeva, sein "Rirschgarten" sei "kein Drama, sondern eine romödie, stellenweise sogar eine Farce" geworden (Vysla u menja ne drama, a komedija, mestami daze (ars) . 131

Fūr die "Möwe" trifft die Bezeichnung "Farce" jedoch nicht in dem Maße zu wie beispielsweise für den "Rirschgarten". Gerade der Schluß dieses stücks, der Tod Treplevs und Ninas Weg in eine ungewisse zukunft sprechen mehr dafür, dieses Drama als "Tragikomödie" zu bezeichnen, wobei Blemente der Farce zu berūcksichtigen sind.130 Darauf deutet schon zu Beginn des Stūcks das Auftreten Masas hin. Die Tragik ihrer Person, die aus Trauer um ihr Leben immer schwarz gekleidet ist, wird durch das farcenhafte Moment des Tabakschnuptens sogleich wieder relativiert.

stereotype und somit komisch wirkende züge tragen auch Dorn, Arkadina und rrigorin. Das ständige singen des Arztes, der Geiz und die Bitelkeit Arkadinas, und die Angelleidenschaft des Schriftstellers untergraben die Ernsthaftigkeit dieser charaktere.

Durch die Typenhaftigkeit in manchen zügen dieser Charaktere wird auch ihr Rollenepiel deutlich, In welchem die

19. Die Briefe, die sich in diesem zusammenhang auf die "Möwe" beziehen, sind in Kapitel 1.2. angefüht.

107 Pis'ma. Bd. 11. S. 248. Cechor scheint den Begrift "Drama" synony̆m für Tragödie 24 verwenden. Dies verdeutlicht ein Brief vom 18.4.1895 an A.S. Suvorin: "Ich werde ein stück schreiben, aber nicht so bald. Bin Drama zu schreiben habe ich keine lust, und eine Romodie habe ich mir noch nicht einfalleu lassea" ( $P^{\prime}$ esy pzost' budu, nc ng skoro. Dramy pisat ne chotetsja, a komedii esce ne pridumal). Pis'ma, Bd. 6, Moskva 1978, S. 55. Cechov gebraucht hier "p'esa" als oberbegriff für das Dramatische, das er in Drama (=Tragödie) und Romödie unterteilt.

1' Papernyj (1980). S. 12, bezeichnet die "Möwe" als "eine der tragischsten Komödien der russischen Komōdienliteratur" l...odna iz tragiknejsich komedij $v$ russkoj komediografiil. 
Grenzen von Kunst und Leben verschwimen. Die Bezeichnung "Romōdie", die Cechov der "Möwe" gegeben hat, enthālt so außer dem Versuch einer gattungstechnischen Bestimung einen zusātzlichen Hinweis auf das Verhāltnis der Protagonisten zur Realitàt. Auch im Russischen bedeutet "Romödie spielen" (razygryoat" komediju), jemandem etwas vortāuschen, vormachen.

4.1.4. Die Bedeutung von Turgeners "Hamlet und Don

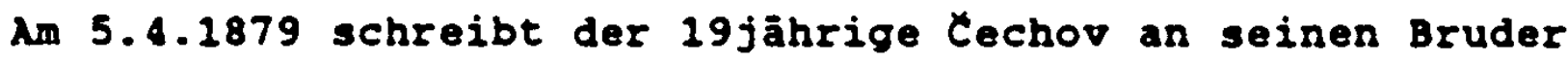
Michail:

Lies die tolgenden Būcher: "Don Quijote" (den ganzen, in 7 oder 8 Teilen). Eine gute Sache. Bin Werk des Cervantes, den man beinahe auf dieselbe stufe wie Shakespeare stellt. Ich rate meinen Brúdern, wenn sie es noch nicht gelesen haben. "Don Quijote und Hamlet" von Turgenev zu lesen.19,

Die Renntnis der Rede "Hamlet und Don Quijote", die Ivan Sergeevit Turgener am 10.1 .1860 gehalten hat.100 ist fúr das Verständnis der "Möwe" von großer Bedeutung.1"1

Turgener stellt in diesem Aufsatz in den Figuren Hamlet und Don Quijote'a zwei literarische Typen einander gegenüber, die grundsätzliche und sich entgegengesetzte Eigen-

19'Pis'ma, Bd. 1, Moskva 1974, S. 29.

100Turgenev, Bd. 8 (1964), S. 171-192. Turgenevs Rede erschien im selben Jahr auch in gedruckter porm.

101Dies übersieht auch winner (1956).

Zur Interpretation und Wirkung von Turgenevs Aufsatz auf die literarische und geistesgeschichtliche Diskussion in Rupland gegen Bnde des 19. Jhds siehe auch: Kagan-Rans (1975).

Smolkin (1967) S. 77 bemerkt zur Bedeutung des Turgenevartikels fúr Eechov: "Turgenev ob'jasnil Cechovu to, to 'vecno i zakonno' $v$ Gamlete."

162 Turgenev bezieht sich hier weitgehend auf den Don Quijote, wie er im zweiten Teil des Romans dargestellt ist. 
tümlichkeiten der menschlichen Natur verkörpern bzw. verschiedene Haltungen einem Ideal gegenüber zeigen.

Hamlet ist der klassische skeptiker, der an nichts glaubt, auch nicht an sich selbst. "Das zweischneidige Schwert der Analyse" (obojudoostryj mec analiza)lo, das er in seinen Hảnden hält, läbt ihn keine Wahrheit akzeptieren. In ihm ist das Prinzip (nacalo) der Verneinung verkörpert.

Hamlet ist derselbe Mephistopheles, aber ein Mephistopheles, der eingeschlossen ist in den lebendigen Rreis der menschlichen Natur; deshalb ist seine verneinung nicht das Böse - sie ist selbst gegen das Böse gerichtet. Die Verneinung Hamlets zweifelt am Guten, aber an Bösen zweifelt sie nicht und tritt mit dem Bösen in einen erbitterten Rampt.

Gamlet tot te Mefistofel', no Mefistofel', zakljucennYj $\nabla$ Zivoj krug teloveceskoj prirody; ottogo ego otricanie ne est' 210 - ono samo napravleno protivu zla. Otricanie Gamleta somnevaetsja $\nabla$ dobre, no vo 210 ono ne somnevaetsja $i$ vstupaet s nim $\nabla$ ozestocennyj boj.1.4

Hamlets Skeptizismus erweist sich deshalb nicht als Indifferentismus; vielmehr setzt er sich für eine Wahrheit ein (die "Gerechtigkeit" schlechthin), an deren Realisierung er selbst nicht glauben kann. Die Folge seines zweifelns, auch an Guten, fūhrt zu Liebesunfảhigkeit und Bgozentrik. so erscheint seine angebliche Liebe 24 ophelia eher als Beschaftigung mit sich selbst. Turgener aieht in Hamlet jene zentripetale kraft in der Natur verkópert, die sich als zentrum betrachtet und alles auf sich bezieht.

Don Quijote dagegen tritt als Ausdruck einer zentrifugalen Rraft auf, die ihren Sinn in der Bxistenz fūr einen anderen sieht.

Diese zwei Rräte der Trāgheit und der Bewegung, des Ronservatismus und des Fortschritts, sind die Grundkrafte alier Bxiztenz.

10jTurgenev, Bd. 8 (1964), S. 176.

104 ebda. S. $182 f$. 
B́ti dve sily kosnosti $i$ dviženija, konservatizma $i$ progressa, sut osnovnye sily vsego sustestrujustego.160

Im Gegensatz zum Skeptizismus des Dänenprinzen drūckt der spanische Ritter vor allem den Glauben an etwas Bwiges, Unerschūtterliches aus, "an eine Wahrheit, die sich außerhalb des einzelnen Menschen befindet" (v istinu, nachodjascujusja vne otdel'nogo celoveka.... .1..

So ist Don Quijote die Verkorperung eines Idealisten, der an die Dinge glaubt, wie sie sich ihm, durch das Prisma seines Ideals gebrochen, darstellen. Br ist zu lieben fāhig und bereit, fūr seine Dulcinea zu sterben, auch wenn diese gar nicht existiert.

Gerade fūr seine zeit und seine Generation konstatierte Turgenev:

Freilich, in unserer zeit sind die Hamlets bei weitem zahlreicher geworden als die Don Quijotes; aber auch die Don Quijotes sind nicht verschmunden.

Pravda, D nase vremja Gamletov stalo gorazdo bolee. Cem Don-Richotov; no i Don-Richoty ne perevelis'.1.7

Anhand des Hamlet-Typs entwirft Turgenev in diesem Aufsatz das Bild einer kritischen Intelligencija, die die rahigkeit zu zielgerichtetem politischem Handeln verloren hat. Für eine Handlung bräuchte man einen willen und eine Idee (mysl'): diese, so der Autor, hatten sich jedoch voneinander getrennt und trennten sich mit jedem Tag mehr.

Nimet man nun Turgenevs Aufsatz als gedanklichen Ausgangspunkt bzw. als Grundlage, so kommt man fūr die "Mōwe" zu interessanten Brgebnissen.

Die Figur Treplevs enthālt wesentliche zūge des Hamlet, in der Interpretation Turgenevs. Sein skeptizismus läbt ihn alle literarischen Ronventionen verneinen. Br setzt diesen jedoch nicht Inhalte einer realistischen Wirklichkeit

\footnotetext{
163 ebda. S. 184 .

* ebda. S. 173.

14 ebda. S. 172.
} 
entgegen, sondern solche, wie sie sich ihm in Trāumen darstellen. Traum bedeutet hier jedoch nicht Utopie im sinne eines erstrebenswerten Idealzustands, ein "Prinzip Hoffnung". Was sich Treplev unter dem Begriff "Traum" vorstellt, sehen wir in seinem Theaterstūck. Bs ist eine Bndzeitvision. Dieser neue Inhalt erfordert andere Ausdrucksmittel. Daher ist sein Rampf um neue Formen eigentlich folgerichtig. Br gewinnt aber weder eine zielrichtung in der Kunst, noch besitzt er die Konsequenz, seine literarische Arbeit als offenen ProzeB zu begreifen und sich in Chaos der Bilder und Träume mit neuen Formen zu behaupten, wie dies bereits die Symbolisten und spāter die Surrealisten taten.

Wie Hamlet glaubt Treplev nicht an Inhalte, die er dem von sich entlarvten "Bósen" entgegensetzen kỏnnte.1" Seine krankhafte Ichbezogenheit hindert ihn, seiner Umwelt unvoreingenommen gegenūberzutreten. Auch seine angebliche Liebe Nina gegenūber, die impulsiven Auftritte, entspringen ebensosehr gekrānkter Bitelkeit als echter zuneigung. Nina hingegen trägt viele zūge eines Don quijote-Typs. Sie ist so sehr in einer Velt von Idealen gefangen, dab sie die Realitat, insbesondere die wirklichen Absichten rrigo-

1. Cechov selbst neigte zu einem solchen skeptizismus. Seine Definition von Freiheit erfolgt ex negativo: d.h. Cechov bezeichnet eine Freiheit von etwas aber nicht zu einer bestimenten Handlung. So schreibt er am 9.4.1889 an A.N. Plesceev: "...das Leben wahrheitsgetreu zu zeichnen und dabei zu zeigen. wie weit dieses Leben von der Norm abweicht. Die Norm kenne ich nicht, niemand von uns kennt sie. Wir alle wissen, was eine ehrlose landlung ist, aber was Bhre ist, wissen wir nicht.Ich werde mich an jenen Rahmen halten, der dem Herzen nâher und bereits von Menschen nrprobt wnrden ist, die stârker und kl.üger sind als ich. Dieser Rahmen ist - die absolute Freibeit des Menschen, die Freiheit von Gewalt, von Vorurteilen, von der Ignoranz, vom Teufel, die Freiheit von Leidenschaften usw." Pis'ma, Bd. 3, Moskva 1976, S. 186.

So auch im Brief an Plesceev vom 4.10.1888: "Mein Allerheiligstes sind - der menschliche Rōrper, Gesundheit, Geist, Talent, Inspiration (vdochnovenie). ilebe und absolute Ereiheit, Freiheit von Gewalt und luge, worin sich die beiden letzteren auch außern mögen." Pis'ma, Bd. 3 , Moskva 1976, S. 11 . 
rins, nicht mehr realistisch einschätzen kann. Selbst am Bnde des Stūcks versucht sie ihre Lage noch zu idealisieren, indem sie ihr schicksal als eine zu erduldende Bestimmung verklārt. Auch ihre Gefühle zu Trigorin haben sich nicht geāndert, trotz der Demütigungen, die er ihr zugefügt hatte.

Der Arzt Dorn besitzt viele Merkmale, die Turgenev Hamlets Freund Horazius zuspricht. zwar ist Dorn kein Anhänger oder Schüler Treplevs, aber doch einer derjenigen, die ihn akzeptieren. Br zeigt Treplevs Theaterstück gegenūber Anerkennung und interessiert sich als einziger fūr die weitere Bntwicklung der Beziehung zwischen Treplev und Mina. Seine Bemūhungen um die jüngeren protagonisten sind aber auch geprāgt von Hilflosigkeit (Szene mit Masa, Bnde erster Akt). Insgesamt jedoch ist Dorns Verhalten dem eines stoikers āhnlich. Dies zeigt sich vor allem in seinem Auftreten den Vertretern der alteren Generation gegenüber. Die besten Menschen, so Turgenev, retteten sich im Mittelalter wie in allen untergehenden Bpochen in einen stoizismus, in welchem sie sich noch inre Menschenwüde bewahren konnten.

Die beobachtende Distanz des Arztes trajgt aber auch deutliche Anzeichen einer asthetischen, dekadenten Lebenshaltung, wie sie Rasch fūr den Trpus des flaneurs konstatiert.

Bntscheidend ist die Distanz, aus der der planeur die Umwelt betrachtet, der Mangel an menschlichem Anteil. Die Menschen erscheinen wie "Aushängeschilder", bloBe Objekte der neugierigen Beobachtung. Sie werden im Blick des Flaneurs losgelöst von ihren Lebensbedingungen und führen, ohne es zu wissen und zu wollen, ein Schauspiel für ihn auf.a'

Auf die Frage Treplevs, warum Genua diejenige stadt im Ausland sei, die Dorn am besten gefallen habe, antwortet dieser:

Dort gibt es eine vortreffliche Nenschenmenge auf den straben. Henn du am Abend aus dem Botel gehst, dann

10 Rasch (1986), S. 61 . 
Ist die ganze straße von Menschen uberflutet. Du bewegst dich dann in der Menge ohne jedes ziel, hierhin, dorthin, im zickzack, lebst mit ihr, verschmilzt psychisch mit ihr und beginnst zu glauben, daß es tatsachlich die Weltseele gibt, in der Art wie die. welche in ihrem Stūck einmal Nina Zarecnaja spielte.

Tam prevoschodnaja ulicnaja tolpa. Kogda vecerom rychodis iz otelja, to vsja ulica byvaet zapruzena narodom. Doizes'sja potom $v$ tolpe bez vsjakoj celi. tuda-sjuda, po lomanoj linii, zives' $s$ neju vmeste. sivaes'sja s neju psichiceski i nacinaes' verit. cto $v$ samom dele vozmozna odna mirovaja dusa, vrode toj. kotoruju kogda-to $\nabla$ vasej p'ese igrala Nina zarecnaja. (S. 49)

Hier zeigt sich deutlich die Lebenshaltung des Flaneurs, unerkannt in der Menge untertauchen zu können, zu beobachten, Bindrücke und stimmungen auf sich wirken zu lassen. Andererseits wird in dem Wunsch, mit der Menge verschmelzen zu wollen, auch erkennbar, daß die Losgelöstheit von der Lebenspraxis als schmerzlich erlebt wird. Die als belastend empfundene Trennung zwischen distanziertem, beobachtendem subjekt und dem Objekt seiner Betrachtungen, aubert sich hier in Verschmelzungsphantasien. Dorn fühlt diese zerrissenheit. Dies zeigt sich vor allem darin. dap er als einziger die Binsamkeit und Losgelóstheit von der Lebenspraxis, die in Treplevs Theaterstück ausgedrückt wird, empeindet. Wie er selbst zugibt, haben ihm bei der Inszenierung sogar "vor dufregung die Hānde gezittert" lot volnenija drozali ruki; s. 18).

Die Haltung Dorns kommt stark einer von Cechov idealisierten Lebenshaltung nahe. Am 4.5 .1889 schreibt er an surorin:

Und man muB auf dieser Welt unbedingt gelassen sein. Nur die Gelassenen sind instande, die Dinge klar zu sehen, gerecht $2 u$ sern und zu arbeiten - das bezieht sich natürlich nur auf. die klugen und anstandigen Menschen; Bgoisten und Boblkojple sind ohnebin schon gelassen genug.170

Cechov sah aber auch, wie in der Figur Dorns dargestellt, die Gefahren. die in einer solch gleichgátigen Binstel-

$170 \mathrm{gis}$ 'ma Bd. 3, Moskva 1976, S. 203. 
lung liegen. Trotz (oder wegen) der Diskrepanz zwischen der frūheren verantwortungsbewußen Tätigkeit als zemstvoArzt und seiner jetzigen asthetischen Lebenshaltung erkennt Dorn in Masa und Nina das zeittypische Rennzeichen der jungen Generation der "Nervösen" und verbindet damit die Metapher vom "Zaubersee".111

Cechov übertrāgt jedoch nicht nur bestimmte Charaktereigenschaften oder Interpretationsmuster aus Turgenevs Artikel auf die Personenkonstellation der "Möwe". Vielmehr steigert er die von Turgenev aufgezeigten Merkmale aus Shakespeares "Hamlet" und Cervantes" "Don Quijote" im Sinne einer bewuten Verfremdung.

Treplevs Kampt gegen das "Bose" verlauft ins Leere, da sich ein wirklicher Gegner nicht ausmachen lāßt. Der $A n-$ trieb für seine Handlungen sind Bhrgeiz. Eifersucht und Minderwertigkeitsgefühle.

Während Don Quijote kurz vor seinem Tod wieder "der gute Alonso" wird, bleibt Nina in ihrer scheinwelt verhaftet. Inre "Idealwelt" ist ein Ronstrukt, das sie vor einer vernichtenden Desillusionierung rettet.

Der stoizismus Dorns schlieblich mündet gegenüber den Vertretern der alteren Generation in Gleichgültigkeit.

wie bereits im porherigen Kapitel aufgezeigt, erweisen sich der intertextuelle Bezug auf Shakespeares "Hamlet"

17 Hier liegt beispielsweise ein deutlicher Bezug zur "Wiener Nervenkunst" und zu Hermann Bahrs Analyse des "Nervösen". als des neuen Typs der Generation der goer Jahre. Wie bei Cechor ist damit die Epoche des "psychologischen" Menschen bezeichnet, der sich vom "ethischen" Menschen des leistungsorientierten Liberalismus in Osterreich bzw. des ideologischen Engagements der "sestidesjatniki" sowie dem daraufolgenden Pragmatismus der Skeptiker der Zemstro-Intelligenz - wie sie Dorn verkórpert - unterscheidet. So kann man Maśa vergleichen mit den hilflos durch symptome protestierenden Hysterikerinnen der Jahrhundertwende (trägt immer schwarz, trinkt, schnupft rabak, tlúchtet in eine frustrierende Bhel. Nina gleicht Ibsens "Nora", der jungen Frau, die aus den vorgezeichneten Wegen ausbricht, um einen eigenen Weg zu gehen. Nina muß dafúr auch den Preis des persónlichen Unglücks und drohenden Wahnsinns zahlen. 
sowie die gedanklichen Entsprechungen zu Turgenevs Aufsatz "Hamlet und Don Quijote" nicht nur als das Kopieren bereits existierender literarischer Typen. Vielmehr apielt Cechov mit der Erwartungshaltung seines literarisch vorgebildeten Publikums. indem er von den Vorlagen bewubt abweicht. Treplev-Hamlet kämpt jetzt eigentlich gegen Windmūhlen, Nina-Don Quijote lebt fūr ein imagināres Ideal. das letztlich niemandem nutzt und Dorn-Borazius kann seinen lāhmenden stoizismus nicht mehr überwinden und verfällt in Gleichgültigkeit.

Der intertextuelle Bezug entkraftet auch den vormur der Ideenlosigkeit, der Cechov beispielsweise von L.N. Tolstoj gemacht wrde. Es erweist sich bier, daB er durchaus seine Gestalten im Licht literarischer Prototypen, bzw. Archetypen der Neuzeit, reflektierte und zudem bereits vorhandene Reflexionen darüber von Turgenev einbezog und seinerseits produktiv aneignete.

So haben diese literarischen Archetypen in Prozeb der intertextuelien Reflexion eine doppelte Bearbeitung erfahren: durch Turgenev und durch Cechov.172

\subsubsection{Hamlet und "Bamletchen"}

Eine Auseinandersetzung mit den Hamlettypus der Moderne führte cechov nicht nur in intertextuell bearbeiteter und verfremdeter Form wie im "Ivanov" oder in der "Mōwe".

\footnotetext{
172 Die Ergebnisse dieses Rapitels widersprechen auch der Meinung smolkins (1967). S. 77. die Charakteristika Hamlets und Don Quijotes aus der sicht rurgenevs stunden sich bei Cechov nicht gegenüber, sondern erganzten sich: "V soznanij Cechova ne bylo mesta dlja protivopostavlenija Gamleta Don-Richotu. oni dopolnjali drug druga."

Bereits in "Platonov" und "Ivanov" sind Personenzeichnungen im Sinne Turgenevs erkennbar. Die beiden Titelhelden erinnern dabei an die Figur Hamlets. Sasa an Don-Quijote. Hie Berdnikov (J 1981). S. 16, feststellt, ist Platonov eine anschauliche Illustration zu Turgenevs Charakteristik Hamlets". einen Don Quijote-Trp im Turgenevschen Sinne habe der junge Cechov damals noch nicht gesehen (...nagljadnaja illustracija $k$ turgenevskoj charakteristike Ganleta).
} 
Am 7.12.1891 exschien in A.S. Suvorins Zeitung "Novoe vremja" ein artikel mit der Oberschrift "In Moskau" ("V Moskve"). Die Unterschrift lautete "Kisljaev" ('Der sāuerIing', oder 'der sauertopf'). Der Autor war jedoch Cechov. wie ein Brief an Suvorin belegt.17s Aus gutem Grund war dieser Artikel mit einem Pseudonym unterschrieben.

Bei der Veroffentlichung handelt es sich un ein bitterböses. sarkastisch-ironisches Pamphlet gegen einen spezielIen Typus des Moskauer Intellektuelien. Der erste Satz lautet: "Ich bin ein Moskauer Hamlet."1" Es ist das in der Ich-Porm gefasste Bekenntnis eines Moskauer Dandys, dessen Hauptproblem die inn qualende Langeweile ist. Die Grūnde hierfūr sind vor allem: Unkultiviertheit, Wichtigtuerei und Neid. Obwohl völlig ungebildet und unkultiviert, will er bei allen kulturelien Anläben mitreden. Da er inhaltich nichts auszusagen hat, ergeht er sich in Floskeln und leeren Redewendungen. Selbst literarisch aktiv, verfast er nur Plagiate und viel zu lange, langweilige Romane. In den modernen Dramen seiner Zeitgenossen vermibt er Ideen und Ideale. Selbst untahig. Iiterarisch gute Arbeiten zu verfassen. Ist er neidisch auf alle erfolgreichen Autoren und verleumdet sie, wo er nur kann.

Hie Bvgenij Onegin ist der Moskauer Hamlet auf allen BalIen und Emptāngen zu finden. immer nach der Mode gekleidet und frisiert. Im Gegensatz zu Pułkins Helden fehlen dem Cechovschen jedoch alle Attribute eines wirklichen Dandytums. Obwohl er die teuersten Mobbel besitzt, spuckt er zu Hause aut den Teppich, die hygienischen zustande sind katastrophal.

Der "Moskauer Hamlet" kỏnnte ein hochgebildeter und kultivierter Mann sein und Bedeutendes schaffen, wenn er "den

1Tد Am 30.11.1891 schreibt Cechov an Suvorin: "Haben Sie etwas dagegen, wenn ich zum nảchsten Samstag ein Moskauer Feuilieton schreibe? Ich móchte die alten zeiten aufleben Iassen." Pis'ma. Bd. 4. Moskva 1976, S. 307.

itpoln.sobr.soc.. Bd. 7. Moskva 1977, S. 500. 
Asiaten in sich ablegen würde" lesli by ja sovlek v sebja azijata). 19

Die Lebenseinstellung des Cechorschen Hamlet ist anstekkend "wie die Intluenza".

... irgend ein halbwüchsiger student hat schon die ohren gespitzt, streicht wichtig mit der Hand über das Haar, und sagt, ein Buch von sich werfend: "Worte, Worte, Worte... Gott, was für eine Langeweile!"

... kakoj-nibud' podrostok-student uze prislusalsja. vazno provodit rukoju po volosam i. brosaja ot sebja knigu, govorit:

"slova, slova, slova... Bože, kakaja skuka!"it"

Diese Anspielung auf Hamlet (Hamlet im Gesprāch mit Polonius. II, 2) Einden wir spāter in der "Möwe" wieder, als Treplev zu Nina sagt:

(Hat Trigorin gesehen, der, ein Buch lesend, kommt.) Da kommt das wahre Talent; er tritt auf wie hamlet. und auch mit einem Buch. (Hānselt) "Worte, Worte. Worte ...."

(Uvidev Trigorina, kotoryj idet, titaja knizku.) Vot idet istinnyj talant: stupaet, kak Gamlet, i toze 3 knizkoj. (Draznit.) "slova, slova, slova..." (s.27E.)

Nur verkennt Treplev die eigene situation. Denn in der Rolle des hamlet befindet sich ja auch er selbst.

Bereits zwei Jahre vor diesem Pamphlet lābt sich Cechov in einem Brief an A.S. Suvorin vom 27.12 .1889 über die russische Inteligencija aus:

Die trāge, apathische, faul vor sich hin philosophierende, kalte Intelligenz, die nicht einmal făhig ist. ein anstāndiges Muster fur Banknoten zu entwerfen. die unpatriotisch, depriniert und farblos ist, die von einem Glas betrunken wird und punfzigkopekenBordelle besucht. die herumnörgelt und gern alles ablehnt. was ein träges Hirn leichter ablehnen als bestatigen kann: die nicht heiratet und es ablehnt, Kinder aufzuziehen usw. Trāges Herz. trāge Muskeln. Mangel an Bewegung. Unbeständigkeit des Denkens - und all das nur, weil das Leben keinen sinn habe, die Frauen Leukorrhōe haben und auch das Geld etwas Bóses sei. Wo Degeneration und Apathie herrschen. da herrschen auch sexuelle Perversion. Unzucht, Abtreibun-

190 ebda. S. 506.

1 1 ebda. 
gen, frühes Alter, nörglerische Jugend, da herrschen Niedergang der Runst, Gleichgültigkeit gegenüber der Wissenschaft: da herrscht Ungerechtigkeit in jeder Form.197

Cechovs Pamphlet "In Moskau" stellt aber weder einen schlüssel fūr den "Ivanov" dar, wie smolkin ausführt, noch $f u ̄ r$ das Hamletthema in der "Mōwe". Vielmehr muß es gesehen werden vor dem Hintergrund der offentlichen Diskussionen über den "Hamletismus" in den 80er Jahren des 19. Jahrhunderts in RuBland.

Sach-Azizova weist darauf hin,179daß besonders im Jahr 1882 viele Artikel von Vertretern der liberalen Narodniki erschienen (P.L. Lavrov, A.M. Skabicevskij. P.P. Jakubovic. N.K. Michajlovskij), die sich in sehr kritischer und polemischer Weise mit einem bestimmten Typus russischer Intellektueller auseinandersetzten.

Beispielsweise verfabte der mit Cechov bekannte schriftsteller N.A. Rubakin in den goer Jahren ein Gedicht, das in der Tendenz dem Pamphlet "In Moskau" sehr nahe komit. 100

179Pis'ma Bd. 3, Moskva 1976, S. 309.

Tosmolkin (1967), S. 83ff. Smolkin vermerke, es seien zwar nicht alle züge des "Moskovskij gamlet" in der Figur des Ivanov vorhanden, wohl aber dessen Egoismus und Pessimismus. Insgesamt konstatiert er: "Fel eton "Moskovskijgamlet napisannyj pocti v odno vremja s 'Ivanovym. sluzit kijucok $k$ ponimaniju social'nogo aspekta obraza Ivanova $i$ otvectaet okoncatel'no na vopros ob otnosenii pisatelja k 'gamletismu'." ebda. S. 83. Diese Einschätung widerspricht jedoch völlig der differenzierten Charakteristik Ivanovs, die Cechov in seinem ausführlichen Brief vom 30.12 .1888 an $A . S$. Suvorin entwirft.

$$
\begin{aligned}
& \text { 19. Sach-Azizova (1977). } \\
& \text { 1 O0 Das Gedicht Rubakovs lautet: }
\end{aligned}
$$

- Ich esse jeden Tag zu Mitttag:/welcher Sinn darin liegtweiB ich nicht./Ich lese jeden Tag:/wozu - verstehe ich nicht!/Ich kann auch nicht verstehen,/weshalb ich nachts schlafen gehe./Ich gehe jeden Tag, sitze/und ein ziel darin finde ich nicht./Ich brauche nichts -/weder paradies noch Hölle./Zuwider bis zum Tod/Sind nir sowohl Bngel als auch Teufel./Zum Teufel schicke ich/sowohl Gefühle als auch Ideen./Den Tod wollte ich nicht,/aber das Leben habe 
In allen Aufsātzen verden die in Untatigkeit und Selbstreflexion gefangenen Vertreter der Intelligencija mit der literarischen figur des Hamlet in verbindung gebracht. Dabei ist ein Bedeutungswandel zu beobachten "vom tragischen Helden, vom eine Niederlage erleidenden Kämpferzum gefäschten Hamlet, zur Parodie auf Bamlet."1:1 Der haltlose und egozentrische Intellektuelie der 80er Jahre wird hãufig auch als "entmagnetisierter Intelligenzler" (razmagnicennyj intelligent) bezeichnet.102

Binen eher aggressiven Artikel verfabte der Literaturkritiker und Ideologe der Iiberalen Narodniki. Nikolaj Konstantinovic Michajlovskij.1." Br unterscheidet zwischen dem Shakespearschen Hamlet und dessen modernen Kopien, den "Bamletchen" (gamletki) und "verhamletisierten Ferkeln" (gamletizirovannye porosjata).1" Weisen die ersteren wenigstens noch zwei echte Hamletzūge auf (das Leiden am Bewrotsein der eigenen Handlungsunfähigkeit und die Egozentrik), so sind die letztgenannten nur noch damit beschätigt, sich und andere von ihrer würde zu überzeugen, die ihnen das Recht. zur Bxtravaganz gibt.

In seinem Aufsatz nober die văter und sôhne und über H. Cechov" (Ob otcach $i$ detjach $i \circ g$. Cechove) aus dem Jahre 1890119 setzt sich Michajlovskij auch sehr kritisch mit Cechovs "Ivanov" und dem gerade erschienen Brzählungsband "Pinstere Menschen" (Chmurye 1judi) auseinander. Br wirft Cechov hierin vor, das schicksal seiner figuren völlig

ich gãnzlich satt./Ich weiß wirklich selber nicht -/lebe oder sterbe ich." Zit. bei Sach-Azizova (1977), S. $235 f$.

1U Sach-Azizova (1977), S. 235.

100 ebda. S. 236.

1.3Zur Rolle Michajlovskijs innerhalb der NarodnikiBewegung siehe Vilenskaja (1979). Das Verhältnis zwischen Cechov und Michajlovskij beschreibt Bjalyj (1981), S. 102173.

104Michajlovskij (1896-1909), Bd. 5 (1897), Sp. 688.

10'Russkie vedomosti. Nr. 104, 1890. Zit. aus: Michajlovskij (1896-1909). Bd. 6 (1909), Sp. 771-784. 
kaltblütig zu beschreiben, außerhalb seiner Werke zu stehen. Das Wichtigste aber sei, daß bei ihw das fehle. "was man als allgemeine Idee oder den Gott des lebenden Menschen bezeichnet." 10 Seine "Idealisierung des Fehlens von Idealen" (idealizacija otsutstoija idealov)10' stehe in krassem Gegensatz zu Autoren wie Saltykov-SCedrin, Ostrovskij, Dostoevskij und Turgenev.

Cechov spielt mit "In Moskau" auch auf den Artikel Michajlovskijs an. Sein "Moskauer Hamlet" urteilt über das moderne Theater und Drama namlich: "Aber wo sind denn die Ideen? Wo die Ideale?" (No ideja Ze gde? Gde idealy?) $\cdots$ Br gibt zu, vom Theater nichts zu verstehen, aber solche vielsagenden Redewendungen habe or bei den Moskauer Rritikern gelernt.

Cechors Pamphlet enthālt also zweierlei: zum einen eine Polemj.k auf Michajlovskijs ein Jahr zuvor erschienen Artikel, zum anderen hat er die gleiche zielrichtung wie die gegen einen bestimmen Hamlettypus der Moderne gerichteten Angriffe der Narodniki.

Die Verbindung des handlungsunfähigen russischen Intellektuellen nit der literarischen Figur des Hamlet ist allerdings nicht neu. Smolkin reist darauf hin, daß bereits in den 30er Jahren des 19. Jahrhunderts, nach dem scheitern der Dekabristenbewegung, die figur des lamlet mit dem "unnūtzen Menschen" (lisnij Celovek) gleichgesetzt murde. Beispielsweise unterschied Belinskij zwischen dem zwar skeptischen aber doch aktiven literarischen Hamlet und den zeitgenössischen apathischen "Hamletchen".10 Binen weiteren Ausdruck fand das Thema des modernen russischen Hamlet dann in Turgeners Brzāhlung "Bin Hamlet aus dem Rreis

10 ebda. Sp. 780 . Michajlorskij gebraucht hier ein zitat aus Cechovs Erzahiung "Skucnaja istorija" aus dem Jahre 1889.

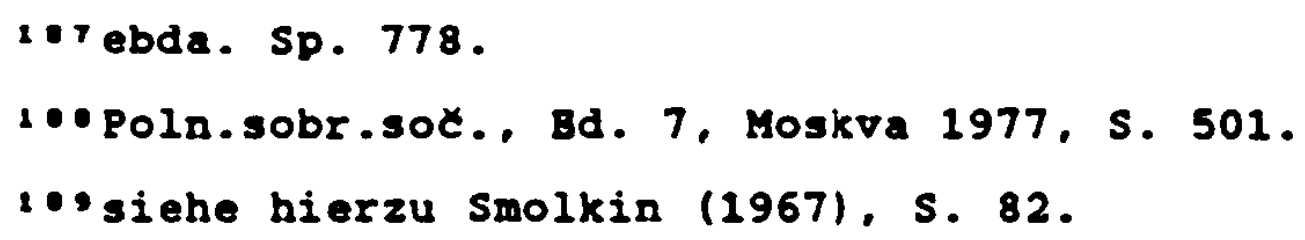


Scigrov" (Gamlet Stigrovskogo uezda) von $184910^{\circ}$ in den "Aufzeichnungen eines Jägers" (zapiski ochotnika). Der hier skizzierte "Provinzhamlet" kann jedoch nicht als Vorstufe $2 u$ dem in dem Aufsatz "Hamlet und Don Quijote" gesehen werden. Br stellt vielmehr eine ànnliche Ironisierung dar wie der "Moskauer Hamlet" Cechovs, der auch nicht mit Ivanov verwechselt werden sollte.

Oberhaupt ist die offentliche Diskussion und Polemik un den russischen Hamlet der $80 e r$ Jahre nur $z u$ verstehen vor dem Hintergrund der gescheiterten Narodniki-Bewegung." 's Deren liberale vertreter um N.R. Michajlovskij und P.L. Lavrov "erklärten das schöperische und mit kritischer vernunft begabte Individuum zur treibenden Rraft der historischen Bntwicklung und lehnten eine deterministischmaterialistische Geschichts- und Gesellschaftstheorie ab."1,2Nachdem das Narodnicestro mit seinem "Gang ins Volk" im "verrückten Sommer" 1874 einen empfindlichen Rūckschlag erlitten hatte und interne Diskussionen über die zukūntige politische vorgehensweise 1879 zur Trennung geführt hatten, setzte das Attentat der "Narodnaja volja" auf Alexander II. allen Hoffnungen auf eine Abschaffung der Autokratie endgültig ein Bnde. Das Manifest Alexanders des III. vom 29.4. (11.5.) 1881 leitete eine Phase der Reaktion und Restauration der Autokratie ein.

Die von den Narodniki als Träger der gesellschaftichen Umwälzungen postulierten vertreter der jungen Intelligencija zogen sich nach dem scheitern ihrer ziele zunächst zurūck.

Suchen nach Grundlagen, unbestimmte sehnsucht und mystisches Brwarten wurier z'm Hauptinhalt das geistigen Lebens der enttäuschten Intelligencija und

100 Turgenev, I.S.: Poln.sobr.soc., Bd. 4. MoskvaLeningrad 1963, S. 270-296.

$1 " 1$ Zur Narodniki-Bewegung siehe vor allem:

Pipes (1964); Galaktionov/Nikandrov (1966); Naimark (1979); Borcke (1979); Schramm (Bg.) (1983), S. 145-169.

192 Schramm (Hg.) (1983), S. 155. 
eines Teils der liberal Gesinnten, die die ideelle Basis fūr den religiōsen Idealismus und die Dekadenz un die Jahrhundertwende bildeten.193

Michajlovskij, Lavrov und deren Anhänger murden in doppelter Hinsicht enttauscht. Heder unterstützte die von ihnen idealisierte Bauernschaft das Narodnicestvo, noch murde die Intelligencija ihrer Rolle als Subjekt der revolutionären Bewegung gerecht.

In der literatur gehörten die großen "Alten" des Realismus schon einer vergangenen Epoche an: 1878 starb Nekrasov. 1881 Dostoerskij, 1883 Turgenev, 1886 ist das Todesjahr Ostrovskijs, 1889 stirbt Saltykov-scedrin und 1891 schlieblich Goncarov. Im Schaffen L.N. Tolstojs dominierten seit "Anna Karenina" mehr und mehr religiōse Aspekte. Die Schriftsteller, die den Narodniki nahestanden (insbesondere Uspenskij. Mamin-Sibirjak und zlatorratskijl erzielten durch ihre naturalistischen "ocerki" beim Publikum nicht die erwartete Bewrutseinsänderung.

\subsubsection{Hamlettrpen in den Dramen Cechovs}

Cechovs Auseinandersetzung mit dem "Hamletismus" seiner zeit verlauft zweigleisig. Einerseits verurteilt er - auf ironische Weise wie mit "In Moskau" oder in direkter Form in seinen Briefen - den Typus des apathischen, zu keiner zielgerichteten Handlung fahigen Intellektuellen. Andererseits aber konstatiert er in seinen Exzählungen und Dramen die psychische Verfassung seiner Helden.

Als Rūnstler interessierte ihn die Psychologie dieses Typs (des modernen Hamlets, P.-J.L.), die lebendigen menschlichen züge der überflüssigen Henschen, und ex schuf ihre figuren in seinen Werken mehr als einmal.1.4

1.3 Kluge (1973), S. 33.

194molkin (1967), S. 82. "Kak chudoznika, ego interesovala psichologija étogo tipa, zivye celoveceskie certy lisnich ljudej. $\frac{i}{n}$ on ne raz sozdaval ich obrazy $v$ svoich proizvedenijach." 
Dabei andert sich die Binstellung des Autors 24 seinen Dramenhelden seit der "Möwe".

Im "Stück ohne Titel" und im "Ivanov" werden die Hauptpersonen noch in kritisch-distanzierter porm dargestellt. Durch Selbstanalysen - in Monologen und Dialogen - sowie Aussagen anderer Personen erfahrt der Leser/Zuschauer von der Vorgeschichte und der augenblicklichen Verfassung Platonovs und Ivanovs. Freilich dringt die Analyse nie bis zu den Ursachen der Apathie und Lethargie vor, sondern konstatiert Symptome. Vergangenheit und Gegenwart werden gegenūbergestellt.

Von Platonov über Ivanov bis Trigorin ist eine Entwicklung zu beobachten vom sich noch gegen die bestehenden Verhälnisse aufbäumenden über den sich selbstzerfleischenden bis hin zum etablierten Intellektuellen.

Platonov wird nicht nur von seiner Umwelt als "der beste Vertreter der zeitgenössischen Unbestimmtheit" (neopredelennost", charakterisiert."'s Von sich selbst sagt er:

Das Bōse wimmelt um mich herum, beschmutzt die Brde, verschlingt meine Brüder in Christo und Landsleute. ich aber sitze da, die Hände in den Schob gelegt, wie nach schwerer Arbeit; ich sitze, schaue zu, schweige... Ich bin 27 Jahre alt, in 30 Jahren werde ich genauso sein - ich sehe keine Veranderungen! - was folgen wird ist ein feistes Schlafrockdasein. Abgestumptheit, vollige Gleichgültigkeit gegenüber allem, was nicht fleisch ist, und dann kommt der Tod!! Das Leben ist verpfuscht! Die Haare stehen mir zu Berge, wenn $i c h$ an diesen Tod denke!

zlo kijit vokrug menja, packaet zemlju, glotaet moich brat'ev vo Christe $i$ po rodine, ja ze sizu sloziv ruki. kak posle tjazkoj raboty; sižu, gljažu, molcu... Hne dvadcat sem' let, tridcati let ja budu takim te - ne predvizu peremeny! - tam dal'Se zirnoe chalatnicestvo, otupenie, polnoe ravnodusie ko vsemu tomu, tetu ne plot', a tam smert'!! Propala zizn'! Volosy stanovjatsja dybom na moej golove, kogda ja dumaju ob etoj smerti!:

Platonov ist jedoch nicht nur mit seinem Leben unzufrieden, er versucht sich auch dagegen aufzubaumen. Davon

19P Poln.sobr.sod., Bd. 11, Moskva 1978, S. 16.

10 ebda. S. 85 . 
zeugen seine zynismen, Streiterein und Provokationen gegen die ihn Umgebenden. Bin weiterer Versuch, der Saturiertheit zu entfliehen, sind seine Liebesaffaren. Das diese aber immer nur Ersatzhandlungen für eine wirkliche Lebensaufgabe waren, sieht platonov selbst.

Anderen Leuten geht es um Eragen von Heltbedeutung. mir aber geht es um die Frau! Das ganze Leben - um die Frau! Bei Cảsar war es der Rubikon, bei mir - die Erau... Nutzloser Brauenheld!

U ljudej mirovye voprosy, a u menja zenstina! Vsja zizn'- Zenscina! U Cezarja - Rubikon, u menja - zenscina... Pustoj babnik!".

Ivanov dagegen fehlen die Versuche des Aufbegehrens. Den Anfeindungen $L$ vovs und der übrigen Umwelt steht er gleichgūltig gegenūber.

Mit 30 Jahren schon Ratzenjammer, ich bin alt, ich trage schon den Hausrock. Mit schwerem Ropf, mit träger seele, erschöpt, uberanstrengt, gebrochen. ohne Glauben, ohne Liebe, ohne ziel, wie ein schatten treibe ich mich zwischen den Menschen herum und wei $\beta$ nicht: wer bin ich, weshalb lebe ich, was will ich? Und mir scheint es schon, dap liebe Unsinn ist. zảrtlichkeiten widerlich sūß sind, daß Arbeit keinen sinn hat. das lied und feurige Reden abgeschmackt und alt sind. Und überall hin bringe ich mit mir Trauer, kalte Langeweile, Unzufriedenheit, Bkel vor dem Leben... Ich bin unwiederbringlich verloren!

$v$ tridcat' let uze pochmel'e, ja star, ja uze nadel chalat. S tjazeloju golovoj. s lenivoju dusoj. utomlennyj, nadorvannyj. nadlomlennyj. bez very, bez ljubvi, bez celi, kak ten', slonjajus ja sredi ljudej i ne znaju: kto ja, zacem zivu, cego chocu? I mne uze kazetsja. cto ljubov'- vzdor, laski pritorny, cto $\checkmark$ trude net smysla. cto pesnja i gorjacie reci posly $i$ stary. I vsjudu ja vnosu s soboju tosku, cholodnuju skuku, nedovol'stvo, otvrascenie $k$ zizni... Pogib bezvozvratno!1"0

Ivanovs kurzzeitige Hoffnung, ein neues Leben mit sasa zu beginnen, ist eher durch sie, als durch ihn selbst initiiert. Sein Selbstmord an Ende des stūcks unterstreicht die Hoffnungs- und Orientierungslosigkeit seines Lebens.

197 ebda. S. 1141.

1. Poln.sobr.soc.. Bd. 12, Moskva 1978, S. 74. 
Trigorin als Altersgenosse Ivanovs und Platonovs hat sich mit seinem Leben abgefunden. Br erscheint zwar nicht glūcklich (Gesprāch mit Nina, zweiter Akt), aber Gleichgültigkeit und Bequemlichkeit lassen ihn das Leben ertragen.

Aber der platz reicht doch für alle, für die Neuen und die Alten (Iiterarischen Formen, F.-J.L.). - wozu sich drängen?

No ved' vsem chvatit mesta, i novym i starym, - zacem tolkat'sja? (s. 34)

Unterschiedlich ist auch der Aspekt der Vergangenheit der Personen. Wảhrend Platonov und Ivanov in jungen Jahren noch fūr soziale Veränderungen kämpften, hatte Trigorin nur seine literarische Karriere im Sinn. Nachdem ihn die offentliche Meinung anerkannt hatte. gehört er heute zu den "Satten". DaB ihn seine situation als Künstler belastet, wird durch seine Ausführungen gegenūber Nina (zweiter Akt) deutlich.

So ist es vor allem die Diskrepanz zwischen Anspruch und Wirklichkeit, zwischen dem Willen zu sozialem Engagement und Handlungsunfahigkeit, die Trigorin zu schaffen macht.

Aber ich bin doch nicht nur Landschaftsmaler, ich bin doch auch Bürger, ich liebe die heimat, das volk, ich fühle, das ich. wenn ich schriftsteller bin. auch verpfiichtet bin, über das volk zu sprechen, über seine Leiden, über seine Zukunft, über die Wissenschaft. über die Rechte des Menschen und anderes mehr und anderes wehr, und ich spreche über alles, beeile nich, man treibt.mich von allen seiten an, ist mir böse, ich hetze hin und her, wie der Fuchs, der von den Bunden gejagt wird.

No ved' ja ne pejzazist tol'ko, ja ved' esce grazdanin, ja ljublju rodinu, narod, ja cuvstvuju, cto esli ja pisatel': to ja objazan govorit o narode, ob ego stradanijach, ob ego huduscem, govorit. o nauke, o pravach celoveka $i$ procee $i$ procee, $i$ ja govorju obo vsem, toropljus'. menja so vsech storon podgonjajut. serdjatsja, ja mecus' iz storony $\nabla$ storonu, kak lisica. zatraviennaja psami...(s. 30)

Trotz seiner Bemühungen hinkt er dem gesellschaftichen und wissenschaftlichen Portschritt hinterher, es gelingen inm nur Landschaftsschilderungen. 
Bs fällt auf, daß Cechov nur in den frūhen Dramen das Hamlet-Motiv aufgreift. Im "Stück ohne Titel", im "Ivanov" und schließlich in der "Möwe". Bine Ausnahme bildet dabei der "Waldschrat".

Im "Stūck ohne Titel" wird der Held zunāchst von seiner Umgebung mit Hamlet verglichen. So sagt die Grekova im 2weiten Akt (1. Bild, Auftritt $X$ ) über Platonov:

Verkehren sie mit diesem Menschen, lieben Sie ihn, beten Sie seinen Verstand an, fürchten sie ihn... Ihnen allen scheint, das er Hamlet ahnlich ist... Also ergotzen sie sich an ihm!

Znajtes' s etin Celovekom, ljubite ego, poklonjajtes' ego umu, bojtes'... Vam vsem kažtsja, tto on na Gamleta pochoz... Nu i ljubujtes' im! 19

Platonov aubert selbst im vierten Akt (Auftritt XI):

Hamlet hatte Angst vor Traunvisionen... Ich habe Angst... vor dem Leben!

Gamlet bojalsja snovidenij... Ja bojus'... Zizni!zoo

Die Attribute, die Hamlet zugeschrieben werden, sind in diesem Drama noch durchweg positiv. Er ist liebenswürdig, man bewundert und fürchtet seinen verstand. Platonov selbst hät sich eines Vergleichs mit dem Shakespearschen Helden für nicht würdig, hatte dieser doch nur "Angst vor Traumvisionen". nicht aber vor dem Leben.

Schlieblich plant Vojnicev im zwaiten Akt (2. Bild, Auttritt XVI), den "Hamlet" aufzufūhren. Dabei hat er sich selbst die Hauptrolle ausgesucht, eine Wahl, die die Figur des Hamlet als eine positive Rolle unterstreicht.

1. Poln.sobr.soc.. Bd. 11, Moskva 1978, s. 70. Platonov wird aber auch mit Byron und Cackij. dem Heiden aus Griboedovs "Gore ot uma" in Verbindung gebracht.

Platonov zu Sofja Bgoroma in I.13: "...damals, als sie in mir einen zweiten Byron sahen..." ebda. S. 33 .

Vengerovic zu Platonov in I.21: "Ich studiere an ihnen die modernen Cackijs..." ebda. s. 50.

200 ebda. S. 175 . 
Ich - bin Hamlet, Sof'ja - Ophelia, du (=Platonor. E.-J.L.l - Claudius, Trileckij-Horaz!201

Die von Vojnicer geplante Besetzung stimmt jedoch nicht mit der Personenkonstellation in "stūck ohne Titel" überein. So ist in Wirklichkeit nicht Trileckij der beste Freund Vojnicevs, sondern Platonovs. Platonov selbst wird nicht Vojnicevs Mutter verführen, sondern dessen Frau. In seiner Unwissenheit und Naivitat waihlt or eine Besetzung. die mit den tatsāchlichen Beziehungen der vorgeschlagenen Schauspieler zueinander nichts zu tun hat. Das zitat aus "gamlet" (III. Akt, Szene \&) ist jedoch tūr Platonov und im äußeren Kommunikationssystem fūr die Leser/zuschauer eine deutliche Anspielung auf die Beziehung zwischen inm und Sof'ja. Vojnicer zitiert:

Und diesem Bösewicht.

vergessend Scham der Frau, der Gattin, der Mutter. konntest Du dich hingeben!...

I ètomu zlodeju.

styd Zenšiny, suprugi, materi zabyv. Hogla otdat'sja ty!...soz

Zwei Auftritte zuror hatte platonov einen Brief von Vojnicevs frau erhalten, in dem sie ihn zum Bhebruch auffordert. Im XV. Auftritt entschliebt sich Platonov dann auch. auf das Angebot Sofja Bgorovnas einzugehen.

In "Ivanov" vergleicht sich die Titelfigur selbst mit Bamlet. Dieser Vergleich wird jedoch von ihm negativ gewertet. Zunächst im zweiten Akt (VI. Auftritt) zu sasa:

Ich vergehe vor scham bei dem Gedanken, das ich, ein gesunder. krāftiger Hensch, mich entweder in einen Hamlet, oder in einen Manfred oder in einen überflūssigen Menschen verwandelt habe... selbst der Teufel wird daraus nicht klug. Bs gibt bedauernswerte Menschen, denen es schmeichelt, wenn wan sie einen Hamlet oder überflüssig nennt, aber fúr mich ist daseine Schande! Das empört meinen stolz. Scham bedrūckt mich, und ich leide...

201 ebda. S. 117.

202 ebda. 
Ja umiraju ot styda pri mysli, tto ja, zdorovyj, sil'nyj Eelovek, obratilsja ne to $\nabla$ Gamleta, ne to $\nabla$ Manfreda, ne to $v$ lisnie ljudi... sam tert ne razberet! Est Zalkie ljudi, kotorym 1'stit, kogda ich nazyvajut Gamletami ili liłnimi, no dlja menja etopozor! Bto vozmuscaet moju gordost. styd gnetet menja, i ja stradaju...202

In dritten Akt (VII. Auftritt) bemerkt er, wiederum zu Sasa :

Mein Jammern flobt dir ehrfurchtsvolle Angst ein, du bildest dir ein. das du in mir einen zweiten Hamlet gefunden hast, aber, meiner Meinung nach, kann diese meine Psychopathie, mit all inren Accessoires, nur als gutes Material zum Lachen dienen und mehr nicht.

Moe nyt'e pnusaet tebe blagogovejnyj strach, ty voobrazaes:. tto obrela vo mne vtorogo Gamleta, a, pomoemu, eta moja psichopatija, so vsemi ee aksessuarami. mozet sluzit chorosim materialom tol'ko dlja smecha $i$ bol'se nicego!204

1m "Ivanor" findet also insofern eine Umwandlung in der Einstellung zum Hamlet-Typus state, als der Beld den Vergleich mit der literarischen Figur aus Shakespeares Drama als abwertend emptindet, welchen seine umwelt aber durchaus noch positiv einschäzt.

Für Cechor muß der Hinweis auf die Hamlet-Problematik wichtig gewesen sein. Die oben angeführten zitate fehlen noch in den beiden ersten Redaktionen von 1887 und 1888. Der Autor hatte sie erst in die dritte Fassung im Jahre 1889 eingearbeitet. Norec bemerkt,20s dab auch die individuellen züge Ivanovs erst im Laufe der verschiedenen Redaktionen stärker gezeichnet werden. So ist beispielsweise der Verweis der Hauptfigur auf Hamlet in der vorletzten Fassung noch allgemeiner (II,6), weil im Plural gehalten (obratilsja ne to $\nabla$ Gamlety, ne to $\nabla$ Manfredy, ne to $v$

20 Poln.sobr.soc., Bd. 12, Moskva 1978, S. 37.

204 ebda. S. $57 E$.

200 Norec (1974), S. 166. 
lisnie ljudi)200, nach der letzten oberarbeitung durch Cechov in singular.

Eine weitere Anspielung auf den Shakespearschen Helden macht Ivanov im vierten Akt (VIII. Auftritt) gegenüber Sasa kurz vor seinem Selbstmord:

Ich habe den Hamlet gespielt, und du die erhabene Jungfrau - und jetzt reichts.

Poigral ja Gamleta, a ty vozvgsennuju devicu - i budet 5 nas. 207

In der "Möwe" schließlich sind die Anspielungen aut den "Hamlet" verschlüsselter, eine direkte Wertung fehlt. Zunāchst zitieren Arkadina und Treplev in ersten Akt eine stelle aus dem Drama, im zweiten Akt versucht Treplev durch ein Ramletzitat, sich über Trigorin lustig zu machen.

20 Poln.sobr.soc., Bd. 12, Moskva 1978, S. 329.

207 ebda. S. 70 .

In einem Brief vom 30.12 .1888 an $A . S$. Suvorin erlāutert Cechor ausfürlich, wie er die Personen in seinem "Ivanov" verstanden wissen will. Br sieht in der Titelfigur einen für das RuBland jener Zeit typischen intellektuellen Adligen, der sich in jungen Jahren große soziale Aufgaben zum ziel setzt, deren Realisierung jedoch seine Rrafte übersteigt. Das Resultat sind frūhzeitige Brmūdung, Langeweile, Schuldgefühle, Binsamkeit und Handlungsunfähigkeit. Die Ursachen für seine Apathie vermag er aber nicht zu finden. "Er sucht die Ursachen auberhalb und findet sie nicht, er beginnt, sie in seinem Inneren zu suchen und findet einzig und allein ein unbestimmtes schuldgefühl." Pis'ma, Bd. 3, Moskva 1976, S. 110.

Cechor sah die gesellschaftliche und psychische Zerrissenheit Ivanovs als exemplarisch an. Seine Brklarungsversuche bleiben jedoch unbestimet. So versteht er die allgemein apathische stimmung unter den jungen Intellektuelien als eine Polge "übermäBiger Brregbarkeit".

"Enttauschtheit, Apathie, Nervenschwàche und Brmūdbarkeit erscheinen als unmittelbare Folge übermäiger Brregbarkeit, und eine solvhe Brregbaikeit ist unserer Jugend in extremem Maße eigen. Nehmen Sie die literatur. Nehmen Sie die Gegenwart... Der Sozialismus ist eine Art der Brregtheit. Wo ist er denn? Br ist im Brief Tichomirovs an den zaren. Die Sozialisten haben geheiratet und kritisieren den Zemstvo. Wo ist der Liberalismus? Sogar Michajlovskij sagt, das jetzt alles durcheinandergekommen ist." Pis'ma, Bd. 3, Moskva 1976, S. 111. 
Die Bedeutung des "Hamlet" fūr die "Mōwe" aut der intertextuellen Bbene - in der Auseinandersetzung mit Turgenevs "Hamlet und Don Quijote" - haben wir bereits in Rapitel 4.1.4. ausfūhrlich dargestellt.

Verfolgt man nun die verschiedenen Anspielungen auf das Bamletmotio vom "stūck ohne Titel" über den "Ivanoo" bis hin zur "Mōwe". so läßt sich folgende Bntwicklung beobachten.

Der Vergleich der Helden mit Hamlet hat im "stũck ohne Titel" noch durchaus positive züge. Im "Ivanov" wird der Bezug zum Shakespearschen Helden von der Titelfigur selbst negativ gewertet. Norec bemerkt hierzu, daB Ivanov dabei nicht die literarische figur des Danenprinzen in duge het. sondern den "Hamletismus" der 80er Jahre."*

In der "Hōwe" schlieblich wird kein direkter Bezug der Protagonisten zur literarischen figur des hamlet ausgesprochen.

Der Wandel in der Wertung und literarischen Verarbeitung des hamlet-Motivs in den Dramen Cechovs ist sowohl Ausdruck offentlicher Auseinandersetzungen iber den gesellschaftichen und politischen standort der russischen Intelligencija (siehe Rapitel 4.1.5.) als auch der kūnstlerischen Bntwicklung des Autors.

Setzt man die Entstehungszeit des "stūcks ohne Titel" etwa auf den zeitraum zwischen 1877-1879 an,*0 so fallt die offentliche Diskussion über den neuen Hamlet-Typus und die negative Umkehrung dieser literarischen Figur in die zeit nach der Entstehung dieses Dramas.

Im "Ivanop" ist dann bereits eine Wandlung feststellbar. Der vom Titelhelden abwertend empfundene Vergleich mit dem

200 Norec (1974). Der Verfasser weist auch darauf hin. das nach Brscheinen des "Ivanov" die Begriffe "gamletizm" und "ivanovicina" synonym gebraucht wurden. Mit beiden Worten verband man Skeptizismus und Handlungsunfahigkeit. Doch hatten die Bedeutungen nur sehr oberflechlich mit den literarischen Vorbildern zu tun.

200 Siehe hierzu vor allem die Anmerkungen der Gesamtausgabe. Poln.sobr.sot.. Bd. 11. Moskva 1978, S. 393-401. 
Shakespearschen Helden geht sicherlich auf die oben angeführte offentliche Diskussion zurūck.

In der "Möwe" schlieblich ist eine direkte Auseinandersetzung mit den "russischen Hamlets" - wie in den beiden ersten Dramen - nicht mehr aktuel1. Nach der ganzen Polemik der 80er Jahre ist dies 1896 fúr den Autor auch nicht mehr relevant.

Cechov geht es jetzt mehr und mehr um nuanciertere psychologische zustandsbeschreibungen. Br beginnt damit bereits kurz nach der Entstehung des "Ivanov" im "Waldschrat", dem Vorläufer zu "Onkel Vanja".

Der Arzt Chruscov gibt gegen Ende der Romödie loierter Akt, fünfte szenel eine Charakteristik ron sich, die Turgenev in seinem Aufsatz Hamlet zuschreibt.

Ich glaube lieber an das Böse, als an das Gute und sehe nicht weiter als meine Nasenspitze.

Ja ochotree verju zlu, cem dobru, i ne vizu dal'se spoego nosa.210

Sonja trägt die zūge des Don Quijote-Typs, wenn sie äuBert:

Man muß sein eigenes Glūck vergessen, Michail L'vovic. und nur an das Giūck der anderen denken. Das ganze Leben muß aus Opfern bestehen.

Nado, Michail L'vovic, zabyt' o svoem scast'e i dumat' tol'ko o scast' drugich. Nuzno, Etob vaja zizn' sostojala iz zert ${ }^{211}$

Da Sonjas Bekenntnis jedoch aus ihrer bis dahin nicht erwiderten und als unglūcklich empfundenen Liebe Chruscov gegenüber entspringt, darf ihre opferbereitschaft, wie auch die Ninas in der "Möwe", nicht wörtlich genommen werden.

Neu in der "Möwe" ist auch der TYp der jüngeren Bauptpersonen "ohne aktive vergangenheit". Gemeint sind damit diejenigen Protagonisten, die, in Gegensatz zu Platonov, Ivanov oder Chruscov, nicht auf eine Lebensphase zurúck-

210 Poln.sobr.soC., Bd. 12, Moskra 1978, S. 187.

212 ebda. S. 189. 
blicken können, in der sie sich einer sozialen Aufgabe widmeten. Nina und Treplev befinden sich auf der suche nach einem Lebensinhalt (siehe 3.2.), werden dabei aber von den Routiniers (Trigorin. Arkadina) nicht unterstützt bzw. daran gehindert.

Der TYp dieser ziellosen, keine bestimmte Aufgabe verfolgenden füngeren personen findet dann seine Fortsetzung in "Drei Schwestern" bei Irina und Masa, im "Rirschgarten" in Anja und varja.

\subsection{7. "Die vaterlose Gesellschaft"}

Bng mit der Hamlet-Thematik verbunden ist auch das Phanomen der "Vaterlosigkeit", das in der Cechov-Porschung bislang kaum Beachtung fand.

Bereits sein erstes Drama, das "Stūck ohne Titel" oder "Platonov", wollte Cechov "Bezotcovstina", also "Vaterlosigkeit" nennen.212

212 Die erste Nennung dieses Titels findet sich in einem Brief Aleksandr Pavlovic Cechovs an seinen Bruder vom 14.10.1878. Anton hatte das stūck an Aleksandr geschickt, un dessen Meinung darüber zu erfahren. Aleksandrs Antwort tällt sehr kritisch aus, er bezeichnet das stūck als eine "unschuldige Lüge". Zit in: Poln.sobr.sot.. Bd. 11. Moskva 1978, S. 396.

Aufgrund von Handschriftenvergleichen, der Bxistenz jugendlicher Dialektismen, bestimeer gramatikalischer Bormen und Fehler sowie der Brwännung einiger Pakten, die sich auf die Jahre 1877-1879 beziehen, setzen die Herausgeber der Gesamtausgabe die Bntstehungszeit des stūcks "Bezotcovstina" auf diesen Zeitraum an. Es ist identisch mit dem bislang als "Platonov" oder "stūck ohne Titel" bezeichneten Drama. Siehe hierzu die Anmerkungen der Gesamt ausgabe. Bd. 11. Moskva 1978, S. 393-402.

Da inm diese Brgebnisse 1974 noch nicht vorlagen, geht Urban in den Anmerkungen zu seiner obersetzung noch davon aus, daß "Bezotcovscina" ein stūck aus Čechovs Gymnasialzeit darstelle, das jedoch nicht mehr erhalten sei.

Urban (Bg.u.übers.) (1974): Anton Cechov: Platonov 'stūck ohne Titel'. Nachbemerkung S. $189 \mathrm{E}$.

Im folgenden werde $i \mathrm{ch}$ mich an die Bezeichnung "Platonov" halten, die sich im deutschen Sprachraum weitgehend durchgesetzt hat. 
Bs murde verschiedentlich darauf hingewiesen, daß "Platonov" schon viele strukturen und Themen der spãteren stūcke enthalte. Unbeachtet blieb aber, daß gerade der von Cechov erwogene Titel "Bezotcovłcina" für alle folgenden Dramen auf ein bedeutsames phānomen hinweist. Denn in allen stükken fehlen entweder die vaterfiguren der jūngeren Hauptpersonen oder sie sind negativ bzw. ironisch dargestellt.

Die vâter

Ober die Herkunft von Platonovs verstorbenen Bltern erfahren wir nichts Genaues. Die bei der Vojniceva anwesenden "Vảter" verachtet er jedoch stellvertretend für seinen eigenen. Zu Petrin und Glagol'ev 1 sagt er:

Ich glaube nicht ihrer greisenhaften, selbstgebastelten Weisheit! Ich glaube nicht daran. Ereunde meines Vaters, zutiefst, zu offen miBtraue ich euren einfachen Reden über komplizierte Dinge, allem, worauf ihr mit eurem eigenen Verstand gekomen seid! $(\ldots)$

Ich spreche nicht über Greise allgemein; ich spreche über die Freunde meines Vaters. (...)

Aber... man muß schon $2 u$ leichtglaubig sein, um an all die soliden Fonvizinschen starodums und zuckrigen Milons zu glauben, die ihr Leben lang mit den Skotinins und Prostakovs aus einem Napf Kohlsuppe gegessen haben, und an all die satrapen, die nur deshalb heilig sind, weil sie weder Bóses noch Gutes tun.

Ne verju ja vasej starCeskoj, samodelkovoj mudrosti! Ne verju, druz'ja moego otca, glubokogo, sliskom iskrenno ne verju vasim prostym recam o mudrengch vescach, vsemu tomu, do Cego vy dosli svoim umom! (..) Ja ne govorju voobśce pro starikov; ja govorju pro druzej moego otca. (...)

No... no nuzno byt sliskom dovercivym, ctoby verovat $\nabla$ tech fonvizinskich solidnych starodumovi sacharnych Milonov, kotorye vsju svoju Zizn' eli sci iz odnoj Caski so Skotininymi i Prostakovymi, iv tech satrapov, kotorye potomu tol'ko $i$ svjaty. teto ne delajut ni $21 a$, ni dobra.213

Cechov lāßt alle Vaterfiguren in "Platonov" in negativem Licht erscheinen. Da sind Glagol'ev 1. und Scerbuk, geschwatzig und ihre Umgebung mit Lobliedern auf die "gute alte zeit" langweilend, der rührselige Oberst a.D. Trilec-

213 Poln.sobr.sot.. Bd. 11, Moskva 1978, S. 37 . 
kij, der in Gesellschaft ständig einschlaft, der eitle, hohle Lebensweisheiten verbreitende Petrin und der selbstgerechte Vengerovit 1.

Voller Haß aubert Platonop in einem Monolog über seine Eltern:

Bine dumme Mutter gebar ein Rind von einem Trunkenbold! Vater... Mutter! Vater... Oh, das euch die Rnochen ausgerenkt werden, so wie ihr im suff und aus Dummheit mein armes Leben ausgerenkt habt! (Pause) Nein... Was habe ich gesagt? Gott wird mix verzeihen ... Gott schenke ihnen das Himelreich...

Glupaja mat rodila ot $p$ 'janogo otca! Otec... mat'! otec... O. Ctob u vas tam kosti tak perevorocilis'. kak vy sp'jana $i$ sduru perevorocili moju bednuju zizn'! (Pauza) Net... tto ja skazal? Bog prostit... Carstro nebesnoe...214

Ivanovs vater wird nicht genannt,21s der des jungen handarztes L'vor lebt nicht mehr (I,7 "Mein Vater ist tot, meine Mutter lebt noch"), Anna Petrovnas Bltern haben ihre Tochter verflucht, weil sie sich umtaufen lieb und den Nicht-Juden Ivanov heiratete (I, 3; I,7; III,6). Sasas Vater Lebedev in "Ivanov" wird als gutmütiger, seiner krankhaft geizigen Prau gegenüber aber als völlig hilfloser Mann dargestellt.

Treplevs vater ist tot.21. Von Ninas vater erfahrt man, dab er seine Tochter zugunsten seiner neuen Prau enterbt hat, am Ende sogar wachen aufstellt, um sie nicht bis zu sich vordringen zu lassen.

Auch Vojnickij in "Onkel Vanja" ist vaterlos.21'Der Vater

214 ebda. S. 124.

213 von Sasa erfahren wir indirekt, daß Ivanovs Vater aber noch leben muB: "Du hast weder Mutter, noch schwester, noch Freunde..." (U tebja ni materi, ni sestry, ni druzej...) Poln.sobr.soc... Bd. 12, Moskva 1978, s. 72. (Nach dem Text der zweiten Redaktion)

21 - Ober die Beziehung Treplevs zu seinem Vater siehe Rapitel 4.1.7.1.

217 Vojnickij ist zwar schon 47 Jahre alt, aus einer Auperung von ihm wird jedoch ersichtlich, das er schon lange ohne Vater lebt: "Fünfundzwanzig Jahre habe ich hier mit dieser Mutter, wie ein Maulmurf, in den vier wảnden 
seiner Nichte Sonja, Professor Serebrjakov, wird negativ dargestel1t. Der Vater von 01 'ga, Masa und Irina in "Drei Schwestern" starb ein Jahr vor Handlungsbeginn. Anja Ranevskaja in "Rirschgarten" hatte sechs Jahre zuvor ihren vater verloren. Ihre Mutter außert dazu im zweiten Nkt, sie habe

einen Mann geheiratet, der einzig und allein schulden machte. Mein Mann ist am Champagner gestorben - er hat schrecklich getrunken...

Fyకla zamuz za Celoveka, kotoryj delal odni tol'ko dolgi. Muz moj umer ot sampanskogo,- on strasno pil...21:

Wird im"Ivanov" der Vater der Hauptperson nicht erwāhnt, so weist Cechov in den übrigen stūcken ausdrūcklich auf das Pehlen der vāter hin.

Dies geschieht entweder in Personenverzeichnis, wo die Arkadina und die Vojnickaja als Witwen angefūhrt werden oder in dramatischen Text selbst ("Platonov", "Möwe", "Drei Schwestern", "Rirschgarten").

\section{Die Onkel}

An die stelle der vāter treten oftmals die Onkel mūtterlicherseits. Für Ivanov ist dies Sabel'skij, in der "Möwe" Treplevs onkel Sorin, fūr Sonja in "Onkel Vanja" Vojnickij, im "Rirschgarten" Gaev.2",

Auffallend ist, daß sich die jüngeren protagonisten zu ihren Onkeln emotional hingezogen fühlen, sie aber nicht als Vaterfiguren akzeptieren bzw. ernstnehmen können. Sabel'skij, Sorin, Vojnickij und Gaev werden von Cechov als verständnisvolle aber letztlich hilflose Bezugspersonen charakterisiert.

gesessen..." (Dvadcat' pjat' let ja vot s ètoju mater'ju. kak krot, sidel $\nabla$ cetyrech stenach...l. Poln.sobr. sot.. Bd. 23. Moskva 1978, S. 101.

210 Poln.sobr.soc.. Bd. 13. Moskva 1978, S. 220.

2'Die Onkel sind immer finanziell mittellos bzw. von anderen Personen abhāngig. Sabel'skij und Gaev verfūgen ūber kein Geld, Sorin ist seinem Verwalter Samraev ausgeliefert, Vojnickij murde von Serebrjakov ausgebeutet. 
Sorin setzt sich für Treplev ein, kann aber nicht zwischen inm und Arkadina vermitteln; auch erkennt er nicht die Katastrophe, aut die sein Neffe zusteuert.

Vojnickij in "Onkel Vanja" rettet zwar das Gut seiner Nichte, muß sich aber am Ende - seines bisherigen Lebensinhalts beraubt - von Sonja trösten lassen.

Gaev in "Rirschgarten" verspricht Anja und varja feierlich, das Landgut 24 retten.

Bei meiner Bhre, bei allem, was du willst, ich schwöre, das Gut wird nicht verkauft! (Erregt.) Bei meinem Glūck schwöre ich es! Hier, meine tand, nenne mich einen schäbigen, ehrlosen Menschen, wenn ich zulasse. daß es zu der Auktion kommt! Ich schwöre es bei meinem ganzen Wesen.

Cest'ju moej, Cem choces'. kljanus', imenie ne budet prodano! (Vozbuzdenno.) Scast'em moim kljanus'! Vot tebe moja ruka, nazovi menja togda drjannym, bescestnym celovekom: esli ja dopuscu do aukciona! Vsem suscestrom moim kljanus'!230

In ihrer Verzweiflung lassen sich die beiden Mädchen durch die Worte Gaevs beruhigen. Sein feierliches Versprechen halt der Onkel allerdings nicht.

Haufig setzen sich die Neffen für ihre Onkel ein. So ăBert sich Ivanov besorgt über Sabel'skij:

Pasa, selbst kannst du trinken, soviel du willst, das ist deine Krankheit, aber ich bitte dich, meinen Onkel nicht zum Trinken zu animieren. Früher hat er bei mir nie getrunken. Es schadet ihm. (...)

Wenn, Gott bewahre, dieses alte Rind stirbt, ist es nicht fûr euch schlimm, sondern für mich...

Pasa, sam ty mozes' pit'. skol'ko tebe ugodno, to troja bolezn', no prosu ne spaivat djadju. Ran'se on u menja nikogda ne pil. Emu vredno. $(. .$.

Ne daj bog, umret etot staryj rebenok, ne vam budet chudo, a mne...223

Treplev bittet in der "Möwe" (dritter Akt) seine Mutter, Sorin Geld zu leihen, damit dieser in der stadt leben kann. Sonja in "Onkel Vanja" verhindert zusammen mit As-

220 Poln.sobr.sod., Bd. 13, Moskva 1978, S. 213.

221 Poln.sobr.sot.. Bd. 12, Moskva 1978, S. 49 (zweite Redaktion). 
trov den Selbstmord Vojnickijs und versucht ihren onkel am Bnde zu trōsten.

\section{Die Mūtter}

Betrachtet man nun das Verhältnis der jüngeren protagonisten zu den Mūttern, so finden sich auch hier in vielen Dramen aufallende Parallelen und Ronstellationen.222 Platonov bezeichnet seine Mutter als dumm und verflucht sie, wüncht ihr aber sofort - selbst über seinen zornesausbruch erschrocken - das ewige Himmelreich.

Ivanov bringt das Bild seiner Mutter in Zusammenhang mit einer hoffnungsvollen Jugend.

Ich hatte einen Glauben, ich blickte in die zukunft. wie in die Augen meiner eigenen Mutter...

Ja veroval, $\nabla$ buduscee gljadel, kak $\nabla$ glaza rodnoj materi...233

In den übrigen Dramen erweisen sich die Beziehungen zu den Müttern ambivalent. Treplev sucht verzweifelt die Anerkennung seiner Mutter und sieht in Trigorin einen Nebenbuhler. Die Auseinandersetzung verlagert Treplev auf die literarische Ebene. Seine Arbeiten erscheinen so als Ausdruck des Kampfes mit dem Geliebten der Mutter wie auch als Mittel, Arkadinas Aufmerksamkeit auf sich zu ziehen. Vojnickij in "Onkel Vanja" verachtet seine Mutter, weil sie den von ihm als Konkurrenten (in Bezug auf Blena Andreevnal empfundenen und als Dilettanten entlarvten Serebrjakov verehrt.

Blena Andreevna: ...Sie hassen meinen Mann und verachten offen inre Mutter...

222 Zur Darstellung der Prau in den Werken Cechovs siehe vor allem: Smith (1973): Hahn (1977), S. 209-236: Moravcevich (1981): Maegd-Soep (1987). Wahrend Smith vor allem anhand der Erzählungen Cechovs Frauenfeindlichkeit zu belegen versucht, erkennt Moravkevich in den Dramen ein differenziertes und keinesfalls negatives prauenbild.

222 Poln.sobr.soc.. Bd. 12, Moskva 1978, S. 53. 

mat....234 nenavidite muza i otkryto preziraete svoju

Ihre unkritische Haltung dem Professor gegenüber und ihre geistige Unflexibilitäzss bedingen die Distanz zwischen Mutter und Sohn. Dennoch wendet sich Vanja im Moment größter Verzweiflung zuerst an seine Mutter, als er von den Plänen Serebrjakovs erfährt. Nach der Brkenntnis, daß er einem "perpetuum mobile" die besten Jahre seines Lebens geopfert hat, droht ihm nun auch noch der materielle Verlust seines Lebenswerks. In höchster Erregung zu Marija Vasil evna:

Matuska! Was soll ich tun? Nein sagen sie nichts! Ich weiß selbst, was ich zu tun habe!

Matuska! Cto mne delat'? Ne nužno, ne govorite! Ja sam znaju, Cto mne delat'!z20

Die Eltern von Ol'ga, Mała und Irina in "Drei Schwestern" sind bereits vor dem Beginn des Dramas gestorben.

Das Verhaltnis Anjas und Varjas im "Rirschgarten" zu ihrer Mutter bzw. Stiefmutter ist liebe- und verständnisvoll. varja verurteilt jedoch die Leichtfertigkeit, mit der Ljubov Andreevna über ihre finanziellen Verhälnisse lebt. Die Beziehungen der Mūtter wiederum zu ihren Kindern orweisen sich in den drei erwähnten Dramen als änlich.

Arkadina ist so sehr auf sich selbst fixiert, dap sie die Probleme ihres Sohnes nicht erkennt bzw. ernst nimmt. Ihr wird nicht bewußt, daß Treplevs Bemühungen auf literarischem Gebiet besonders auf ihre Anerkennung zielen.

Marija Vasil'evna in "Onkel Vanja" hat über ihrer Lektūre wissenschafticher Broschūren und der Verehrung des Pro-

\section{Poln.sobr.soC., Bd. 13, Moskva 1978, S. 79.}

225 Dies belegt vor allem folgende Aussage Marija Vasil'evnas über den Autor einer Broschūre: "Interessant. aber irgendwie merkwürdig. Br widerruft das, was er sieben Jahre zuvor noch selbst verteidigt hat. Das ist entsetzIich!n (Interesno, no kak-to stranno. Oprovergaet to. tto sem' let nazad sam ze zaściscal. Bto uzasno!l. ebda. S. 70 .

22 ebda. S. 102. 
fessors den Rontakt zu Vanja verloren. Der tiefen Bemubtseinskrise ihres Sohnes steht sie vollkommen ratlos und gleichgūltig gegenüber.

Ljubov' Ranevskaja im "Rirschgarten" war in den vergangenen sechs Jahren zusammen mit ihrem Geliebten im Ausland. Dabei hatte sie "hemmungslos mit Geld un sich geworten, wie eine verrūckte..." (sorila den'gami bez uderžu, kak sumassedsaja).221 Das Gut muß schließlich versteigert werden, Anja und Varja bleiben mittellos zurũck. Die Ranevskaja reist ihrem Geliebten nach, schon jetzt wissend, dab sie das von ihrer Tante geliehene Geld bald ausgegeben haben wird.

Von stark emotionalem Charakter sind die Beziehungen der Geschwister zueinander. Dies gilt sowohl fūr die jüngeren Protagonisten (0l'ga, Masa. Irina: Anja und ibre Stiefschwester Varjal als auch fūr die Elterngeneration. Arkadina und Sorin (bedingt) sowie Ranevskaja und Gaev bringen auf der analogen bzw. emotionalen Ebene Verständnis für einander auf. Als Beispiel mag die Regieanweisung im "Kirschgarten" gelten, kurz bevor Ljubov' Andreevna und ihr Bruder endgültig das haus verlassen mūssen.

Ljubov' Andreevna und Gaev sind allein geblieben. Als hảtten sie nur darauf gewartet, werfen sie sich einander um den Hals und schluchzen verhalten, leise. fürchtend, gehöt zu werden.

Ljubov' Andreevna i Gaev ostalis' vdvoem. Oni toćno tdali etogo, brosajutsja na seju drug drugu $i$ rydajut sderżanno, ticho, bojas', etoby ich ne uslysali.220

\section{Die Arzte}

Ansatzweise findet sich eine auf Arbeit und Verantwortung gründende Lebenseinstellung bei den Arzttypen in Ċechovs Dramen. Da Cechov selbst als Arzt praktizierte, kannte er die Nöte und Strapazen eines zemstvo-Arztes. Doch auch das Bild der Mediziner ist ambivalent und wandelt sich von

\footnotetext{
237 ebda. S. 220.

220 ebda. S. 253.
} 
"Platonov" bis "Drei Schwestern". Baumz" unterscheidet bei den xrzten in den Werken Čechovs Prototypen und Antitypen, wobei die positiv gezeichneten Typen besonders in den Dramen überwiegen. Dabei erkennt sie von L'vov in "Ivanov" über Dorn in der "Möwe" bis hin zu Astrov in "Onkel Vanja" eine Bntwicklung, die für einen Landarzt jener zeit nicht selten war. Der Anfanger L'vov ist noch voller Bnthusiasmus und übertriebenem Bhrgefühl. Cechov selbst aubert sich über ihn in einem Brief vom 30.12 .1888 an A.S. Suvorin:

Das ist der Typ des ehrenhaften, geraden, hitzigen, aber beschrankten und eingleisigen Menschen. Ober solch kluge Menschen sagt man: "Br ist dumm, aber er ist eine ehrliche Haut." Alles, was mit weitgreifenden Anschauungen oder spontanem Gefühl $2 u$ tun hat. ist ing fremd. L'vov ist die personifizierte schablone, die gägige Tendenz.230

Der 30 Jahre altere Dorn spielt seiner morbiden Umgebung Gleichgūltigkeit vor (sicherlich aus Grūnden des selbstschutzes), zeigt Masa und Treplev gegenüber aber Interesse und Mitgefühl. Astrov flūchtet sich vor einer verständnislosen Umwelt, die weder seine Tātigkeit als Arzt noch seinen Binsatz für die Okologie würdigt, in den Alkohol und wird zum Menschenverächter.

Mehr oder weniger ausgeprägt leiden alle bisher erwahnten Arztfiguren an ihrem Beruf, an ihrer Ungebung, an der Dummeit der Mitmenschen. Sie sehen sich aber auBerstande, etwas an den bestehenden Verhältnissen zu andern. weil es einem Rampt mit WindmūhlenElügeln gleichkäme. Stattdessen merden entweder die eigenen Hoffnungen in eine ferne zukunft projiziert. oder aber die person verliert sich in hohen Gedankenflügen, die das eigene Gewissen beschwichtigen sollen. Die "Prototypen" sind alle intelligent und mit der nötigen Făhigkeit zur Einsicht in die Mißstände begabt. Rlar erkennen sie die eigene Passivitát, das

\section{Baum (1979).}

20.Pis'ma Bd. 3, Moskva 1976, S. 112. DaB er L'vov aber nicht als Karikatur sehen will, aubert Cechov im gleichen Brief: "Solche Menschen sind nótig und meistens sympathisch. Sie als Rarikaturen zu zeichnen, und sei es im Interesse der Būhne, ist unredlich, und führt auch zu nichts." ebda. S. 113. 
eigene Unvermögen, retten sich aber lieber in einen bequemen Fatalismus.231

Gānzlich gleichgültig und zynisch seinen Mitmenschen gogenüber wird schließlich Čbutykin in "Drei Schwestern". der in diesem Drama auch nur noch eine (negative) Nebenrolle einnimmt.

Trileckij in "Platonovmzz enthält bereits züge aller Arzttrpen, die Ćechov in den folgenden Dramen entwirft. Durch die Morbiditat seiner Ungebung murde er schon früh zum zyniker, wirkt völlig hilflos, seiner Aufgabe als Arzt gegenüber als wenig pflichtbewrbt. Br erweist sich jedoch als einer der wenigen, die in der turbulenten situation am Ende des Dramas die Nerven bewahren, und hält bis zum Schlub zu Platonov.

Die Arztypen in den Dramen Ćechovs tragen zwar einige positive züge, sind aber nicht in der Lage, den jungen Protagonisten als Vaterersatz 24 dienen. Als bestes Beispiel mag Dorn dienen, der der inm von Masa angetragenen Vaterrolle (Bnde erster Akt) nicht gerecht werden kann.

\section{Interpretationsansatze}

Die ungewöhnlichen Ronstellationen innerhalb der Familienstrukturen haben sicherlich verschiedenerlei ursachen.

Ein Erklärungsmuster für die problematischen Vaterbeziehungen findet sich in Cechovs Biographie. Das Verhaltnis zu seinem Vater war bekanntlich gespannt. Man kann nicht sagen, dab er ihn verachtete, besonderen Respekt brachte er ihw allerdings auch nicht entgegen. Dies mundert nicht, wonn man sich dis Familiensituation der Cechovs in Taganrog vergegenwartigt. Auf den Despotismus und die extreme Bigotterie, mit denen der vater seine Familie tyrannisieraus.

221 ebda. S. $44 f$.

sasaum klammert diese Pigur in ihrer Untersuchung 
te und quảlte, machen alle Biographen aufmerksam.233 Die unerträgliche Athmosphàre in seinem Elternhaus erwāhnt Cechov auch in einigen seiner Briefe.234 Hingley und Wolftheim weisen darauf hin, dab die folgende Passage aus "Tri goda" stark autobiographisch geprägt ist.

Ich entsinne wich: mein Vater begann mich zu unterrichten oder, einfacher gesagt, zu prūgeln, da war ich noch keine fünf Jahre. Br züchtigte mich mit Ruten, $20 g$ mich an den Ohren, schlug mich auf den Kopf, und jeden Morgen, wenn ich aufwachte, dachte ich zuallererst: wird man mich heute prúgeln? zu spielen und ausgelassen 24 sein war mir ... verboten; wir mußten zur prühmesse und zum Mittagsgottesdienst gehen, den Popen und Mönchen die kande küssen, zu Hause die Lobgesảnge lesen... Wenn ich an einer Kirche vorbeigehe, fält mir meine kindheit ein und mir wird unheimlich zumute.2s,

Bine solche literarische verarbeitung findet sich bei Cechov aber selten. Wie bereits angefüht, geht er in den Dramen einer direkten Auseinandersetzung mit den Vaterfiguren aus dem Heg. Diese Form der Verdrängung lảßt auf eine unbewätigte Vater-Sohn-Beziehung schlieben, der sich der Autor wahrscheinlich nicht bewut war. Dieser Ausklammerung der vater in seinen Dramenfamilien entgegen steht eine eher verständisvolle Haltung Cechovs seinem eigenen Vater gegenüber in den späteren Briefen.

Bine weitere Ursache lür das Phänomen der "Vaterlosigkeit" liegt sicherlich im Fehlen von "Vatern" als Leitfiguren. In unserem Exkurs über die gesellschaftliche und kulturelle situation im RuBland des ausgehenden 19. Jahrhunderts haben wir bereits darauf hingewiesen. Nach dem Scheitern der Narodniki-Bewegung und der dann eintretenden Phase der Reaktion und Verfolgung fehlten der Intelligencija Vorbilder im politischen und gesellschaftichen Bereich. Die

23 Lafitte (1960): Simmons (1963); Hingley (1976): Wolftheim (1982): Berdnikov (1985): Troyat (1987).

$20 \lambda$ m eindrucksvollsten in den Briefen vom 2.1.1889. $7.1 .1889,9.3 .1892$.

23 Poln.sobr.soc.. Bd. 9, Moskva 1977, s. 39. Hingley (1976). S. 8: Wolfthein (1982). S. 16. 
großen "Vater" der realistischen Literatur waren größtenteils schon gestorben.

Bxkurs: Cechov und Schnitzler

Das in den Dramen so auffallige Phänomen der "Vaterlosigkeit" wird durch die spezifik der gesellschaftlichen Verhälnisse jener zeit determiniert. Dies verdeutlicht ein Vergleich mit dem Werk des österreichischen Zeitgenossen Ċechovs, Arthur Schnitzler.236 Dessen Schauspiel in fünf Akten "Der einsame Weg" aus dem Jahre 1903 thematisiert Ahnliches wie die "Möve".

In den Figuren stephan von salas und Julian Fichtners finden wir zwei Varianten eines ganz im Asthetizismus lebenden Rünstlertyps. Die Generation der Rinder befindet sich, wie in der "Möwe", auf der Suche nach Lebensinhalten. Bine zentrale stelle nimm dabei der Ronflikt zwischen leiblicher und ideeller vaterschaft ein.

Der etwa $17 j a ̈ h r i g e ~ F e l i x$ erfährt nach dem Tod seiner mutter, wer sein wirklicher Vater ist. Es ist nicht Professor Wegrat, "Direktor der Akademie der bildenden Rüste", in dessen haus er aufmuchs, sondern der Maler Julian Fichtner. Der künatler unterhielt ein Verhaltnis mit pelix' Mutter, ließ diese dann aber sitzen. Br hatte bislang sein Leben als eine Ansammlung von schönen Augenblicken genossen, ohne irgendwelche Rücksichten auf das Glück anderer Menschen zu nehmen. Alter geworden, will er seinem Leben einen sinn geben, indem er Felix an sich zu binden versucht - vergeblich. Der Junge akzeptiert ihn nicht als Vater, sondern tūhlt sich noch stärker als zuvor (auch bedingt durch den Selbstmord seiner Schwester Johannal Professor Wegrat verbunden. Den leiblichen, aber egozentrischen und genußsūchtigen künstler-Vater stellt Schnitzler den liebevollen, ptlichtbewaten bürgerlichen stiefva-

23 Auf Parallelen in den Werken Cechovs und Schnitzlers machten schon deren zeitgenossen aufmerksam. Zur

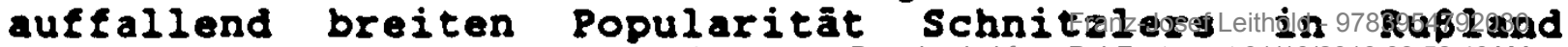
siehe vor allem: Heresch (1976; D 1982 off from PubFactory at 01/10/2019 03:52:40AM 
ter entgegen. Schon im Namen Neg-rat ist der familiāre und gesellschaftliche standort dieses vatertyps angedeutet. Bine solche Ronstellation findet sich jedoch nicht in Ċechovs Dramen. Den fehlenden bzw. negativen Vaterfiguren wird kein Brsatz gegenübergestellt. Die bereits erwāhnten Onkel können ihren Nichten und Neffen eben nicht zu einem Weg raten.

Čechov hät der untergehenden Welt des russischen Landadels in seinen Dramen kein Būrgertum entgegen, das durch seine Wertvorstellungen von Ehre, Moral und Pflichterfüllung an die stelle der alten ordnung treten kōnnte. Im Gegensatz zur österreichischen Gesellschaft des ausgehenden 19. Jahrhunderts befand sich das russische Būrgertum nicht in einer gesellschaftlichen und politischen Position, aus der es den Adel hātte übergangslos ablösen kōnnen.

\subsubsection{Treplev und Hamlet: Der Geist der Vàter}

Treplev erwāhnt seinen Vater (im Gesprāch mit Sorin, erster Akt) eher beilaufig:

...ich habe kein Talent, keinen Groschen Geld, und laut $\mathrm{PaB}$ bin $\mathrm{ich}$ - ein Riever Rleinbürger. Denn mein Vater war ein Riever Kleinbürger, obwohl auch er ein berühter Schauspieler war.

...nikakich talantov, deneg ni groša, a po pasportu ja - kievskij mesccanin. Moj otec ved kierskij mešcanin. chotja toże byl izvestnym akterom. (S.8f.)

Aus dem Gesagten wird aber deutlich, dab er sich seinem Vater gegenüber minderwertig fühlt. War dieser doch, trotz kleinbürgerlicher Herkunft, ein erfolgreicher schauspieler. Der Sohn aber ist talentlos und finanziell von seiner Mutter abhängig. Wie sehr Treplev unter diesem zustand leidet, erfahren wir - neben seinem streben nach Anerkennung - vor allem im dritten Akt. Wahrend der Auseinandersetzung mit seiner Mutter widerruft er sein im ersten Akt Sorin gegenūber gemachtes zugestandnis:

Ich bin begabter als ihr alle, wenn es darauf ankommt! 
Ja talantlivee vas vsech, koli na to pozlo! (s. 40) Das Gefühl, der Position des Vaters nicht gerecht werden zu kōnnen und des "stiefvater" Trigorin unterlegen zu sein, Iösen Treplevs psychischen Konflikt aus.

Die Parallelen zu Hamlets situation sind offensichtich, unterscheiden sich jedoch in einem wesentlichen Punkt. Hamlet trifft den Geist seines Vaters, dem er das versprechen gibt, Claudius' Tat zu entlarven und zu rachen. Die Forderung des Geistes zu Beginn des Dramas und die zusage des Sohnes, motivieren fortan die Handlungen und Reflexionen des Dānenprinzen.

Dem Geist von Hamlets Vater, der - gestützt aut ein festes moralisches und ethisches Nertesystem - seinem Sohn eindeutige Vorgaben $t u \bar{r}$ sein weiteres Bandeln gibt, steht das vage Bild von Treplevs Vater gegenüber. Der en passant erwahnte erfolgreiche Schauspieler lst für Ronstantins Entwicklung nur indirekt verantwortlich. Anstelle einer Vaterfigur als Symbol eindeutig definierter Handlungskriterien steht fūr rreplev die "grobe Figur seines Vaters" wie ein Hinweis auf die eigene Unzulänglichkeit standig im Hintergrund, ohne jedoch genau unrissene Forderungen oder Brwartungen zu zußern. Dessen künstlerische wie gesellachaftiche Grōße werden für Konstantin (neben dem Brfolg seiner Mutterl unbewubt zu einem Mabstab seines Tuns.s' Das Trauma wird perfekt, als auch der "stiefvater" und Nebenbuhler Trigorin eine berühnte Persōnlichkeit ist. Bine Vaterfigur kann dieser für Treplev jedoch nicht sein. Biner klar gestellten Aufgabe brw. Verpelichtung des Sohnes in shakespeares Tragōdie steht bei Ċechov nur noch ein unbestimmtes schuldgefühl und das Bmptinden der eigenen Unzulānglichkeit gegenūber.

Daß Ċechov den Geist ron Hamlets Vater als eine Instanz verstanden wissen will, die zu einem zielgerichteten Ban-

s'Diesen wesentlichen Unterschied in der Bedeutung
der Vaterfiguren Hamlets und Treplevs ubersieht Peace (1983). S. 21, wenn er schreibt: "Treplev's father, like Hamlet's own, is present only as a disquize thathold ghors 
deln aufordert, bringt der Autor in einem Brief rom 25.11.1892 an A.S. Suvorin deutlich zum Ausdruck:

Uns tehlt das "Btwas", das ist wahr, und das bedeutet, daß, wenn Sie unserer Muse den Rocksaum hochheben. Sie dort eine flache stelle sehen werden. Denken Sie daran, daß Schriftsteller, die wir ewig oder einfach gut nennen und die uns betrunken machen, ein gemeinsames und sehr wichtiges Merkmal besitzen: sie kommen von irgendwo ber und rufen sie dorthin, und Sie spüren es nicht mit dem Verstand, sondern mit Ihrem ganzen Hesen, daß sie ein bestimmes ziel haben, so wie der Geist von Hamlets Vater (kak u teni otca Gamleta), der nicht ohne Grund erschienen ist und die Gemūter beunruhigt. Die einen haben, je nach Raliber, nahe ziele - die Leibeigenschaft, die Befreiung der Heimat, die Politik, die Schönheit oder einfach den Vodka, wie Denis Davydov, die anderen haben Fernziele - Gott, das Leben nach dem Tode, das Glück der Menschheit usw. Die besten von ihnen sind Realisten und beschreiben das Leben so, wie es ist. weil aber jede zeile wie von Saft durchtrankt ist von dem Bewußtsein des Ziels, spüren Sie außer dem Leben, wie es ist, auch noch dasjenige Leben, so wie es sein soll, und das tesselt Sie. Wir dagegen? Wir! Wir beschreiben das Leben so, wie es ist, und weiter weder piep noch pup... Heiter prügeln Sie uns nicht mal mit der Peitsche. Wir haben weder Nah- noch Fernziele. unser Herz ist wie leergefegt. Wir haben keine Politik, an eine Revolution glauben wir nicht. wir haben keinen Gott, haben keine Angst vor Gespenstern, ich persónlich habe nicht einmal Angst vor dem Tod oder dem Erblinden. Her nichts will, auf nichts hofft und vor nichts Angst hat, der kann kein Künstler sein.s.

Das in allen Dramen Ćechovs ausgedrūckte problematische Verhāltnis der jūngeren Protagonisten zu fhren vătern markiert einen Hendepunkt in der Vater-kind-Beziehung innerhalb moderner Gesellschaften. Mitscherlich beschreibt diesen Wandel in seinem Buch "Auf dem Weg zur vaterlosen Gesellschaft." 23 ,

In vorindustriellen zeitalter erhielt das Rind vom Vater im Laufe seiner Rindheit und Jugend in der Regel ein festgefügtes Bild moralisch, religiós etc. geprägter verhaltensmuster, deren Summe Mitscherlich mit dem Begriff "Gewissen" bzw. in Anlehnung an Freud mit "Ober-Ich" bezeich-

23: P1s'ma Bd. 5, Moskva 1977, S. 1331.

239itscherlich (1*1986). 
net. Unter "Bewältigungspraxis" versteht er dann die BrEahrungen, die das Rind innerhalb seiner Sozialisation und im geinsamen Leben und Arbeiten mit dem Vater sammeln und auf die es später in modifizierter form zurúckgreifen kann. So werden viele Situationen "nach dem Muster der vorbildverinnerlichung und unveränderten vorbildwiederholung bewältigt...ns40

In der immer anonymeren, arbeitsteiligen industriellen Gesellschaft nehmen zunehmend geselischaftliche Insitutionen (Schule, Lehre etc.) die erzieherischen Funktionen des Vaters. Das Resultat ist schlieblich ein "Defizit an sozialbildung".241 Mitscherlich konstatiert:

Bs ist vielmehr an ein Brlöschen des Vaterbildes zu denken, das im Hesen unserer zivilisationselbst begründet ist und das die unterweisende Funktion des Vaters betrifft: Das Arbeitsbild des vaters verschwindet, wird unbekannt. Gleichzeitig mit diesem von geschichtilchen Prozessen erzmungenen verlust der Anschauung schlägt die Hertung un. Der hymnischen Verherrlichung des Vaters - und des vaterlandes!folgt in der Breite ein "sozialisierter Vaterhab". die "Verwerfung des Vaters". die Entfremdung und deren seelische Bntsprechungen: "Angst" und "Aggressivitat." 242

Die jungen Protagonisten in Ċechovs Dramen haben von ibren vätern keine "Bewäligungspraxis" erhalten, ihr vaterbild ist rein emotionell. Die eigentlich natūrliche Identitātskrise beim Obergang von der Kindheit in das Brwachsensein. in der sich das emotionale Verbalten gegenüber den Bezugs-

240 ebda. S. 182. Um MiBverständnissen vorzubeugen: Bs soll hier nicht einer Verherrlichung oder Verklärung patriarchaler Verhältnisse das Wort geredet werden (dies betont auch Mitscherlich). Vielmehr geht es un sozialpsychologische Aspekte, die Verdeutlichung des Hechselverhälinisses faniliảrer und gesellschaftlicher Konsteliationen und ihrer Auswirkung auf die Psyche des Individuuns, die dann ihrerseits wiederum tûr den zustand der Gesellschaft relevant wird.

$$
\begin{aligned}
& 24 \text { ebda. S. } 180 . \\
& 242 \text { ebda. S. } 177 \text {. }
\end{aligned}
$$


personen ambivalent gestaltet,243 verzógert sich bei allen "Helden". Ihnen gelingt es nicht, neue vorbilder zu finden und so ihre Identifikationskrisen zu bewältigen. Sie venden sich zwar affektio an ihre onkel, kōnnen in ihnen aber keine Leitfiguren fūr ihr Handeln entdecken.

Bereits Turgenev schilderte in seinem Roman "väter und Söhne" einen Generationenkonflikt vor dem Bintergrund des gesellschaftichen Umbruchs is Rupland der 60er Jahre des 19. Jahrhunderts. Zwischen den Standorten Bazarovs und den jugendlichen Helden in den Dramen Ćechovs besteht jedoch ein wesentlicher Unterschied. Für den Turgenevschen Nihilisten existiert noch sichtbar die Welt der Vāter, gegen die er sich wendet. Cuechovs Protagonisten leben in einem traditionslosen Raum, der keine Angriffsflache mehr bietet. Sie kōnnen sich in ihren Handlungen nicht gegen die Aubenwelt richten, sondern lenken ihre skepsis und aggression nach innen, projizieren so die ronflikte in die eigene Person.

\subsection{Heitere intertextuelle Bezūge}

\subsubsection{Maupassants "Sur I'eau"}

Il faut vraiment etre bien résolu a la suprême indifférence pour ne pas pleurer de chagrin. de degoat et de honte quand on entend l' homme parler.

Sur $I^{\prime} \mathrm{eau}^{24} 4$

Wir haben bereits in Rapitel 3.1.1. darauf hingewiesen, welche Bedeutung Maupassants Reisenotizen fūr die Charak-

243"Diese ambivalente Zerrissenheit der Pubertat besitzt eine Vorstufe in der Gefühlskrise des ódipalen Konflikts um das funfte Lebensjahr. wenn das kind in peinvollem Zwiespalt zartlichkeit und Bifersucht. Bewunderung und neidvolien $\mathrm{Ha \beta}$ den beiden Eltern gegenüber in außerster Beftigkeit erlebt." ebda. S. 192. 
terisierung Arkadinas haben. Was sie als unwahr und belanglos bezeichnet, gewinnt spätestens im dritten akt an Beweiskraft. Die Textstelle aus "Sur I'eau", die sie nicht lesen will, s4s beschreibt treffend ihr Verhalten gegenüber Trigorin.

Kurz vor dieser passage finden wir bei Maupassant noch einen anderen interessanten Hinweis. Was der französische Autor über die Romanciers schreibt, entspricht dem Verhalten Trigorins. Denn ein Romanschreiber

ronge, pille et exploite tout ce qu'il a sous les yeux. Avec lui on ne peut jamais etre tranquille. jamais sor qu'il ne vous couchera point, un jour. toute nue, entre les pages d'un livre. Son oeil est comme une pompe qui absorbe tout. comme la main d'un voleur toujours en travail. Rien ne lui echappe: il cueille et ramasse sans cesse: il cueille les mouvements. les gestes, les intentions, tout ce qui passe et se passe devant lui: il ramasse les moindres paroles. les moindres actes. les moindres choses. II emmagasine du matin au soir des observations de toute nature dont il fait des histoires a vendre...

Diese ironischen Ausführungen des zivilisationskritikers Maupassant ahneln den Worten Trigorins gegenūber Nina im zweiten Akt. DaB er schlieblich seine Affare mit der Zarecnaja literarisch verarbeitet, unterstreicht den Binweischarakter, den Ċechov Maupassants "Sur l'eau" beimiBt. Auf Thnifchkeiten zwischen dem französischen autor und Trigorin weist Ratsell hin.24 Bs existiert aber ein bedeutsamer Unterschied. Der Iranzösische Novellist und Romancier versucht der verhabten zivilisation zu enteliehen, indem er auf seinem schiff "Bel Ami" an der Mittelmeerkūste entlangsegelt. Trigorin trãumt von einer flucht vor dem Literaturbetrieb, von einem ruhigen Leben als angelnder Privatier. Doch unternime er keinen Versuch. seine vorstellungen zu realisieren.

24s siehe S. 86.

24Maupassant (1947), S. 30 .

2'TRatsell (1981). Jussel (1960) vergleicht nur Prosawerke Cechovs und Maupassants. 
Wie auch in der Bamlet-Thematik haben wir es hier mit einer graduellen Verschiebung bzw. bewußten Verfremdung zu tun. Maupassant wendet sich ab von gesellschaftlichen zwảngen (wenn er auch am Ende in Casino von Monaco zu finden ist) und begibt sich aufs offene Meer. Čechovs Erfolgsschriftsteller trảumt nur davon, dem literarischen Markt $2 u$ entfliehen. Der Neite des Meeres steht bei inm der überschaubare Raum des Sees auf dem sorinschen Gut entgegen.

Auch Treplev spricht davon zu fliehen. "wie Maupassant vor dem Biffelturm geflohen ist, der ihm in seiner Geschmacklosigkeit das Gehirn erdrūckte" (Kak Mopassan beżal ot Ejfelevoj baśni. kotoraja davila enu mozg svoeju poślost'ju. S. 8). Jedoch ist Ronstantins Flucht keine räumliche, sondern eine geistige. Er versucht sich vor den literarischen Ronventionen in neue künstlerische Formen zu retten. Doch muß er am Ende feststellen, dab ihm dies nicht den gewünschten Erfolg brachte.

Cechov konnte davon ausgehen, daß seinem Publikum das Werk des franzōsischen Autors nicht unbekannt war. Maupassants Novellen und Romane besaben in RuBland eine breite Leserschaft, Ċechov schrieb in einem Brief vom 29.9 .1886 sogar von einer "Maupassantmode" (mopassanovičina). 240

Ansonsten sind Bemerkungen über den franzōsischen Autor bei Čechov nur vereinzelt zu finden. DaB er ihn aber als einen bedeutenden schriftsteller ansah, brachte er in einem Brief vom 24.11.1896 zum Ausdruck. Hier erlāutert er in einem Begleitschreiben $z u$ einer Būchersendung an die Taganroger Bibliothek, daB er auber einer gerade erworbenen 12 bandigen Maupassantausgabe in zukunft noch weitere Werke dieses bedeutenden Autors schicken wolle.

Interessant ist ein anderer sachverhalt, der die Affinität beider Autoren und deren gleiche Einschātzung des zeitgeistes wiederspiegelt.

In seinem 1888 erschienenen Reisetagebuch "Sur I'eau" 
charakterisiert Maupassant das Bemutsein der kritischen Intellektuelien jener zeit wie folgt:

Dès qu'ils touchent a trente ans, tout est fini pour eux. Qu'attendaient-ils? Rien ne les distrait plus: ils ont fait le tour de nos maigres plaisirs. Heureux ceux qui ne connaissent pas l'écoeurement abominable des mêmes actions toujours répétées $(\ldots)$. Heureux ceux qui ne $s$ apercoivent pas avec un immense dégout que rien ne change, que rien ne passe et que tout lasse.24,

Diese Aussage trifft auffallend auf Ivanov 24 , den Helden aus Ćechovs gleichnamigem Drama, das bereits 1887 Premiere hatte.

\subsubsection{Puškirs "Rusalka"}

Als Treplev im vierten Akt Dorn über das Schicksal Ninas berichtet, erzahlt er auch, dab sie ihre Briefe an ihn mit "Die Mōwe" unterschrieben häte. So wie sie sich eine Möwe nannte, hãtte sich der Mūller in Aleksandr Puśkins lyrischem Dramenfragment "Rusalka" als Raben bezeichnet.

Die situation der zarečnaja und die des müllers lassen sich jedoch nur schwer miteinander vergleichen. Der vater aus Puskins Versdrama nennt sich einen Raben, weil ex durch den Selbstmord seiner Tochter wahnsinnig wurde. Denn an tragischen Bnde des Mädchens war er nicht schuldlos. hatte er doch aus materieller Berechnung nichts gegen die Liaison mit dem fürsten unternommen. Oder aber man lāßt sich bei seiner Interpretation auf die phantastische Bbene des Stūcks ein. Dann wurde der Mũller tatsāchlich in einen Raben verwandelt, als Strafe für die Mitschuld am Unglūck seiner Tochter.

In beiden fällen kann man aber das Bild des Raben nicht mit dem der Mōwe vergleichen, das schicksal des Müllers ist ein anderes als das Ninas.

Und auch, was die dramentechnische Funktion betrifft, besteht ein Unterschied: Die Metapher des Raben-Vaters ist 
relativ eindeutig zu interpretieren. Die Môwe erhält jedoch in Cechovs stūck einen symbolcharakter, der fūr das ganze Drama eine strukturierende, handlungstreibende rraft entwickelt (siehe Kapitel 1.5.).

Die Erwāhnung der "Rusalka" durch Treplev enthät aber einen Hinweis auf die Handlungslinien Konstantin-Nina und Nina-Trigorin. Er zeigt verschlūsselt auf, daß die beiden Handlungsstränge seit dem schieben der Mōwe durch Treplev parallel verlaufen sind, ohne direkten Bezug zueinander. Denn wenn Konstantin gewubt hãte, daß Trigorin in Bezug zu Nina und der Mōwe von einem sujet fūr eine kleine Erzāhlung gesprochen hatte und sich dieses literarische Motiv mehr und mehr mit dem realen Schicksal der zarecnaja deckte, hātte er verstanden, warum Nina ihre Briefe mit "Die Mōwe" unterzeichnete.

\subsubsection{Verweise auf Turgenev}

Ċechovs Einschātzung der Werke Turgenevs war insgesamt zwiespältig. Beispielsweise bemerkt er in einem Brief an A.S. Suvorin vom 24.2.1893, das er von "otcy i deti" begeistert sei. den úbrigen Werken aber kritischer gegenüberstehe. Vor allem seien oft "die Frauen und Madchen Turgenevs unerträglich in ihrer affektiertheit und, verzeihen sie, Verlogenheit. 250

Daß diese Einschātzung auch geprägt ist durch Cechovs eigenes problematisches Frauenbild, beweist smith.2s An 13.2.1902 schreibt er an O.L. Rnipper-Ćechova:

"Ich lese Turgenev. Nach diesem Schriftsteller wird ein Achtel oder ein zehntel dessen bleiben, was er schrieb, alles Obrige geht nach 25-35 Jahren in die Archive." 23 Und am 23.3.1903 außert čchov in einem Brief an seine Frau, dab inm Turgenevs Drama "Mesjac $\nabla$ derevne" nicht

250 Pis'ma. Bd. 5, Moskva 1977, S. 174.

231 Smith (1973). S. 36ff.

232 Pis'ma, Bd. 10, Moskva 1981, S. 194. 
gefalle, das stūck "Nachlebnik" dagegen finde er "nicht übel" (nedurno) .23

Bicilli belegt, daß die Rezeption Turgenevs durch Čechov. vor allem in Bezug auf das prosaschaffen, noch differenzierter zu sehen ist.2s4 Br spricht von einer schōpferischen Aneignung. was bestimmte Topoi und "Ćechovs Finale mit dem Thema des Abgangs" betrifft.sos Br zeigt aber auch die bewubten Abweichungen in der Prosa Ċechovs auf.

Die Dramen Turgenevs "mūssen zweifellos in einer Bntwicklungslinie mit jenen Cechovs gesehen werden." "s" was durch die Arbeit Roschmals deutlich vird.

In der "Mōwe" findet man einen direkten Hinweis auf Turgenev zunächst im zweiten Akt. Trigorin gesteht hier Nina seine angst, nur ein mittelmābiger schriftsteller zu sein. der hinter den großen russischen Realisten zurūcksteht. Br befūrchtet, daß das publikum inn folgendermaben einschãtzt:

... "Ganz hũbsch, aber ein Tolstoj ist er nicht". oder: "eine sehr schōne sache, aber Turgenevs 'vảter und Söhne" sind besser." Und so wird es gehen bis ich sterbe, immer nur ganz hübsch und talentiert, ganz hübsch und talentiert - weiter nichts, und wenn ich tot bin. werden meine Bekannten, die an meinem Grab vorbeigehen, sagen: "Hier liegt Trigorin. Br war in guter Schriftsteller, aber er schrieb schlechter als rurgenev."

...Milo, no daleko do Tolstogo", ili: "Prekrasnaja veśc. no 'otcy $i$ deti Turgeneva lučse." I tak do grobovoj doski vse budet tol'ko milo i talantlivo. milo i talantlivo - bol'se ničego, a kak umru, znakomye, prochodja mimo mogily. budut govorit: " "zdes" lezit Trigorin. Chorosij byl pisatel', no on pisal chuže Turgeneva." (S. 30 )

Wir haben bereits darauf hingewiesen, das Trigorin viele züge Cechovs trāgt (Kap. 3.1.3.). Auch die Befürchtung. nicht an die groben vertreter des russischen Realismus

203 Pis'ma, Bd. 11, Moskva 1982, S. 184.

24 Bicilli (1966).

235 ebda. S. 31.

3 Koschmal (1983). S. 378. 
heranreichen zu können, die Angst por der Mittelmäßigkeit, hat Cechov selbst belastet.29?

In der Mówe gibt es aber noch ein direktes zitat aus Turgeners 1856 erschienenem Roman "Rudin". Indem Nina (vierter Akt) auf das stūrmische Wetter hinweist, sagt sie zu Treplev:

Bei Turgenev heibt es an einer Stelle: Wohl dem, der in solchen Nächten ein Dach über dem Ropf hat, der einen warmen Winkel hat." Ich bin die Mowe... Nein. nicht. (Reibt sich die stirn) Wo war ich stehengeblieben? Ja... Turgener ... "Gott helfe allen obdachlosen Wanderern..."

U Turgeneva est" mesto: "Chorošo tomu, kto $\nabla$ takie noči sidit pod krovom doma, u kogo est teplyj ugol". $\mathrm{Ja}$ - ćajka... Net, ne to (Tret sebe lob) o cem ja? Da... Turgenev.... "i da pomozet gospod' vsem besprijutnym skital'cam"... (s. 57)

Nina zitiert hier eine stelle aus dem Bpilog. Leznev und Rudin hatten sich fūr immer voneinander verabschiedet und der Titelheld geht in die stürmische, unheilverkündende Herbstnacht davon. In folgenden erhalten wir nur noch einen kurzen Bericht über seinen Tod auf den Barrikaden im Paris des Jahres 1848. Zuvor zieht der bereits stark gealterte Rudin die Bilanz seines rastlosen Lebens: niemals hatte ex es vermocht, seine hohen Ideale in die Tat umzusetzen, seine Reden und Vorträge über gesellschaftliche verantwortung und Nächstenliebe blieben für ihn selbst nichts als Worte.

DaB gerade Nina diese stelle aus Turgenevs Roman erwännt, hat wiederum eine zweifache, verfremdende Bedeutung. Bigentlich ahnelt sie der romantischen Heldin Natal'ja Alekseevna, die sich in Rudin verliebt, diesen aber letztlich als handlungsunfahigen Theoretiker entlarvt. Anders bei Nina: sie fallt auf den von ihr idealisierten Trigorin herein und wird von ihm sitzengelassen.

Indem Cechov ihr die Worte Turgenevs in den Mund legt, die auf die Binsamkeit und das tragische Ende Rudins hinwei-

23rsiehe die Brinnerungen Iran Bunins. In: A.P. Ćechov $\nabla$ vospominanijach sovremennikov (1986), s. 482-506. 
sen, relativiert er Ninas folgende Horte darūber, ihr schicksal zu erdulden und ihr leid zu ertragen. Durch diese verfremdende Anspielung auf Turgeneva "Rudin" bewahrt Cechov der "Möwe" die offenheit, die ihr die sovetische Forschung gerne zugunsten einer starken, heldenhaften Nina Zarečnaja abspricht.

Peace sieht in dem zitat aus Turgenevs Roman auch eine indirekte Anspielung auf die situation Treplevs.

Nina is obviously referring to herself, but if she is contrasting her position with that of Treplev, her words must have a bitterly ironic ring for one who feels himself to be 'superfluous in the house'.250

\subsubsection{Ibsens "Wildente"}

Cechovs Aussagen über den norwegischen Autor sind marginal, erscheinen jedoch widersprūchlich. Am 12.4 .1900 soll er anläblich einer Inszenierung der "Hedda Gabler" in Sevstopol zu K.S. Stanislavskij gesagt haben, daB Ibsen fūr ihn kein Dramatiker sei.s', Diese Rußerung kann jedoch durch die schlechte Aufführung, auf die čechov ebenfalls hinweist, beeinflupt sein. Andererseits versuchte er wenn möglich. jede Ibsen-Inszenierung (und auch Theaterprobe) zu besuchen; beispielsweise bittet er in einem Brief rom 7.11.1903 A.L. Višnevskij, ind einen Platz in dem stück "Stützen der Gesellschaft" zu reservieren und fügt hinzu:

...ich möchte mir dieses munderbare norwegische spiel ansehen und werde den Platz sogar bezahlen. Sie wissen. Ibsen ist mein Lieblingsschriftsteller.200

...choču posmotret' udivitel'nuju norveżkuju igru i daže zaplaču za mesto. Vy znaete. Ibsen moj ljubimyj pisatel'.

In dem bereits erwāhnten Begleitschreiben fūr eine Būchersendung an die Taganroger Bibliothek vom 24.11 .1896 ver-

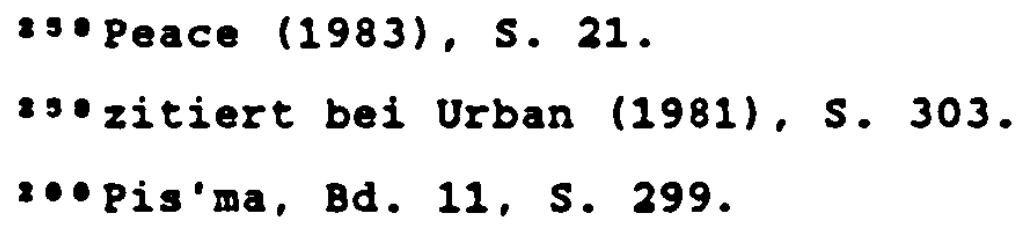


nerkt der Autor, daß er eine Ibsen-Gesamtausgabe subskribiert habe und sie, wenn alle Bande erschienen sind. schicken werde.

Čechov nimmt in der "Möwe" keinen direkten Bezug auf Ibsens Drama "Die Wildente". Doch die Titel der beiden stūkke sowie die zentrale symbolische und handlungskonstituierende Bedeutung der Motive der Wasservōgel deuten drauf hin, daß das Drama des norwegischen Autors nicht ohne Einfluß auf die "Möwe" geblieben ist.

Auf Entsprechungen zwischen Ibsens "Wildente" und Čechovs "Möwe" murde schon hingewiesen.2.1 Diese sollen daher nur kurz angerissen werden. Ċechovs stūck spielt auch auf die russische Romanze vom jungen Mādchen an, das von einem Premden - wie eine Möwe von einem Jäger - zugrundegerichtet wird. Ibsens Motiv der Hildente liegt das Gedicht des norwegischen Dichters J.S. Helhaven zugrunde, "Der Seevogel', die Rlage un einen jungen Hildvogel, der angeschossen untertaucht und sich im seegrund festbeibt, um zu sterben..."2:2 Wie die Möwe ist auch die Wildente ein dramatisches Leitmotiv. das das stūck strukturiert und die Handlung vorantreibt.s.2 Ebenso ist das symbol der Vildente zunāchst offen. d.h. meherere dramatis personae setzen sich (Hjalmar, Gregers) oder eine andere Person (HjalmarGina: Gregers-Hjalmarl zu dem Bild des Wasservogels und seiner Geschichte direkt in Verbindung oder kōnnen vom Rezipienten darauf bezogen werden (Hedwig. Ekdal). Weitere metaphorische Bedeutung erhalten in Ibsens Drama vor allem die zahl 13 sowie das immer wiederkehrende Bild der Blindheit.

Ċechov hat jedoch in der "Mōwe" die symbolik und die mit ihr verbundene Handlungsfühung konzentrierter und strukturierender angewandt.

\footnotetext{
201Lamm (1947); Nilsson (1958); Nag (1964): SachAzizova (1966): Mrosik (1967).

202 Pongs (21963), S. 18.

202 siehe hierzu bes. Kapitel 1.5.
} 
Wāhrend Ibsen sein Drama aus dem Jahre 1885 noch in funf Akten konzipiert hatte und das Motiv der vildente erst im zweiten Akt vorstellt. genūgen Cechov vier Akte. das Bild der Mōwe (sowie des sees und der Theaterkulisse) bringt er bereits im ersten Akt ins spiel. Auch verlagert Cechov wichtige Handlungsmomente stärker als Ibsen "hinter die Būhne". In der "Wildente" erfährt Hjalmar von Gregers bei einem spaziergang fūr den zuschauer nicht sichtbar (zwischen drittem und viertem Akt) von der füheren Beziehung zwischen Gina und Werle. Hedwig erschiebt sich schlieblich auf dem Dachboden, also hinter den Kulissen.

In der "Mōwe" vollzieht sich noch mehr fūr den zuschauer unsichtbar: Treplevs erster selbstmordversuch, seine Duellforderung an Trigorin. Ninas unglūckliche Beziehung mit Trigorin (wāhrend der zweijāhrigen zeitspanne zwischen drittem und viertem Akt) und ihre hieraus resultierenden MiBerfolge auf der Būhne, Treplevs erste Erfolge als schriftsteller und schlieblich sein selbstmord. Ober all diese wichtigen Ereignisse erfahren wir nur aus Gesprächen.

Das Gesamtbild der "Möwe" wirkt dadurch geraffter. Dennoch behālt das symbol der Möwe eine grōBere offenheit als das der Wildente, das durch die Identifikation Hedwigs mit ihm schlieblich (relativ) fstgelegt wird.

Insgesamt verzichtet Cechov auch darauf, eine dem stück zugrundeliegende Thematik klar auszusprechen. In der "Wildente" weist Relling im letzten akt mehrmals auf das zentrale Problem der "Lebenslüge" hin.

Hierin liegen also die zwei wesentlichen Unterschiede zu Ibsens stūck: Ċechov gelingt durch einen strukturierenden Gebrauch von Symbolmotiven und die Verlagerung von Geschehnissen hinter die Būhne eine Ronzentration auf die psychische situation und Entwicklung seiner Protagonisten. Anderersejts bewahrt er seinem stūck eine gröbere offenheit, indem er den symbolträgern letztlich keine eindeutigen Inhalte zuspricht (siehe hierzu Kapitel 1.5.). 
Schlubbemerkung

Die vorliegende Arbeit zeigt, daß Ċechovs "Möwe" ein in Handlungsführung, Romnunikation, Thematik und Intertextualitat komplex gestaltetes und vielschichtiges Drama ist.

Es stellt eine russische variante zum Problembereich Kunst-Leben dar, der in der europaischen Dramenliteratur der Jahrhundertwende viel diskutiert murde.

Der extreme Subjektivismus der alteren Generation, hier in den Personen Arkadina und Trigorin aufgezeigt, und die Einsamkeit der jungen Protagonisten Nina und Treplev spiegelt sich auf der kompositorischen Ebene darin wieder, daß ein zentraler Handlungskonflikt zugunsten einzelner Handlungsstrānge aufgegeben wird.

Die einseitige Ausrichtung auf eigene ziele und Interessen läbt die Wahrnehmung des Kommuikationspartners nur noch partiell zu. So erweist sich die Auflösung einer zentralen dramatischen Handlung und die Beschreibung gerade auch heute noch aktueller Kommunikationsstorungen als logische Polge eines sich wandelnden Verhätnisses des subjekts zu seiner Umwelt.

In der Handlungsführung lenkt Ċechov durch die zentralen Symbolmotive des Sees, der mówe und der Theaterkulisse den Blick sowohl auf das Gesamtgeschehen als auch auf einzelne Handlungsebenen.

Dabei erhalten die Symbolmotive eine doppelnde Funktion. Indem sie sich entsprechend den ihnen zugewiesenen protagonisten und dem mit ihnen verbundenen Geschehen verăndern, verstārken sie den Bindruck von Rontinuität und stringenz.

Zudem leisten sie einen Beitrag zur Charakterisierung einzelner protagonisten, die in ihren Verhätnis zu den Symbolmotiven eine für sie typische Verhaltensweise offenbaren. Dennoch bewahren die Symbole der "Möwe" einen Grad von offenheit, der fūr neue Interpretationen Raum läbt.

Durch die direkten Hinweise und Anspielungen auf shakespeares "Hamlet" verdeutlicht Cechov, daß die Beziehung des 
dramatischen Helden zu seiner Umgebung eine andere geworden ist. Eine Tragödie, die eine Auseinandersetzung des Helden mit verschiedenen Wertesystemen thematisiert. ist in einer râumlichen und geistigen Isolation, aus der die Welt immer undurchsichtiger und anonymer wird, nicht mehr möglich. Čechov weist gerade durch die Abweichungen von Shakespears "Hamlet" daraut hin, daß die "Mowe" keine Tragödie sein kann.

Die Anspielungen auf die angeführten literarischen vorlagen Shakespeares, Maupassants, Turgenevs, Puškins und schließlich Ibsens wirken im äuberen wie inneren Rommunikationssystem strukturierend.

Čechor spielt jedoch mit den Erwartungen seines (literarisch vorgebildeten) Publikums. Denn er kopiert die Texte nicht nur oder zitiert aus ihnen, sondern er geht bewubt verfremdend mit ihnen un.

Cechovs Interpretation des Hamlet-Typs ist dabei sowohl beeinflubt durch die Vermittlung Turgenevs als auch durch die Diskussion über die Rolle der Intelligencija innerhalb der Narodniki-Bewegung.

Das Fehlen von Leitfiguren und eindeutigen Handlungsvorgaben schlägt sich in den Dramen Čechovs im Phanomen der "Vaterlosigkeit" nieder. Vaterfiguren trifft man in den stūcken des russischen Dichters nicht an oder findet sie negativ gezeichnet. So läßt sich am Ende festhalten:

Die Thematisierung moderner Bewutseinskonflikte und ihre verschlusselte wie vielschichtige Umsetzung in eine adàquate dramatische Form machen die Brisanz und Aktualität der Dramen Čechovs aus. 


\section{Literaturverzeichnis}

Primārliteratur

Cechov. Anton Pavlovic (1974-1983): Polnoe sobranie socinenij i pisem $v$ tridcati tomach. Moskva.

Cechov, Anton (1973-1981): Das dramatische Werk (in 8 Bànden). Herausgegeben und übersetzt von P. Urban. Zürich.

Cechov, Anton (1979): Briefe (in 5 Bänden). Herausgegeben und übersetzt von $P$. Urban. Zūrich.

Cechov, Anton (1983): Tagebūcher - Notizbūcher. Herausgegeben und übersetzt von P. Urban. zürich.

Ibsen, Henrik (1913): Die Wildente. In: Sämtiche Werke. Volksausgabe in funf Bänden, Bd. 4, S. 299-420. BerIin.

Maupassant, Guy de (1947): Sur I'eau. In: Oeuvres compldtes, Bd. 21, Paris.

Puskin, Aleksandr Sergeevic (1948): Rusalka. In: Polnoe sobranie socinenij. Bd. 7, S. 319-347. Moskva.

Schnitzler, Arthur (1962): Der einsame Heg. In: Gesammelte Werke. Die dramatischen Werke. Bd. 1. S.759-836. Erankfurt a.M.

- (1967): Aphorismen und Betrachtungen. Hg.v. Robert O. Weiss. Brankfurt a.M.

Shakespeare, William (1987): The Tragedy of Hamlet, Prince of Demarke. Ed. by G.R. Hibbard. Oxford.

Turgenev, Ivan Sergeevic (1960-1968): Polnoe sobranie soCineniji pisem $v$ dvadcati vos'mi tomach. Moskva-Leningrad.

Sekundārliteratur

In die liste der Sekundārliteratur aufgenommen sind nur (vorwiegend neuere) Titel, die direkt in die Arbeit eingeflossen sind. Zum Wandel des Cechov-Bildes bis in die 50 er Jahre siehe vor allem Bmmer (1954).

Die Rezeption im deutschen Sprachraum vor 1945 beschreibt Deppermann $(1986 \mathrm{c})$, nach 1945 Hielscher (1984). Die englischsprachigen Arbeiten zu Cechov fassen zusammen: Mirokij (1927). Heifetz (1947), Yachniss (1960). Filips-Juswigg (1985). Meister (1985), Polakiewicz (1985), Sendich 
(1985). Bine Auswahlbibliographie sovetischer Arbeiten bis 1954 iiefern Polockaja (1955). Osarova (21979). neuere veroffentlichungen verzeichnet Ivanov-Natov (1985).

A.P. Cechov $v$ vospominanijach sovremennikov (1986). Moskva.

Adler, J.H. (1970/71): Two Hamlet Plays: The Wild Duck and The Seaguli. In: Journal of Modern Literature $1 . S$. 226-248.

Alekseev, M.P. (Hg.) (1965): Sekspir i russkaja kul'tura. Moskva.

Asmuth, B: (21984): Einfūhrung in die Dramenanalyse. stuttgart.

Avdeev, Ju.R. (1973): Cechov. Lika. Levitan i "Cajka". In: Cechovskie ctenija valte, s. 72-77.

Baluchatyj. S.D. (1927) : Problemy dramaturgiceskogo anali2a. Cechov. Leningrad.

- (1936): Cechov-dramaturg. Leningrad.

Barricelli, J.-P. (Hg.) (1981): Chekhov's Great Plays. A Critical Anthology. New York.

Bates, H.B. (1988): Cechov und Maupassant. In: Urban (Hg.) $(1988)$, S. 172-179.

Bayer, R: (Hg.) (1982): Studienbuch: Mūndliche Rommunikation. Paderborn, München, Hien, zūrich.

Berdnikov, G.P. ('1981): Cechov-dramaturg. Tradicii i novatorstvo v dramaturgii A.P. Cechova. Moskva.

- (31984): A.P. Cechov. Idejnye i trorCeskie iskanija. Moskva.

- (1985): Anton Tschechow. Bine Biografie. Berlin.

Berkovskij, N. (1969): Cechov: ot rasskazov i povestejk dramaturgii. In: ders.: Literatura i teatr. Moskva. S. 48-182.

Best, O. R. (1984): Handbuch literarischer Fachbegriffe. Definitionen und Beispiele. Prankfurt a.M.

Bicilli, P. M. (1966): Anton P. Cechov. Das Werk und sein Stil. München.

Bjalyj, G. A. (1981): Cechov i russkij realizm. Oxerki. Leningrad. 
Borcke, A. von (1979): Gewalt und Terror im revolutionāren Narodnicestvo: Die Partei Narodnaja volja 1879-1883. Zur Entstehung und Typologie des polit. Terrors im RuBland des 19.Jh. Köln.

Borisova, L.M. (1985): O prirode podteksta $\nabla$ dramaturgii A.P. Cechova. In: Voprosy russkoj literatury $1 / 85, \mathrm{~S}$. 44-48.

Brahms, C. (1976): Reflections in a Lake. A study of Chekhov's four Greatest Plays. London.

Brauneck, M. (1982): Theater im 20. Jahrhundert. Programmschriften, Stilperioden, Reformodelle. Reinbek.

Brauneck, M./Schneilin, G. (Hg.) (1986): Theaterlexikon. Begriffe und Epochen. Bühnen und Bnsembles. Reinbek.

Bristow, E. R. (Hg.) (1977): Chekhov's Plays. New York.

Bruford. H.H. (1963): Chekhov and his Russia. London.

Büntzel, H.-M. (1975): A.P. Tschechow als Arzt und Patient. Berlin.

Būrger, P. (1974): Theorie der Avantgarde. Frankfurt a.M.

Camus, A. (1969): Le mythe de Sisyphe. Essai sur 1'absurde. Paris.

Cechov $i$ ego vremja (1977). Moskva.

Cechov. M. P. (1923): Anton Cechov i ego sjuzety. Moskva.

Cechov segodnja (1983). Sbornik statej. Moskva.

Cechovskie ttenija Jalte (1978). Cechov i russkaja literatura. Sbornik naucnych trudov. Moskva.

Cechovskie ctenija v Jalte (1983). Cechov $v$ Jalte. Sbornik naucnych trudov. (Materialy konf.. Jalta 1981g.) Moskva.

Cervinskene, B. (1976): Edinstro chudokestrennogo mira. A. P. Cechov. Vilnius.

Chudozestrennyj metod A.P. Cechova (1982). Mezruzovskij sbornik naucnych trudov. Rostov-na-Donu.

Clyman, T.H. (Hg.) (1985): A Chekhov Companion. London.

Cudakov, A.P. (1971): Poltika Cechova. Moskva.

Cukovskij. K.I. (1967): o Cechove. Moskva.

Davis, J. M. (1978): Earce. London. 
Deppermann, M. (1986a): Tschechow. "Onkel Wanja." In: Zelinsky, B. (Hg.) (1986), S. 147-161.

- (1986b): "Zarte Anspielungen auf ziemlich starke stükke." Psychologische Motivierung und dramentechnische Innovation in Cechovs "OnkeI Vanja". In: Mauser, W./ Renner, U./Schōnau, W. (Hg.): Phantasie und Deutung. Psychologisches Verstehen von Literatur und Film. Rönigshausen, S. 96-111.

- (1986c): Cechov in Deutschland. Das Cechov-Archiv 2u Badenweiler im Rontext der Rezeptionsgeschichte. Salzburg. (maschinenschr. Habilitationsschrift)

Dittmann, J. (1979): Was ist, 24 welchen zwecken und wie treiben wir Ronversationsanalyse? In: Ders. (Hg.): Arbeiten zur Ronversationsanalyse. Tübingen, S. 1-43.

Divis, R. (1983): Rommunikative strukturen im tschechischen Drama der 60er Jahre. Prankfurt, Bern.

Dlugosch, I. (1977): Anton Pavlovic Cechov und das Theater des Absurden. Mūnchen.

Dobrev, C. (1982): PoetiCeskaja drama. Moskva.

Dürrenmatt, F. (1966): Theaterprobleme. In: TheaterSchriften und Reden. Hg.v. B. Brock-Sulzer, S. 92131. Zürich.

Bekman. T. (Hg.) (1960): Anton Cechov. 1860-1960. Some Essays. Leiden.

Bmmer, H. (1954): Die Wandlung des Bildes Tschechows. In: Osteuropa, 4, S. $422-430$.

Ermilov, v.v. (1948): Dramaturgija Cechova. Moskva.

- (21949): Anton Pavlovic Cechov. 1860-1904. Moskva.

Esslin. M. (1985): Das Theater des Absurden. Von Beckett bis Pinter. (Brweiterte Ausgabe) Reinbek.

Freytag, G. (131965): Die Technik des Dramas. Darmstadt.

Filips-Juswigg. B. (1985) : Doctoral Dissertations on Chekhov in the U.S. and Canada. In: Transactions of the Association of Russian-American Scholars in the U.S.A. Vol. XVIII, S. 171-174. Nen York.

Galaktionov, A.A./Nikandrov, P.F. (1966): Ideologi russkogo narodnicestva. Leningrad.

Geiger, H./Haarmann, H. (21982): Aspekte des Dramas. Opladen. 
Gitovic. N.I. (1955): Letopis' Zizni i tvorcestva A.R. Cechova. Moskva.

Gontarenko. N.B. (1987): Sovremennaja "D'esa dlja dvoich" i Zanrovye osobennosti dramaturgii A. Cechova. In: voprosy russkoj literatury $1 / 87$, S. 51-60.

Greiner, N./Hasler, J./Kurzenberger, H./Rikulik, L. (1982): Einführung ins Drama. Handlung-Pigur-Szenezuschauer. ( 2 Bde.) München.

Gromov, P. (1970): Stanislavskij, Cechov, Mejerchol'd. In: Teatr Nr. 1, S. 83-89. Moskva.

GroBe, B. U. (1976): Text und Rommunikation. Bine Iinguistische Binführung in die Funktion der Texte. Stuttgart, Berlin. Köln, Mainz.

Grossman, L. (1967): Roman Niny Zarexnoj. In: ders.: Prometei. Bd. 2, S. 219-289. Moskva.

Gruber, G. (1950): Das Stimmungdrama Anton Cechovs. Wien.

Gruzinskij-Lazarev, A.S. (1914): Propavbie romany i p'esy Cechova. In: Bnergija. kn. 3. S. 153-173. Sanktpeterburg.

Hahn, B. (1977): Chekhov. A study of the Major stories and Plays. Cambridge.

Hamburger, K. ('1977): Die Logik der Dichtung. Frankfurt. Berlin. Wien.

Hauser, A. (1953): Sozialgeschichte der Runst und Literatur. München.

Heifetz, A. (1947): Chekhov in English: A List of Works by and about Him. New York.

Heresch. E. (1976): Zur Rezeption Arthur Schnitzlers in RuBland. Graz.

- (1982): Schnitzler und RuBland. Aufnahme, Nirkung, Kritik. Hien.

Hermann, R. (1976): Das dramatische Bild. Bine Skizze. In: Reller. W. (Hg.): Beitrāge zur Poetik des Dramas, $S$. 260-278. Darmstadt.

Hielscher, K. (1984): Die Rezeption A.P. Cechovs im deutschen Sprachraum seit 1945. In: Girke, W. U. Jachnow, H. (Hg.): Aspekte der Slavistik. Festschrift für Josef Schrenk, S. 73-101. München.

- (1987): Tschechow. Bine Binfūhrung. Mūnchen-zürich. 
Hollosi, C. (1983): Chekhov's Reactions to two Interpretations of Nina. In: Theatre Survey XXIV, S. 117-126.

Hũbler, A. (1973): Drama in der Vermittlung von Handlung. sprache und szene. Bonn.

Hūbner, F. (1971): Die Personendarstellung in den Dramen Anton P. Cechovs. Ansterdam.

Istorija russkoj dramaturgii. Vtoraja polovina XIX-nacalo XX veka do 1917 g. (1987). Leningrad.

Ivanov-Natov, A. (1985): Chekhov - A Bibliography of Latest Publications in Russian on Chekhov. In: Transactions of the Association of Russian-American Scholars in the U.S.A. Vol. XVIII. S. 175-186. New York.

Jackson, R. L. (1981): Chekhov's Seagul1: The Empty Well, the Dry Lake, and the Cold Cave. In: Barricelli (Hg.) (1981). S. 3-17.

Jussel, A. (1960): Guy de Maupassant und A.P. Tschechor. Innsbruck. (Diss. Maschinenschr.)

Kagan-Kans, E. (1975): Hamlet and Don Qixote: Turgenev's Ambivalent Vision. The Hague-Paris.

Kalkofen, H. (1983): Bestimungselemente der Kommunikation. In: Dutz, K. D./Wulff, H. J. (Hg.): Rommunikation. Eunktion und Zeichentheorie. Zur Terminologie der Semiotik (3), S. 111-163. Münster.

Kataev, V.B. (Hg.) (1982): Sputniki Cechova. Sobranie tekstov, stat'i i kommentarii. Moskva.

Ratsell. J. H. (1981): The Seagull and Maupassant's Sur 1'eau. In: Barricelli (Hg.) (1981), S. 18-34.

Rierkegaard. S. (1957): Entweder/Oder. Zweiter Teil. Düsseldorf.

Rirschstein-Gamber, B. (1979): Die Cechov-szene. Untersuchungen zu Text und Realisierung der Regieanweisung im Drama Anton Pavlovic Cechovs. Freiburg.

Klotz, V. (1960): Geschlossene und offene Form im Drama. München.

Kluge, R.-D. (1973): Vom kritischen zum sozialistischen Reaismis. Studien zur literarischen Tradition in RuBland 1880-1925. München.

Roschmal. W. (1983): Das poetische System der Dramen I.S. Turgenevs. Studien zu einer pragmatischen Dramenanalyse. Munchen. 
Kuznecova, M.V. (1978): TrorCeskaja èolucija A.P. Cechova. Tomsk.

- (1984): A.P. Cechov. Grani velikogo darovanija. Char'kov.

Lafitte, S. (1960): Anton Tschechow in Selbstzeugnissen und Bilddokumenten. Reinbek.

Lamn, M. (1947): Ibsen och Tjekov. In: Edda 47, S. 119129. Os10.

Lehrmann, B.H. (1985): A Handbook to Eighty-Six of Chekhov's stories in Russian. Ohio.

Literaturnoe nasledstvo (1960): Bd. 68. Cechov. Moskva.

Maegd-Soêp, C. de (1987): Chekhov and Homen: Homen in the Life and Hork of Chekhov. Columbus.

Magarshack, D. (1972): The Real Chekhov. An Introduction to Chekhov's Last Plays. London.

- (1980): Chekhov the Dramatist. London.

Materialy Literaturnogo muzeja Puskinskogo doma (1982). A.P. Cechov. Leningrad.

Meister, C. H. (1985): Chekhov Bibliography: Horks in English by and about Anton Chekhov. American. British and Canadian Performances. London.

Melchinger, S. (21974): Anton Tschechow. Velber.

Meve, B.B. (1961): Medicina $\nabla$ trorCestre i zizni A.P. Cechova. Riev.

Michajlovskij, N.K. (1896-1909): Polnoe sobranie socinenij. Sanktpeterburg.

- (1957): Literaturno-kriticeskie stat'i. Moskva.

Milych, M.R. (Hg.) (1983): Problemy jazyka i stilja A.P. Cechova. Rostov-na-Donu.

Mirskij. D.S. (1927): Chekhov and the English. In: The Monthly Criterion, Nx. 6, S. 292-309.

- (1964): Geschichte der russischen Literatur. München.

Mitscherlich, A. (1*1986): Auf dem Weg zur vaterlosen Gesellschaft. Ideen zur Sozialpsychologie. München.

Mrosik. J. (1967): Vom Symbolmotiv der Mōve in Cechovs "Ćajka" und seiner Herkunft. In: HdSI XII. 1. S. 2258 . 
Moravtevich, N. (1981): Nomen in Chekhov's Plays. In: Barricelli (Hg.) (1981), S. 201-217.

Müller-Dietz, H. (Hg.) (1979): Doktor Anton P. Cechov. Berlin.

Mūller-zannoth. I. R. (1977): Der Dialog in Harold Pinters Dramen. Aspekte seiner kommunikativen Funktion. Frankfurt. Bern.

Mur'janov, M.F. (1974/75): O simvolike Cechovskoj "Cajki". In: Hasl XIX/XX, S. 105-123.

Nabokov, V. (1984): Anmerkungen zu "Die Mōwe". In: ders.: Meisterwerke der russischen Literatur, S. 374-392. Frankfurt a.M.

Nag, M. (1964): Ibsen, Cechov und Blok. In: Scando-SlaviCa, Bd. X, S. 30-48.

Naimark, N. M. (1979): The "Proletariat" and "People's Will". A History and Comparison of Polish and Russian Revolutionary Socialism, 1878-1886. Ann Arbor.

Nilsson, N.A. (1958): Ibsen in RuBland. Stockholm.

Norec, 2.S. (1974): Ivanov i Gamlet. (Opyt sravnitel'noj charakteristiki) In: stranicy russkoj literatury serediny XIX v.. S. 160-172. Leningrad.

offermanns. B.L. (1973): Arthur Schnitzler. Das Romōdienwerk als Rritik des Impressionismus. München.

Osarova, T.V. (21979): Bibliografija literatury o A.P. Cechove. Saratov.

Pailer. W. (1978): Die Erühen Dramen M. Gor'kijs in ihrem Verhältnis zum dramatischen schaffen A.P. Cechovs. Mūnchen.

Papernyj, Z.S. (1980): "Cajka" A.P. Cechova. Moskva.

- (1982): Vopreki vsem pravilam. P'esy i vodevili Cechova. Moskva.

Peace, R. (1983): Chekhov. A study of the Four Major plays. New Haven.

- (1986): Anton Tschechow. "Die drei Schwestern." In: Zelinsky $(1986)$, S. 162-177.

- (1987): Chekhov's "Modern Classicism". In: The SIavonic and Bast Buropean Review, Vol. 65, 1/1987, S. 13-25. 
Penzkofer, G. (1984): Der Erzählungen Cechovs. Erzählen. München.
Bedeutungsaufbau in den spāten "Offenes" und "geschlossenes"

Pfister, M. (1982): Das Drama. Theorie und Analyse. München.

Pipes, R. (1964): Narodnicesto: $\lambda$ Semantic Inquiry. In: Slav. Rev. 23, S. 441-458.

Pitcher, H. (21985): The Chekhov Play. A New Interpretation. Berkeley-Los Angeles-London.

Polakiewicz, L. (1985): Selected Bibliography. In: Clyman (Hg.) (1985), S. 311-331.

Polockaja, E.A. (1955): Anton Pavlovic Cechov. Rekomendatel'nyj ukazatel'literatury. Moskva.

- (1960): Cechov i Mejerchol'd. In: Literaturnoe nasledstvo, Bd. 68, S. 417-434.

- (1979): A.P. Cechov. Dvizenie chudozestrennoj mysli. Moskva.

Pongs, H. (2 1963): Das Bild in der Dichtung. Bd II: Voruntersuchungen zum Symbol. Marburg.

- (1978): Symbol als Mitte. Marburg.

Porter, R. (1981): Hamlet and The Seagull. In: Journal of Russian Studies 41, S. 23-32.

Rasch, W. (1986): Die literarische Decadence un 1900. Mūnchen.

Rayfild, D. (1975): Chekhov. The Evolution of His Art. London.

Roskin, A. I. (1959): A.P. Cechov. Stat'i i oterki. Moskva.

Sach-Azizova, T.K. (1966): Cechov i zapadno-evropejskaja drama ego vremeni. Moskva.

- (1977): Russkij Gamlet. ("Ivanov" i ego vremja). In: Cechov i ego vremja (1977), S. 232-246.

Scheibitz, Ch. (1972): Mensch und Mitmensch im Drama Anton Cechovs. Analyse der Dialogtechnik. Göpingen.

Schmeling, M. (1977): Das Spiel im Spiel. Bin Beitrag zur vergleichenden literaturkritik. (o. ort). 
Schmid, H. (1973): Strukturalistische Dramentheorie. Semantische Analyse von Cechovs "Ivanov" und "Der Rirschgarten". Rronberg Ts.

- (1978): Die Bedeutung des dramatischen Raums in A.P. Cechovs "Visnevyj sad" (Der Rirschgarten) und $A$. Strindbergs "Gespenstersonate". In: Referate und Beiträge zum VIII. Internationalen Slavistenkongre $\mathrm{Za}$ greb, S. 149-198. München.

-(1984a): Cechov's Drama and Stanislavskij's and Mejerchol'd's Theories of Acting. In: Rleberg, L./Nilsson, N. ${ }^{\circ}$ ( $\left.\mathrm{Hg}.\right)$ : Theater and Literature in Russia 19001930. A Collection of Essays. Stockholm.

- (1984b): Die Umstrukturierung des theatralischen Zeichens in Cechovs Einakter "Predlozenie" (Der Heiratsantrag). In: Resteren, $A$. van/Schmid, H. (Hg.): Semiotics of Drama and Theatre, S. 305-367. Amsterdam/Philadelphia.

- (1986a): Cechov-Inszenierungen auf deutschen Bühnen: 1964-1984. In: Porum modernes Theater, 1/86, S. 8183.

- (1986b): 'Zwei zu eins': Bine charakteristische Dialogkonstellation im absurden Theacer. In: Forum modernes Theater, 2/86, S. 141-165.

Schmid, W. (1987): Analysieren oder Deuten? Oberlegungen zur Rontroverse zwischen Strukturalismus und Hermeneutik am Beispiel von Cechovs "Nevesta". In: WdS1, 1/87, S. 101-120.

Schramm, G. (Hg.) (1983): Handbuch der Geschichte RuBlands. Bd. 3: Von den autokratischen Reformen zur Sowjetstaat (1856-1945). Bd. 3.1.. S. 145-169: "Die revolutionãe Bewegung." (Von M. Hildermeier). Stuttgart.

Schultze, B. (1984): Studien zum russischen literarischen Binakter. Von den Anfängen bis A.P. Cechov. Wiesbaden.

Searle, J. R. (21970): Speech Acts: An Essay in the Philosophy of Language. Cambridge.

Sendich, M. (1985): Anton Chekhov in Bnglish: A Comprehensive Bibliography of Works About and By Him (18891984). In: Russian Language Journal, Vol. XXXIX, s. 227-263.

Senelick, L. (1981): Chekhov's Drama, Maeterlinck, and the Russian Symbolists. In: Barricelli (Hg.) (1981), S. $161-180$. 
Selge G. (1970): Anton Cechovs Menschenbild. Materialien zu einer poetischen Anthropologie. München.

Simmons, E.J. (1962): Chekhov. A. Biography. Boston-Toronto.

Skaftymov. A. P. (1948): R voprosu o principach postroenija p'es A.P. Cechova. In: UC.zap. Saratovskogo gos.un-ta, Bd. XX, S. 158-185. Saratov.

Smith, V. L. (1973): Anton Chekhov and the Lady with the Dog. London-New York-Toronto.

Smolkin. M. (1967): Sekspir v zizni i tvor Cestve Cechova. In: Šekspirovskij sbornik, S. 72-84. Moskva.

Sobolevskaja. N.N. (1983): Poètika A.P. Ćechova. UČebnoe posobie. Novosibirsk.

stanislavskij, K.S. (1960): Sobranie sočinenij $\nabla$ vos'mi tomach. Bd. 7. Moskva.

steltner. U. (1980): Zur Bvolution des russischen Dramas. Ostrovskij und cechov. In: WdS1, XXV, 1. S. 1-21.

stempel. W.-D. (1983): Intertextualitat und Rezeption. In: Schmid, W./Stempel. W. -D. (Hg.): Dialog der Texte. Hamburger Rolloqium zur Intertextualitát, S. 85-109. Wien.

stierle. R. (1983): Werk und Intertextualitāt. In: Schmid, W./Stempel. W.-D. (Hg.): Dialog der Texte. Hamburger Rolloquius zur Intertextualitä, S. 7-26. Wien.

Stroud. T.A. (1958): Hamlet and The Seagull. In: Shakespeare quarterly 9 , S. 367-372.

Subin. B.M. (J1982): Doktor A.P. Ċechov. Moskva.

szondi. P. (1०1983): Theorie des modernen Dramas 18801950. Brankfurt a.M.

Trautmann, R. (1948): Turgenjew und Tschechow. Bin Beitrag zum russischen Geistesleben. Leipzig.

Troyat, H. (1987): Tschechow. Leben und Werk. Stuttgart.

Turkov, A. M. (1980): A.P. Ċechov i ego vremja. Moskva.

Trorčeskij metod A.P. Čechova (1983). Mežvuzovskij sbornik naucinych trudov. Rostov-na-Donu.

Trorčestvo A.P. Čechova (1956). Sbornik statej. Moskva. 
Trorcestro A.P. Cechova (1981). Osobennosti chudoz. metoda. Mežruzovskij sbornik naučngch trudov. Rostov-naDonu.

Trorčestro A.P. Cechova (1984). Mežruzovskij sbornik naučnych trudov. Rostov-na-Donu.

Urban, P. (1981): Cechov-Chronik. Daten zu Leben und Werk. zürich.

- (Hg.u.übers.) (1983): Anton Ċechov. Tagebücher. Notizbūcher. Zürich.

- (Hg.) (1987): Anton Čechov. Sein Leben in Bildern. 2ũrich.

- (Hg.) (1988): Ober Ċechov. Zürich.

Valency, M.J. (1983): The Breaking String; the Plays of Anton Chekhov. New York.

Valtink, B. (Bg.) (1987): Von den Schmerzen ungelebten Lebens. Zum Werk Anton Tschechows. Hofgeismar.

Vilenskaja, B. S. (1979): N.R. Michajlovskij i ego idejnaja rol'v narodničeskom dviżenii $70 \mathrm{ch}$ - naćala $80 \mathrm{ch}$ godov 19. veka. Moskva.

vokrug Cechova (1981). Vstreçi i vpećatlenija B.M. Ċechova. Vospominanija. Moskva.

volkov. N. D. (1966): Šekspirovskaja p'esa Čechova. In: Ders.: Teatral'nye vecera, S. 431-436. Moskva.

Hatzlawick, P./Beavin, J. H./Jackson, D. D. (41974): Menschliche Rommunikation. Formen, Storungen, Paradoxien. Bern, Stuttgart, Hien.

Wellek, N. D. and R. (Hg.) (1984): Chekhov. New Perspectives. Englewood Cliffs.

Wilpert, G. von ('1969): Sachworterbuch der Literatur. Stuttgart.

Hinner, T.G. (1956): Chekhov's Seagull and Shakespeare's Hamlet. $\lambda$ Study in Dramatic Device. In: The American Slavic and East Buropean Review, XV, S. 103-111. Textgleich abgedruckt in: Hellek (Hg.) (1984), S. 107-117.

Wolftheim. B. (1982): Anton Cechor in Selbstzeugnissen und Bilddokumenten. Reinbek.

Yachniss, R. (1960): Chekhov in English: A Selected List of Works by and about Hin. 1949-1960. New York. 
Zamanskij, S. (1960): sila Cechorskogo podteksta. In: Teatr, Bd. 21, Nr. 5, S. 101-106.

Zelinsky. B. (Hg.) (1986a): Das russische Drama. Düsseldore.

- (1986b): Anton Tschechow. "Der Kirschgarten." In: Ders.: $(1986 a)$, S. 178-199.

Zingerman, B. (1988): Teatr Čechova i ego mirovoe značenie. Moskva. 


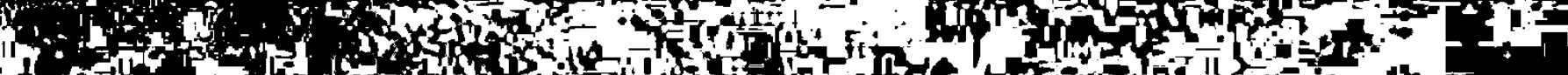

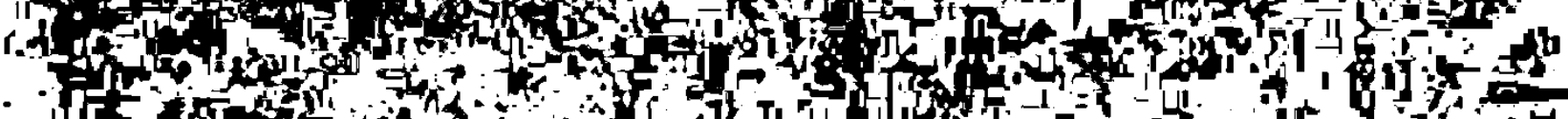

If C. H.

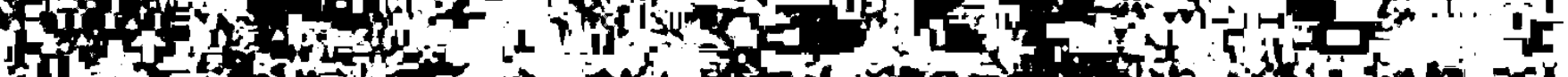

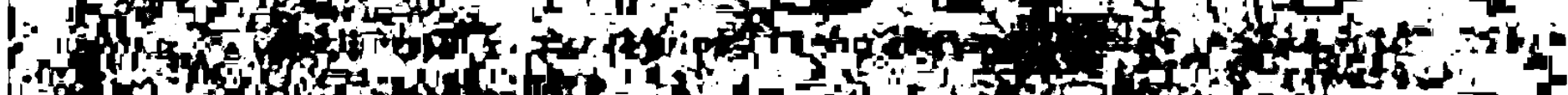

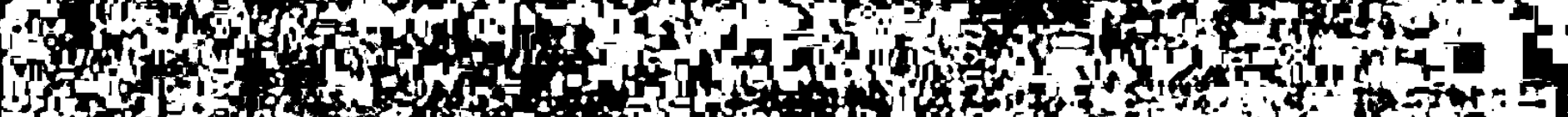
if

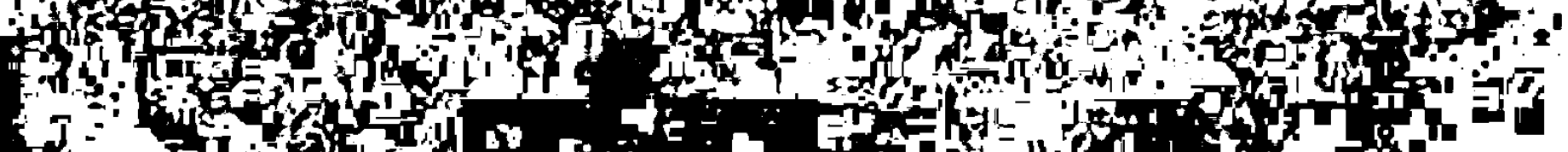

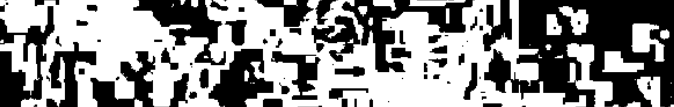
4ato and It in

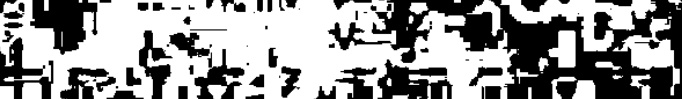

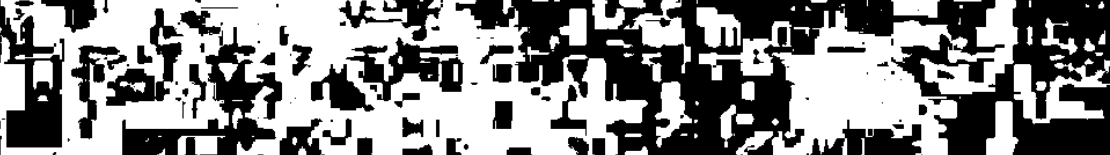

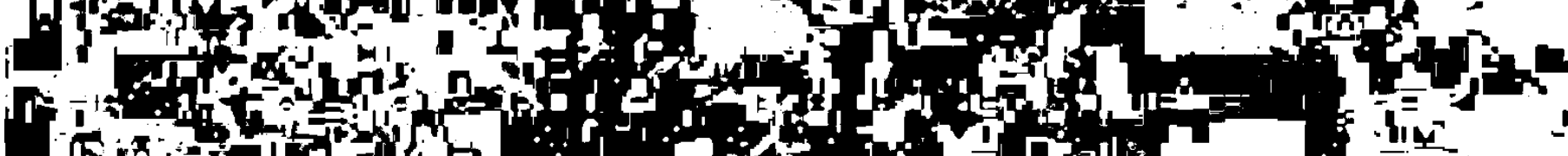
af

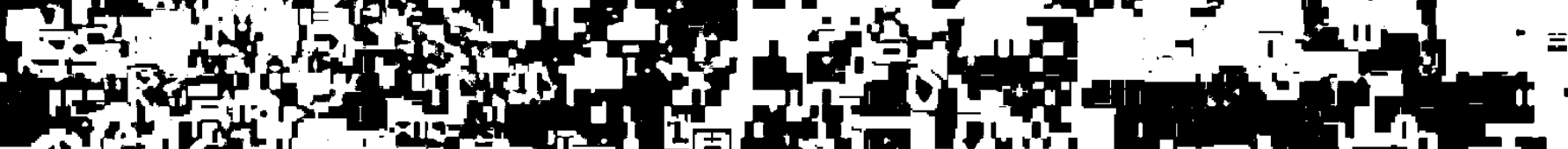

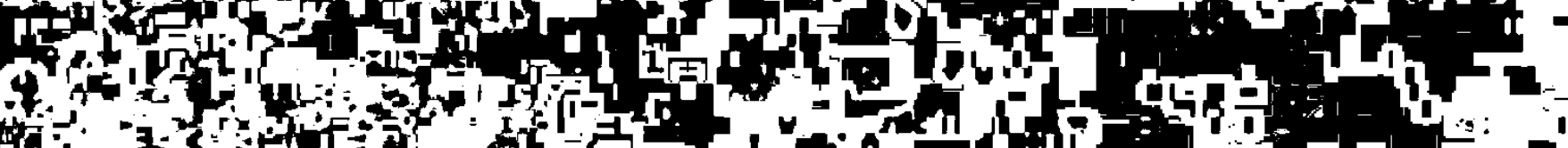

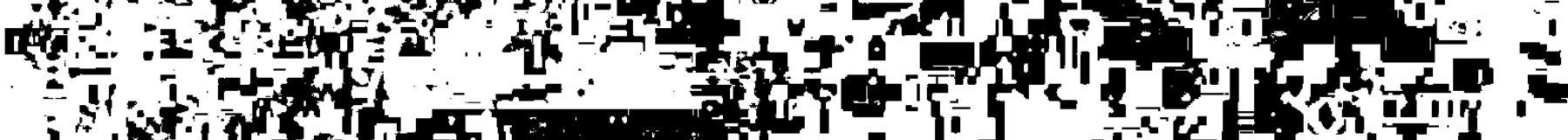
i

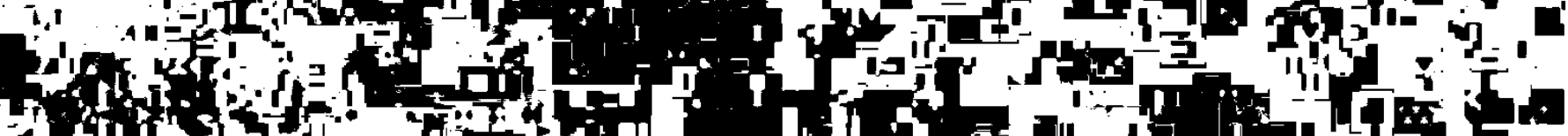

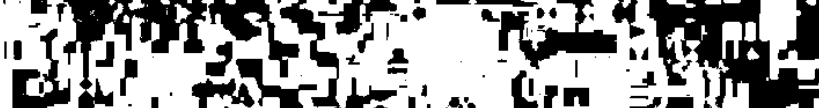

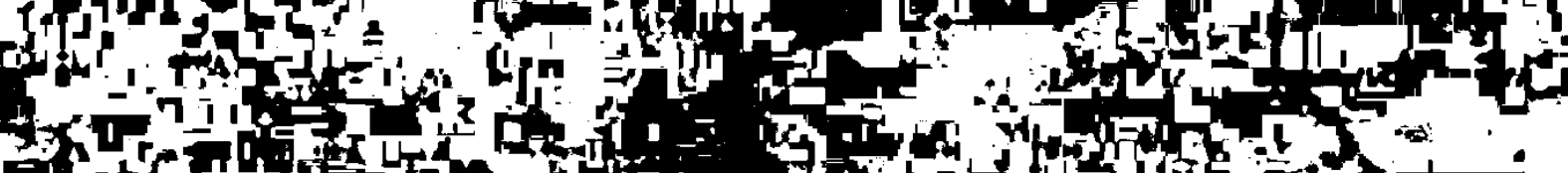

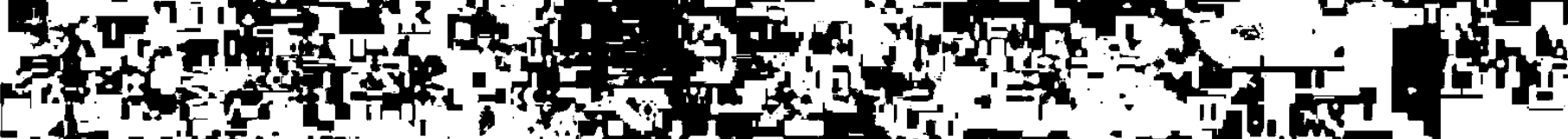
1

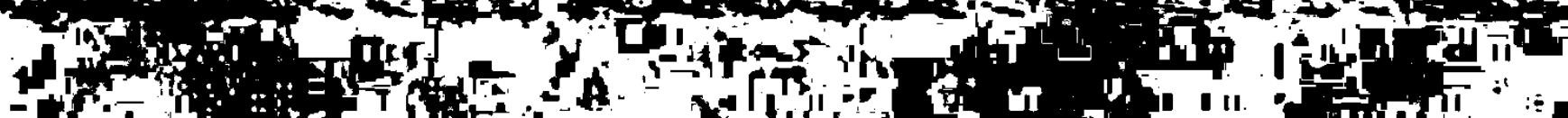

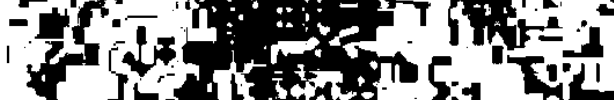
S i

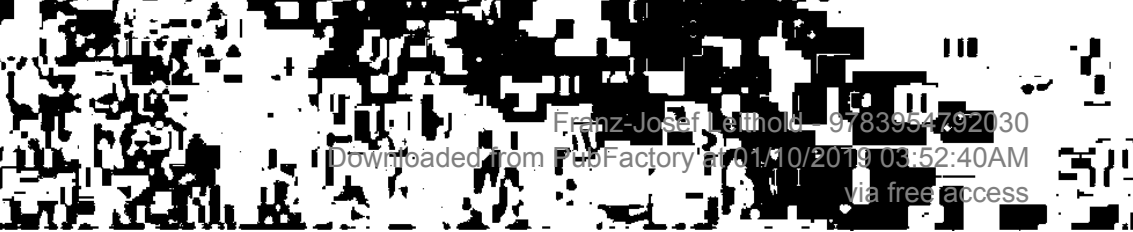




\section{SLAVISTISCHE BEITRAGE}

$(1988-1989)$

218. Besters-Dilger, Juliane: Zur Negation im Russischen und Polnischen. 1988. VI, $400 \mathrm{~S}$.

219. Menke. Elisabeth: Die Kultur der Weiblichkeit in der Prosa Irina Grekovas. 1988. VI, 309 S.

220. Hong, Gabriel: Palatalisation im Russischen und Chinesischen. 1988. X, $193 \mathrm{~S}$.

221. Kannenberg, Gudrun: Die Vokalwechsel des Polnischen in Abhängigkeit von Flexion und Derivation. Eine generative Beschreibung. 1988. $353 \mathrm{~S}$.

222. Fuchs, Ina: "Homo apostata". Die Entfremdung des Menschen. Philosophische Analysen zur Geistmetaphysik F. M. Dostojevskijs. 1988. 802 S.

223. Thomas, George: The Impact of the Illyrian Movement on the Croatian Lexicon. 1988. $291 \mathrm{~S}$.

224. Filonov Gove, Antonina: The Slavic Akathistos Hymn. Poetic Elements of the Byzantine Text and Its old Church Slavonic Translation. 1988. XIII, 290 S.

225. Eggers. Eckhard: Die Phonologie der deutschen Lehnwörter im Altpolnischen bis 1500. 1988. IX, $221 \mathrm{~S}$.

226. Srebot-Rejec, Tatjana: Word Accent and Vowel Duration in Standard Slovene. An Acoustic and Linguistic Investigation. 1988. XXII, $286 \mathrm{~S}$.

227. Hoelscher-Obermaier. Hans-Peter: Andrzej Kuśniewicz' synkretistische Romanpoetik. 1988. 248 S.

228. Ammer, Vera: Gottmenschentum und Menschgottum. Zur Auseinandersetzung von Christentum und Atheismus im russischen Denken. 1988. X, 243 S.

229. Poyntner, Erich: Die Zyklisierung lyrischer Texte bei Aleksandr A. Blok. 1988. XII, 275 S.

230. Slavistische Linguistik 1987. Referate des XIII. Konstanzer Slavistischen Arbeitstreffens Tubingen 22.-25.9.1987. Herausgegeben von Jochen Raecke. 1988. $444 \mathrm{~S}$.

231. Fleischer. Michael: Frequenzlisten zur Lyrik von Mikołaj Sep Szarzyński. Jan Jurkowski und Szymon Szymonowic und das Problem der statistischen Autorschaftsanalyse. 1988. $336 \mathrm{~s}$. 
232. Dunn, John F.: "Ein Tag" vom Standpunkt eines Lebens. Ide:elle Konsequenz als Gestaltungsfaktor im erzählerischen Werk von Aleksandr Isaevic Solzenicyn. 1988. $\mathrm{x}, 216 \mathrm{~s}$.

233. Kakridis, Ioannis: Codex 88 des Klosters Decani und seine griechischen Vorlagen. Ein Kapitel der serbisch-byzantinischen Literaturbeziehungen im 14. Jahrhundert.. 1988. $\mathrm{X}, 362 \mathrm{~S}$.

234. Sednidubský, Miloš: Die Struktur der tschechischen Lyrik zu Beginn des 20. Jahrhunderts. Untersuchungen zum lyrischen Frühwerk von $K$. Toman, F. Srámek und F. Gellner. 1988. 291 S.

235. Standard Language in the Slavic World. Papers on Sociolin.guistics by Hamburg Slavists. Edited by Peter Hill and Volkmar Lehmann. 1988. $161 \mathrm{~S}$.

236. Ulff-Moller. Nina K.: Transcription of the Stichera Idiomela for the Month of April from Russian Manuscriots from the 12th Century. 1989. VIII. $245 \mathrm{~S}$.

237. Cienki, Alan J.: Spatial Cognition ard the Semantics of Prepositions in English. Polish, and Russian. 1989. $\mathrm{x}, 172 \mathrm{~s}$.

238. Leithold. Franz-Josef: Studien 24 A. P. Cechovs Drama "Die Mowe". 1989. 193 S.

239. Bock, Hildegard: Die Lerntheorie P. Ja. Gal'perins und ihre Anwendbarkeit im Fremdsprachenunterricht. 1989. $\mathrm{X}, 365 \mathrm{~S}$. 


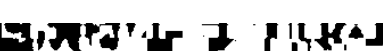

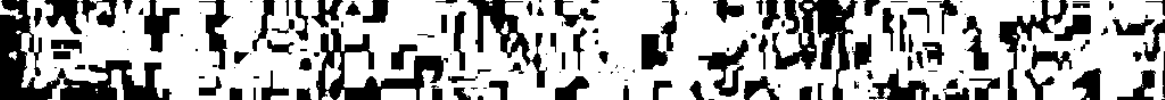

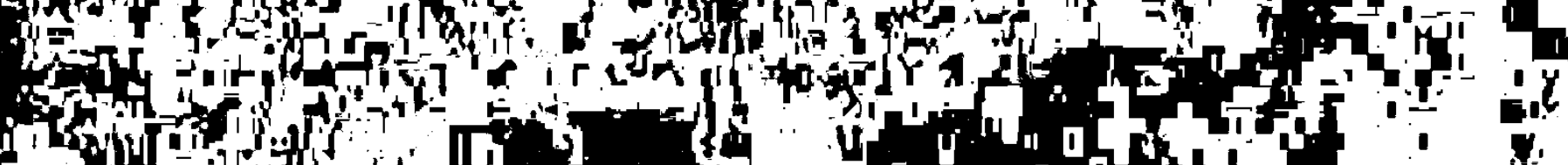

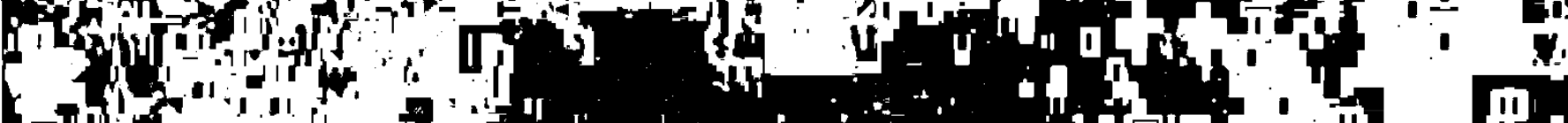

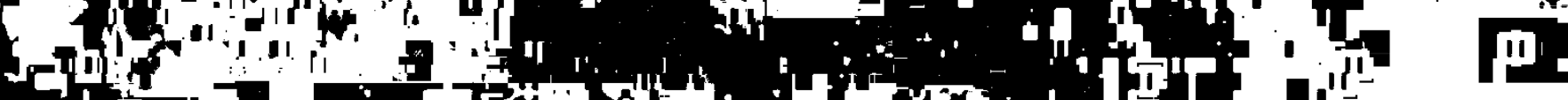
1

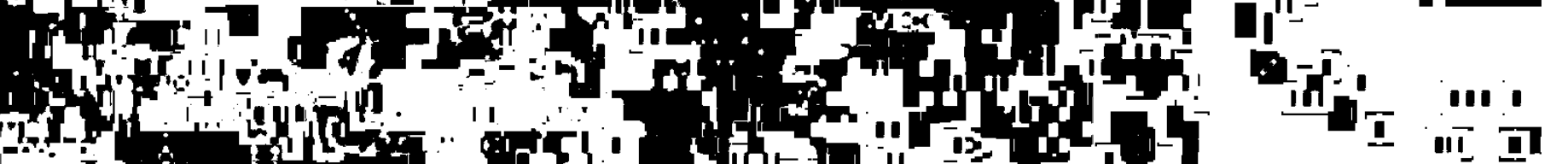

\&

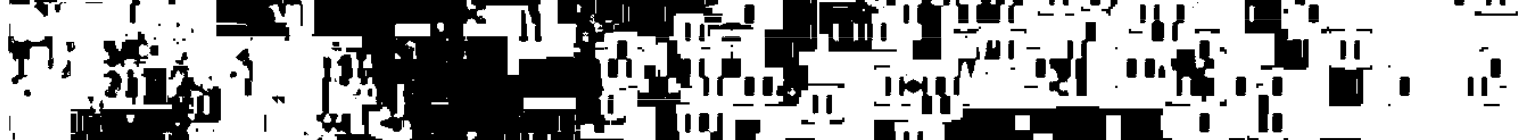

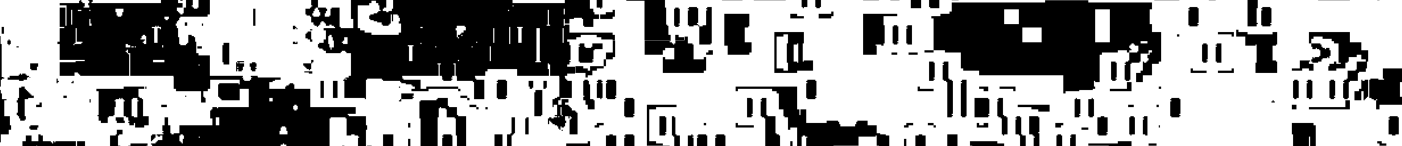
(f.

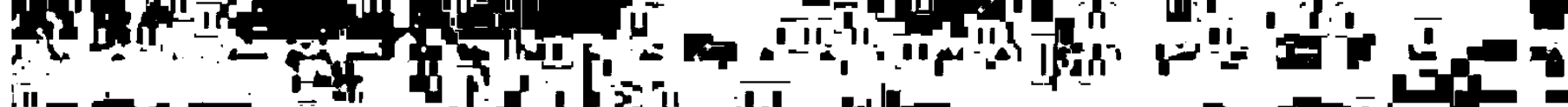

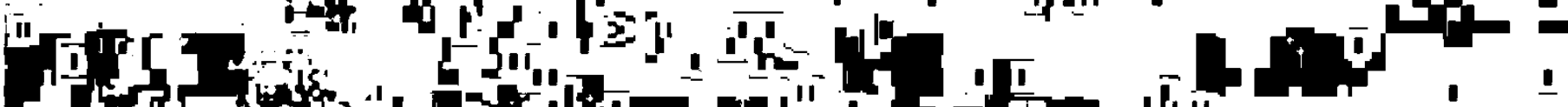

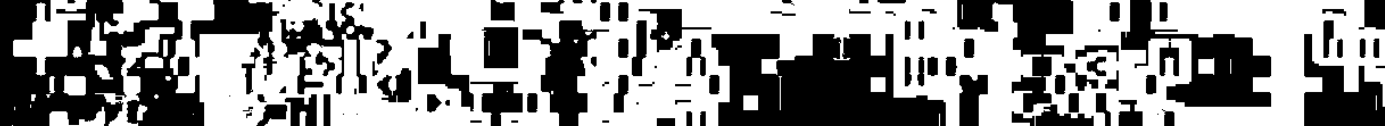

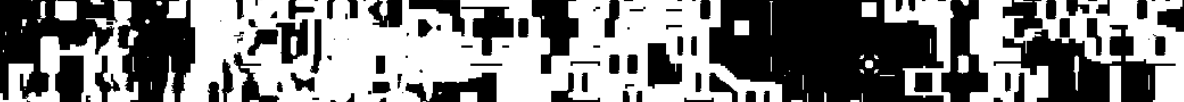

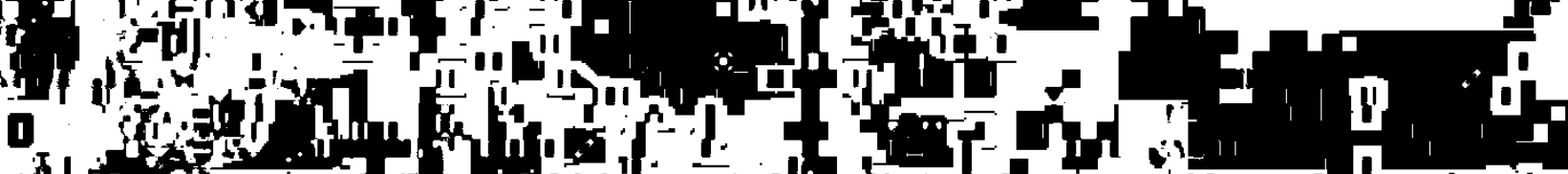
Afis

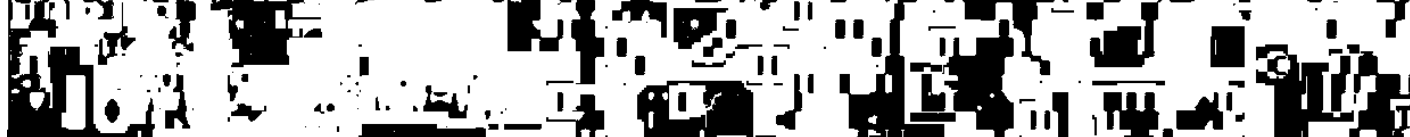
d. A :

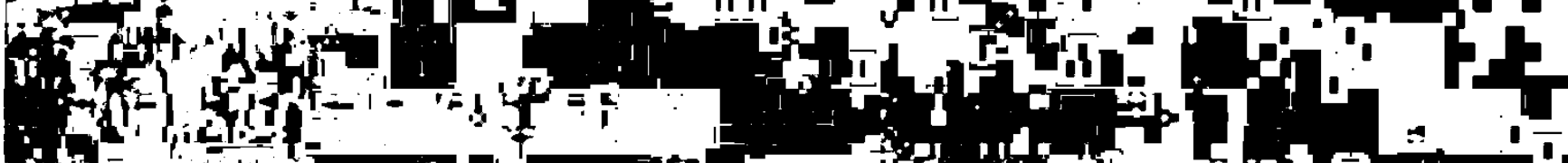

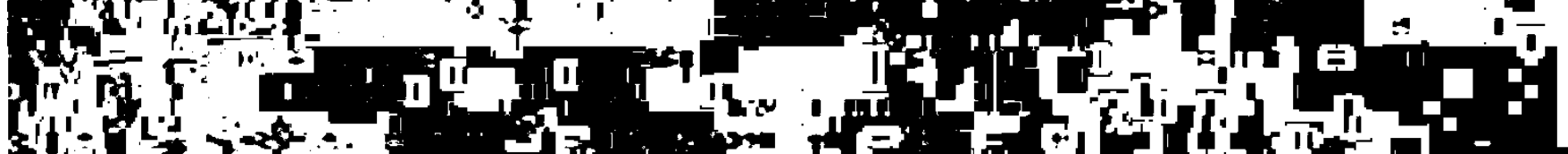

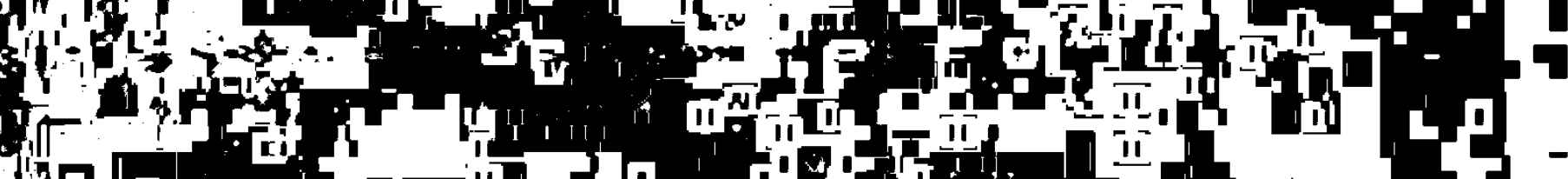
t2 50 .

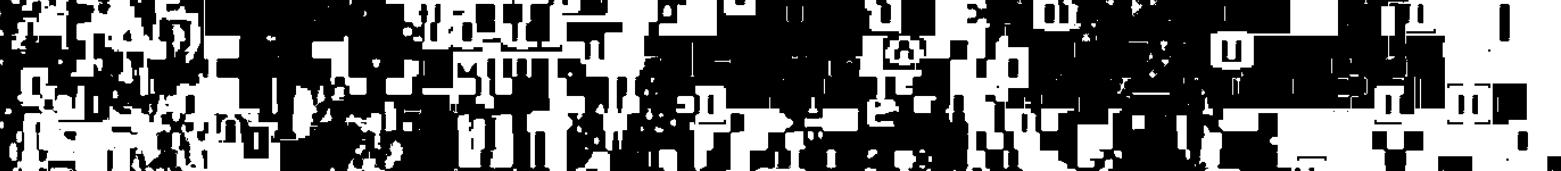

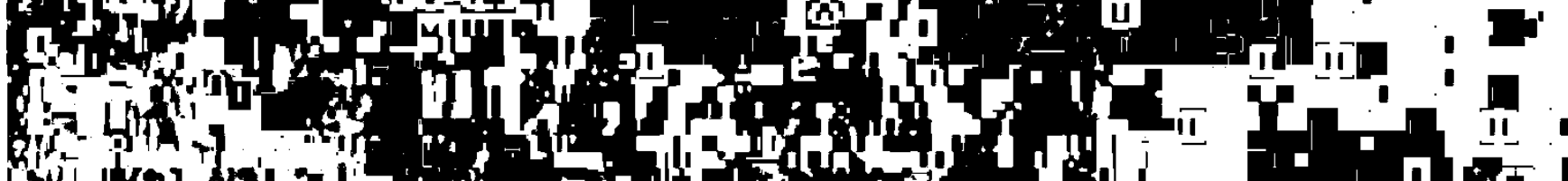

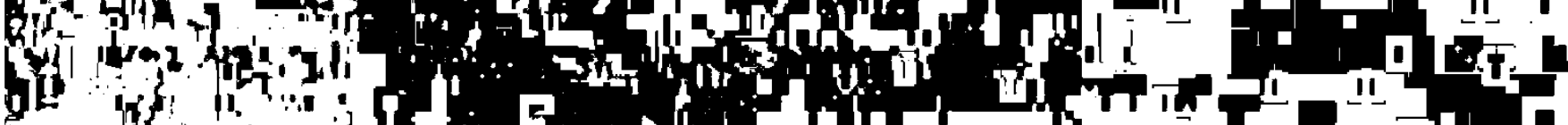

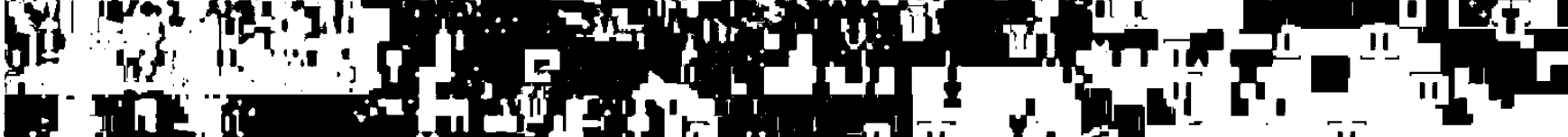

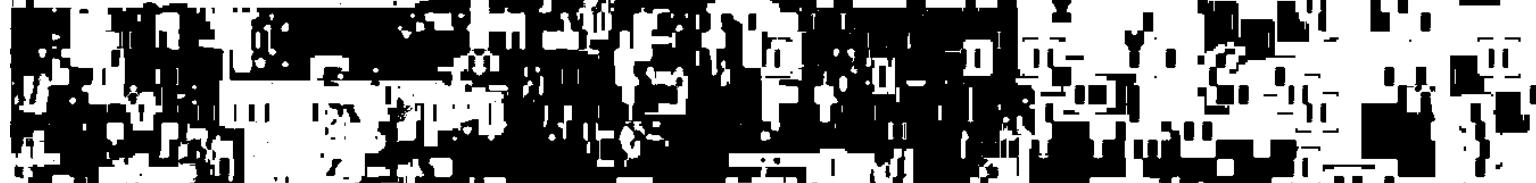

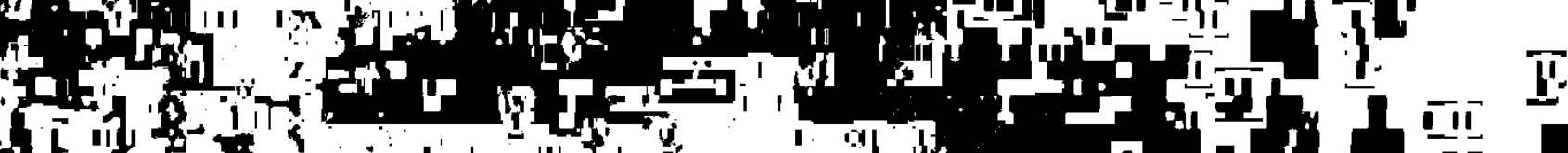

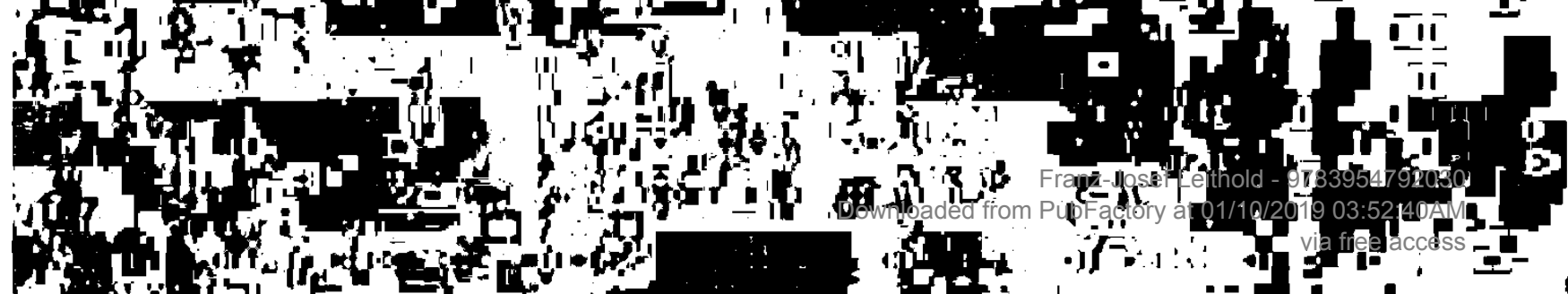

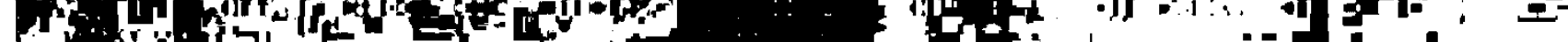

